\title{
Interaktion von Leukozyten mit endothelialen Adhäsionsmolekülen und ihre Inhibition durch \\ Expression von konkurrierenden \\ Fusionsproteinen
}

\author{
Dissertation \\ zur Erlangung des Doktorgrades \\ der Mathematisch-Naturwissenschaftlichen Fakultäten \\ der Georg-August-Universität zu Göttingen
}

vorgelegt von

Sabine Marheineke

aus Hildesheim

Göttingen 2002 
D7

Referent: Prof. Dr. R. Hardeland

Korreferent: Prof. Dr. K. Jungermann

Tag der mündlichen Prüfung: 25.04.02 


\section{Inhaltsverzeichnis}

Titel der Arbeit

$\underline{\text { Inhaltsverzeichnis }}$

Abkürzungen

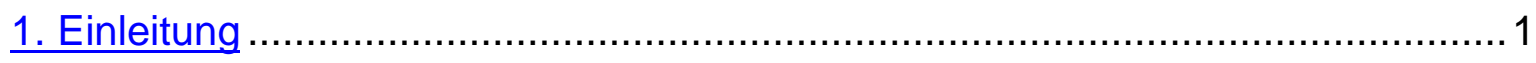

1.1 Allgemeine Grundlagen der Adhäsion ............................................ 1

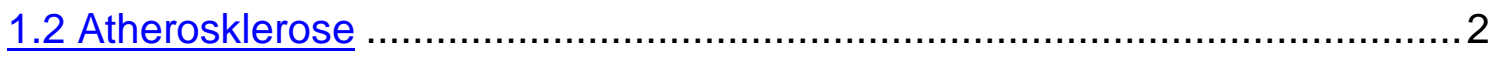

1.3 Einteilung der Adhäsionsmoleküle ..................................................... 4

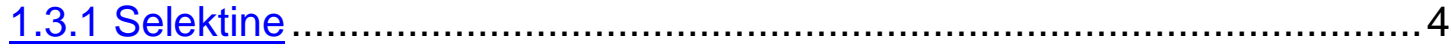

1.3.2 Immunglobulin-Superfamilie (lg-Superfamilie) ............................... 5

1.3.2.1 Interzelluläres Adhäsionsmolekül-1 (ICAM-1) ........................... 6

1.3.2.2 Vaskuläres Adhäsionsmolekül-1 (VCAM-1) .............................. 7

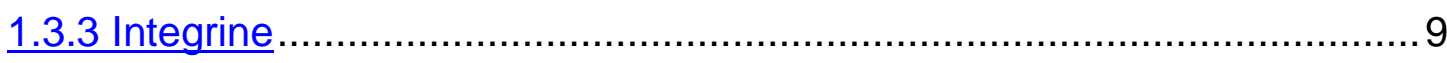

1.4 Monozytenadhäsion und -transmigration: Das Zusammenspiel von E-

Selektin, ICAM-1 und VCAM-1 ….................................................... 10

1.5 Zytoskelettverankerung der Oberflächenrezeptoren .............................. 13

1.6 Hemmung der Monozytenadhäsion........................................................ 14

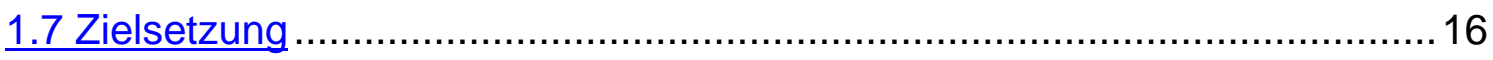

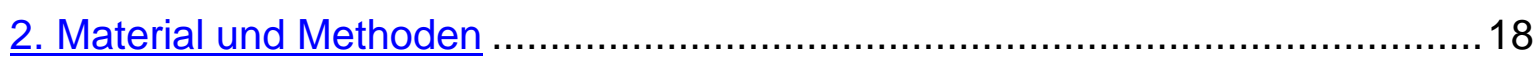

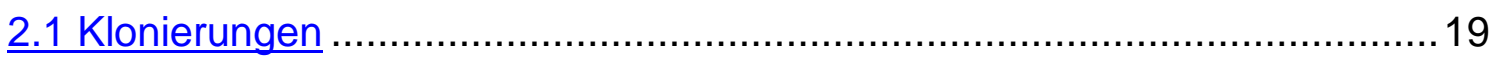

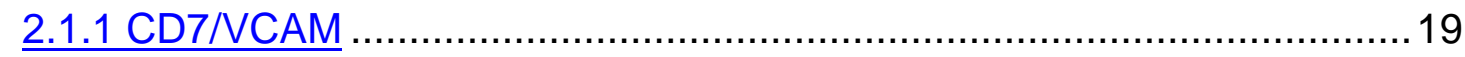

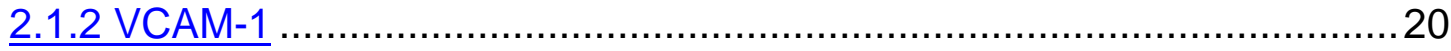

2.2 Heterologe Expression in Säugerzellen durch stabile Transfektion.............20

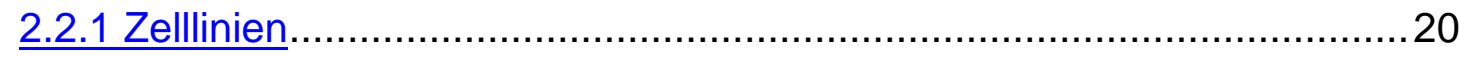

2.2.2 Regulation der Transgenexpression durch das Tet Off ${ }^{\text {TM}}$-System........21

2.2.3 Vorversuche für die Etablierung einer stabilen Zelllinie: Bestimmung des Selektionsdrucks und der Zelldichte ....................................23

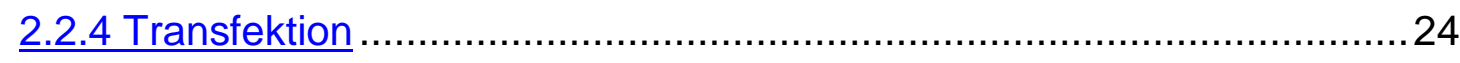


2.3 Expressionsbestimmung in der Durchflusszytometrie .............................25

2.3.1 Titration der Antikörper für die Durchflusszytometrie ............................26

2.3.2 Zellfärbung mit fluoreszenzmarkierten Antikörpern.............................26

2.4 Kontrolle des Tet Off ${ }^{\mathrm{TM}}$-Systems durch Doxycyclin ................................2

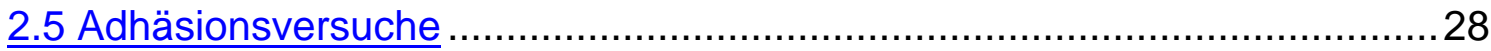

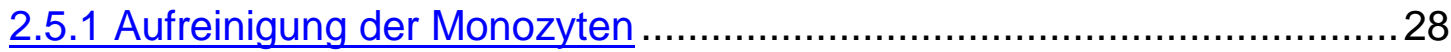

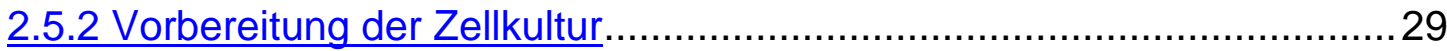

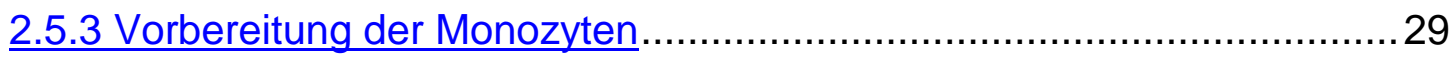

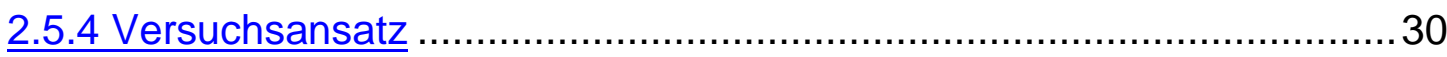

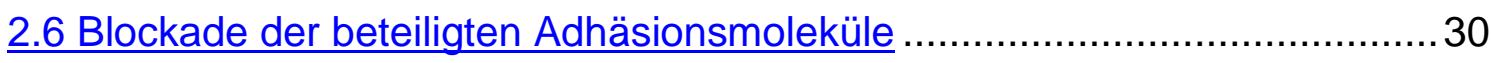

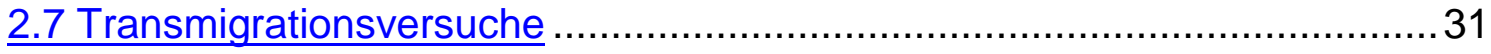

2.8 Inhibition der Zytoskelettverankerung durch Cytochalasin D........................32

2.9 Die Arbeit an humanen primären Endothelzellen (HUVECs)........................33

2.10 Präparation der Zellen aus Nabelschnurvenen ......................................33

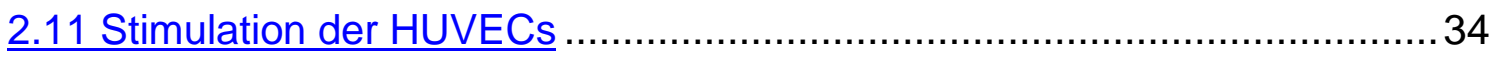

2.12 Adhäsionsversuche: HUVECs + Monozyten .........................................34

2.13 Transmigration von Monozyten durch eine HUVECs-Zellschicht .............. 35

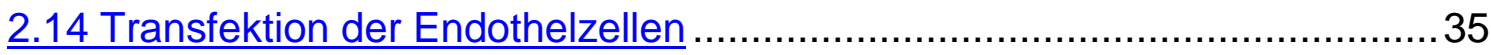

2.15 Nachweis der GFP-Expression in der Immunfluoreszenz ........................36

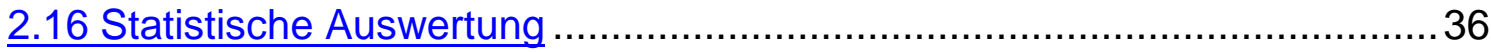

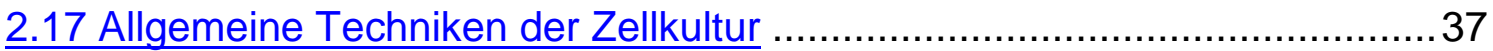

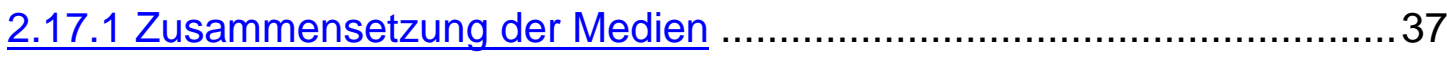

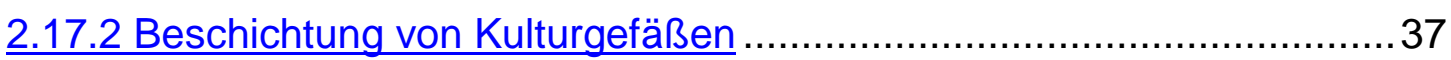

2.17.3 Zellzählung durch den Trypanblau-Ausschlusstest.............................37

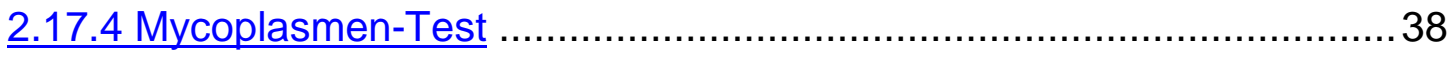

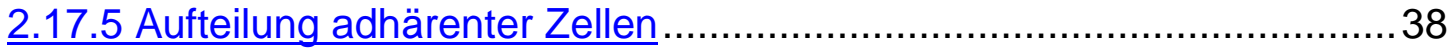

2.17.6 Auftauen und Einfrieren von Säugerzellen........................................39

2.18 Allgemeine Techniken der Bakterienkultur .......................................... 40

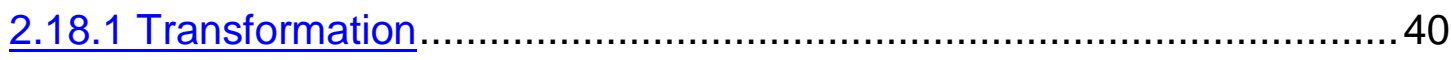

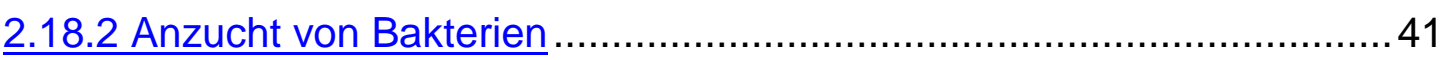

2.18 .3 Isolierung und Aufreinigung von Plasmid-DNA ............................... 42

2.19 Konzentrationsbestimmung von Nucleinsäurelösungen ............................43 


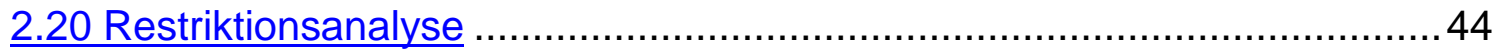

2.21 Native Agarose-Gelelektrophorese für DNA ……............................... 44

2.22 Anfärbung von Nucleinsäuren in Gelen mit Ethidiumbromid und ihre

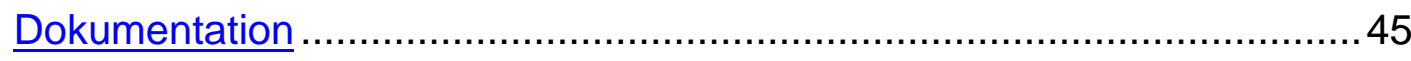

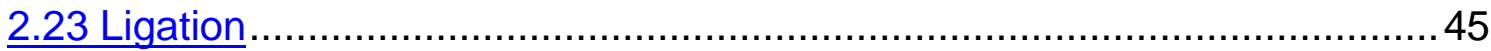

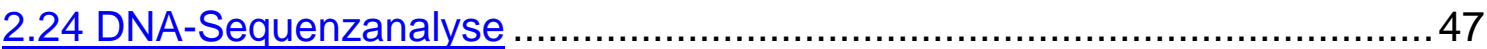

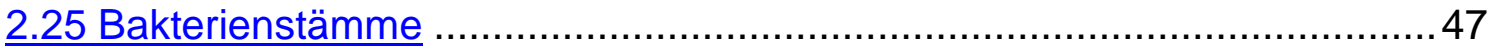

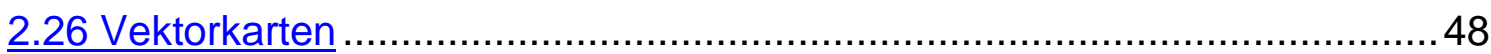

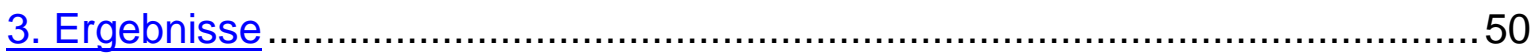

3.1 Bestimmung der Transgen-Expression von E-Selektin, ICAM-1, VCAM-1

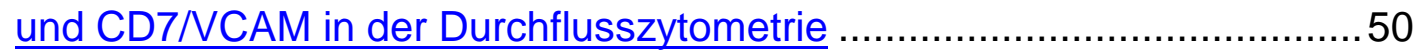

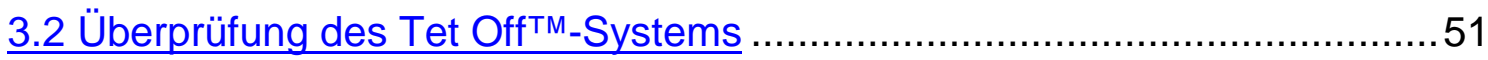

3.2.1 Bestimmung der maximal hemmenden Doxycyclin-Konzentration .......52

3.2.2 Induktion und Hemmung der Transgen-Expression durch Doxycyclin

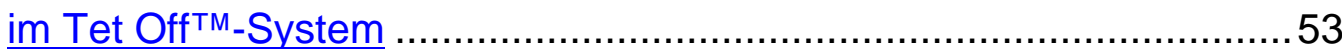

3.2.3 Überprüfung des Tet Off ${ }^{\top \mathrm{M}}$-Systems bei der doppelt transgenen

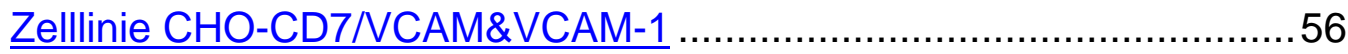

3.3 Untersuchungen an dem Oberflächenrezeptor VCAM-1 ….......................58

3.3.1 Adhäsion der Monozyten an VCAM-1 .............................................5

3.3.2 Hemmung der Monozytenadhäsion durch anti-VCAM-1 ......................60

3.3.3 Hemmung der VCAM-1 vermittelten Monozytenadhäsion auf leukozytärer Seite 62

3.3.4 Adhäsion von Monozyten an den Oberflächenrezeptor VCAM-1 nach

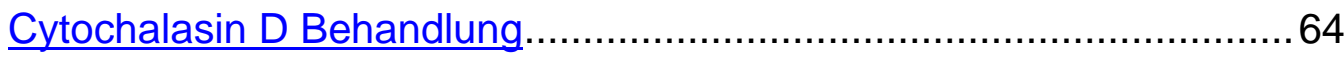

3.3.5 VCAM-1 vermittelte Transmigration von Monozyten .............................66

3.3.6 Blockade des Rezeptors mit anti-VCAM-1 in Transmigrationsversuchen

3.3.7 Hemmung der VCAM-1 vermittelten Transmigration von Monozyten durch Cytochalasin D.............................................................. 70

3.4 Untersuchungen an dem Oberflächenrezeptor ICAM-1 …........................72

3.4.1 ICAM-1 vermittelte Adhäsion von Monozyten .................................... 72 
3.4.2 Vergleich der Monozytenadhäsion an die transgenen Zelllinien

CHO/ICAM-1 und CHO/ICAM-1\&CD7/VCAM .................................. 74

3.4.3 Inhibition der ICAM-1 Zytoskelettverankerung durch Cytochalasin D ...76

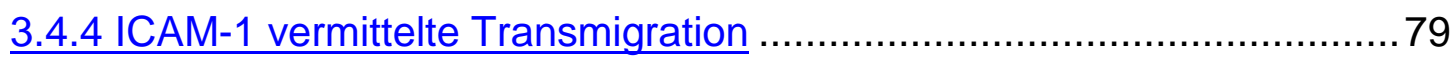

3.4.5 Hemmung der ICAM-1 vermittelten Monozytenmigration durch

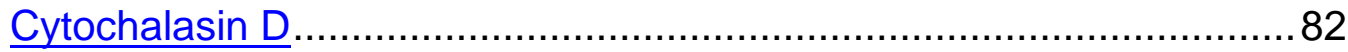

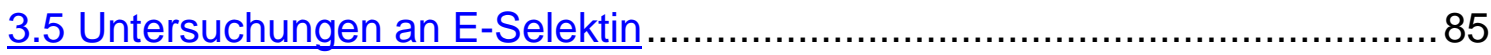

3.5.1 E-Selektin-vermittelte Adhäsion der Monozyten …............................... 85

3.5.2 Monozytenadhäsion an die Zelllinien CHO/E-Selektin und CHO/E-

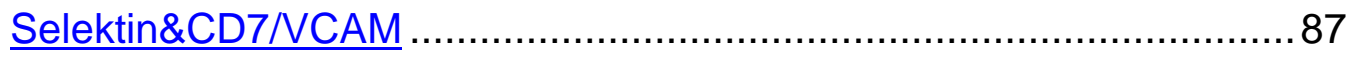

3.5.3 Monozytenadhäsion an die Zelllinien CHO/E-Selektin und CHO/E-

Selektin\&CD7/VCAM nach Behandlung mit Cytochalasin D.................88

3.5.4 E-Selektin vermittelt keine Transmigration.......................................90

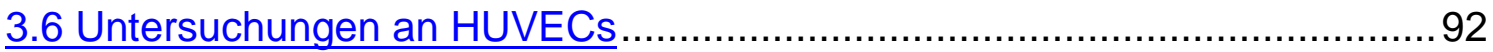

3.6.1 Expression der Oberflächenrezeptoren E-Selektin, ICAM-1 und

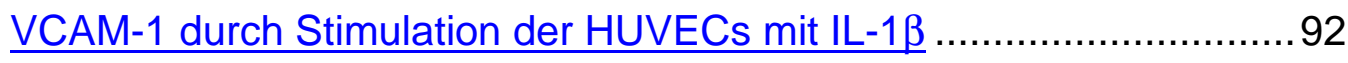

3.6.2 Adenovirus-assoziierte (AAV)-Transfektion der HUVECs..................... 94

3.6.3 Adhäsion von Monozyten an CD7/VCAM exprimierende HUVECs ......96

3.6.4 Transmigration von Monozyten durch eine Zellschicht transgener

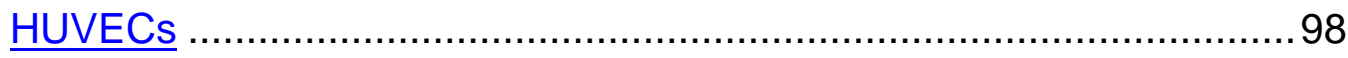

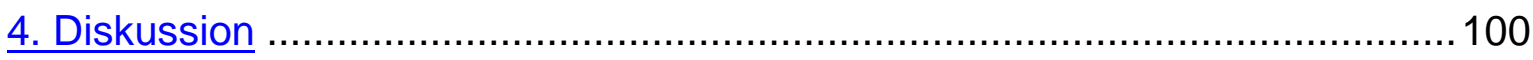

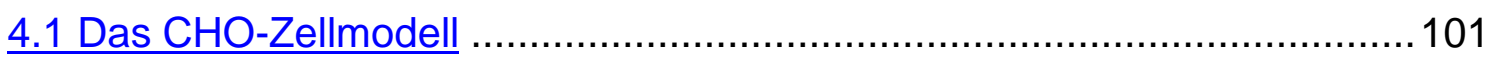

4.2 Die Rolle von CD7 als extrazellulärer Marker ……................................. 102

4.3 Die VCAM-1 vermittelte Adhäsion von Monozyten im CHO-Zellmodell..... 103

4.4 Die VCAM-1 vermittelte Transmigration von Monozyten ............................. 105

4.5 Die Auswirkung von CD7/VCAM auf die VCAM-1 vermittelten Prozesse

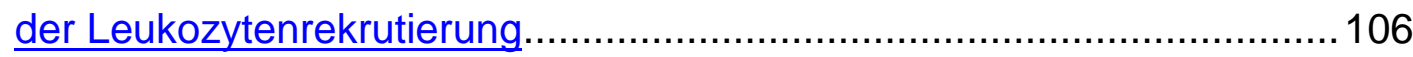

4.6 Behandlung der VCAM-1 exprimierenden Zelllinie mit Cytochalasin D .....108

4.7 Die Adhäsion und Transmigration von Monozyten unter der Vermittlung

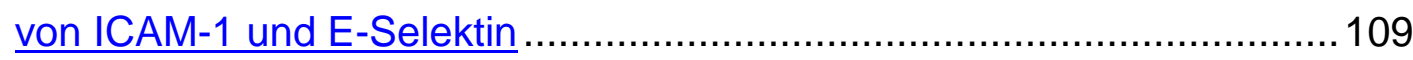

4.8 Die Auswirkung von Cytochalasin D auf die Funktion von ICAM-1 und ESelektin 
4.9 CD7/VCAM hat keinen Einfluss auf ICAM-1 und E-Selektin 112

4.10 Die Expression von CD7/VCAM in HUVECs verringerte die VCAM-1 vermittelte Adhäsion und Transmigration von Monozyten. 113

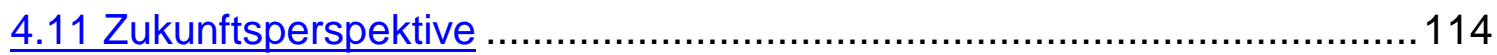

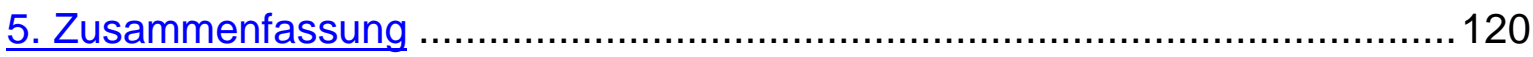

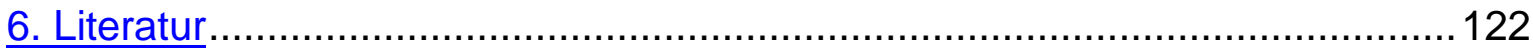

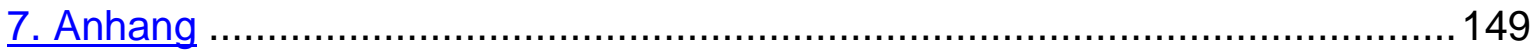




\section{Abkürzungen}

$\begin{array}{ll}\text { AAV } & \text { Adeno-assoziierter Virus } \\ \text { Abb. } & \text { Abbildung } \\ \text { AP-1 } & \text { Aktivierungsprotein-1 } \\ \text { BSA } & \text { Rinderserumalbumin (bovine serum albumine) } \\ \text { CHO } & \text { immortale Epithelzellinie, die aus einer Ovarienkultur } \\ & \text { des Hamsters hervorgegangen ist (chinese hamster } \\ & \text { ovary) } \\ \text { CMV } & \text { Cytomegalie-Virus } \\ \text { DMEM } & \text { Nährlösung der CHO-Zellen (Dulbecco's modified } \\ \text { DMSO } & \text { Eagle's medium) } \\ \text { ECGM } & \text { Dimethylsulfoxid } \\ \text { NCährlösung der HUVECs (endothelial cell growth } \\ \text { medium) } \\ \text { Zusatz der HUVEC-Nährlösung (endothelial cell } \\ \text { EDTA } & \text { growth supplement) } \\ \text { EGF } & \text { Ethylendiamintetraessigsäure } \\ \text { endothelialer Wachstumsfaktor (endothelial growth } & \text { factor) } \\ \text { ELAM-1 } & \text { endotheliales Leukozyten-Adhäsionsmolekül-1 } \\ \text { ELISA } & \text { Enzym-gekoppeltes Immunosorbent Verfahren } \\ \text { ESL-1 } & \text { (enzyme-linked immunosorbent assay) } \\ \text { Fc } & \text { E-Selektin Ligand-1 } \\ \text { FITC } & \text { kristallines Fragment eines Antikörpers } \\ \text { FKS } & \text { Fluorescein-5-isothiocyanat } \\ \text { fötales Kälberserum } & \text { Erdbeschleunigung } \\ \text { GPIIb/IIIa } & \text { grün-fluoreszierendes Protein } \\ \text { Glucoprotein IIb/IIIa } & \text { Stunde (hour) } \\ & \end{array}$


HUVEC

ICAM

IFN

$\lg$

Ig-Superfamilie

IL

LAM-1

LB

LDL

LFA-1

LPS

MCP-1

MCS

MOPS

NCAM

NEAA

$N F-\kappa B$

NK

$\mathrm{p}$

PECAM

Pen / Strep

PMN primäre Endothelzelle, die aus einer humanen

Nabelschnurvene gewonnen wird (human umbilical

vein endothelial cell)

interzelluläres Adhäsionsmolekül (intercellular

adhesion molecule)

Interferon

Immunglobulin

Immunglobulin-Superfamilie

Interleukin

leukozytäres Adhäsionsmolekül-1

Luria-Bertani

Lipoproteine geringer Dichte (low density lipoproteins)

Oberflächenrezeptor der Integrinfamilie (leukocyte function associated antigen-1)

Lipopolysaccharid

chemotaktisches Monozytenprotein-1 (monocyte chemotactic protein-1)

Klonierungsabschnitt eines Vektor (multiple cloning side)

3-Morpholino-1-propansulfonsäure

neuronales Zelladhäsionsmolekül (neural cell adhesion molecule)

Nicht-essentielle Aminosäuren (non essential aminoacids)

nucleärer Faktor $\kappa \mathrm{B}$

natürliche Killerzelle

Wahrscheinlichkeit (probability)

Plättchen / Endothel-Zelladhäsionsmolekül-1 (platelet / endothelial cell adhesion molecule-1)

Penicillin / Streptomycin

polymorph-nucleäre Zelle 


\begin{tabular}{|c|c|}
\hline PSGL-1 & P-Selektin Glycoprotein Ligand-1 \\
\hline \multirow[t]{2}{*}{ ROS } & nicht näher bezeichnetes Sauerstoffradikal (radical \\
\hline & oxygen species) \\
\hline rpm & Umdrehungen pro Minute (rounds per minute) \\
\hline $\mathrm{RT}$ & Raumtemperatur \\
\hline SDS & Natriumdodecylsulfat (sodium dodecyl sulfate) \\
\hline$s L e^{x}$ & sialysierte Lewissäure \\
\hline SV 40 & Simian Virus 40 \\
\hline \multirow[t]{2}{*}{ sVCAM-1 } & lösliches vaskuläres Adhäsionsmolekül-1 (soluble \\
\hline & VCAM-1) \\
\hline TAE & Tris-Acetat-EDTA \\
\hline TNF & Tumor-Nekrose-Faktor \\
\hline Tris & Tris-(hydroxymethyl)-aminomethan \\
\hline u & Einheit für die spez. Enzymaktivität (unit) \\
\hline V & Volt \\
\hline \multirow[t]{2}{*}{ VCAM-1 } & vaskuläres Adhäsionsmolekül-1 (vascular cell \\
\hline & adhesion molecule-1) \\
\hline \multirow[t]{2}{*}{ VLA-4 } & Oberflächenrezeptor der Integrinfamilie (very late \\
\hline & antigen-4) \\
\hline VWF & von Willebrand-Faktor \\
\hline $\mathrm{w} / \mathrm{v}$ & Gewichtsverhältnis (weight / volume) \\
\hline
\end{tabular}




\section{Einleitung}

\subsection{Allgemeine Grundlagen der Adhäsion}

Die spezifische Adhäsion von Zellen untereinander oder deren Anheftung an die extrazelluläre Matrix ist eine grundlegende Voraussetzung für die Zellerkennung und Prozesse der Zellmigration. Neben der Funktion bei morphologischen Ereignissen während der Entwicklung wird dadurch auch bei Adulti die normale Organisation von Geweben bestimmt. Sie ist Grundlage für so vielfältige Prozesse wie das Überleben von Zellen, Apoptose, Zelldifferenzierung, Proliferation, Homöostase oder Wundheilung. Bei diesen Phänomenen zeichnet sich die Adhäsion durch Spezifität (Interaktionen von Rezeptoren mit ihren Liganden), Dynamik (Veränderung der Expression und / oder der Affinität von Adhäsionsmolekülen) und Informationsgehalt (Veränderung von Phänotyp, Zellform, Stadium der Zelldifferenzierung oder Position im Zellzyklus) aus.

Zell / Zell-Interaktionen und die Adhäsion von Zellen an die extrazelluläre Matrix spielen neben wichtigen physiologischen Phänomenen aber auch eine Schlüsselrolle bei vielen pathologischen Veränderungen wie Tumormetastasierung, Organabstoßungen nach Transplantationen, Ischämie und Autoimmunkrankheiten (Springer, 1990; Frenette \& Wagner, 1996a;b). Viele dieser Krankheiten werden durch Inflammation charakterisiert, einem Phänomen, welches die Anhäufung von Leukozyten in dem entsprechenden Gewebe beinhaltet und in unterschiedlichem Ausmaß in Zellschäden, Ablösung von der extrazellulären Matrix und Organdysfunktion resultiert. Obwohl die Entzündung in erster Linie eine Abwehrreaktion des Organismus darstellt, weitet sich dieses Phänomen oft genug zu unerwünschten Krankheiten aus. Die dabei zu beobachtende chronische Adhäsion von inflammatorischen Leukozyten an das vaskuläre Endothel und ihre Rekrutierung in die Gefäßwand bedürfen einer Therapie. In diesem Zusammenhang ist besonders die Entstehung und das Fortschreiten der Atherosklerose hervorzuheben, die in den USA, Europa und 
großen Teilen Asiens die Haupttodesursache darstellt (Breslow, 1997; Braunwald, 1997).

\subsection{Atherosklerose}

Bei der Atherosklerose liegt eine komplexe, chronisch entzündliche Krankheit vor, die als Antwort auf eine Dysfunktion des Endothels entsteht (Ross, 1999). Neben den bekannten Risikofaktoren wie männlichem Geschlecht, erhöhtem Alter, Übergewicht oder hohem Blutdruck (Dawber \& Kannel, 1966) scheinen eine Vielzahl weiterer Faktoren ursächlich zu der Dysfunktion beizutragen:

- Verzweigungen und Krümmungen der Gefäße stellen lokale Risikofaktoren dar, da sie die ansonsten uniformen laminaren Scherkräfte stören und Turbulenzen verursachen, wodurch eine Aktivierung des Endothels hervorgerufen wird (Davies \& Tripathi, 1993; Gimbrone et al., 1997)

- erhöhte Cholesterol-Plasmakonzentrationen von Lipoproteinen mit einem geringen spezifischen Gewicht (low density lipoproteins, LDL) (National Cholesterol Education Program, 1993)

- Modifikation der LDL durch Oxidation, da so die Entstehung von Lipidperoxiden begünstigt, und die Anhäufung von Cholesterolestern ermöglicht wird, was in der Bildung von Schaumzellen resultiert (Steinberg, 1997; Griendling \& Alexander, 1997)

- Bildung von freien Sauerstoffradikalen durch Rauchen (Cross et al., 1998)

- Diabetes mellitus (Wang et al., 1993)

- Hypercholesterinämie (Kullo et al., 2000)

- erhöhte Homocystein-Plasmakonzentrationen, die prothrombotische Wirkung haben (Nehler et al., 1997)

- erhöhte Angiotensin II-Konzentrationen, da das Wachstum von glatten Muskelzellen stimuliert wird (Chobanian \& Dzau, 1996)

- $\quad$ infektiöse Mikroorganismen wie Chlamydia pneumoniae (Libby et al., 1997) 
- Herpesviren (Jackson et al., 1997).

Die endotheliale Dysfunktion wiederum zieht kompensatorische Antworten nach sich, durch die sich die gegebenen homöostatischen Eigenschaften des Endothels verändern. Zum einen wird die deutliche Zunahme von adhärenten Leukozyten und Thrombozyten von einer erhöhten Durchlässigkeit für diese Zellen begleitet. Ferner zeigen die Endothelzellen nun prokoagulante anstelle antikoagulanter Fähigkeiten und produzieren vasoaktive Moleküle, Zytokine und Wachstumsfaktoren. Bei einem ungehinderten Fortschreiten der Entzündungsreaktion werden im fortgeschrittenen Stadium der Krankheit glatte Muskelzellen zur Migration und Proliferation angeregt (Ross \& Glomset, 1973). Sie geben ihren kontraktilen differenzierten Zelltyp auf und wandern aus der Media durch die interne elastische Lamina in die Intima. Als dedifferenzierte Muskelzellen bilden sie dort die Neointima. Die Arterienwand verdickt sich dadurch zunehmend, wodurch das Gefäß versucht, das Lumen durch graduelle Dilatation (remodeling) konstant zu halten (Glakov et al., 1987). Während aller beschriebenen Vorgänge wandern weiter vermehrt Leukozyten in die Gefäßwand ein, wobei neben spezifischen T-Zellen vor allem die Anzahl der Monozyten zunimmt, die zu Gewebemakrophagen differenzieren. Die Aktivierung der Makrophagen bedingt die Ausschüttung von hydrolytischen Enzymen, Zytokinen, Chemokinen und Wachstumsfaktoren (Libby \& Ross, 1996; Raines et al., 1996), die weitere Schädigungen induzieren und zu fokalen Nekrosen führen können. Die genannten Phänomene resultieren in der Bildung eines fibrösen Gewebes, des atherosklerotischen Plaques, der im fortgeschrittenen Stadium einreißen kann (Falk et al., 1996) und durch einen Thrombus abgedeckt wird. An einem bestimmten Punkt ist das Gefäß zudem nicht mehr in der Lage, die zunehmende Verdickung durch Dilatation zu kompensieren, woraus eine zunehmende Verengung resultiert, die u.U. bis zum völligen Verschluss des Gefäßes führen kann.

Die Adhäsion von Leukozyten an das vaskuläre Endothel und ihre darauffolgende Diapedese ist eines der ersten Phänomene, die bei akuten Entzündungen oder 
chronisch entzündlichen Krankheiten wie der Atherosklerose beobachtet werden können. Da die vorliegende Arbeit die Phänomene der Entstehung und des Fortschreitens der Atherosklerose behandelt, zu denen vor allem die Adhäsion und Transmigration von Monozyten beitragen, wird hier im weiteren Verlauf ausschließlich von diesen Immunzellen die Rede sein. Ihre Rekrutierung wird - analog zu anderen Leukozyten - ermöglicht durch die Interaktion von verschiedenen endothelialen Oberflächenmolekülen mit ihren Liganden.

\subsection{Einteilung der Adhäsionsmoleküle}

Die beteiligten Zelladhäsionsmoleküle lassen sich unterschiedlichen Familien von Zelloberflächen-Rezeptoren zuordnen:

- Selektine

- Immunglobulin-Superfamilie

- Integrine

Es sei erwähnt, dass neben den o.a. Familien außerdem Cadherine und verschiedene, nicht miteinander verwandte Oberflächenmoleküle mit adhäsiven Fähigkeiten existieren. In der vorliegenden Arbeit waren diese jedoch nicht relevant und werden hier nicht erläutert.

\subsubsection{Selektine}

Selektine sind $\mathrm{Ca}^{2+}$-abhängige transmembrane Glykoproteine, deren Vertreter eine Lektin-ähnliche aminoterminale Domäne besitzen, der eine variierende Zahl von sich wiederholenden Einheiten mit Homologie zu regulatorischen Proteinen der Komplementkaskade folgt (Gearing \& Newman, 1993). Ferner sind sie durch das Auftreten eines EGF-repeats (endothelial growth factor) gekennzeichnet (Bevilacqua, 1993). Trotz ihrer kurzen intrazellulären Domäne (Bevilacqua \& Nelson, 1993) sind sie in der Lage, nach der Interaktion mit ihren Liganden kostimulatorische Signale zu generieren, die zu der Aktivierung von Leukozyten 
beitragen (Brenner et al., 1996; Lo et al., 1997). Sie spielen u.a. eine wichtige Rolle bei der Schmerzkontrolle während inflammatorischer Prozesse (Machelska et al., 1998). Die Vertreter der Selektine vermitteln darüber hinaus die schwache, reversible Bindung von Leukozyten an die Gefäßwand (Gearing \& Newman, 1993). L-Selektin (LAM-1; CD62L) kommt auf Leukozyten vor (Gearing \& Newman, 1993) und wird dort konstitutiv exprimiert (Bevilacqua \& Nelson 1993). P-Selektin (PADGEM; GMP-140; CD62P) wird vorgebildet und in den $\alpha$-Granula von Blutplättchen oder den Weibel-Palade Körperchen von Endothelzellen gespeichert (Gearing \& Newman, 1993). Es kann durch Thrombin, Histamin, terminale Komplement-Faktoren, Endotoxine, TNF, Virusinfektionen und $\mathrm{H}_{2} \mathrm{O}_{2}$ aktiviert werden und wird innerhalb von Sekunden an die Zelloberfläche befördert (Bevilacqua, 1993). E-Selektin (ELAM-1; CD62E) wird ausschließlich von Endothelzellen nach der Aktivierung durch Zytokine wie IL-1 oder TNF gebildet (Gearing \& Newman, 1993; Bevilacqua, 1993). Das humane E-Selektin enthält Sequenzen, die mit Bindungsstellen von NFkB und AP-1 übereinstimmen (Bevilacqua, 1993). Wie L-Selektin auf der leukozytären Seite, stellt E-Selektin auf endothelialer Seite einen der Hauptvermittler des rolling der Leukozyten auf dem Endothel dar.

Als unspezifische Liganden finden sich bei allen Vertretern der Selektine Kohlenhydrate wie Sialyl-Lewis $\mathrm{X}$ - $\left(\mathrm{sLe} \mathrm{e}^{\mathrm{x}}\right.$ ) verwandte Strukturen (Bevilacqua \& Nelson, 1993), sulfatisierte Polysaccharide (Heparin, Fucoidan) und Mannose-6Phosphat (Rosen \& Bertozzi, 1994). Für P- und E-Selektin sind darüber hinaus spezifische Liganden wie PSGL-1 (Sako et al., 1993) und ESL-1 (Steegmaier et al., 1995) beschrieben worden. E-Selektin spielt des weiteren wahrscheinlich eine wichtige Rolle bei der Entstehung der Atherosklerose, da es in atherosklerotischen Plaques in erhöhtem Maß exprimiert wird (Abe et al., 1998).

\subsubsection{Immunglobulin-Superfamilie (Ig-Superfamilie)}

Die Mitglieder der Ig-Superfamilie sind ebenfalls transmembrane Glykoproteine, welche die Membran einmal durchspannen (single-pass-Glykoproteine) und 
vornehmlich eine $\mathrm{Ca}^{2+}$-unabhängige Adhäsion vermitteln (Sluiter et al., 1993; Springer, 1994). Sie kommen im Organismus auf verschiedenen Organen und Geweben vor und besitzen mindestens eine Ig-ähnliche Domäne, die auch für Antikörper charakteristisch ist (Springer, 1990). Die vermittelte Zell / Zell-Adhäsion erfolgt sowohl über einen homophilen als auch heterophilen Mechanismus (González-Amaro et al., 1998). Den Adhäsionsmolekülen dieser Familie wird u.a. eine große Bedeutung bei der Entwicklung von Wirbeltieren zugeschrieben. So konnte gezeigt werden, dass Mäuse, denen VCAM-1 bei der Entwicklung fehlt, entweder anormale Herzen entwickeln, vor der Geburt sterben oder bei Trächtigkeit eine Fehlentwicklung der Plazenta zeigen, da die Allantois nicht mit dem Chorion fusionieren kann (Kwee et al., 1995; Gurtner et al., 1995).

Zu den wichtigsten Vertretern zählen neben PECAM (CD31; auf Endothelzellen, Blutplättchen, Neutrophilen und Monozyten) und NCAM (CD56; auf Nervenzellen) vor allem interzelluläres Adhäsionsmolekül-1 (ICAM-1) und vaskuläres Adhäsionsmolekül-1 (VCAM-1). Letztere werden nach Aktivierung während inflammatorischer Prozesse verstärkt exprimiert und sind wichtig für die Adhäsion und transendotheliale Migration von Leukozyten (Gearing \& Newman, 1993; Carlos \& Harlan, 1994). Das Zusammenspiel von ICAM-1 und VCAM-1 ist in der Vergangenheit als eines der wichtigsten Ereignisse bei der Bindung von Leukozyten an Endothelzellen beschrieben worden (Kaplanski et al., 1998). Daraus ergibt sich auch ihre Bedeutung für die Ausbildung der Atherosklerose: In vivo-Tierstudien und immunhistochemische Studien von humanen Geweben zeigten, dass die Expression von ICAM-1 und VCAM-1 in atherosklerotischen Plaques stark erhöht ist (Davies et al., 1993).

\subsubsection{Interzelluläres Adhäsionsmolekül-1 (ICAM-1)}

ICAM-1 (CD54) wird auf Fibroblasten, Leukozyten, Endothel-, Epithel- und vielen Tumorzellen exprimiert (Gearing \& Newman, 1993; Van de Stolpe \& van der Saag, 1996). Als Liganden sind sowohl $\beta_{2}$-Integrine (LFA-1; Mac-1) auf Leukozyten (Rothlein et al., 1986; Staunton et al., 1988), als auch Rhinoviren (Staunton et al., 
1988; Greve et al., 1989) und Plasmodium falciparum-infizierte Erythrozyten beschrieben worden (Hynes \& Lander, 1992; Ockenhouse et al., 1992a; 1992b). Darüber hinaus konnte gezeigt werden, dass ICAM-1 direkt Fibrinogen binden kann (Altieri et al., 1993; Languino et al., 1995). Auf Endothelzellen wird es in geringen Mengen konstitutiv exprimiert und kann dort nach Stimulation mit TNF, IFN- $\gamma$ und IL-1 verstärkt nachgewiesen werden (Dustin et al., 1986, 1988; Rothlein et al., 1988). Durch Antikörper-Blockade ließ sich in vitro die ICAM-1 vermittelte Transmigration von Neutrophilen inhibieren (Furie et al., 1991).

\subsubsection{Vaskuläres Adhäsionsmolekül-1 (VCAM-1)}

VCAM-1 (CD106) kommt auf endothelialen, epithelialen, dendritischen Zellen und Makrophagen vor (Gearing \& Newman, 1993). Das Transmembranprotein ist ursprünglich als ein induzierbares Molekül auf humanen Endothelzellen entdeckt worden, das in der Lage ist, sowohl Lymph- als auch Tumorzelllinien zu binden (Osborn et al., 1989; Rice \& Bevilacqua, 1989). Die DNA-Sequenzanalyse zeigte, dass VCAM-1 zur Familie der Ig-Superfamilie gehört. Innerhalb der Ig-Superfamilie ist es am engsten mit ICAM-1 (Rothlein et al., 1986; Staunton et al., 1988), ICAM-2 (Staunton et al., 1989), ICAM-3 (Fawcett et al., 1992) und MadCAM (Briskin et al., 1993) verwandt. Es weist sowohl beim Menschen als auch bei Mäusen am häufigsten sieben Ig-artige Domänen auf (Osborn et al., 1989; Cybulsky \& Gimbrone, 1991). Im humanen Organismus existiert außerdem eine alternative Form mit sechs Domänen (Cybulsky et al., 1991a), darüber hinaus sind in Kaninchen sieben und acht Domänen beschrieben worden (Cybulsky et al., 1991b).

Die Adhäsion wird durch Bindung des Hauptliganden VLA-4 vermittelt (Sluiter et al., 1993; Peter et al., 1999) und erfolgt über die erste und vierte Ig-artige Domäne (Osborn et al., 1992, 1994; Vonderheide et al., 1994). Die endotheliale VCAM-1 Expression kann durch die Zytokine IL-1 $\alpha$ bzw. $-1 \beta$, TNF- $\alpha$ und IL-4 induziert werden (Neish et al., 1992; lademarco et al., 1992, 1993; Couffinal et al., 1994), wodurch es die darauffolgende stärkere Adhäsion (Masinovsky et al., 1990; 
Thornhill et al., 1991) und Migration (Briscoe et al., 1992; Meerschaert \& Furie, 1994) von Monozyten und Lymphozyten mitbestimmt. Neben der Stimulation durch Zytokine ist unter pathologischen Bedingungen (systemischer Lupus erythematodes, rheumatoide Arthritis (Carter \& Wicks, 2001), AtheroskleroseModelle wie $\mathrm{apoE}^{-}{ }^{-}$- (Nakashima et al., 1998) und LDL Rezeptor (LDLR//) defizienten-Mäusen, atherogenetisch ernährten Kaninchen (Li et al., 1993; liyama et al., 1999), Abstoßungsreaktionen nach Transplantationen) ebenfalls eine vermehrte Synthese dieses Oberflächenrezeptors auf Endothelzellen zu beobachten (Springer, 1994). Die VCAM-1 Expression, die mit Entzündungen assoziiert ist, kann sowohl auf dem Endothel großer wie auch kleiner Gefäße aus den unterschiedlichsten Geweben detektiert werden. Auf dem Endothel des Knochenmarks wird es konstitutiv in hohen Mengen exprimiert, da es an der Leitung von hämatopoetischen Vorläuferzellen in das Knochenmark beteiligt ist (Mazo et al., 1998). Eine konstitutiv hohe Expression ist ebenfalls bei dendritischen Zellen in lymphoidalen Geweben (Freedman et al., 1990; Koopman et al., 1991), Epithelzellen des Thymus (Salomon et al., 1997), Gewebemakrophagen (Rice et al., 1991), Stromazellen des Knochenmarks (Miyake et al., 1991), Perizyten der neuronalen Gewebe (Verbeek et al., 1995) oder Chondrozyten (Kienzle \& Kempis, 1998) gegeben. Es ist unbekannt, inwiefern VCAM-1 im Menschen als viraler Rezeptor fungieren kann, obwohl der Spirochäte Borrelia burgdorferi die VCAM-1 Expression auf Endothelzellen induzieren soll (Ebnet et al., 1997). Darüber hinaus belegten in vitro-Studien, dass der endotheliale Rezeptor ebenfalls als Ligand für Plasmodium falciparum infizierte Erythrozyten fungiert (Ockenhouse et al., 1992a). Murines VCAM-1 konnte als Rezeptor für Encephalomyocarditis-Virus detektiert werden (Huber, 1994).

Ferner sind im humanen Serum lösliche Formen von VCAM-1 (sVCAM-1) entdeckt worden. Die Mechanismen, die zur Absonderung von sVCAM-1 führen, sind bisher ungeklärt, ebenso ihre Funktion. Möglicherweise wird dadurch die Zelladhäsion reguliert (Pigott et al., 1992). Des weiteren könnte sVCAM-1 als chemotaktischer Gradient für T-Lymphozyten (Kitani et al., 1998) und Monozyten (Tokuhira et al., 2000) dienen oder Angiogenese begünstigen (Koch et al., 1995). 
Die Rolle von sVCAM-1 als potentieller Marker der Atherosklerose sollte daher überlegt werden (Peter et al., 1999; Blankenberg et al., 2001).

Unter den endothelialen Adhäsionsmolekülen muss VCAM-1 eine besondere Rolle bei der Leukozytenadhäsion zugeschrieben werden, da es vermutlich sowohl die primäre Adhäsion (rolling) als auch die finale Phase der Adhäsion (spreading und tethering) vermitteln kann (Alon et al., 1995; Berlin et al., 1995).

\subsubsection{Integrine}

Die Mitglieder der Integrin-Familie zählen zu den wichtigsten Oberflächenrezeptoren, die Adhäsion von Zellen untereinander und / oder an die extrazelluläre Matrix vermitteln. Im folgenden soll nur eine kurze Charakterisierung gegeben werden, da sie hier vornehmlich in ihrer Funktion als Liganden für die lgSuperfamilie auftreten. Die Erkenntnisse über die Funktionsweise der Integrine liefern allerdings Aspekte, die zur Aufklärung der Rolle anderer Oberflächenrezeptoren beitragen könnten.

Integrine sind Zelloberflächenrezeptoren, die Interaktionen zwischen Zellinnerem und Zellumgebung ermöglichen (Hynes, 1992). Es handelt sich um $\alpha \beta$-heterodimere, transmembranäre Glykoproteine (Corbí, 1996), die neben Zell / SubstratInteraktionen auch Zell / Zell-Adhäsion vermitteln, indem sie die zellulären Adhäsionsmoleküle der Ig-Superfamilie binden. Viele Integrine werden konstitutiv an der Zelloberfläche exprimiert, sind aber inaktiv und müssen erst durch ihren Agonisten aktiviert werden (Sánchez-Mateos et al., 1996). Sie übernehmen wichtige Funktionen sowohl bei der hämatopoetischen Zellentwicklung, bei der Zellmigration als Antwort auf Verletzungen, der Angiogenese und für den extrazellulären Matrixkontakt. Die Angehörigen dieser Familie sind ubiquitär und übernehmen Signalwirkung (outside-in-signaling), wobei Liganden-besetzte und angehäufte (clustered) Integrine sowohl Zellform als auch Organisation des Zytoskeletts kontrollieren und eine Vielzahl von biochemischen Signalen generieren (Juliano \& Haskill, 1993; Clark \& Brugge, 1995). Im Gegensatz zu klassischen Rezeptoren lösen sie außerdem extrazelluläre Effektorantworten aus 
(inside-out-signal) (Shattil \& Ginsberg, 1997). Als wichtige Vertreter seien hier die Liganden für die lg-Superfamilien-Moleküle ICAM-1 und VCAM-1 erwähnt. $\alpha_{\llcorner} \beta_{2}$ (LFA-1; CD11a/CD18) ist einer der Hauptvermittler der Adhäsion von Lymphozyten, Monozyten und Granulozyten an das Endothel und wird von ICAM-1 gebunden. $\alpha_{4} \beta_{1}$ (VLA-4; CD49d/CD29) kommt auf Neutrophilen, Monozyten, Lymphozyten und natürlichen Killerzellen vor und ist der Ligand für VCAM-1 (Postigo et al., 1993).

Alle Familien tragen mit spezifischen Vertretern zu der Adhäsion und Transmigration von Monozyten bei der Atherosklerose bei. Erst das Zusammenspiel der verschiedenen Zelladhäsionsmoleküle gewährleistet die Rekrutierung der inflammatorischen Zellen (Springer, 1990; Kansas, 1996). Dabei können unterschiedliche Prozesse unterschiedlichen Rezeptoren zugeordnet werden.

\subsection{Monozytenadhäsion und -transmigration: Das Zusammenspiel von E-Selektin, ICAM-1 und VCAM-1}

Die Bindung der Monozyten erfolgt durch eine Kaskade von Adhäsionsschritten (Springer, 1990; Frenette \& Wagner, 1996b), die durch aufeinanderfolgende Interaktionen von spezifischen Adhäsionsrezeptoren mit spezifischen Liganden oder Gegenrezeptoren bestimmt wird (Springer \& Cybulsky, 1996; Silverstein, 1998). Dabei erfolgt die Rekrutierung der Monozyten bei chronischen Entzündungen wie der Atherosklerose - soweit bekannt - nach einem ähnlichen Mechanismus wie bei akuter Inflammation.

Die Adhäsion wird zunächst durch die Aktivierung des Endothels durch inflammatorische Zytokine wie TNF- $\alpha$, IL-1 und -4 (Raines \& Ross, 1996) oder Thrombin (Kaplanski et al., 1998) signifikant erhöht. Daraufhin wird auf der Endothelzelle die Expression der verschiedenen Oberflächen-Adhäsionsmoleküle induziert, die als Rezeptoren für monozytäre Liganden fungieren (Carlos \& Harlan, 
1994). Die Oberflächenrezeptoren agieren im Verbund mit chemotaktischen Molekülen wie MCP-1 (monocyte chemotactic protein-1) oder Osteopontin und ermöglichen die Anlagerung der Monozyten.

In der ersten Phase adhärieren die Zellen durch eine reversible Bindung, die seitens der Gefäßwand durch P- und E-Selektin vermittelt wird (rolling). Im weiteren Verlauf interagieren nun die endothelialen Oberflächenrezeptoren ICAM-1 und VCAM-1 mit ihren monozytären Liganden. Die anfänglich lockere Bindung über E-Selektin wird dadurch nunmehr durch das irreversible sticking abgelöst, so dass die Monozyten fest an der Gefäßwand haften und sich ausbreiten können (spreading). VCAM-1 und ICAM-1 ermöglichen neben $\beta_{2}$-Integrinen die darauffolgende Transmigration der Leukozyten. Aufgrund des chemotaktischen Gradienten, der von Entzündungsherden ausgeht, wandern die Monozyten dann zwischen angrenzenden Endothelzellen zum Ort der Inflammation. 


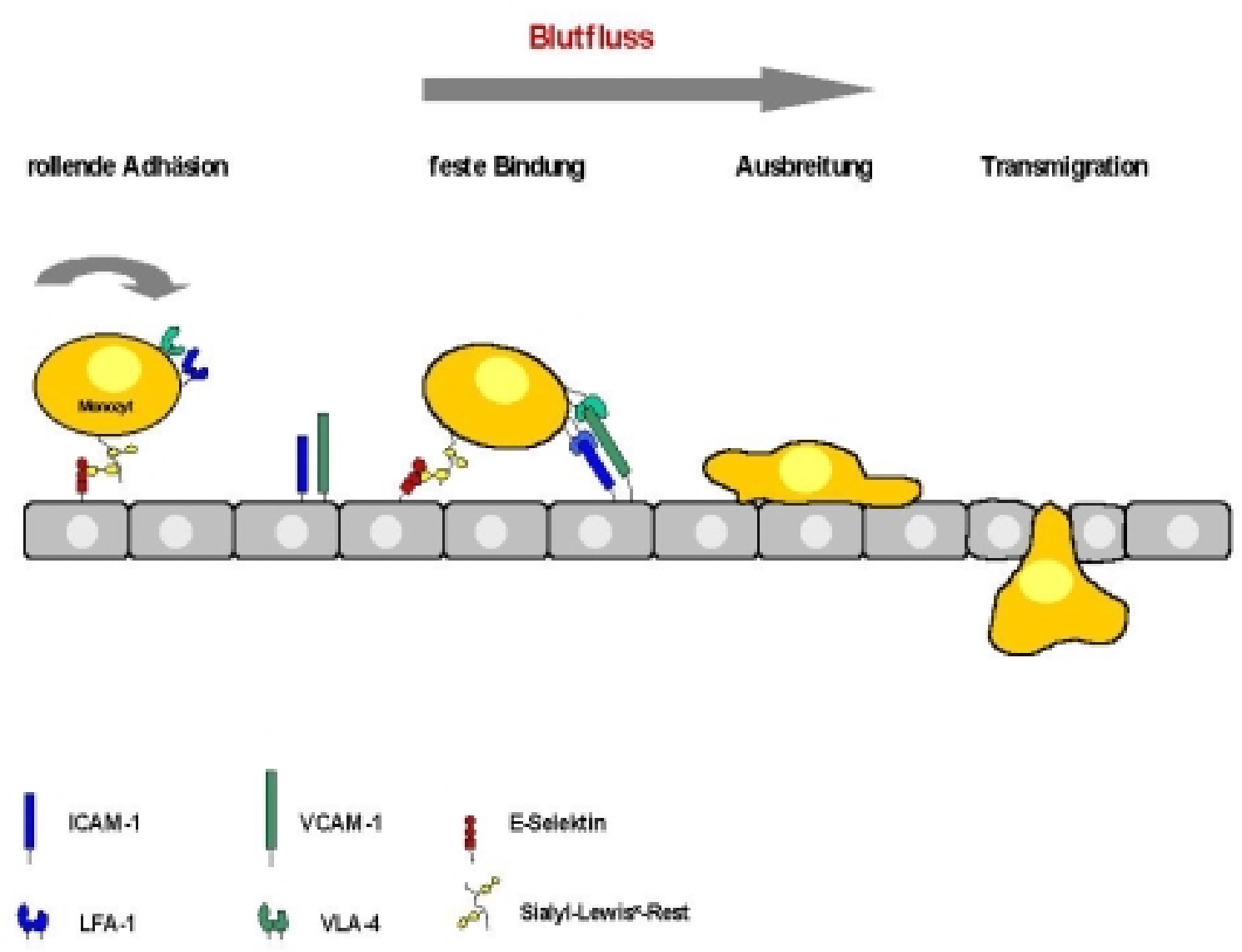

Abb. 1.1: Monozytenrekrutierung bei der Atherosklerose. In der Abbildung sind nur die in der vorliegenden Arbeit untersuchten Oberflächenrezeptoren und ihre Interaktion mit dem jeweiligen Liganden wiedergegeben. Erklärung s. Text.

Die beteiligten Adhäsionsmoleküle übernehmen bei diesem Prozess mehrere Funktionen. Zum einen vermitteln sie die Bindung der Monozyten an Endothelzellen, zum anderen vermögen sie über freigesetzte Zytokine die Expression von weiteren Adhäsionsmolekülen zu stimulieren. Dies bedingt seinerseits eine Verstärkung der Monozytenadhäsion und infolgedessen eine erhöhte Einwanderung ins Gewebe. Darüber hinaus kann durch die Bindung des Liganden an seinen Zelloberflächen-Rezeptor ein Signal generiert werden, das intrazelluläre Veränderungen bewirkt. Nicht zuletzt müssen Oberflächenrezeptoren auch Verbindungen zum Zytoskelett aufweisen, um ihre Funktion ausüben zu können. 


\subsection{Zytoskelettverankerung der Oberflächenrezeptoren}

Eine Verankerung des zytoplasmatischen Anteils des Oberflächenrezeptors ist erforderlich, damit Zellen an andere Zellen oder die extrazelluläre Matrix adhärieren können. Fehlt diese Voraussetzung, können Zellen nicht an der Unterlage ziehen oder sich zu einheitlichen Geweben zusammenlagern. Die Interaktion zwischen intrazellulären Anteilen der Oberflächenrezeptoren und dem Zytoskelett der Zelle ist ausgiebig untersucht worden, um sowohl Aufschluss über inter- bzw. extrazelluläre Kontakte, als auch über die Aktivierung von Rezeptoren zu erhalten. Das Modell, durch das die Assoziation von integralen Membranproteinen mit dem Zytoskelett wohl am besten charakterisiert wird, ist die fokale Adhäsion, wie sie bei der Integrin-vermittelten Zelladhäsion von Gewebekultur-Fibroblasten an die extrazelluläre Matrix vorkommt (Burridge \& Chrzanowska-Wodnicka, 1996; Hemler, 1998). Die äußere Domäne bindet dabei an einen Bestandteil der extrazellulären Matrix, während der zytoplasmatische Anteil an die Actinfilamente von Stressfasern gekoppelt wird. Dabei liegt eine indirekte Verbindung vor, die auf mehreren Anheftungsproteinen beruht. Der in das Zytoplasma ragende Teil bindet an Talin, das sich seinerseits an Vinculin heftet. Dieses Strukturprotein wiederum lagert sich mit $\alpha$-Actinin zusammen und wird so an ein Actinfilament gekoppelt.

Den zytoplasmatischen Domänen der beiden Untereinheiten kommen bei der Integrin-vermittelten Adhäsion wahrscheinlich noch andere wichtige Funktionen zu, da sie dem intrazellulären Signalapparat direkt zugänglich sind. Eine hierarchische Organisation kann vermutet werden. In Versuchen mit mutierten oder trunkierten $\beta$-Untereinheiten konnte gezeigt werden, dass dadurch sowohl Integrin-verstärkte Signale als auch die Organisation des Zytoskeletts unterbrochen wurden (Peter \& O'Toole, 1995). Die Überexpression von $\beta$ Untereinheiten konnte sowohl inside-out als auch outside-in-signaling unterdrücken (O'Toole, 1990). Die Zerstörung von Zytoskelettfasern durch Cytochalasin D hatte außerdem in Versuchen mit LFA-1 gezeigt, dass sich die dadurch vermittelte Leukozytenadhäsion veränderte (Peter \& O'Toole, 1995). 
Inwiefern Oberflächenrezeptoren der Selektine und der Ig-Superfamilie eine Bindung an das Zytoskelett benötigen, um ihre Funktion ausüben zu können, ist ungeklärt. Für VCAM-1 finden sich bisher keine richtungsweisenden Ergebnisse, die es ermöglichen würden, diese Fragestellung zu klären. Sowohl für E-Selektin als auch für ICAM-1 sind in der Vergangenheit zwar Assoziationen zum Actinskelett nachgewiesen worden (Carpén et al., 1992; Federici et al., 1996), aber auch hier liegen keine weiterführenden Untersuchungen vor.

Aufgrund der Untersuchungsergebnisse, die bislang fast ausschließlich für Integrine vorliegen, erscheint es daher sinnvoll, die Rolle der Zytoskelettverankerung weiterer Oberflächenrezeptoren aufzuklären, die während entzündlicher Reaktionen wichtige Funktionen übernehmen. Dabei sollte hinsichtlich der Atherosklerose zunächst ein besonderer Augenmerk auf den Oberflächenrezeptor VCAM-1 gerichtet werden, da er sowohl die Anheftung als auch die darauffolgende Diapedese von Monozyten vermittelt. Durch eine funktionelle Blockade von VCAM-1 wäre es somit eventuell möglich, zwei unerwünschte Prozesse der chronischen Rekrutierung von Monozyten gemeinsam zu inhibieren.

\subsection{Hemmung der Monozytenadhäsion}

Die genannten Adhäsionsmoleküle sind transmembranär lokalisierte Glykoproteine, die einerseits in der Zelle verankert sind und andererseits extrazellulär spezifische Liganden binden. Wie bereits für Integrine gezeigt, ist die Vermittlung der Zelladhäsion von ihrer Zytoskelettverankerung abhängig (Kaapa et al., 1999). Die Hemmung der Verankerung bietet somit einen möglichen therapeutischen Ansatz, um die Adhäsion von Monozyten an das vaskuläre Endothel zu inhibieren. Ein Oberflächenrezeptor, der ohne Kontakt zum Zytoskelett vorliegt, könnte eventuell nicht in der Lage sein, seine adhäsive Funktion auszuüben. 
Ein experimenteller Zugang zur Hemmung der Zytoskelettverankerung besteht in der Expression von Fusionsproteinen nach entsprechender Transfektion. Dadurch ergeben sich völlig neue Möglichkeiten, die chronische Rekrutierung von Monozyten zu inhibieren. Im Falle der Atherosklerose ließe sich dadurch möglicherweise ein Fortschreiten der Plaquebildung verhindern. Für den IntegrinRezeptor $\alpha_{\| b} \beta_{3}$ (CD41; GPIIb/IIla) konnte mit diesem Ansatz bereits eine dominant negative Hemmung der GPIlb/llla-vermittelten Adhäsion erzielt werden (Lee, 1997).

Das Fusionsmolekül, das hierzu entwickelt worden war, setzte sich aus CD7 und $\beta_{3}$ zusammen. Die intrazelluläre $\beta_{3}$-Domäne konnte in dieser Arbeit erfolgreich mit dem intakten Rezeptor um dessen Bindungsstellen zum Zytoskelett konkurrieren. Der klonierte CD7-Anteil, der die transmembranäre und extrazelluläre Domäne umfasste, diente als extrazellulärer Marker, der daneben den Vorteil bot, keine spezifischen Liganden zu binden. 

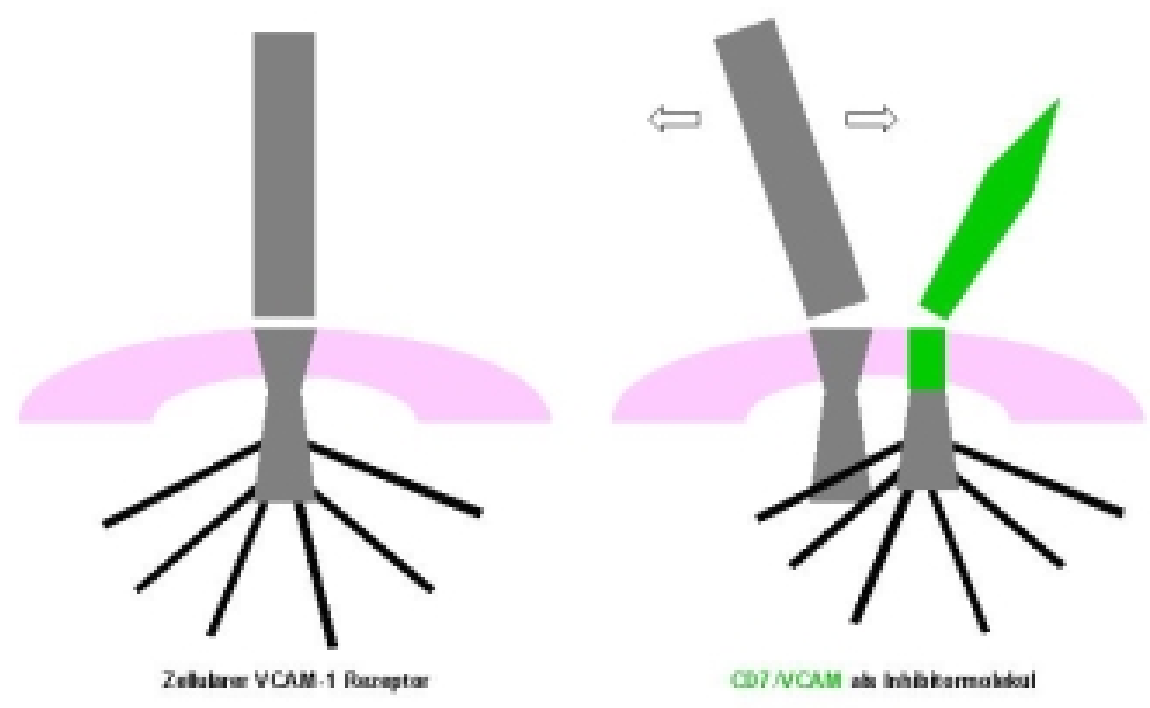

Abb. 1.2: Hemmung der Zytoskelettverankerung von VCAM-1 durch CD7/VCAM. Die gleichzeitige Expression von CD7/VCAM und VCAM-1 führt zu einer Konkurrenz um die Bindung der intrazellulären VCAM-1 Domäne an das Zytoskelett. Aus der erfolgreichen Verdrängung von VCAM-1 durch das Fusionsprotein CD7/VCAM resultiert ein funktionsloser nativer Rezeptor.

\subsection{Zielsetzung}

In der vorliegenden Arbeit sollte die Funktion von VCAM-1 bei der Rekrutierung von Monozyten untersucht, und diese selektiv durch die Transfektion eines Fusionsmoleküls blockiert werden. Da VCAM-1 mit zu den wichtigsten endothelialen Rezeptoren zählt, die bei chronisch entzündlichen Prozessen Leukozyten rekrutieren, könnte ein inhibierender Effekt des transfizierten Fusionsmoleküls auf die Zelladhäsion zukünftige gentherapeutische Möglichkeiten der Unterdrückung chronisch entzündlicher vaskulärer Prozesse einschließlich der Atherosklerose eröffnen.

Um eine Wechselwirkung mit anderen Oberflächenrezeptoren weitgehend ausschließen zu können, war zunächst ein transgenes Zellmodell zu entwickeln, 
das ausschließlich VCAM-1 exprimieren sollte. Die Zelllinie war funktionellen Tests zu unterziehen, um sowohl die VCAM-1 vermittelte Adhäsion als auch Transmigration von Monozyten aufzuklären.

Zur Untersuchung der Zytoskelettverankerung waren die transgenen Zellen mit einem Fusionsprotein zu transfizieren. Zu diesem Zweck sollte ein Fusionsmolekül aus Anteilen von CD7 und VCAM-1 entwickelt werden. Zweck des intrazellulären Sequenzanteils aus VCAM-1 bestünde in der Interaktion mit dem Zytoskelett und der selektiven Kompetition mit zellulärem VCAM-1 um dessen Bindungsstellen.

Darüber hinaus sollte erarbeitet werden, inwiefern die Blockade für VCAM-1 spezifizierbar ist. $\mathrm{Da}$ die Adhäsion und Transmigration von Monozyten vornehmlich auf das Zusammenspiel der drei Oberflächenrezeptoren E-Selektin, ICAM-1 und VCAM-1 zurückgeführt wird, waren die o.a. Untersuchungen auf die beiden Oberflächenmoleküle auszuweiten.

Die Ergebnisse der transgenen Zelllinien sollten des weiteren Grundlage für Untersuchungen am humanen endothelialen Zellmodell sein. Humane Endothelzellen exprimieren die drei untersuchten Oberflächenrezeptoren in geringen Mengen konstitutiv an ihrer Oberfläche, so dass die Wechselwirkung mit Monozyten zwischen unstimuliertem (nicht-inflammatorischer Situation) und stimuliertem (inflammatorischer Situation) Endothel verglichen werden sollte. Die funktionelle Blockade von VCAM-1 durch die Transfektion von cd7/vcam war ebenfalls zu untersuchen. 


\section{Material und Methoden}

Die Untersuchung der endothelialen Oberflächenrezeptoren E-Selektin, ICAM-1 und VCAM-1 erfolgte zunächst im Zellmodell. Dazu wurden CHO-Zellen mit dem entsprechenden Gen transfiziert und anschließend das Fusionsprotein CD7/VCAM eingebracht.

Die transgene Zelllinie CHO/E-Selektin lag im Labor von PD Dr. K. Peter an der Universitätsklinik Freiburg bereits vor. CHO/ICAM-1 wurden von Dr. A. Duperray, Laboratoire de Migration Cellulaire et Infiltration Tumorale, Institut Albert Bonniot, Domaine de la Merci, La Tronche Cedex, Frankreich, zur Verfügung gestellt. Bei diesen Zelllinien musste folglich nur das Fusionsprotein CD7/VCAM transfiziert werden.

Für die Untersuchungen an VCAM-1 wurde das Tet Off TM-System (Clontech Heidelberg, Deutschland) verwendet. Das Fusionsprotein wurde hierzu in den Vektor pTRE kloniert und zusammen mit dem Selektionsvektor pTKHyg in die Zelllinie CHO-AA8 transfiziert, die bereits den Regulationsvektor pTet Off ${ }^{\mathrm{TM}}$ stabil exprimierte. In einer weiteren Transfektion wurde VCAM-1 in pZeoSV(+) stabil in die Zellen eingebracht. Als Kontrolle wurde ausserdem die Zelllinie CHO/VCAM-1 eingesetzt, um einen möglicherweise existierenden Einfluss des Tet Off ${ }^{\mathrm{TM}}$ Systems detektieren zu können. Sie wurde von Y. Takada entwickelt, The Scripps Institute, La Jolla, Kalifornien, USA.

Weiterführende Untersuchungen wurden an primären humanen Endothelzellkulturen aus Nabelschnurvenen (human umbilical vein endothelial cells, HUVECs) durchgeführt. Zur Einschleusung von cd7/vcam wurde auf das System der Adenovirus-assoziierten-(AAV)-Transfektion zurückgegriffen. Zu diesem Zweck war das Fusionsmolekül in den Vektor pTR-UF5 zu klonieren. 


\subsection{Klonierungen}

\subsubsection{CD7/VCAM}

cd7 und vcam-1 lagen bereits in dem Vektor pcDNA1 (Invitrogen) im Labor von Dr. C. Bode an der Ludolf-Krehl-Klinik der Albert-Ludwigs-Universität Heidelberg, Abteilung für Herzinfarktforschung, vor. Für die Fusion der beiden Gene waren zunächst einige Umklonierungen erforderlich.

cd7 wurde mit Xho I geschnitten, so dass anschließend die kodierende Sequenz für die extrazelluläre und transmembranäre Domäne vorlag. Um eine kompatible Schnittstelle zum vcam-1 zu erhalten, die eine Fusion der beiden Sequenzen ermöglichte, wurde das Gen mit EcoR I verdaut.

vcam-1 wurde mit EcoR I und Xho I geschnitten, so dass nur noch der kodierende Anteil für die zytoplasmatische Domäne des Gens vorlag. Anschließend erfolgte die Ligation der beiden Teilstücke in dem Vektor pcDNA1. Das somit fertig vorliegende Fusionsmolekül cd7/vcam wurde mittels Xho I erneut geschnitten. Über die Polymeraseketten-Reaktion unter Zugabe der erforderlichen Primer wurden die Schnittstellen Hind III- bzw. Mlu I- ergänzt, die eine Klonierung in den Vektor pZeoSV (Invitrogen) ermöglichten.

Um adäquate Schnittstellen für den AAV-Vektor pTR-UF5 und das Tet Off TM System zu erhalten, musste das Molekül folgendermaßen umkloniert werden:
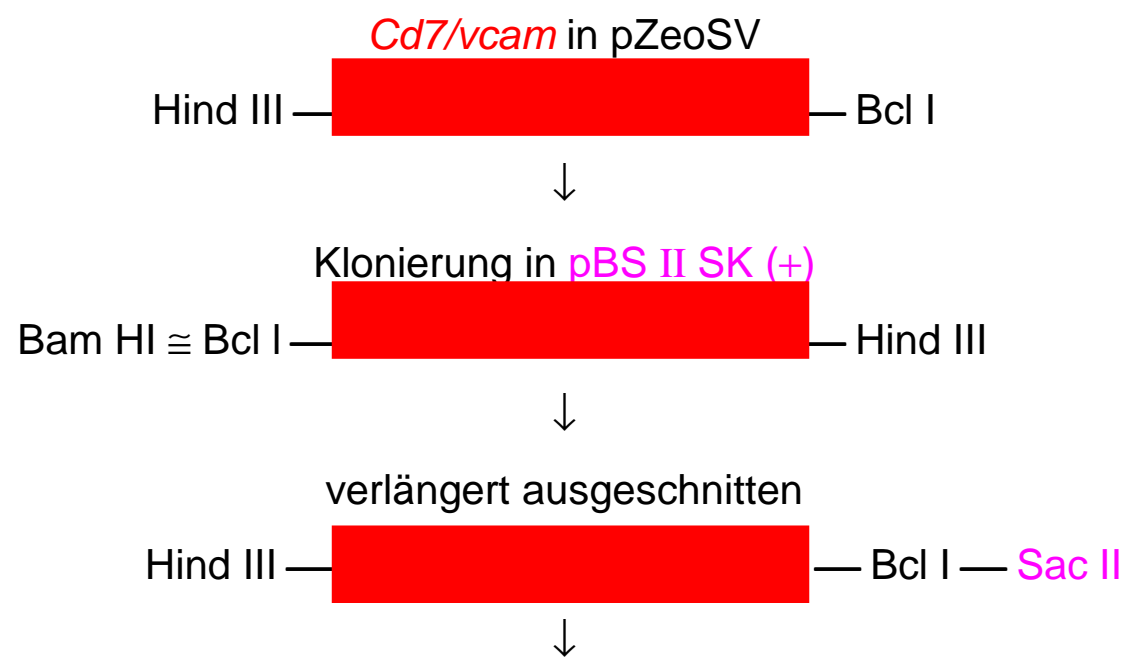


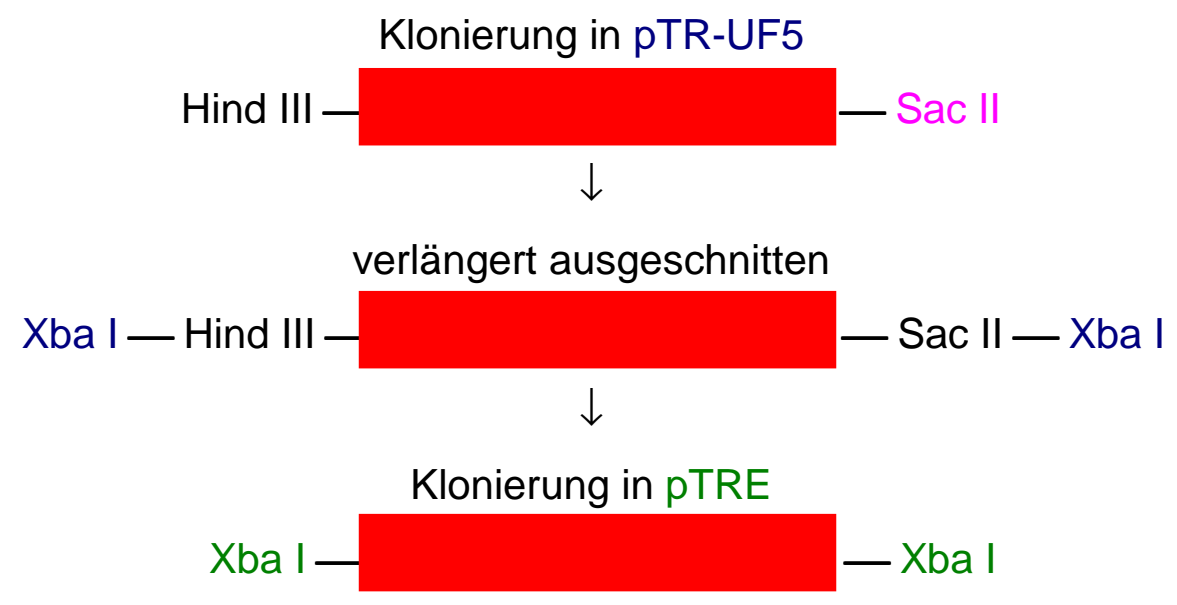

Der Vektor pTR-UF5 wurde von Dr. M. Gawaz, Deutsches Herzzentrum München, Experimentelle Kardiologie, zur Verfügung gestellt. Dabei handelt es sich um den modifizierten Vektor pBS II (+) (Stratagene), der von J.A. Kleinschmidt, Deutsches Krebsforschungszentrum, Abteilung für angewandte Tumorvirologie, Heidelberg, Deutschland, entwickelt wurde.

\subsubsection{VCAM-1}

vcam-1 wurde für die stabile Transfektion in pZeoSV2(+) (Invitrogen) umkloniert, welches eine Selektion über Zeocin ${ }^{\mathrm{TM}}$ ermöglichte. Zu diesem Zweck wurden Gen und Vektor mittels Pst I und Xho I geschnitten and anschließend ligiert.

\subsection{Heterologe Expression in Säugerzellen durch stabile Transfektion}

\subsubsection{Zelllinien}

Alle Arbeiten erfolgten mit CHO-K1 (Deutsche Sammlung für Mikroorganismen und Zellkulturen (DSMZ), Braunschweig, Deutschland). Bei der adhärenten Zelllinie liegt die Subkultur einer parenteralen CHO-Zelllinie vor, die 1957 durch Biopsie aus gesundem Gewebe des Ovariums eines adulten chinesischen 
Hamsters (chinese hamster ovary) gewonnen worden war. Die diploiden Zellen zeigen eine fibroblastenartige Morphologie und weisen als Charakteristikum einen einfachen Karyotyp auf (Puck et al., 1958).

Für die Untersuchungen an VCAM-1 unter Verwendung des Tet Off ${ }^{\mathrm{TM}_{\text {-Systems }}}$ wurde die Zelllinie CHO-AA8 eingesetzt. Dabei handelt es sich um Zellen der Linie $\mathrm{CHO}-\mathrm{K} 1$, die kommerziell mit bereits integriertem Regulationsplasmid pTet Off ${ }^{\mathrm{TM}}$ zu erhalten sind (Clontech, Heidelberg, Deutschland).

Die Zellen wurden in $175 \mathrm{~cm}^{2}$ Zellkulturflaschen (Nunc) in Zellkulturschränken (Thermoquest, Nunc) bei $37{ }^{\circ} \mathrm{C}$ mit $95 \%$ iger Luftfeuchtigkeit unter $5 \%$ iger $\mathrm{CO}_{2^{-}}$ Begasung gehalten. Die benötigten Medien zur Kultivierung der Zellen sind in 2.17.1 erläutert. Alle Arbeiten wurden unter den sterilen Bedingungen der Werkbank (Heraeus) durchgeführt.

\subsubsection{Regulation der Transgenexpression durch das Tet Off ${ }^{\mathrm{TM}}$ - System}

Das Tet-Off TM-System basiert auf negativ kontrollierter Genexpression, bei der durch die Bindung des Repressors an seinen Operator die Transkription eines benachbarten Gens inhibiert wird. Die Bindung des Repressors an den Operator wird durch einen Liganden reguliert und kann nur erfolgen, wenn der Ligand zuvor vom Repressor gebunden wurde.

Das Prinzip dieses genetischen „Ein- und Ausschalters" wird von vielen Organismen genutzt wie beim Tryptophan-Repressor von E. coli. Dem gleichen Mechanismus unterliegen auch die Gene des Tetracyclinresistenz-Operons der Bakterien, auf dem das Tet-Off ${ }^{T M}$-System beruht (Gossen \& Bujard, 1992; Gossen et al., 1995). 


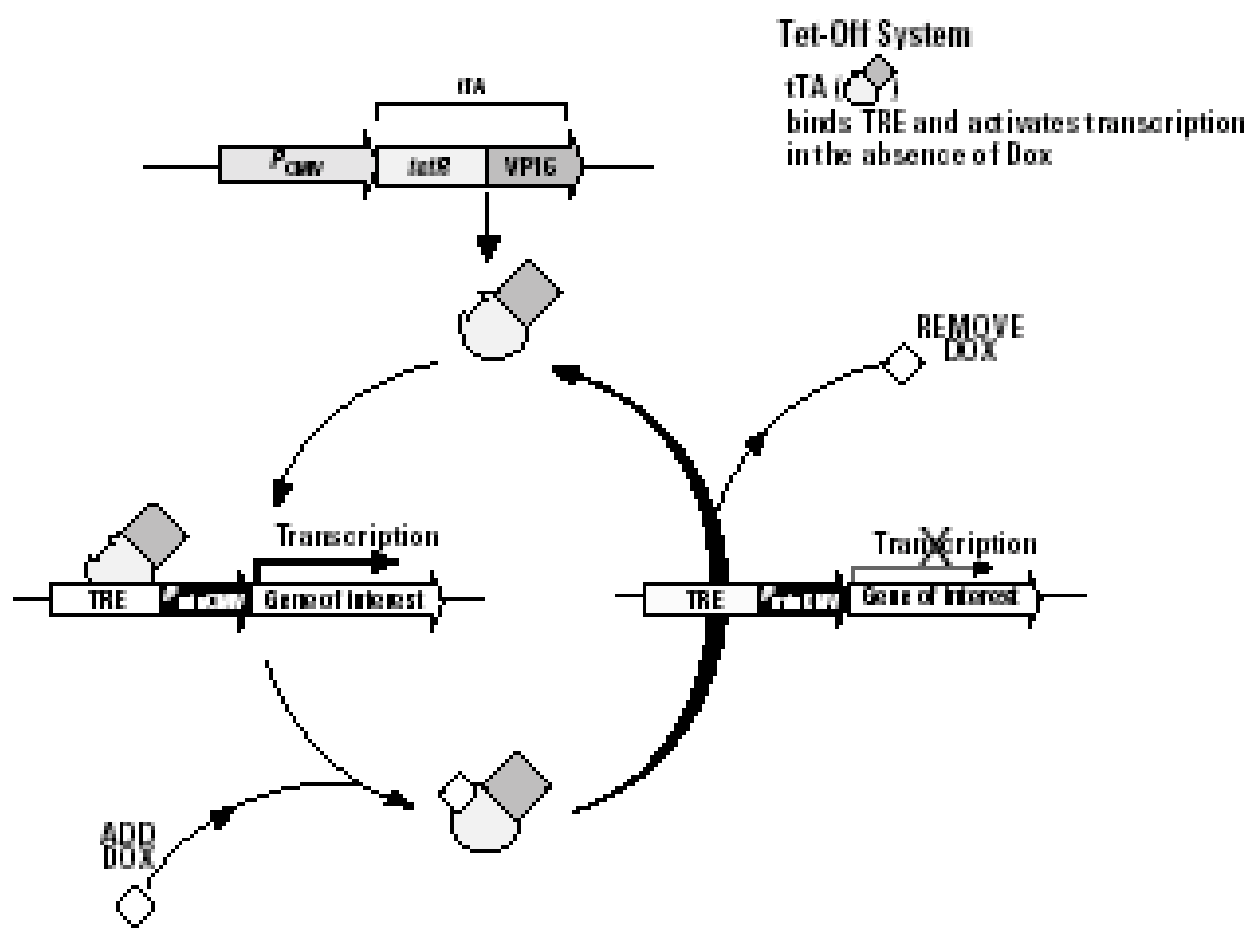

Abb. 2.1: Funktionsweise des Tet Off ${ }^{\mathrm{TM}}$-Systems.

Der Wildtyp des Tet-Repressors (TetR) wurde in diesem System mit der VP16Domäne des Herpes simplex Virus fusioniert. VP16 agiert in Säugetierzellen als Transkriptions-Aktivator (Triezenberg et al., 1988), so dass TetR nunmehr als Aktivator fungiert. Das Hybridprotein aus Repressor und Aktivator wird auch als Tetracyclin-regulierter Transaktivator (TTA) bezeichnet und ist durch eine Region auf dem Regulationsplasmid pTet-Off codiert (s. Vektorkarte).

Als "Operator" dient ein weiterer Vektor, der sich u.a. aus mehreren Kopien der E. coli tet-Operatorsequenz zusammensetzt und als pTRE (tet-responsive element) bezeichnet wird. Der Operator liegt oberhalb des CMV Promotors ( $\left.p_{\text {mincmv }}\right)$, an den die multiple Klonierungsstelle des Vektors angrenzt.

Die Bindung des TTA an pTRE erfolgt im Tet-Off TM-System nur bei fehlendem Liganden, woraufhin das klonierte Gen transkribiert wird und exprimiert werden kann. Als Ligand dient Tetracyclin bzw. dessen Derivat Doxycyclin. Die Transkription ist abhängig von der zugefügten oder entfernten Menge des Antibiotikums, so dass die Expression des klonierten Gens runter- bzw. hochreguliert werden kann. 
In dieser Arbeit wurde für die Untersuchungen an VCAM-1 das Fusionsmolekül cd7/vcam in den pTRE-Vektor kloniert und eine doppelt stabile Zelllinie entwickelt, die es ermöglichte, zunächst das Tet Off ${ }^{\top M}$-System zu untersuchen. Erst in einer weiteren Transfektion wurde vcam-1 eingebracht und Funktionsanalysen durchgeführt.

\subsubsection{Vorversuche für die Etablierung einer stabilen Zelllinie: Bestimmung des Selektionsdrucks und der Zelldichte}

Um eine stabile Zelllinie zu entwickeln, muss gewährleistet sein, dass Genpositive Zellen nicht von untransfizierten Zellen überwachsen werden. Daher waren vor Beginn der Arbeiten sowohl die Antibiotika-Konzentration als auch die Zelldichte für die jeweilige transgene Zelllinie zu bestimmen.

Zur Bestimmung des Selektionsdrucks wurden $2 * 10^{5}$ Zellen in Zellkulturschalen ausgesät ( $\varnothing 10 \mathrm{~cm}$; Nunc), die $10 \mathrm{ml}$ Vollmedium mit unterschiedlichen Konzentrationen $(100,200, \ldots, 1000 \mu \mathrm{g} / \mathrm{ml}$ ) des jeweiligen Antibiotikums enthielten. Die Platten wurden 14 Tage inkubiert, wobei das Medium jeden zweiten Tag gewechselt, und die Anzahl der lebenden Zellen lichtmikroskopisch bestimmt wurde. Um stabile Transformanten zu selektionieren, war diejenige Konzentration zu wählen, bei der nach fünf Tagen massiver Zelltod zu beobachten war und nach 14 Tagen keine lebenden Zellen im Mikroskop ausgemacht werden konnten.

Demnach ergaben sich folgende Antibiotika-Konzentrationen:

CHO-CD7/VCAM im Tet Off ${ }^{\mathrm{TM}}$-System: $\quad 100 \mu \mathrm{g} / \mathrm{ml}$ Geneticin (Gibco) $600 \mu \mathrm{g} / \mathrm{ml}$ Hygromycin (Roche) 


\begin{tabular}{|c|c|}
\hline \multirow[t]{3}{*}{ CHO-CD7/VCAM\&VCAM-1 (Tet Off ${ }^{\mathrm{TM}}$ ): } & $100 \mu \mathrm{g} / \mathrm{ml}$ Geneticin \\
\hline & $600 \mu \mathrm{g} / \mathrm{ml}$ Hygromycin \\
\hline & $600 \mu \mathrm{g} / \mathrm{ml}$ Zeocin TM (Invitrogen) \\
\hline CHO/E-Selektin: & $750 \mu \mathrm{g} / \mathrm{ml}$ Geneticin \\
\hline \multirow[t]{2}{*}{ CHO/E-Selektin\&CD7/VCAM: } & $750 \mu \mathrm{g} / \mathrm{ml}$ Geneticin \\
\hline & $600 \mu \mathrm{g} / \mathrm{ml}$ Zeocin ${ }^{\mathrm{TM}}$ \\
\hline CHO/ICAM-1: & $500 \mu \mathrm{g} / \mathrm{ml}$ Geneticin \\
\hline \multirow[t]{2}{*}{ CHO/ICAM-1\&CD7/VCAM: } & $500 \mu \mathrm{g} / \mathrm{ml}$ Geneticin \\
\hline & $600 \mu \mathrm{g} / \mathrm{ml}$ Zeocin TM \\
\hline
\end{tabular}

Um die Zelldichte zu bestimmen, waren darüber hinaus unterschiedlich große Zellpopulationen $\left(5 * 10^{6}, 1 * 10^{6}, 5 * 10^{5}, 2 * 10^{5}, 1 * 10^{5}, 5 * 10^{4}\right.$ Zellen) in Zellkulturschalen $(10 \mathrm{~cm} \varnothing)$ zu kultivieren, die $10 \mathrm{ml}$ Vollmedium mit der ermittelten Antibiotika-Konzentration enthielten. Es war diejenige Zelldichte zu wählen, bei der die Zellen nach fünf Tagen zu 80 \% konfluent waren.

Bei allen zu etablierenden Zellinien konnte demnach mit $2 * 10^{5}$ Zellen / ml gearbeitet werden.

\subsubsection{Transfektion}

Die Einschleusung der DNA in die Zellen erfolgte mittels Elektroporation, bei der durch einen kurzen elektrischen Impuls temporäre Poren in der Zytoplasmamembran erzeugt werden (Neumann et al., 1982; Potter, 1988), über die DNA aus dem Medium sowohl passiv durch Diffusion, als auch elektrophoretisch in die Zelle gelangen kann (Sukharev et al., 1994).

Die Zellen wurden unter normalen Bedingungen bis zu ca. $80 \%$ Konfluenz kultiviert. Zur Transfektion wurden 20 - $60 \mu \mathrm{g}$ DNA für $1 * 10^{7}$ Zellen eingesetzt. Das Gesamtvolumen von $1 \mathrm{ml}$ (Zellen + DNA) wurde in $4 \mathrm{~mm}$ Einwegküvetten (Biorad) in Medium (ohne Zusätze) vorgelegt und zehn Minuten auf Eis inkubiert. Als Kontrolle wurden Zellen ohne DNA elektroporiert. Die notwendigen 
Gerätevorgaben wurden nach Empfehlungen des Herstellers (BTX) vorgenommen.

Geräteeinstellung: Kapazität $970 \mu \mathrm{F}$

Spannung $370 \mathrm{~V}$

Widerstand R 3

Anschließend wurden die Zellen in $9 \mathrm{ml}$ Vollmedium ohne Selektionsdruck aufgenommen und im Brutschrank kultiviert. Nach $48 \mathrm{~h}$ wurden die Kulturen 1 : 10 aufgeteilt und die ermittelten Antibiotika-Konzentrationen zugesetzt. Die Kolonien, die sich ca. 14 Tage später im Mikroskop zeigten, wurden mittels Klonierungsringen vereinzelt und in $\operatorname{Costar}^{\circledR}$ 6-Loch-Platten (Corning Incorporated) überführt. Ungefähr drei Wochen nach der Transfektion konnten die Mischklone in der Durchflusszytometrie auf die jeweilige Expression untersucht werden.

Um Nachkommen eines Klons zu erhalten, wurden Mischklone mit besonders hoher Expression subkloniert. Dazu wurde die Zellzahl auf 1 Zelle / $100 \mu \mathrm{l}$ eingestellt und die Zellsuspension auf 96-Loch-Platten (Nunc) ausgesät. Durch anschließende Betrachtung im Lichtmikroskop konnten alle Löcher mit zwei oder mehr Zellen ausgeschlossen werden.

\subsection{Expressionsbestimmung in der Durchflusszytometrie}

Bei der Durchflusszytometrie im FACScan ${ }^{\mathrm{TM}}$ (fluorescence activated cell scanning, BD, Heidelberg, Deutschland) wurden antikörpermarkierte Zellen mit der Anregungswellenlänge $488 \mathrm{~nm}$ eines 15 Watt Argon-Lasers bestrahlt. Die markierten Zellen emittieren das Licht bei einer charakteristischen Wellenlänge.

Die Daten der folgenden Parameter wurden aufgenommen:

- Vorwärtsstreulicht (Maß für die Zellgröße)

- Seitwärtsstreulicht (Maß für die Granularität einer Zelle)

- Grün-Fluoreszenz Fluorescein-Isothiocyanat-(FITC) gekoppelter Zellen, emittieren Licht bei $525 \mathrm{~nm}$ und $575 \mathrm{~nm}$. 
Rot-Fluoreszenz Phycoerythrin-(PE) gekoppelter Zellen, emittieren Licht bei $545 \mathrm{~nm}$ und $576 \mathrm{~nm}$.

Die aufgenommenen Daten wurden über das Analyseprogramm FACScan Research (BD, Heidelberg, Deutschland) ausgewertet. Tote Zellen und Zelltrümmer wurden anhand des Streulichts identifiziert und von der Analyse ausgeschlossen.

\subsubsection{Titration der Antikörper für die Durchflusszytometrie}

Zur Bestimmung der optimalen Antikörperkonzentration wurde eine Zellsuspension unter standardisierten Bedingungen (Zellzahl, Volumen, Inkubationszeit) mit verschiedenen Antikörperkonzentrationen inkubiert und durchflusszytometrisch analysiert. Jeder Antikörper wurde sorgfältig austitriert. Die geeignete Konzentration wurde so definiert, dass eine spezifische Anfärbung der positiven Zellen und keine unspezifische Anfärbung der negativen Zellen erreicht wird. Markierte und unmarkierte Zellen müssen dabei als zwei gut zu unterscheidende Populationen sichtbar sein (Radbruch, 1992).

\subsubsection{Zellfärbung mit fluoreszenzmarkierten Antikörpern}

Für die durchflusszytometrische Analyse wurden $3 * 10^{5}$ Zellen pelletiert und in $50 \mu \mathrm{l}$ Tyrode's Lösung zur Absättigung der Fc-Rezeptoren $15 \mathrm{~min}$ auf Eis inkubiert. Die Zellen wurden mit jeweils $10 \mu$ des titrierten Antikörpers für 20 min auf Eis gefärbt. Die Ansätze wurden zentrifugiert und das Pellet in CellFix (BD) aufgenommen. Die Daten von $1 * 10^{5}$ Zellen wurden im FACScan aufgenommen und mit dem FACScan Research Programm analysiert. Bei allen Versuchen wurden Isotypenkontrollen mitgeführt, d.h. ein weiteres Aliquot wurde mit einem Antikörper gleichen Isotypes ohne Spezifität für das Antigen in der gleichen Verdünnung gefärbt und dadurch das Ausmaß der unspezifischen Markierung bestimmt. 
Tyrode‘s Lösung:

$\begin{array}{cl}150 \mathrm{mM} & \mathrm{NaCl} \\ 2,5 \mathrm{mM} & \mathrm{KCl} \\ 1 \mathrm{M} & \mathrm{CaCl}_{2} \\ 1 \mathrm{M} & \mathrm{MgCl}_{2} * 6 \mathrm{H}_{2} \mathrm{O} \\ 1,2 \mathrm{mM} & \mathrm{NaHCO}_{3} \\ 1 \%(\mathrm{w} / \mathrm{v}) & \text { Glucose } \\ 1 \%(\mathrm{w} / \mathrm{v}) & \text { BSA }\end{array}$

Verwendete Antikörper:

Isotypen-Kontrolle: IgG1 Maus anti-Human FITC (PE) Klon 679.1Mc7 (Coulter Immunotech)

CD7-Expression: IgG3 Maus anti-Human FITC Klon WM31 (Cymbus Biotechnology LTD)

CD54-Expression: IgG1 Maus anti-Human FITC Klon15.2 (Cymbus Biotechnology LTD)

CD62E-Expression: IgG1 Maus anti-Human FITC Klon BBIG-E5 (R\&D Systems) CD106-Expression: IgG1Maus anti-Human R-PE Klon 51-10C9 (BD)

\subsection{Kontrolle des Tet Off ${ }^{\mathrm{TM}}$-Systems durch Doxycyclin}

Aufgrund der höheren Wirksamkeit bei geringeren Mengen wurden alle Versuche mit dem Antibiotikum Doxycyclin (Sigma) anstelle Tetracyclins durchgeführt. Bei diesen Untersuchungen wurde ermittelt, ab welcher Dosis bzw. ab welchem Zeitpunkt eine maximale Induktion oder Repression des transfizierten Gens zu verzeichnen war.

Doxycyclin-Stammlösung: $1 \mathrm{mg} / \mathrm{ml}$ aqua dest, steril filtrieren 
Es wurden zunächst $1 * 10^{5}$ Zellen in $5 \mathrm{ml}$ Medium $\left(2 * 10^{4}\right.$ Zellen $\left./ \mathrm{ml}\right)$ auf Costar $^{\circledR}$ 6-Loch-Platten verteilt. Zur Repression wurden unterschiedliche Doxycyclin-Konzentrationen $(0 ; 0,001 ; \ldots ; 1000 \mathrm{ng} / \mathrm{ml})$ pipettiert und die Zellen $48 \mathrm{~h}$ unter diesen Bedingungen kultiviert. Zur Auswertung wurden die Zellen trypsiniert und die CD7-Expression mit o.a. Antikörper in der Durchflusszytometrie ermittelt. Nach der Bestimmung der maximal inhibierenden Antibiotika-Konzentration wurden sowohl Induktion als auch Repression in Abhängigkeit von der Zeit ermittelt. Dabei wurde den Zellen über einen Zeitraum von null bis 48 Stunden in sechsstündigem Abstand Doxycyclin zugesetzt oder entfernt. Die TransgenExpression wurde auch hier in der Durchflusszytometrie bestimmt.

\subsection{Adhäsionsversuche}

Im Anschluss an die Etablierung der transgenen Zelllinien war die Interaktion zwischen dem jeweiligen Oberflächenrezeptor und Monozyten zu untersuchen.

\subsubsection{Aufreinigung der Monozyten}

Citrat-Vollblut wurde 1: 2 mit PBS verdünnt. Für die Gewinnung der Monozytenfraktion aus Buffy Coat wurde nach einer $1: 5$ Verdünnung analog verfahren.

Jeweils $20 \mathrm{ml}$ der Suspension wurden über $15 \mathrm{ml}$ eines Ficoll-Gradienten mit einer Dichte von 1,077 (Biochrom KG) in einem $50 \mathrm{ml}$ Röhrchen (Falcon) geschichtet und 20 min bei 2700 rpm zentrifugiert (Heraeus). Die Leukozyten-Fraktion wurde isoliert, wiederum 1:2 mit PBS verdünnt und erneut $20 \mathrm{~min}$ bei $2700 \mathrm{rpm}$ zentrifugiert, um Ficollrückstände vollständig zu entfernen. Der Überstand wurde verworfen, das Pellet in $5 \mathrm{ml}$ Medium resuspendiert und in weiteren $25 \mathrm{ml}$ Medium aufgenommen. Während der darauffolgenden zweistündigen Inkubation im Brutschrank konnten die Monozyten adhärieren und so von den übrigen, nicht adhärenten Leukozyten getrennt werden. Die Monozyten wurden zweimal mit PBS 
gewaschen und direkt für Versuche eingesetzt. Die Aufreinigung ergab einen Monozyten-Anteil von ca. $90 \%$. Andere Leukozyten wurden in den Versuchen durch Antikörperfärbung von der Analyse ausgeschlossen.

PBS: $\quad 140 \mathrm{mM} \mathrm{NaCl}$

$$
\begin{aligned}
& 2,5 \mathrm{mM} \mathrm{KCl} \\
& 8,0 \mathrm{mM} \mathrm{Na}_{2} \mathrm{HPO}_{4} \\
& 1,5 \mathrm{mM} \mathrm{KH}_{2} \mathrm{PO}_{4}
\end{aligned}
$$

\subsubsection{Vorbereitung der Zellkultur}

Die Zellen wurden 48 Stunden vor dem Versuch in 24-Loch-Platten (Nunc) ausgesät und mit 1,5 ml Vollmedium unter normalen Bedingungen inkubiert. Um einen konfluenten Monolayer zu garantieren, wurde die Zellzahl auf $1 * 10^{6}$ Zellen / $\mathrm{ml}$ eingestellt und 0,2 $\mathrm{ml} /$ Loch pipettiert. Vor Versuchsbeginn wurden die Zellen unter dem Lichtmikroskop überprüft und zweimal mit $0,5 \mathrm{ml}$ PBS gewaschen.

Beim Tet Off ${ }^{\mathrm{TM}}$-System wurde in den erforderlichen Ansätzen bei Aussaat der Zellen die ermittelte Konzentration von Doxycyclin zugesetzt.

\subsubsection{Vorbereitung der Monozyten}

Der Überstand der Monozytenkulturen wurde verworfen. Die Zellen wurden mit $10 \mathrm{ml}$ PBS überschichtet und mit einem Zellschaber (Nunc) vorsichtig von ihrer Unterlage gelöst. Die Suspension wurde in ein $50 \mathrm{ml}$ Falcon pipettiert, $13 \mathrm{~min}$ bei 900 rpm zentrifugiert und in Tyrode's Lösung resuspendiert. Die Zellzahl wurde auf $2 * 10^{6}$ Zellen $/ \mathrm{ml}$ eingestellt. 


\subsubsection{Versuchsansatz}

Die Versuche wurden nach der Methode von Zapolska-Downar et al. (2000) durchgeführt. Bei dieser Versuchsanordnung werden die Aggregate zwischen Monozyten und Zellen indirekt bestimmt.

Für die Ausbildung von Aggregaten wurde $0,5 \mathrm{ml}$ Monozytensuspension zu den Zellen pipettiert und die Ansätze eine Stunde im Brutschrank inkubiert. Danach wurden die einzelnen Löcher jeweils zweimal mit 0,5 ml PBS gewaschen, um ungebundene Monozyten zu entfernen. Die verbliebenen Aggregate aus Monozyten und Zellen wurden mit $0,5 \mathrm{ml}$ Trypsin von der Unterlage gelöst und in FACS-Röhrchen (BD) überführt, in denen $1 \mathrm{ml}$ serumhaltiges Medium vorgelegt worden war, um die enzymatische Wirkung des Trypsins zu inhibieren. Nach achtminütiger Zentrifugation (900 rpm) wurde das Pellet in $50 \mu \mathrm{l}$ Tyrode's Lösung resuspendiert.

Um die Monozyten von den übrigen Leukozyten differenzieren zu können, erfolgte eine Doppelfärbung der Ansätze mit jeweils $10 \mu \mathrm{lg}$ Ig1 CD45 FITC Maus antiHuman Klon HI30 (BD) und IgG2a Maus anti-Human CD14 PE Klon RMO52 (Coulter Immunotech). Als Isotypenkontrolle wurde neben der bereits erwähnten IgG1 Kontrolle IgG2a Maus anti-Human FITC (PE) Klon U7.27 (Coulter Immunotech) mitgeführt. CD45 markierte alle Leukozyten, wohingegen CD14 als Monozyten-spezifischer Antikörper fungierte. Die transgenen CHO-Zellen ließen sich mit keinem der beiden Antikörper anfärben, so dass die Ansätze in der anschließenden durchflusszytometrischen Messung als eindeutig voneinander zu trennende Populationen aufgezeichnet werden konnten. Die Titration der Antikörper sowie Zellfärbung als auch Analyse der Proben mit dem Programm FACScan Research erfolgte wie bereits unter 2.3 erläutert.

\subsection{Blockade der beteiligten Adhäsionsmoleküle}

Zur Spezifizierung der Wechselwirkung zwischen dem jeweiligen Oberflächenrezeptor und Monozyten wurden die CHO-Zellen durch vorherige 
Inkubation mit dem erforderlichen Antikörper blockiert. In einer weiteren Versuchsreihe erfolgte die Blockade des jeweiligen Liganden auf Monozytenseite.

Die CHO-Zellen wurden vor Versuchsbeginn zweimal mit 0,5 ml PBS gewaschen. Anschließend wurden 0,2 ml Antikörper-PBS-Lösung zu den Zellen pipettiert (10 $\mathrm{ng} / \mathrm{ml}$ ) und $15 \mathrm{~min}$ bei RT inkubiert. Nach erneutem Waschen wurden die eingestellten Monozyten dazugegeben und es wurde wie bereits erwähnt verfahren.

Bei Ansätzen, in denen monozytäre Liganden zu blockieren waren, wurde der jeweilige Antikörper direkt zu den eingestellten Zellen pipettiert $(10 \mathrm{ng} / \mathrm{ml})$. Im Anschluss an die Inkubation (s.o.) wurde überschüssiger Antikörper durch erneute Zentrifugation entfernt. Die Monozyten wurden erneut in dem erforderlichen Volumen gelöst und zu den $\mathrm{CHO}$-Zellen gegeben.

\section{Blockierende Antikörper:}

- CD106: Klon 51-10C9 IgG1 Maus anti-Human (Pharmingen)

- CD49d: Klon HP2/1 IgG1 Maus anti-Human (Coulter Immunotech)

- CD54: Klon 84H10 lgG1 Maus anti-Human (Coulter Immunotech)

- CD62E: Klon BBIG-E4(5D11) lgG1 Maus anti-Human (R\&D Systems)

\subsection{Transmigrationsversuche}

Neben der Adhäsion von Monozyten an E-Selektin, ICAM-1 und VCAM-1, war es Gegenstand der vorliegenden Untersuchungen, die Rolle dieser Oberflächenrezeptoren bei der anschließenden Transmigration der Leukozyten zu untersuchen.

Die transgenen Zellen wurden auf die Membraneinsätze einer Costar ${ }^{\circledR} 24$ LochTranswell-Platte (5 $\mu \mathrm{m}$ Porengröße; Polycarbonat-Membran) pipettiert und diese zur Kultivierung der Zellen in Löcher mit 1,5 ml Medium gestellt. Nach $48 \mathrm{~h}$ wurden 
die Zellen in unbenutzte Löcher mit $0,5 \mathrm{ml}$ frischem Medium umgesetzt und dazu $0,2 \mathrm{ml}$ Monozytensuspension $\left(1 * 10^{6}\right.$ Zellen / ml) pipettiert. Die Transmigration wurde für drei Stunden ermöglicht und unter dem Lichtmikroskop verfolgt. Zur Attraktion der Monozyten waren dem Medium zuvor $50 \mathrm{ng} / \mathrm{ml}$ MCP-1 (R\&D Systems) als chemotaktischer Gradient zugesetzt worden. Im Anschluss an den Versuch wurden die Filtereinsätze mit den $\mathrm{CHO}$-Zellen und verbliebenen Monozyten entfernt. Die migrierten Monozyten wurden mittels Wright's Färbung (Sigma) visualisiert und im Lichtmikroskop ausgezählt.

MCP-1 Stammlösung: $\quad 10 \mu \mathrm{g} / \mathrm{ml}$ PBS

\subsection{Inhibition der Zytoskelettverankerung durch Cytochalasin D}

In weiterführenden Versuchen wurde die Rolle der Zytoskelettverankerung der Oberflächenrezeptoren untersucht. Um den möglicherweise existierenden Kontakt zu unterbrechen, waren die Zellen mit Cytochalasin D zu behandeln. Das Ausscheidungsprodukt von Pilzen verhindert die Polymerisation von Actinfilamenten und somit eine intakte Ausbildung des Zytoskeletts. Dies könnte Einfluss auf die Verankerung der untersuchten Oberflächenrezeptoren haben.

Der Einfluss der Inhibition durch Cytochalasin D wurde sowohl in Adhäsions- als auch in Transmigrationsversuchen untersucht. Die CHO-Zellen und Monozyten wurden dafür wie bereits beschrieben für die Versuche vorbereitet. Die transgenen $\mathrm{CHO}$-Zellen wurden vor Versuchsbeginn vier Stunden mit $50 \mathrm{ng} / \mathrm{ml}$ Cytochalasin D inkubiert.

Cytochalasin D Stammlösung: $100 \mu \mathrm{g} / \mathrm{ml}$ Chloroform 


\subsection{Die Arbeit an humanen primären Endothelzellen (HUVECs)}

Zur Verifikation der Ergebnisse, die durch das $\mathrm{CHO}$-Zellmodell erlangt wurden, waren weiterhin Versuche an humanen Endothelzellen durchzuführen. Dieses Modell zeichnet sich durch ein Zusammenspiel multipler Oberflächenrezeptoren und ihrer Liganden aus.

\subsection{Präparation der Zellen aus Nabelschnurvenen}

Die Endothelzellkulturen wurden durch Collagenaseperfusion von menschlichen Nabelschnurvenen nach der Methode von Jaffe et al. (1973) und Gimbrone et al. (1974) angelegt. Als Nachweis dienten Untersuchungen der Expression endothelspezifischer Zelloberflächenantigene wie CD31 (Parks et al., 1985). Da nicht immer genügend Material zur Verfügung stand, wurde alternativ auf kommerziell erhältliche HUVECs (PromoCell, Heidelberg, Deutschland) zurückgegriffen. Es wurden ausschließlich HUVECs aus der zweiten Passage für Versuche eingesetzt, um ein verändertes Verhalten von unterschiedlich oft passagierten Kulturen ausschließen zu können.

Um Asepsis zu gewährleisten, wurden die Nabelschnurstücke zunächst $30 \mathrm{~s}$ in $70 \%$ igen Ethanol gelegt. Anschließend wurde das Ende eines ca. $10 \mathrm{~cm}$ langen Stückes an eine $5 \mathrm{ml}$ Plastikspritze gebunden und das Gefäß mit $20 \mathrm{ml}$ PBS gespült, um Blutreste zu entfernen. Die Collagenaselösung (Sigma) wurde solange eingefüllt, bis sie am offenen Ende wieder austrat, woraufhin die Öffnung mit einer Klammer verschlossen wurde. Nach zehn Minuten Inkubationszeit bei RT wurde die Klammer abgeschnitten und die Lösung mit den darin befindlichen Endothelzellen in einer Petrischale aufgefangen. Das Blutgefäß wurde nochmals mit $10 \mathrm{ml}$ PBS durchspült und das gesamte Volumen der Petrischale anschließend fünf Minuten bei $100 \mathrm{~g}$ zentrifugiert. Das Pellet wurde in Medium resuspendiert und erneut zentrifugiert. Nach nochmaligem Waschen wurden die Zellen mit $10 \mathrm{ml}$ Medium in $75 \mathrm{~cm}^{2}$ Zellkulturflaschen (Nunc) mit 0,5\% iger Gelatine-Beschichtung bei $95 \%$ Luftfeuchtigkeit und $5 \% \mathrm{CO}_{2}$ im $37^{\circ} \mathrm{C}$ Brutschrank inkubiert. 


\begin{tabular}{|c|c|c|}
\hline \multirow[t]{8}{*}{ Medium: } & ECGM & $500 \mathrm{ml}$ \\
\hline & ECGS/H & $0,4 \%$ \\
\hline & FKS & $2 \%$ \\
\hline & EGF & $0,1 \mathrm{ng} / \mathrm{ml}$ \\
\hline & Hydrocortison & $1 \mu \mathrm{g} / \mathrm{ml}$ \\
\hline & Basic Fibroblast Factor & $1 \mathrm{ng} / \mathrm{ml}$ \\
\hline & Amphotericin B & $50 \mathrm{ng} / \mathrm{ml}$ \\
\hline & Gentamicin & $50 \mu \mathrm{g} / \mathrm{ml}$ \\
\hline
\end{tabular}

\subsection{Stimulation der HUVECs}

Die Zellen wurden zur Stimulation mit $30 \mathrm{ng} / \mathrm{ml} \mathrm{IL-1 \beta} \mathrm{(R \& D} \mathrm{Systems)} \mathrm{inkubiert.}$ Die Kinetiken der erwähnten Adhäsionsmoleküle wurden über einen Zeitraum von $12 \mathrm{~h}$ in zweistündigem Abstand vermerkt und in der Durchflusszytometrie mit den bereits erwähnten Antikörpern detektiert.

$\underline{\text { IL-1 } 1 \beta \text { Stammlösung: }}$

$1 \mu \mathrm{g} / \mathrm{ml} 1 \%(\mathrm{w} / \mathrm{v})$ BSA-PBS-Lösung

\subsection{Adhäsionsversuche: HUVECs + Monozyten}

Die HUVECs wurden für Experimente in gelatinierte Costar ${ }^{\circledR} 24$ Loch-Platten pipettiert. Versuche fanden statt, wenn unter dem Mikroskop ein vollständiger Monolayer erkennbar war (48 - 72 h nach Aussaat), um eine Adhäsion der Monozyten auf der Plastikoberfläche auszuschließen. Die Aufbereitung der Monozyten sowie die Versuchsanordnung bzw. -auswertung entsprachen den Adhäsionsversuchen zwischen stabilen $\mathrm{CHO}$-Zelllinien und Monozyten. Im Gegensatz dazu wurde die Möglichkeit zur Bildung von Aggregaten für 15 min gegeben. 


\subsection{Transmigration von Monozyten durch eine HUVECs- Zellschicht}

Die Untersuchungen stimmten mit den Versuchen an transgenen CHO-K1 Zellen überein. Die Endothelzellen wurden auf die Membraneinsätze einer Costar $^{\circledR} 24$ Loch-Transwell-Platte pipettiert und bis zum Erreichen der Konfluenz im Brutschrank inkubiert. $\mathrm{Zu}$ den HUVECs wurden 0,2 ml Monozytensuspension $\left(1 * 10^{6}\right.$ Zellen $\left./ \mathrm{ml}\right)$ pipettiert und zur Attraktion der Monozyten MCP-1 (R\&D Systems) dazugegeben. Nach dreistündiger Transmigration wurden die migrierten Monozyten gefärbt und ihre Anzahl unter dem Lichtmikroskop in einer Neubauer-Zählkammer bestimmt.

\subsection{Transfektion der Endothelzellen}

HUVECs wurden in gelatinierten 24-Loch-Platten (Nunc) bzw. Costar ${ }^{\circledR} 24$ LochTranswell-Platten ausgesät und bis ca. $80 \%$ Konfluenz inkubiert. Zu diesem Zeitpunkt erfolgte die Einbringung von $c d 7 / v c a m$ mittels Adenovirus-assoziierter Transfektion. Das Fusionsprotein, das zu diesem Zweck in den Vektor pTR-UF5 kloniert worden war, war zuvor zur Fertigstellung an die Firma Procorde, PlaneggMartinsried, Deutschland, weitergeleitet worden, die infektiöse Viren synthetisierten.

Die Zellen wurden zunächst mit PBS gewaschen, um Mediumrückstände und Debris zu entfernen. Anschließend wurden die Endothelzellen zwei Stunden unter normalen Zellkulturbedingungen mit $1 * 10^{9} \mathrm{pfu} /$ Loch inkubiert. Die Viruslösung wurde entfernt und die Zellen nach Waschen mit PBS in 1,5 ml Medium / Loch für $48 \mathrm{~h}$ kultiviert. Die erfolgreiche Infektion der Zellen erfolgte zum einem im Fluoreszenzmikroskop, da der Vektor für die Virusproduktion ebenfalls für das Gen gfp (green fluorescence protein) kodierte, und zum anderen durch Kontrolle der CD7 Expression in der Durchflusszytometrie. Die darauffolgenden Experimente wurden analog zu den Adhäsions- und Transmigrationsversuchen 
unter 2.6 - 2.8 durchgeführt. Bei allen durchflusszytometrischen Versuchen wurden CD7 und Isotypenkontrollen mitgeführt. Als interne Kontrolle dienten Endothelzellen, die nur mit dem Originalvektor (incl. gfp) infiziert worden waren. Damit konnten unspezifische Effekte durch die Infektion ausgeschlossen werden.

\subsection{Nachweis der GFP-Expression in der Immunfluoreszenz}

Bei allen Versuchen, die mit transfizierten HUVECs durchzuführen waren, wurden zusätzlich Expressionskontrollen durchgeführt. Dafür wurden Glasplättchen in die Vertiefungen von 24-Loch-Platten gelegt und anschließend Endothelzellen wie unter 2.14 beschrieben ausgesät und transfiziert.

Für die Detektion der grünen Fluoreszenz wurden die Glasplättchen auf Objektträger gelegt, auf denen sich ein Tropfen Vectashield-Einbettungsmedium für die Immunfluoreszenz (Vector Laboratories) befand. Die Betrachtung erfolgte unter dem Zeiss Axioplan II Imaging und wurde anschließend mit dem Programm AxioVision 3.0 ausgewertet.

\subsection{Statistische Auswertung}

Alle Experimente wurden dreimal in drei Parallelen durchgeführt, wodurch die Reproduzierbarkeit der Versuche sichergestellt wurde. Die Daten wurden als arithmetische Mittelwerte plus Standardabweichung (+SD) dargestellt. Die Analyse der Varianzen erfolgte mit ANOVA. Signifikanzen wurden mit dem zweiseitigen Student's t-Test berechnet. 


\subsection{Allgemeine Techniken der Zellkultur}

\subsubsection{Zusammensetzung der Medien}

Mit Ausnahme von $\alpha$-MEM (Sigma) wurden alle Medien und Zusätze von Bio Whittaker bezogen.

\begin{tabular}{|l|c|c|c|}
\hline & CHO-K1 & CHO-AA8 & Monozyten \\
\hline Medium & DMEM & $\alpha-M E M$ & RPMI1640 \\
\hline Pen / Strep & $1 \%$ & $1 \%$ & $1 \%$ \\
\hline L-Glutamin & $1 \%$ & $1 \%$ & $1 \%$ \\
\hline FCS & $10 \%$ & $10 \%$ & $10 \%$ \\
\hline NEAA & $1 \%$ & ---- & ---- \\
\hline
\end{tabular}

\subsubsection{Beschichtung von Kulturgefäßen}

Für die Kultivierung der HUVECs mussten die Zellkulturgefäße mit Gelatine beschichtet werden.

$1 \%(\mathrm{w} / \mathrm{v})$ Gelatinelösung: $\quad 1 \mathrm{~g}$ Gelatine / $100 \mathrm{ml}$ Milli-Q- $\mathrm{H}_{2} \mathrm{O}$, autoklavieren

Der Boden der Zellkulturgefäße wurde mit der sterilen Gelatinelösung bedeckt und mindestens eine Stunde im Brutschrank inkubiert. Nach Entfernung der Lösung wurden die Gefäße mit PBS gewaschen und bei $4{ }^{\circ} \mathrm{C}$ gelagert.

\subsubsection{Zellzählung durch den Trypanblau-Ausschlusstest}

Zur Bestimmung der Zellzahl sowie zur Unterscheidung lebender und toter Zellen wurden diese mit Trypanblau inkubiert. Während vitale Zellen in der Lage sind, 
den Farbstoff auszuschließen und im mikroskopischen Bild hell erscheinen, nehmen tote Zellen Trypanblau auf und sind tiefblau gefärbt.

Die Färbung wurde beim Aufteilen der Zellen durchgeführt. Dazu wurden $10 \mu \mathrm{l}$ Zellsuspension mit $10 \mu \mathrm{l}$ 0,5 \% (v/v) Trypanblaulösung (Sigma) gemischt und 5 min bei RT inkubiert. Anschließend wurde die Lösung in eine NeubauerZählkammer gegeben und unter dem Lichtmikroskop (Zeiss) ausgezählt. Der Prozentsatz an lebenden Zellen ergibt sich nach:

ungefärbte Zellen

$\%$ lebende Zellen = ungefärbte Zellen + gefärbte Zellen $* 100$

\subsubsection{Mycoplasmen-Test}

Um eine Verfälschung der Ergebnisse durch Mycoplasmen-Kontamination auszuschließen, wurden in regelmäßigen Abständen Kontrollen durchgeführt (Myco-plasma Detection Kit; Boehringer Mannheim). Das Testprinzip basierte auf der ELISA-Technik und beinhaltete polyclonale Antikörper zum Nachweis der am meisten verbreiteten Mycoplasmen / Acholeplasmen-Spezies in der Zellkultur ( $M$. arginini, M. hyorhinis, M. laidlawii, M. orale). Für alle im Rahmen dieser Arbeit durchgeführten Versuche wurden ausschließlich Mycoplasmen-freie Kulturen eingesetzt.

\subsubsection{Aufteilung adhärenter Zellen}

CHO-Zellen wurden in 48-stündigen Abständen (80 - 90 \% Konfluenz) aufgeteilt. Die Zellen wurden hierfür zur Entfernung von Serumrückständen mit $10 \mathrm{ml}$ PBS gewaschen und anschließend 1-5 min mit Trypsin-EDTA (Bio Whittaker) bei $37^{\circ} \mathrm{C}$ inkubiert. Nach Betrachtung der Zellen unter dem Mikroskop wurde die enzymatische Wirkung des Trypsins durch Zugabe von serumhaltigem Medium inhibiert. 
Ein Teil des Volumens wurde weiterkultiviert (1:20 - $1: 25)$, der Zellüberschuss für Versuche eingesetzt.

HUVECs wurden nach der Kultivierung bis ca. 90 \% Konfluenz inkubiert und dann für die durchzuführenden Versuche entsprechend ausgesät, so dass ausschließlich Kulturen aus der zweiten Passage für Versuche eingesetzt wurden.

\subsubsection{Auftauen und Einfrieren von Säugerzellen}

Von allen $\mathrm{CHO}-Z e l l i n i e n$ wurden Dauerkulturen angelegt, die bei Bedarf wieder kultiviert werden konnten.

Zum Einfrieren wurden die Zellen nach dem Ablösen zentrifugiert und mit $2 * 10^{6}$ Zellen / $\mathrm{ml}$ in DMSO-Einfriermedium (Gibco) resuspendiert. Jeweils $1 \mathrm{ml}$ wurde in Kryoröhrchen (Greiner) pipettiert und in Einfrierboxen bei $-80^{\circ} \mathrm{C}$ eingefroren. Nach $24 \mathrm{~h}$ konnten sie zur dauerhaften Lagerung in der Gasphase über flüssigem Stickstoff umgesetzt werden.

Das Auftauen erfolgte im $37^{\circ} \mathrm{C}$ Wasserbad. Das Volumen der Kryoröhrchen wurde anschließend in $50 \mathrm{ml}$ Falcons mit $15 \mathrm{ml}$ Auftaumedium (20\% FKS) überführt und 5 min mit $900 \mathrm{rpm}$ zentrifugiert. Der Überstand wurde verworfen, die Zellen in $15 \mathrm{ml}$ Medium resuspendiert und in $75 \mathrm{~cm}^{2}$ Zellkulturflaschen ausgesät. Bei Zellen, die unter Selektionsdruck gehalten wurden, konnte das entsprechende Antibiotikum nach zwei Tagen zugesetzt werden. Ab diesem Zeitpunkt wurden alle Zellen unter Wachstumsbedingungen mit $10 \%$ FKS gehalten.

Bei allen Zelllinien wurde bei diesen Arbeiten und außerdem in regelmäßigen Abständen die Expression des Transgens mit dem entsprechenden Antikörper kontrolliert. 


\subsection{Allgemeine Techniken der Bakterienkultur}

\subsubsection{Transformation}

Kompetente E. coli wurden auf Eis aufgetaut und Aliquots von $100 \mu \mathrm{l}$ in vorgekühlten 1,5 ml Reaktionsgefäßen vorgelegt. Die Bakterien wurden mit 50 $100 \mathrm{ng}$ DNA für $30 \mathrm{~min}$ auf Eis inkubiert. Anschließend erfolgte für $60 \mathrm{~s}$ ein Hitzeschock im Heizblock (Eppendorf) bei $42{ }^{\circ} \mathrm{C}$, woraufhin die Bakterien zwei Minuten auf Eis gelagert wurden. Die Ansätze wurden mit 0,9 ml SOC-Medium (RT) versehen und eine Stunde bei $37^{\circ} \mathrm{C}$ unter Schütteln mit $200 \mathrm{rpm}$ inkubiert. Jeweils $100 \mu$ l einer Verdünnungsreihe $\left(10^{-2}, 10^{-3}, 10^{-4}\right)$ der Bakteriensuspension wurden auf LB-Selektiv-Agarplatten ausgestrichen und über Nacht bei $37^{\circ} \mathrm{C} \mathrm{im}$ Brutschrank inkubiert.

Bei allen Transformationen liefen Positiv- und Negativkontrollen mit. Für Positivkontrollen wurden Kontrollplasmide wie pUC 18 in die Zellen eingebracht, wohingegen die Negativkontrollen nur aus dem jeweiligen E. coli-Stamm bestanden.

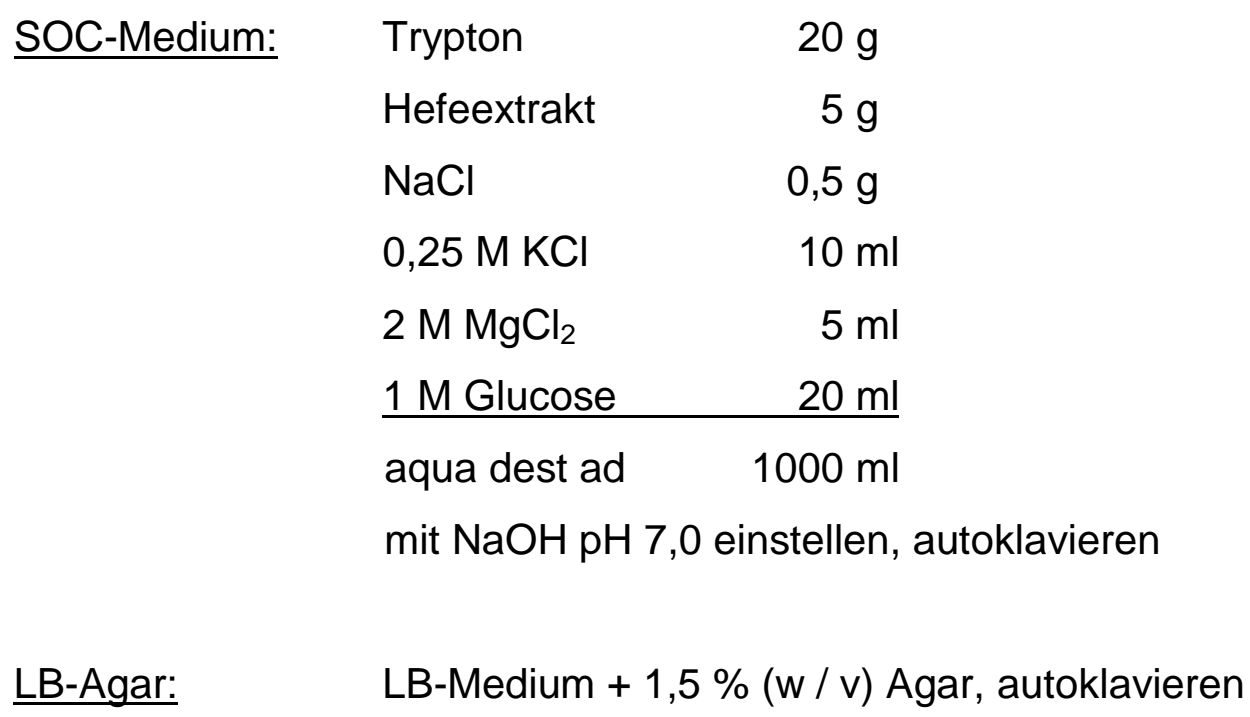


Antibiotika-Konzentrationen:

\begin{tabular}{|l|l|l|}
\hline Antibiotikum & Arbeitskonzentration $(\mu \mathrm{g} / \mathrm{ml})$ & Stammlösung $(\mathrm{mg} / \mathrm{ml})$ \\
\hline Ampicillin (Amp) & 50 & 50 in $\mathrm{H}_{2} \mathrm{O}$ \\
\hline Tetracyclin (Tet) & 12,5 & 12,5 in Ethanol \\
\hline Zeocin® & 25 & 100 in $\mathrm{H}_{2} \mathrm{O}$ \\
\hline
\end{tabular}

\subsubsection{Anzucht von Bakterien}

Für die Anzucht von E.coli wurden $5 \mathrm{ml}$ LB-Selektiv-Medium mit einer einzelnen Kolonie von einer frischen selektiven Agarplatte beimpft und acht bis zehn Stunden unter Schütteln (270 rpm) bei $37^{\circ} \mathrm{C}$ inkubiert. Im nächsten Schritt wurden $100 \mathrm{ml}$ LB-Selektiv-Medium mit $50-100 \mu \mathrm{l}$ der Vorkultur beimpft und die Kultur $12-16 \mathrm{~h}$ bis zum Erreichen der frühen stationären Phase unter Schütteln bei $37^{\circ} \mathrm{C}$ inkubiert.

\begin{tabular}{|c|c|c|}
\hline LB-Medium: & Trypton & $10 \mathrm{~g}$ \\
\hline & Hefeextrakt & $5 \mathrm{~g}$ \\
\hline & $\underline{\mathrm{NaCl}}$ & $10 \mathrm{~g}$ \\
\hline & aqua dest ac & $000 \mathrm{ml}$ \\
\hline
\end{tabular}

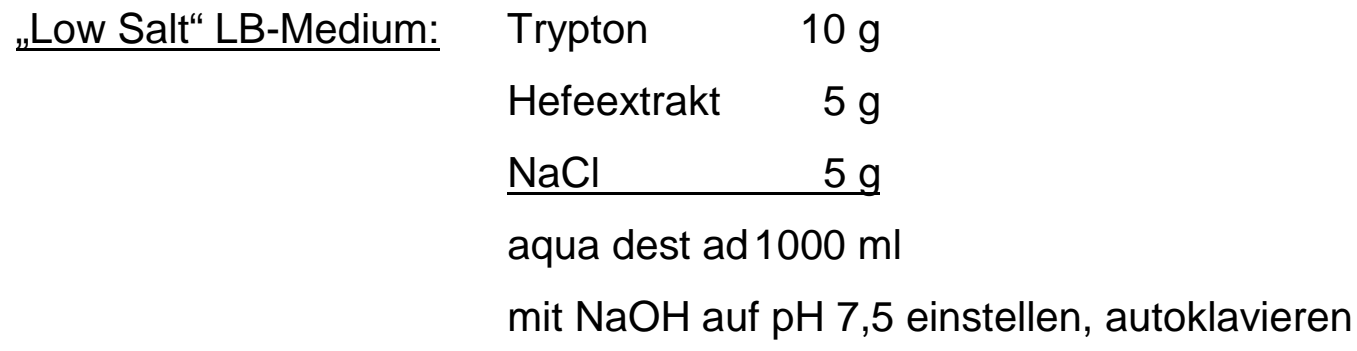




\subsubsection{Isolierung und Aufreinigung von Plasmid-DNA}

Alle Arbeiten wurden mit Produkten der Firma Qiagen (Mini- bzw. EndoFree-MaxiKit) durchgeführt, wobei die Herstellerprotokolle ohne Modifikation übernommen werden konnten. Die Isolierung der Plasmid-DNA erfolgt durch alkalische Lyse der Bakterien und basiert auf dem Verfahren von Birnboim \& Doly (1979).

Nach Anzucht der Kulturen (s. 2.18.2) wurden die Bakterien in ein JA-10-Zentrifugenbecher (Nalgene) überführt und im entsprechenden Rotor (Beckman) bei $6000 \times \mathrm{g}$ für 15 min bei $4{ }^{\circ} \mathrm{C}$ abzentrifugiert. Das Bakteriensediment wurde in Resuspensionspuffer gelöst und mit alkalischem Lysepuffer versetzt. Nach fünfminütiger Inkubation bei Raumtemperatur wurde Neutralisierungspuffer zum Lysat pipettiert, wodurch genomische DNA, Proteine und Zelltrümmer ausgefällt wurden. Zur Aufreinigung wurde das Bakterienlysat auf eine Anionenaustauschersäule aufgetragen, die vorab mit Äquilibrierungspuffer vorbereitet worden war. Die Plasmid-DNA band in diesem Schritt an die Matrix der Säule, während RNA, Proteine oder andere Kontaminationen die Säule passierten. Anschließend wurde die DNA mittels Waschpuffer gereinigt und durch Elutionspuffer von der Säule gelöst. Das Eluat mit der Plasmid-DNA wurde mit 0,7 Volumen Isopropanol versetzt und sofort für $30 \mathrm{~min}$ mit $15.000 \times \mathrm{g}$ bei $4^{\circ} \mathrm{C}$ gefällt. Nach Entfernung des Überstands wurde das Eluat mit $5 \mathrm{ml} 70 \%$ igem Ethanol gewaschen und erneut zehn Minuten zentrifugiert. Das Sediment mit der Plasmid-DNA wurde daraufhin zehn Minuten an der Luft getrocknet und abschließend in $50-200 \mu$ TE-Puffer $(\mathrm{pH} 8)$ resuspendiert.

$\begin{array}{lcl}\text { Resuspensionspuffer (P1): } & 50 \mathrm{mM} & \text { Tris/HCl, pH 8,0 } \\ & 10 \mathrm{mM} & \text { EDTA } \\ 1 \mu \mathrm{g} / \mathrm{ml} & \text { RNAse } \\ & & \\ \text { Lysepuffer (P2): } & 200 \mathrm{mM} & \mathrm{NaOH} \\ & 1 \%(\mathrm{w} / \mathrm{v}) & \text { SDS }\end{array}$


Neutralisierungspuffer (P3): $\quad 2,55 \mathrm{M} \quad \mathrm{KAc}, \mathrm{pH} 4,8$

Äquilibrierungspuffer (QBT): $\quad 750 \mathrm{mM} \quad \mathrm{NaCl}$

$50 \mathrm{mM} \quad$ MOPS, $\mathrm{pH} 7,0$

$15 \%(v / v)$ Ethanol

Waschpuffer (QC):

$\begin{array}{cl}1 \mathrm{M} & \mathrm{NaCl} \\ 50 \mathrm{mM} & \text { MOPS, pH 7,0 } \\ 15 \%(\mathrm{v} / \mathrm{v}) & \text { Ethanol }\end{array}$

Elutionspuffer (QF):

$\begin{array}{ll}1,2 \mathrm{M} & \mathrm{NaCl} \\ 50 \mathrm{mM} & \text { MOPS, pH 8,0 } \\ 15 \%(\mathrm{v} / \mathrm{v}) & \text { Ethanol }\end{array}$

\subsection{Konzentrationsbestimmung von Nucleinsäurelösungen}

Die Konzentrationsbestimmung erfolgte in der Regel über die Messung der optischen Dichte, da vorwiegend große Mengen Nucleinsäurelösungen (mindestens $50 \mu \mathrm{g} / \mathrm{ml}$ ) zur Verfügung standen. Die Konzentration errechnet sich nach:

$$
\begin{aligned}
& \mathbf{c}[\boldsymbol{\mu g} / \mathbf{m l}]=\mathrm{OD}_{260} * \mathbf{V} * \mathbf{F} \\
& \mathrm{C}:=\text { Konzentration der Ausgangslösung } \\
& O D_{260}:=\text { optische Dichte bei } 260 \mathrm{~nm} \text { Wellenlänge } \\
& \mathrm{V}:=\text { Verdünnungsfaktor } \\
& \mathrm{F}:=\text { Multiplikationsfaktor }
\end{aligned}
$$

(50; 40; 37; 20 bei dsDNA; RNA; ssDNA; einzelsträngige Oligonucleotide) 
Das Verhältnis $\mathrm{OD}_{260}: \mathrm{OD}_{280}$ wurde ebenfalls ermittelt, um Proteinverunreinigungen auszuschließen. Eine proteinfreie Nucleinsäurelösung sollte ein Verhältnis zwischen 1,8 und 2 aufweisen.

Um geringe Mengen quantifizieren zu können, wurde die Konzentration über ein Agarosegel bestimmt. Ein Aliquot der Nucleinsäurelösung wurde gemeinsam mit einer Verdünnungsreihe eines DNA-Größenmarkers aufgetragen, von dem sowohl Fragmentlänge als auch Menge bekannt waren, so dass der optische Vergleich eine Abschätzung der zu quantifizierenden Probe ermöglichte.

\subsection{Restriktionsanalyse}

Für die Restriktion wurden 0,3 $\mu \mathrm{g}$ DNA mit $3 \mu \mathrm{l}$ des erforderlichen Enzyms und $3 \mu \mathrm{l} 10 *$ Restriktionspuffer (Roche) in 1,5 ml Reaktionsgefäßen gemischt und mit $\mathrm{H}_{2} \mathrm{O}$ auf ein Volumen von $30 \mu$ eingestellt. Der Verdau erfolgte für 60 min bei der erforderlichen Temperatur im Heizblock. Die linearen DNA-Fragmente wurden anschließend in Agarosegelen analysiert.

\subsection{Native Agarose-Gelelektrophorese für DNA}

Zur Herstellung eines 1 \%igen Agarosegels wurde $1 \mathrm{~g}$ Agarose (Biorad) in $100 \mathrm{ml}$ 1 * TAE-Puffer (Tris-Acetat-EDTA-Puffer) suspendiert und aufgekocht. Nachdem die Lösung auf $50-60{ }^{\circ} \mathrm{C}$ abgekühlt war, wurde sie luftblasenfrei in die Gelkammer gegossen (4 mm Schichtdicke) und anschließend die Taschenschablone an der Kathodenseite eingesetzt. Ungefähr 30 - 60 min später war das Gel erstarrt und konnte für die Elektrophorese eingesetzt werden.

Dazu wurde das Gel in die Elektrophoresekammer (Eurogentec) gelegt und mit $1 *$ TAE-Elektrophoresepuffer überschichtet. Jeweils $10 \mu \mathrm{l}$ der Restriktionsansätze plus $2 \mu \mathrm{l}$ Farbmarker (Blue / Orange $6 *$ Loading Dye, Promega) wurden in die Probentaschen eingebracht. Der DNA-Größenstandard ( $\phi$ X-174-RF DNA Hae III Digest bzw. Lambda DNA-Hind III Digest, Amersham Parmacia Biotech) wurde 
ebenfalls mit Farbmarker versetzt, mit $\mathrm{H}_{2} \mathrm{O}$ auf ein Gesamtvolumen von $12 \mu \mathrm{l}$ eingestellt und in die Probentaschen pipettiert. Anschließend wurde die Elektrophorese solange durchgeführt, bis der Marker die erforderliche Strecke zurückgelegt hatte (ca. 30 min bei $100 \mathrm{~V}$ ). Das Gel wurde daraufhin gefärbt und dokumentiert.

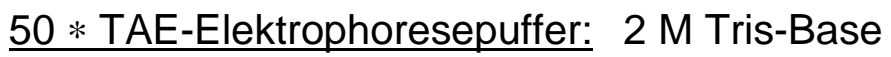

$242 \mathrm{~g}$

$1 \mathrm{M}$ Essigsäure

$57,1 \mathrm{ml}$

$\underline{0,1 \mathrm{M} \text { EDTA } \mathrm{pH} 8,3}$ $100 \mathrm{ml}$ aqua dest ad $1000 \mathrm{ml}$

\subsection{Anfärbung von Nucleinsäuren in Gelen mit Ethidiumbromid und ihre Dokumentation}

Die Agarosegele wurden nach der Elektrophorese kurz mit $\mathrm{H}_{2} \mathrm{O}$ abgespült und anschließend unter gelegentlichem Schütteln in Ethidiumbromid-Lösung für 10 - 15 min gefärbt.

Ethidiumbromid-Färbelösung: $\quad 0,4 \mathrm{ml}$ Ethidiumbromid-Stammlösung $(0,5 \mathrm{mg} / \mathrm{ml})$ ad $400 \mathrm{ml} \mathrm{H} \mathrm{H}_{2} \mathrm{O}$ (finale Konzentration: $50 \mu \mathrm{g} / \mathrm{ml}$ )

Zur Dokumentation wurden die Gele bei durchscheinendem UV-Licht (302 nm) auf einem Transilluminator (Vilber Lourmat) mit einer MP4-Polaroidkamera fotografiert (Polaroid Schwarz-Weiß-Sofortbildfilm Type 667; ASA 3000).

\subsection{Ligation}

Vektor und Donor-DNA-Fragment wurden mit den erforderlichen Restriktionsenzymen geschnitten, elektrophoretisch aufgetrennt, gefärbt und 
dokumentiert. Anschließend wurden die gewünschten Fragmente mit einem Skalpell ausgeschnitten und nach Hersteller-Protokoll aufgereinigt (Qiagen Gel Extraction Kit). Ein Teil der eluierten DNA (5 $\mu$ Insert-, bzw. $1 \mu$ l Vektor-DNA) wurde erneut auf ein $1 \%$ iges Agarose-Gel aufgetragen, um die Konzentration der Fragmente abschätzen zu können.

Vektor und Insert wurden im Verhältnis $1: 3$ für die Ligation eingesetzt. Die erforderliche DNA-Menge des Inserts wurde nach folgender Formel ermittelt:

$\underline{\text { ng Vektor * kb Größe Insert }}$ kb Größe Vektor Insert molares Verhältnis Vektor $=$ ng Insert

Um eine Religation der Klonierungsvektoren auszuschließen, wurden sie vor der Ligation mittels alkalischer Phosphatase aus Kälberdarm (Roche) dephosphoryliert.

$\begin{array}{llll}\text { Ligationsansatz: } & \text { Vektor DNA } & \text { xng (s.o.) } & \\ & \text { Insert DNA } & \text { y ng (s.o.) } & \\ & \text { T4 Ligase (Weiss Units) } & 1 \mathrm{u} & \text { (Roche) } \\ & \text { Ligase } 10 * \text { Puffer } & 1 \mu \mathrm{l} & \\ & \text { aqua dest ad } & 10 \mu \mathrm{l} & 16 \mathrm{~h} ; 4^{\circ} \mathrm{C}\end{array}$

Als Religationskontrolle wurden Ansätze pipettiert, die nur vektorielle, dephosphorylierte DNA enthielten.

Die Plasmide wurden in die erforderlichen E.coli-Stämme (s. 2.25) transformiert und auf LB-Selektiv-Platten ausgestrichen. Durch anschließende Mini- bzw. Maxipräparation der Plasmid-DNA wurden ausreichende Mengen für Transfektionen und Sequenzanalysen synthetisiert. 


\subsection{DNA-Sequenzanalyse}

Alle im Rahmen dieser Arbeit durchgeführten Klonierungen wurden durch Sequenzanalysen auf Mutationen und ihre korrekte Klonierungsposition in Vektoren untersucht. Die notwendigen Reaktionen wurden von MediGenomix $\mathrm{GmbH}$, DNA Analytics and Genomics, Planegg-Martinsried, Deutschland, durchgeführt. Die Sequenzen wurden anschließend mit verschiedenen GenDatenbanken (NCBI, DKFZ, EMBL) mittels der üblichen Analyseprogramme (FASTA, BLAST, etc.) verglichen.

\subsection{Bakterienstämme}

\section{Stratagene:}

- $\underline{\text { SCS } 110}$ (Amplifikation von CD7/VCAM in pZeoSV): rpsL (Str') thr leu endA thi-1 lacY galK galT ara tonA tsx dam dcm supE44 $\Delta$ (lac-proAB) [F' traD36 proAB lacl $\left.{ }^{q} Z \Delta M 15\right]$

- XL1-Blue MRF' (pBS II SK (+)): $\Delta(m c r A) 183 \Delta$ (mcr-hsdSMR-mrr)173 endA1 supE44 thi-1 recA1 gyrA96 relA1 lac [F' proAB lac/ ${ }^{q} Z \Delta M 15$ Tn 10 (Tet $\left.\left.^{r}\right)\right]$

- Epicurian Coli $^{\circledR}$ SURE $^{\circledR}$ (CD7/VCAM in pTRE; pTet Off; pTRE; pTKHyg; CD7/VCAM in pTR-UF5): e14"(McrA') $\Delta$ (mcrCB-hsdSMR-mrr)171 endA1 supE44 thi-1 gyrA96 relA1 lac recB recJ sbcC umuC::Tn5 (Kan') uvrC [F' proAB lacl $\left.{ }^{q} \mathrm{Z} \Delta M 15 \operatorname{Tn} 10\left(\mathrm{Tet}^{\mathrm{r}}\right)\right]$

Invitrogen:

- $\mathrm{MC}$ 1061/P3 (VCAM-1 in pcDNAI): $\mathrm{F}^{-} h s d \mathrm{R}\left(\mathrm{r}_{\mathrm{k}}{ }^{-}, \mathrm{m}_{\mathrm{k}}{ }^{+}\right) \operatorname{araD139} \Delta$ (ara ABC leu)7679 gall galK $\Delta$ lacX74 rpsL thi mcrB [P3: $\left.\operatorname{Kan}^{R} \mathrm{Amp}^{\mathrm{R}}(\mathrm{am}) \mathrm{Tet}^{\mathrm{R}}(\mathrm{am})\right]$

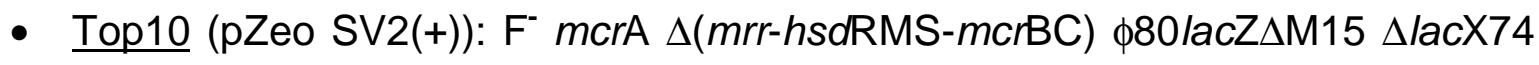
deoR recA1 araD139 $\Delta\left(\right.$ ara-leu)7697 galN ga/K rpsL $\left(\mathrm{Str}^{\mathrm{R}}\right)$ endA1 nupG 
Clontech:

- Dh5 $\left(\mathrm{pDG} ; \mathrm{pTR}\right.$-UF5): deoR, endA1, gyrA96, hsdR17(rk- mk ${ }^{+}$), recA1, relA1,

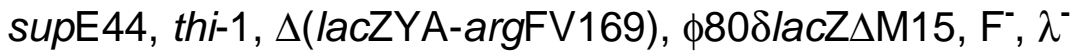

\subsection{Vektorkarten}
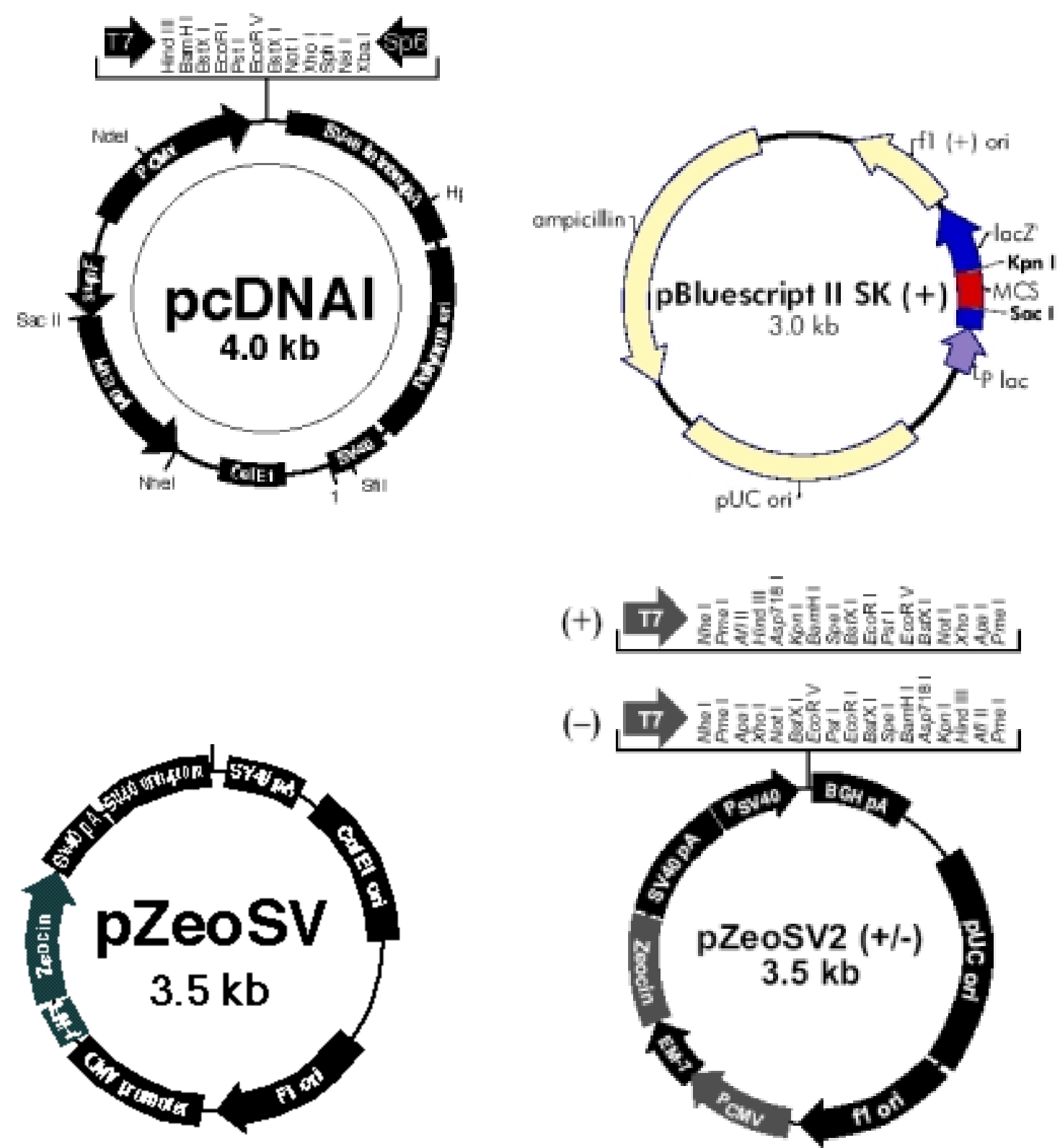

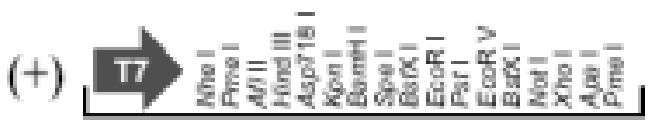
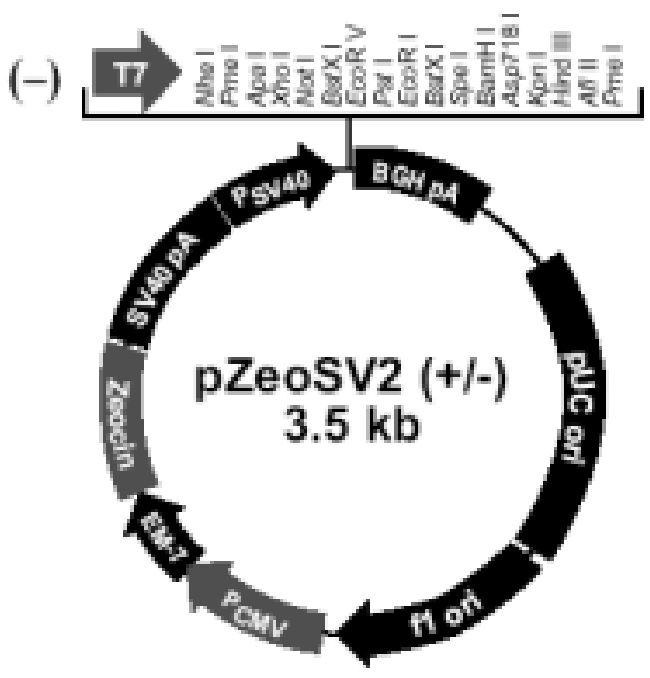

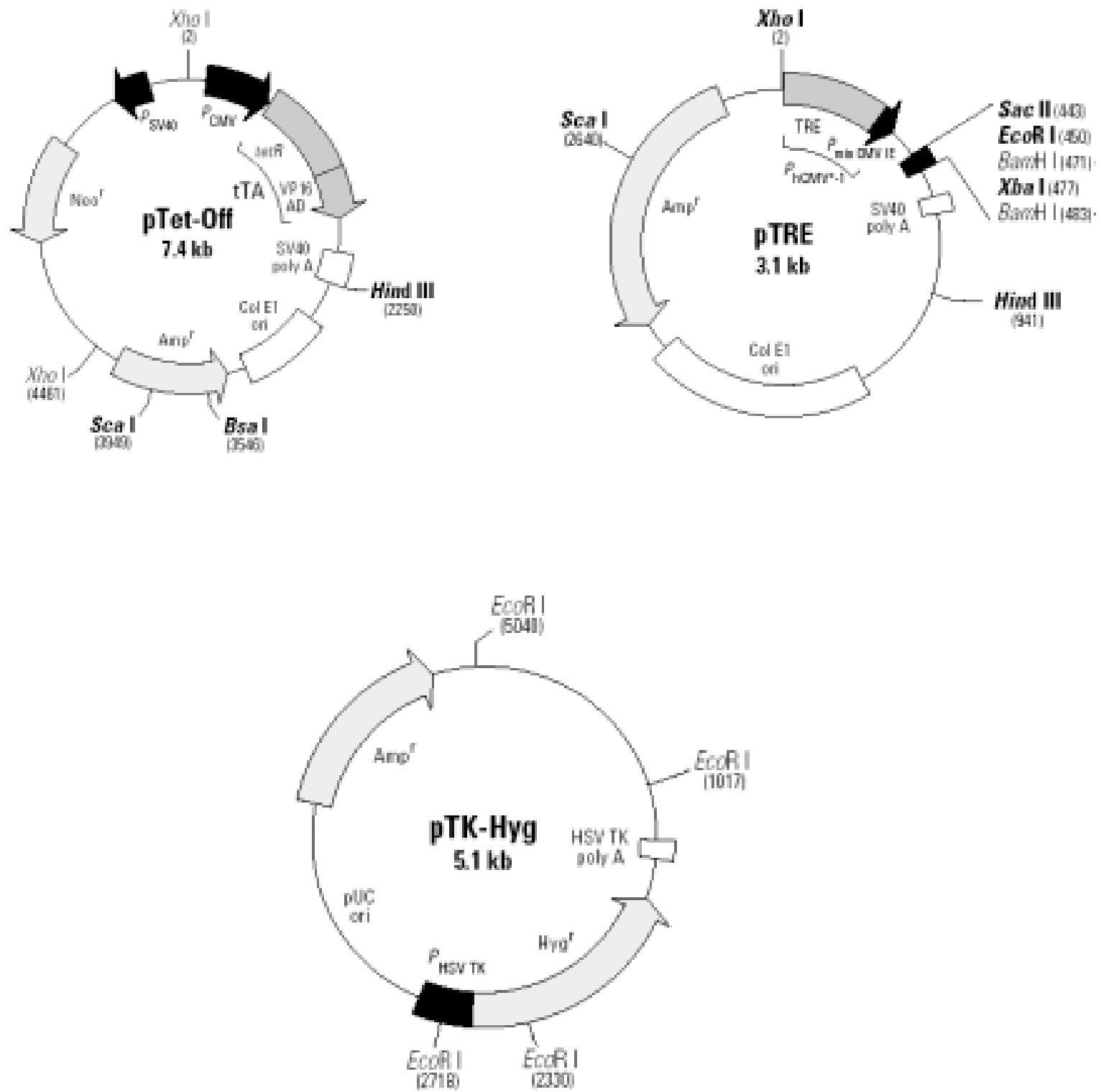


\section{Ergebnisse}

\subsection{Bestimmung der Transgen-Expression von E-Selektin, ICAM- 1, VCAM-1 und CD7/VCAM in der Durchflusszytometrie}

Die erfolgreiche Transfektion der CHO-Zellen mit vcam-1, icam-1, e-selektin und cd7/vcam wurde in der Durchflusszytometrie ermittelt. Als Kontrolle dienten $\mathrm{CHO}$ K1 ( $\mathrm{CHO}$ ) bzw. CHO-AA8 Zellen, die mit dem entsprechenden Antikörper gefärbt worden waren, um eine unspezifische Bindung ausschließen zu können. Darüber hinaus wurden Isotypen-Kontrollen für den jeweiligen detektierenden Antikörper eingesetzt, die ebenfalls dazu beitrugen, falsch-positive Klone nicht zu berücksichtigen.

Bei allen Transfektionen konnten zahlreiche positive Klone ermittelt werden. Die hier abgebildeten Histogramme der Transgen-Expression stehen daher nur vertretend für viele gen-positive Klone.
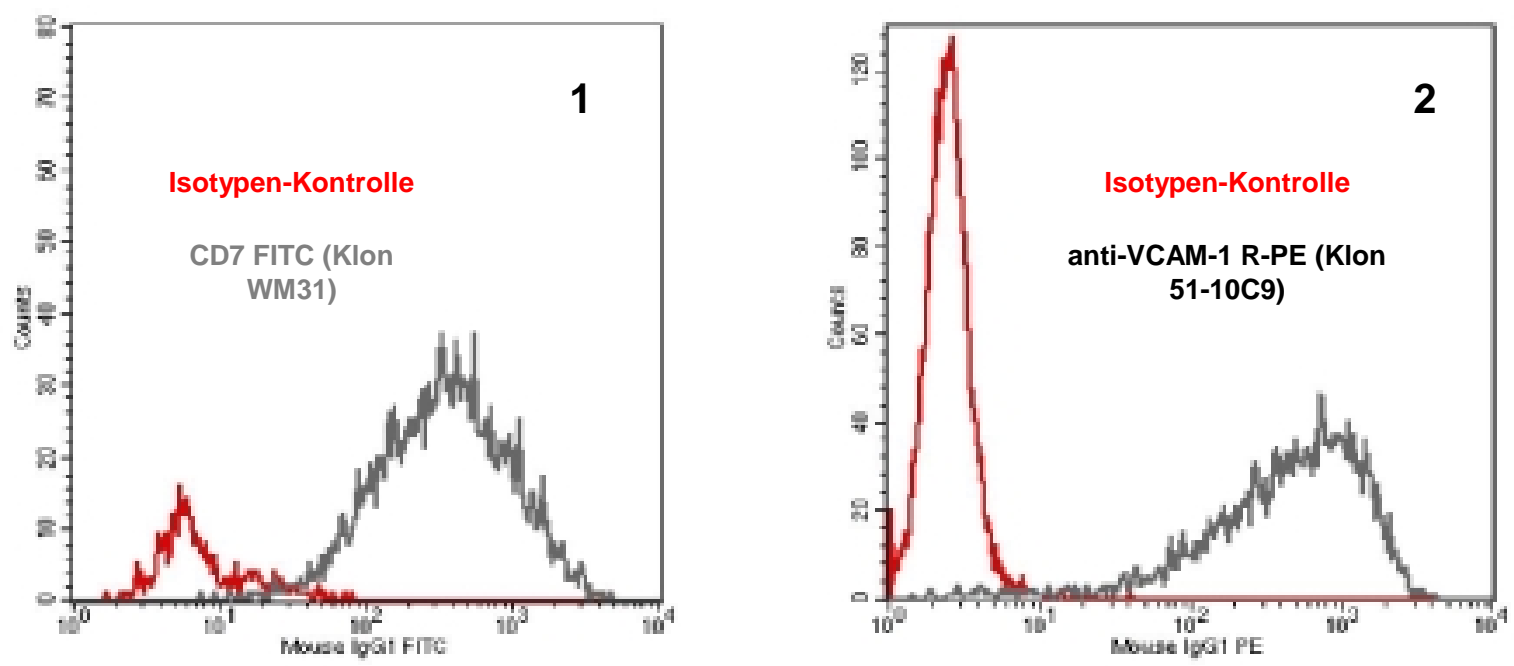

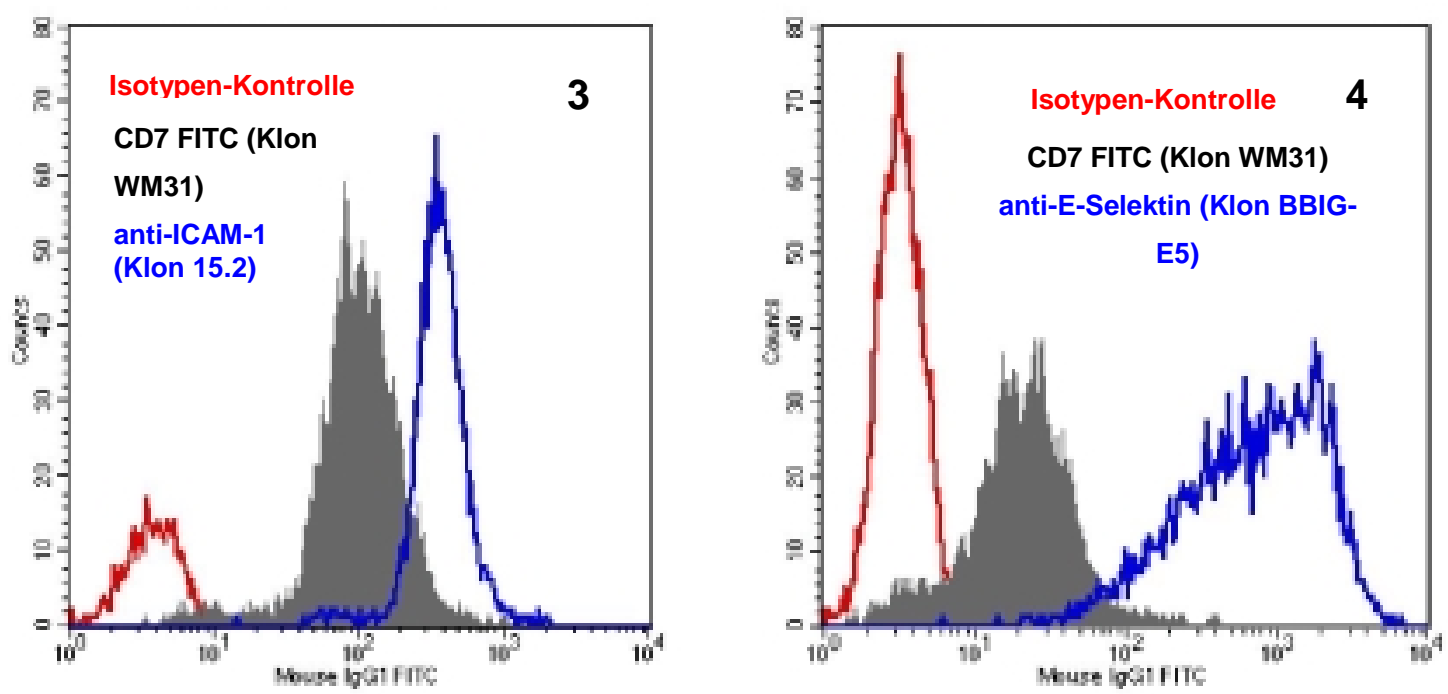

Abb. 3.1-4: Expression von CD7, VCAM-1, ICAM-1 und E-Selektin. Die Oberflächenrezeptoren wurden mit FITC- und PE-gekoppelten Antikörpern markiert und in der Durchflusszytometrie detektiert.

Wie aus den Abb. 3.1-4 ersichtlich, war die jeweilige Transgen-Expression deutlich von den Histogrammen der untransfizierten Zellen abgesetzt und somit zweifelsfrei nachweisbar. Nur Klone, die dieses Kriterium erfüllten, wurden für die weiteren Versuche eingesetzt. Darüber hinaus wurden alle Proteine durch Western-Blotting nachgewiesen (nicht dargestellt).

\section{2 Überprüfung des Tet Off ${ }^{\mathrm{TM}}-$ Systems}

Bei den Untersuchungen an VCAM-1 wurde das Tet-Off ${ }^{\mathrm{TM}}$ verwendet, das es erlaubte, die Transkription des zu untersuchenden Gens cd7/vcam durch Zugabe oder Entfernung des Antibiotikums Doxycyclin je nach Belieben an- und auszuschalten. Zu Beginn der Arbeiten wurde dieses System daher zunächst auf seine Funktionalität untersucht. Es war zu ermitteln, ab welcher Konzentration eine maximale Hemmung der Transkription erreicht werden konnte. Mit der ermittelten Konzentration konnten weiterführende Untersuchungen durchgeführt 
werden, in denen die Zeitabhängigkeit der Transkriptionshemmung bestimmt wurde.

\subsubsection{Bestimmung der maximal hemmenden Doxycyclin- Konzentration}

Wie aus Abb. 3.5 ersichtlich, wurde die Zelllinie CHO-CD7/VCAM zunächst über einen Zeitraum von $48 \mathrm{~h}$ mit Konzentrationen zwischen null und $1000 \mathrm{ng} / \mathrm{ml}$ Doxycyclin inkubiert und anschließend die Transgen-Expression in der FACSAnalyse ausgewertet. Dabei zeigte sich, dass die CD7-Expression, die hier als mittlere Fluoreszenz wiedergegeben wurde, bereits bei Inkubation mit $0,001 \mathrm{ng} / \mathrm{ml}$ Doxycyclin gegenüber der Kontrolle (0 ng / ml) abnahm. Mit steigender Konzentration des Antibiotikums ließ sich die Transkription des Gens zunehmend inhibieren, bis die maximale Hemmung bei einer Konzentration von $1 \mathrm{ng} / \mathrm{ml}$ Doxycyclin erreicht wurde.

Die Abhängigkeit der Genexpression von der zugesetzten Menge des Antibiotikums war somit nachgewiesen. Demnach war eine Kontrolle der cd7/vcam-Transkription durch das Tet Off ${ }^{\mathrm{TM}}$-System gegeben.

Alle darauffolgenden Versuche, die die Zeitabhängigkeit der Transkriptionshemmung bzw. -induktion untersuchten, wie auch alle Funktionsanalysen, bei denen eine Hemmung der Transkription von cd7/vcam gefragt war, wurden fortan mit $1 \mu \mathrm{g} / \mathrm{ml}$ Doxycyclin durchgeführt. 


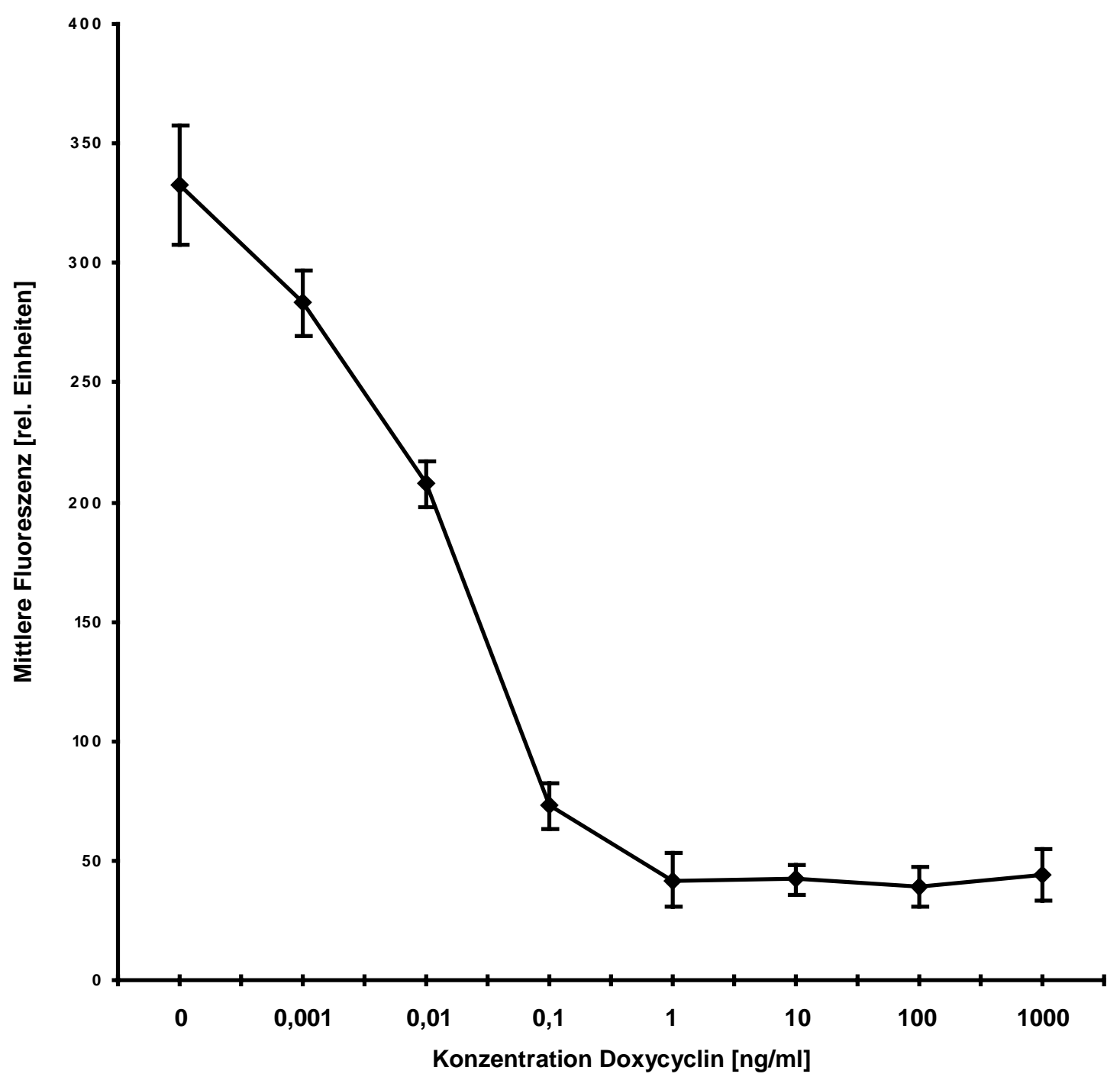

Abb. 3.5: Kontrolle des Tet Off ${ }^{\mathrm{TM}}-$ Systems durch Doxycyclin. Die Zelllinie CHO-CD7/VCAM wurde $48 \mathrm{~h}$ mit unterschiedlichen Konzentrationen Doxycyclin inkubiert und anschließend in der Durchflusszytometrie auf CD7-Expression untersucht. Vertikale Balken: Standardfehler

\subsubsection{Induktion und Hemmung der Transgen-Expression durch Doxycyclin im Tet Off ${ }^{\mathrm{TM}}$-System}

Im folgenden wurde zunächst die Induktion der Transgen-Transkription ermittelt. Die Abb 3.6 zeigt, dass die CD7-Expression bereits $24 \mathrm{~h}$ nach Entfernung des Antibiotikums wieder signifikant zunahm. Aus dem weiteren Verlauf der Kurve lässt sich ablesen, dass die Transkription immer weniger reprimiert wurde und sich 
der maximalen CD7-Expression näherte. Nach $48 \mathrm{~h}$ war wieder die maximale CD7-Expression erreicht.

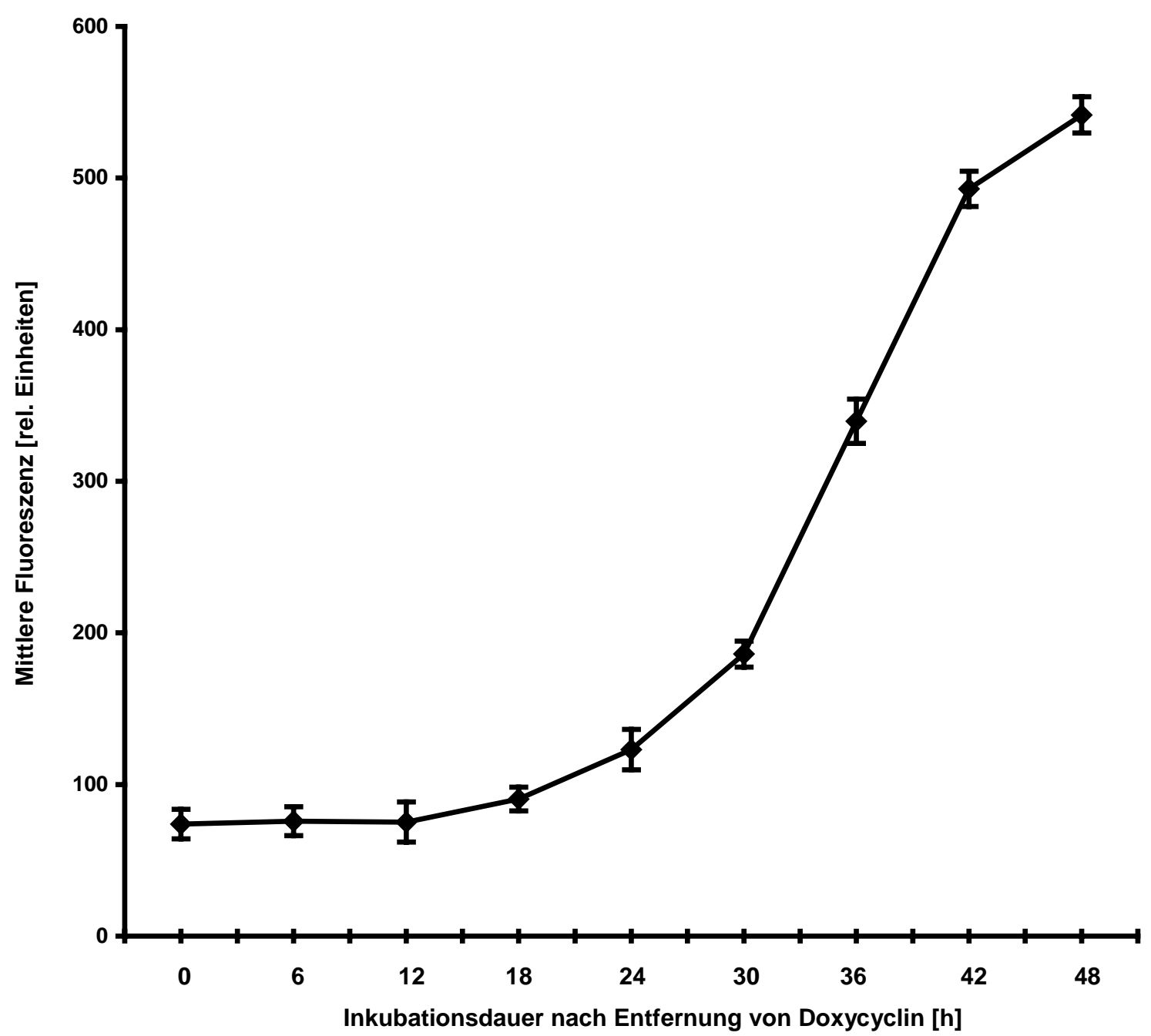

Abb. 3.6: Zeitliche Abnahme der Doxycyclin-Wirkung im Tet Off ${ }^{\mathrm{TM}}$-System: Induktion der CD7-Transkription. Die Zelllinie CHO-CD7/VCAM wurde mit $1 \mu \mathrm{g} / \mathrm{ml}$ Doxycyclin inkubiert, das 0 bis $48 \mathrm{~h}$ vor dem Messzeitpunkt entfernt wurde. Die CD7-Expression wurde in der Durchflusszytometrie ermittelt. Vertikale Balken: Standardfehler

Die Untersuchungen über die zeitliche Abhängigkeit der Transkriptionshemmung führten zu vergleichbaren Ergebnissen (Abb. 3.7). Auch hier konnte gezeigt werden, dass ein Zusammenhang zwischen der Inkubationsdauer mit Doxycyclin 
und der CD7-Expression bestand. Bereits nach 12-stündiger Inkubation mit Doxycyclin ging die Expression deutlich zurück und erreichte nach $30 \mathrm{~h}$ ihre maximale Inhibition.

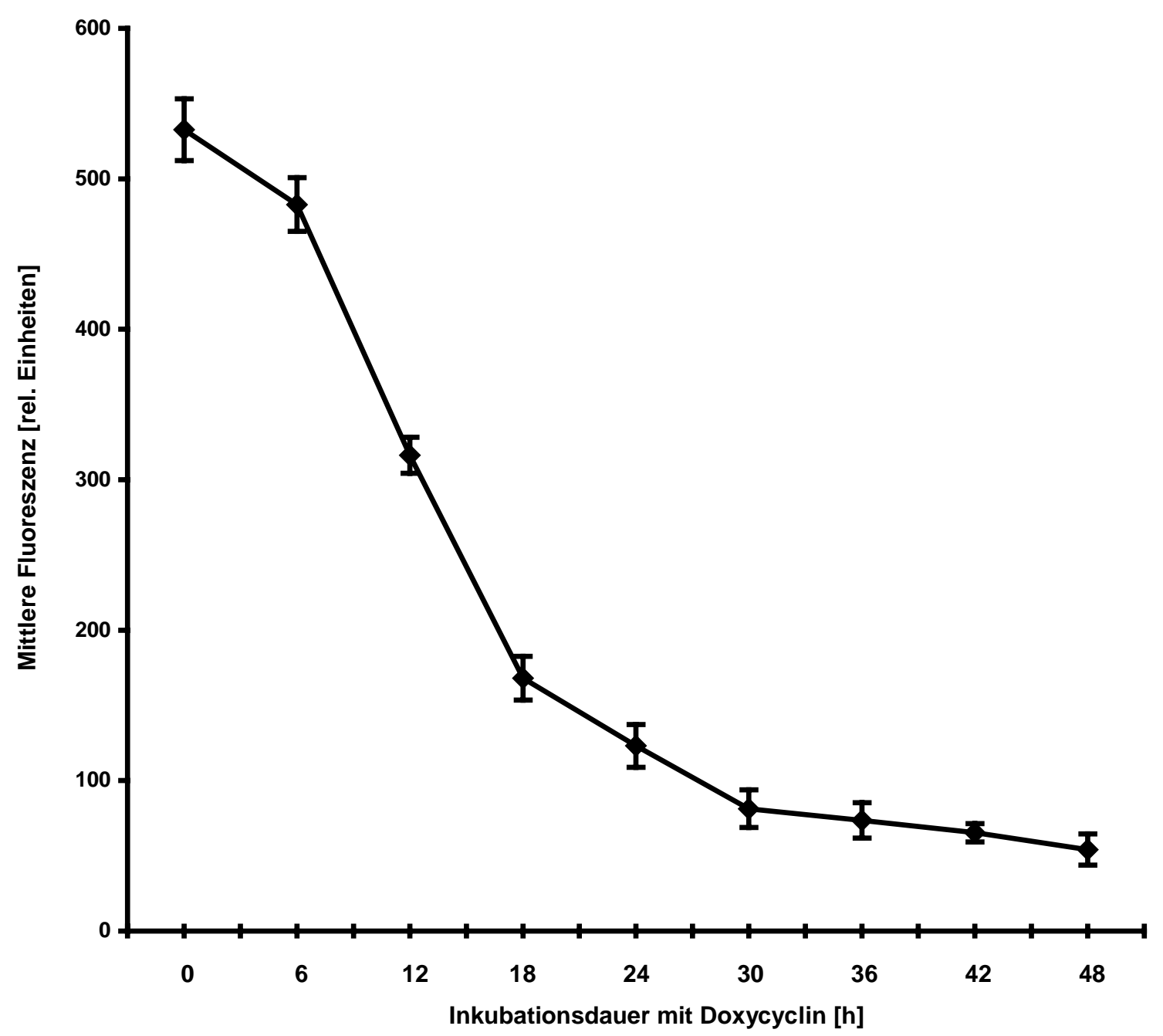

Abb. 3.7: Kontrolle des Tet Off ${ }^{\mathrm{TM}}$-Systems durch Doxycyclin: Hemmung der CD7 Transkription. Die Zelllinie CHO-CD7/VCAM wurde mit $1 \mu \mathrm{g} / \mathrm{ml}$ Doxycyclin inkubiert, das 0 bis $48 \mathrm{~h}$ vor dem Messzeitpunkt zugesetzt wurde. Die CD7-Expression wurde in der Durchflusszytometrie ermittelt. Vertikale Balken: Standardfehler

Aufgrund der in dieser Versuchsreihe erlangten Ergebnisse wurden fortan alle Untersuchungen, die unter Verwendung des Tet Off ${ }^{\mathrm{TM}}$-Systems stattfanden und 
eine Hemmung der Transgen-Transkription erforderten, nach 48-stündiger Inkubation mit Doxycyclin durchgeführt.

\subsection{3 Überprüfung des Tet Off ${ }^{\mathrm{TM}}$-Systems bei der doppelt transgenen Zelllinie CHO-CD7/VCAM\&VCAM-1}

Nachdem die Zelllinie CHO-CD7/VCAM mit vcam-1 transfiziert worden war, wurde zunächst untersucht, ob das Tet Off ${ }^{\mathrm{TM}}$-System anschließend noch funktionsfähig war. Die Zellen wurden hierzu wie bereits beschrieben inkubiert und die CD7 bzw. VCAM-1 Expression durchflusszytometrisch bestimmt. Als Kontrollen wurden unbehandelte CHO-CD7/VCAM\&VCAM-1, CHO-AA8 bzw. CHO/VCAM-1 eingesetzt.

Auch nach der Transfektion mit vcam-1 unterlag die cd7-Transkription der Kontrolle durch das Tet Off TM-System (Abb. 3.8). Ferner zeigten die Untersuchungen, dass das Antibiotikum keinen Einfluss auf die VCAM-1 Expression ausübte. Damit war sichergestellt, dass die Transfektion mit vcam-1 oder die Inkubation mit dem Antibiotikum keine unerwünschten Nebeneffekte ausübten. 


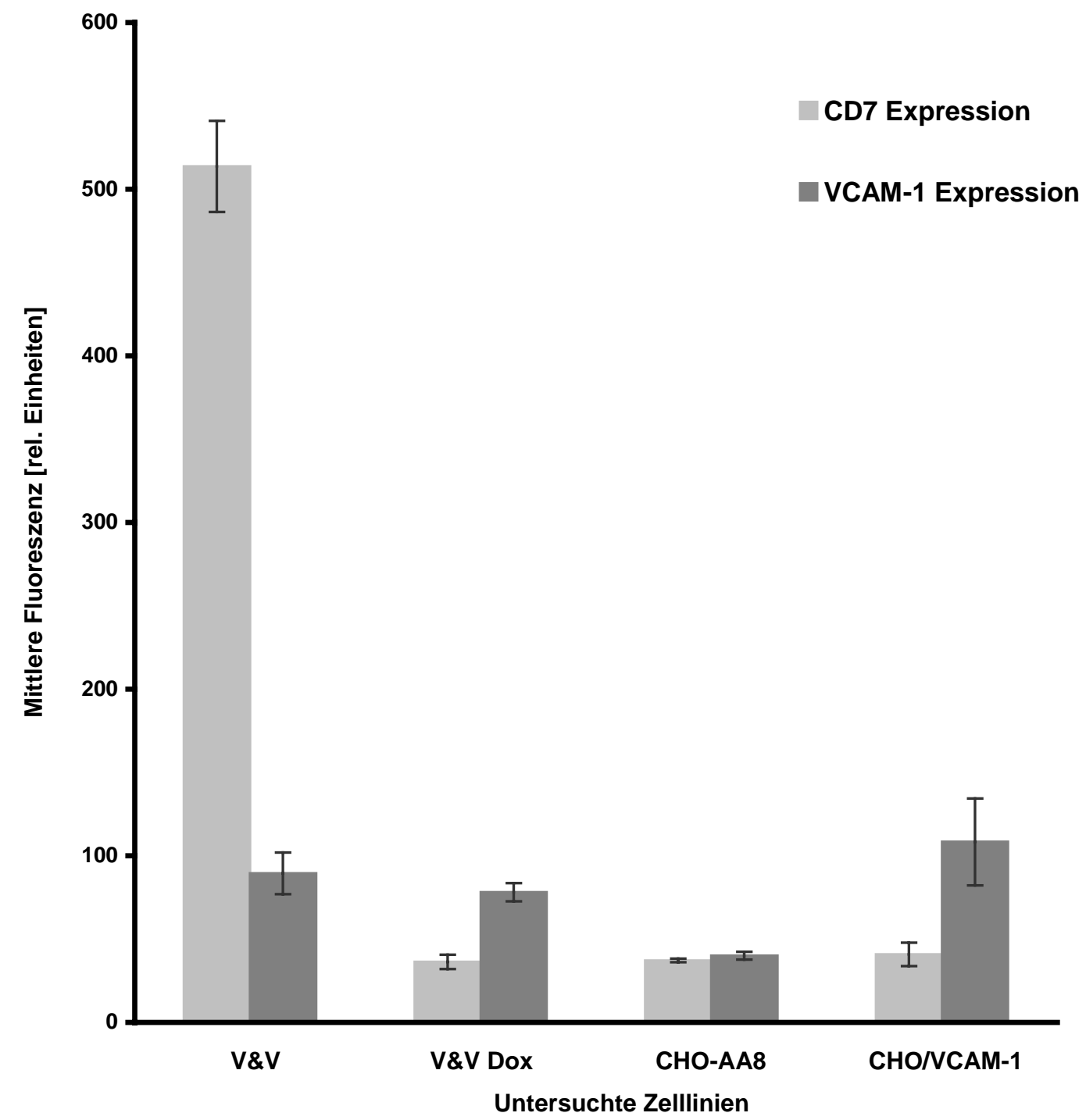

Abb. 3.8: Überprüfung des Tet Off ${ }^{\mathrm{TM}}$-Systems in CHO-CD7/VCAM\&VCAM-1. Die Zellen wurden $48 \mathrm{~h}$ mit $1 \mu \mathrm{g} / \mathrm{ml}$ Doxycyclin inkubiert. Die CD7 und VCAM-1 Expression wurden in der Durchflusszytometrie bestimmt. Untersuchte Zelllinien: V\&V: CHO-CD7/VCAM\&VCAM-1; V\&V Dox: Inkubation von CHO-CD7/VCAM\&VCAM-1 mit Doxycyclin. Vertikale Balken: Standardfehler 


\subsection{Untersuchungen an dem Oberflächenrezeptor VCAM-1}

\subsubsection{Adhäsion der Monozyten an VCAM-1}

Der Einfluss von CD7/NCAM auf die VCAM-1 vermittelte Monozytenadhäsion konnte durch das Tet Off ${ }^{\mathrm{TM}}$-System direkt untersucht werden. Als Kontrolle wurde neben CHO-AA8 außerdem eine Zellinie mit stabil integriertem VCAM-1 untersucht (CHO/VCAM-1), um dadurch einen möglicherweise bestehenden unspezifischen Effekt des Tet Off TM-Systems auf die Monozytenadhäsion aufdecken zu können.

Die Auswertung der FACS-Analysen zeigte, dass bei den Zellen der Linie CHO-AA8 im Mittel 5,35 \% Monozyten adhäriert waren (Abb. 3.9). Vergleichbare prozentuale Anteile von Monozyten wurden für $\mathrm{CHO}-\mathrm{CD} 7 /$ VCAM verzeichnet. Diese Zellinie, die sowohl mit als auch ohne exprimiertem Fusionsmolekül untersucht wurde, wies mit durchschnittlich 2,88 (ohne Doxycyclin) bzw. 3,71\% (mit Doxycyclin) gebundenen Monozyten keine statistisch signifikanten Unterschiede zu der CHO-AA8 Kontrolle auf. Dadurch konnte ausgeschlossen werden, dass die Transfektion von CHO-AA8 mit cd7/vcam einen unspezifischen Effekt auf die Leukozytenadhäsion ausübte. Ein Einfluss des Doxycyclin konnte ebenfalls nicht festgestellt werden.

Die Adhäsion von Monozyten an Doxycyclin-behandelte Zellen von $\mathrm{CHO}$ CD7/VCAM\&VCAM-1 war demgegenüber um ein Vielfaches erhöht. Aufgrund der Kontrollen kann dies dem Oberflächenrezeptor VCAM-1 zugeschrieben werden. Bei diesen Zellen war die Transkription von cd7/vcam durch das Antibiotikum inhibiert. Im Gegensatz zu dem prozentualen Anteil von durchschnittlich 6,97\% adhärenten Monozyten bei CD7/VCAM-exprimierenden Zellen dieser Zelllinie wurden von CHO-CD7/VCAM\&VCAM-1 Dox im Mittel 32,2 \% gebunden. Die statistische Analyse bestätigte diesen Unterschied mit hoher Signifikanz $(p<0,001)$.

Durch den Vergleich mit CHO/VCAM-1 wurde diese Beobachtung weiter belegt. Mit durchschnittlich 27,18 \% adhärierenden Monozyten wies CHO/VCAM-1 in der 
statistischen Analyse ebenfalls hochsignifikante Differenzen $(p<0,001)$ zu den Kontrollen auf, aber keine Unterschiede gegenüber CHO-CD7/VCAM\&VCAM-1 Dox.

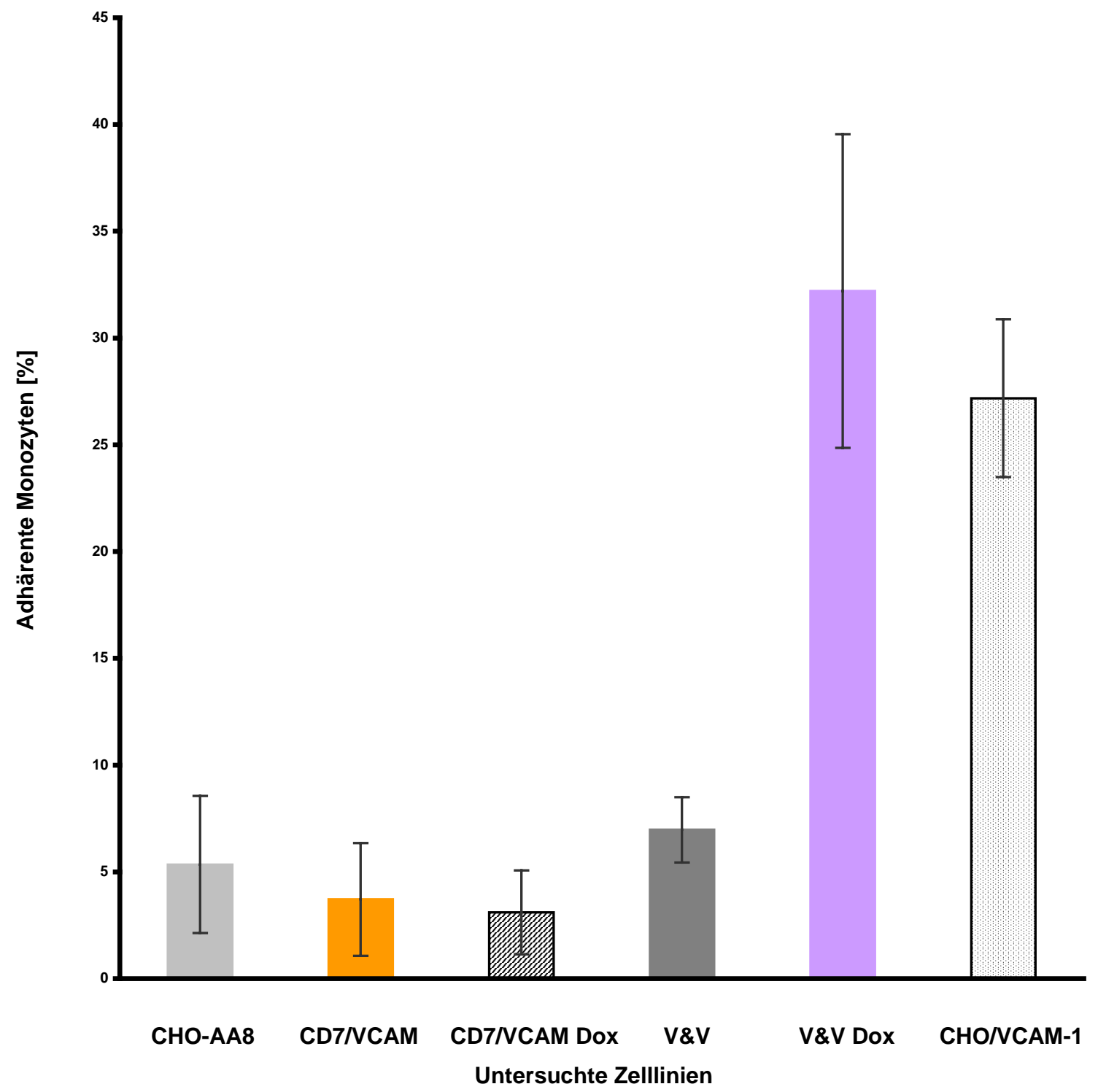

Abb. 3.9: Adhäsion von Monozyten an CHO-AA8, CHO-CD7/VCAM, CHO-CD7/VCAM\&VCAM1 bzw. CHO/VCAM-1. Der Prozentsatz der gebundenen Monozyten wurde in der Durchflusszytometrie ermittelt. Untersuchte Zelllinien: CD7/VCAM: CHO-CD7/VCAM; CD7/VCAM Dox: Inkubation von CHO-CD7/VCAM mit Doxycyclin; V\&V: CHO-CD7/VCAM\&VCAM-1; V\&V Dox: Inkubation von CHO-CD7/VCAM\&VCAM-1 mit Doxycyclin. Vertikale Balken: Standardfehler 
Demnach konnte der Oberflächenrezeptor VCAM-1 nur dann die Adhäsion von Monozyten vermitteln, wenn das Fusionsprotein nicht exprimiert wurde. Die Bindung von Monozyten, die ansonsten über VCAM-1 erfolgte, konnte somit erfolgreich durch CD7/VCAM gehemmt werden.

\subsubsection{Hemmung der Monozytenadhäsion durch anti-VCAM-1}

Die Bindung der Monozyten an VCAM-1 war weiter zu spezifizieren. Dafür wurde der Rezeptor vor Zugabe der Monozyten mit anti-VCAM-1 blockiert.

Die Kontrollansätze bestanden aus CHO-CD7/VCAM, die mit Doxycyclin inkubiert worden waren. Unblockierte und VCAM-1-blockierte Ansätze dieser Zelllinie wiesen im Mittel 8,27 (unblockiert) bzw. 6,05 \% (anti-VCAM-1) adhärente Monozyten auf (Abb. 3.10). Die Inkubation mit dem Antikörper konnte in diesen Ansätzen demnach keine Abnahme der aggregierten Monozyten bewirken.

Ähnliche prozentuale Anteile adhärierender Monozyten zeigten sich bei Zellen von CHO-CD7/VCAM\&VCAM-1, die ohne Doxycyclin-Inkubation für die Versuche eingesetzt worden waren und somit das Fusionsmolekül exprimieren konnten. Gegenüber den unblockierten Ansätzen mit durchschnittlich 6,7 \% Monozyten hatten hier die blockierten Zellen im Mittel zwar 8,12 \% Monozyten gebunden, aber bei der Analyse mit dem Student's t-Test ließen sich ebenfalls keine statistisch signifikanten Unterschiede ermitteln.

Anders verhielt es sich mit CHO-CD7/VCAM\&VCAM-1, die aufgrund der Inkubation mit dem Antibiotikum nicht in der Lage waren, CD7/VCAM zu exprimieren. An unblockierten Zellen wurden hier im Mittel 33,85 \% Monozyten gebunden, ein deutlicher Unterschied zu allen anderen Ansätzen. Diese Beobachtung wurde mit 0,1\% iger Irrtumswahrscheinlichkeit in der statistischen Analyse belegt. Auf gleichem Signifikanzniveau konnten für diese Zelllinie Aussagen über den Unterschied zwischen unblockierten und blockierten Ansätzen getroffen werden. Bei vorheriger Blockade durch anti-VCAM-1 sank der Prozentsatz der adhärenten Monozyten auf durchschnittlich 9,28\%. 
Demnach konnte gezeigt werden, dass die Bindung der Monozyten an die transgenen $\mathrm{CHO}$-Zellen, die in dieser Versuchsreihe verzeichnet wurde, über den Oberflächenrezeptor VCAM-1 erfolgte. Die Blockade mit anti-VCAM-1 und der damit einhergehende Rückgang der gebundenen Monozyten bekräftigten somit die Ergebnisse der vorhergehenden Versuchsreihe.

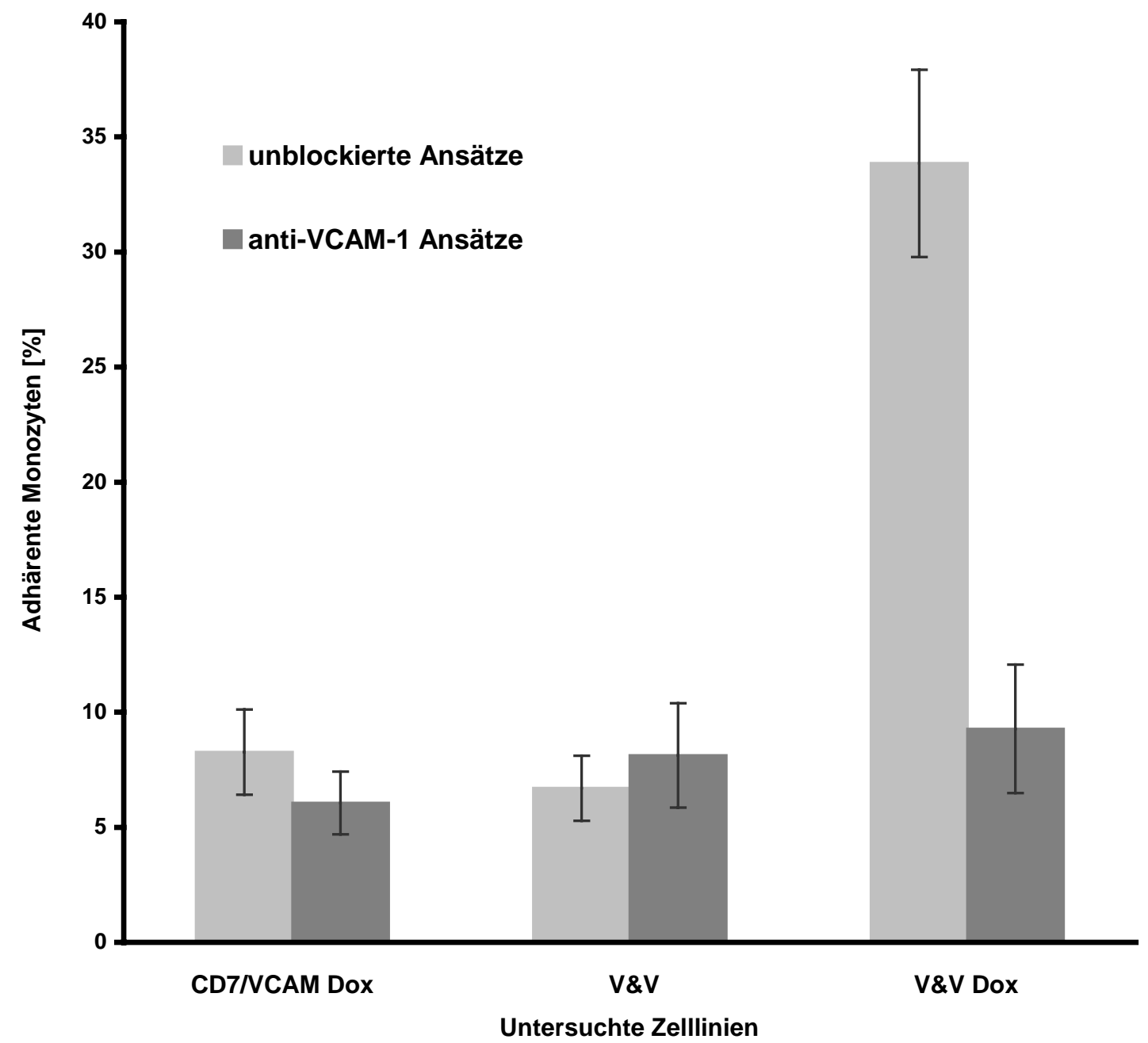

Abb. 3.10: Adhäsion von Monozyten an CHO-CD7/VCAM und CHO-CD7/VCAM\&VCAM-1. Vor Zugabe der Monozyten waren die Ansätze im entsprechenden Experiment mit anti-VCAM-1 inkubiert worden. Der Prozentsatz der gebundenen Monozyten wurde in der Durchflusszytometrie ermittelt. Untersuchte Zelllinien: CD7/VCAM Dox: Inkubation von CHO-CD7/VCAM mit Doxycyclin; V\&V: CHO-CD7/VCAM\&VCAM-1; V\&V Dox: Inkubation von CHO-CD7/VCAM\&VCAM-1 mit Doxycyclin. Vertikale Balken: Standardfehler 


\subsubsection{Hemmung der VCAM-1 vermittelten Monozytenadhäsion auf leukozytärer Seite}

Zur weiteren Spezifizierung wurde der Ligand VLA-4 (CD49d/CD29) von VCAM-1 vor Zugabe der Monozyten mit anti-CD49d blockiert.

Durch diese Versuchsreihe konnte die Bindung über VCAM-1 weiter belegt werden, zeigten sich doch vergleichbare Ergebnisse wie bei vorheriger Blockade der Zellen mit anti-VCAM-1 (Abb. 3.11). Die Kontrollansätze aus CHOCD7/VCAM, die mit Doxycyclin inkubiert worden waren, wiesen im Mittel unblockiert 5,55 \%, bzw. blockiert 4,63 \% Monozyten auf. Die Werte für $\mathrm{CHO}$ CD7/VCAM\&VCAM-1, die ohne Antibiotika-Behandlung eingesetzt wurden, unterschieden sich davon nicht (unblockiert: 8,2 \% bzw. blockiert 9,22 \% adhärente Monozyten). Auch blockierte Ansätze von CHO-CD7/VCAM\&VCAM-1 mit transkribiertem Fusionsmolekül wichen mit 8,64 \% Monozyten nicht von den bereits beschriebenen Kombinationen ab.

Alleinige Expression von VCAM-1 bei CHO-CD7/VCAM\&VCAM-1 unter Doxycyclin führten zu abweichenden Ergebnissen. Die unblockierten Zellen dieser Linie zeigten mit durchschnittlich $36,97 \%$ adhärenten Monozyten deutliche Unterschiede, die in der statistischen Analyse mit hoher Signifikanz $(p<0,001)$ bestätigt wurden. Die Blockade des Liganden mit anti-CD49d erzielte eine ebenso effektive Verminderung der Monozytenadhäsion wie die Inkubation der Zelllinie CHO-CD7/VCAM\&VCAM-1 Dox mit anti-VCAM-1. 


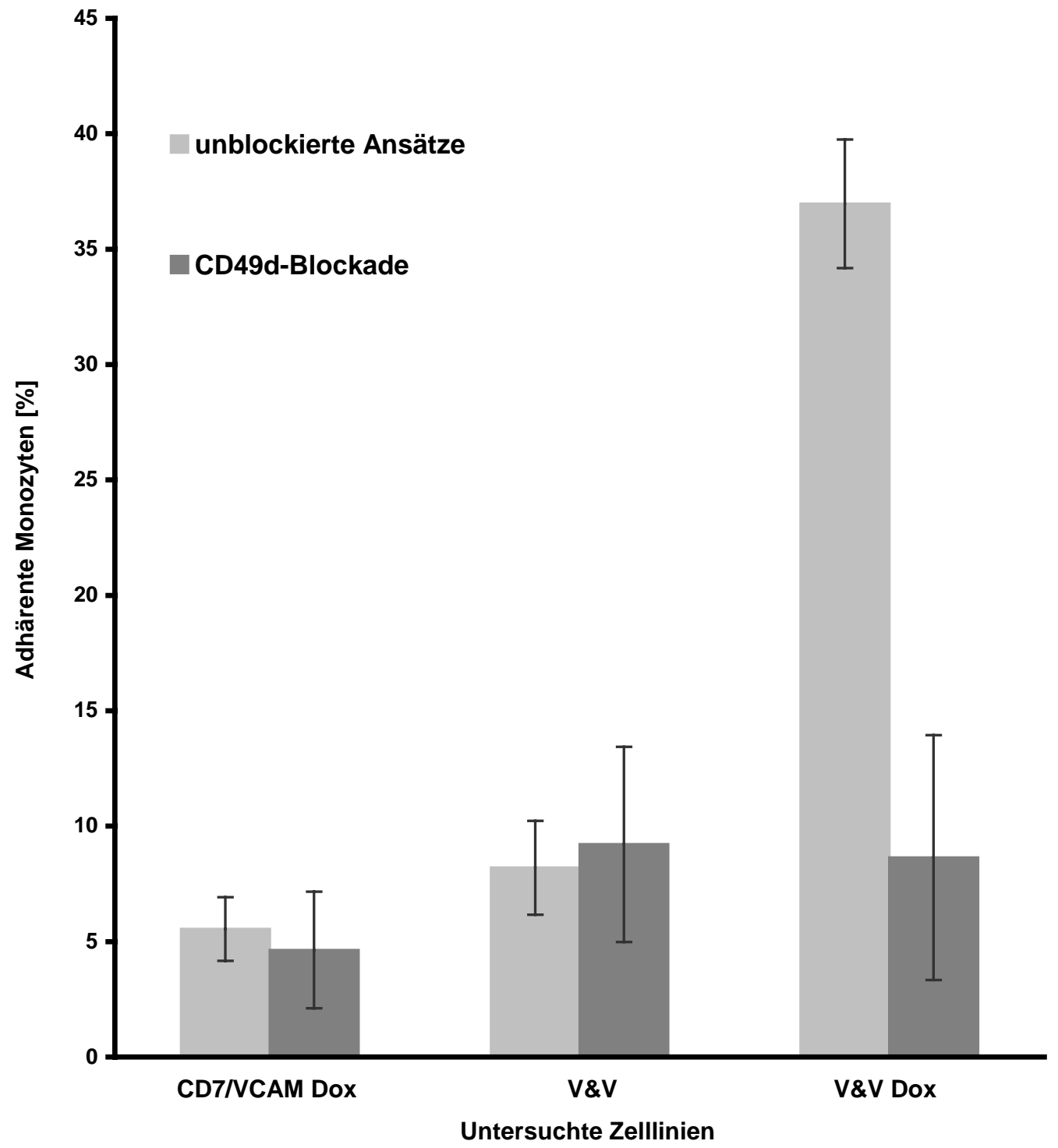

Abb. 3.11: Adhäsion von Monozyten an CHO-CD7/VCAM und CHO-CD7/VCAM\&VCAM-1. Vor Zugabe der Monozyten waren die Ansätze im entsprechenden Experiment mit anti-CD49d inkubiert worden. Der Prozentsatz der gebundenen Monozyten wurde in der Durchflusszytometrie ermittelt. Untersuchte Zelllinien: CD7/VCAM Dox: Inkubation von CHO-CD7/VCAM mit Doxycyclin; V\&V: CHO-CD7/VCAM\&VCAM-1; V\&V Dox: Inkubation von CHO-CD7/VCAM\&VCAM-1 mit Doxycyclin. Vertikale Balken: Standardfehler 


\subsubsection{Adhäsion von Monozyten an den Oberflächenrezeptor VCAM-1 nach Cytochalasin D Behandlung}

Der Oberflächenrezeptor VCAM-1 sollte in der vorliegenden Arbeit weiterhin auf seine Verankerung im Zytoskelett der Zelle untersucht werden. Zu diesem Zweck waren die Zellen mit Cytochalasin $D$ zu behandeln, wodurch die Polymerisation von Actinfilamenten und somit die Ausbildung eines intakten Zytoskeletts verhindert wurde. Es sollte die Hypothese geprüft werden, ob eine fehlende Bindung des Rezeptors an diese Strukturen seine Funktionalität beeinträchtigt.

Die Behandlung der Kontroll-Ansätze (CHO-AA8, CHO-CD7/VCAM [Dox]) mit Cytochalasin $D$ hatte keinen Einfluss auf den Prozentsatz der gebundenen Monozyten (Abb. 3.12). Die Anteile bewegten sich bei CHO-AA8 und CD7/VCAM (jeweils mit und ohne vorherige Behandlung mit Cytochalasin D) im Mittel zwischen 5,10 und 7,11 \% gebundenen Monozyten. Zellen von $\mathrm{CHO}$ CD7/VCAM\&VCAM-1, die ohne Doxycyclin-Inkubation CD7/VCAM exprimieren konnten, hatten unbehandelt durchschnittlich 7,08 \%, bzw. Cytochalasin D behandelt 6,47\% Monozyten gebunden. Auch hier ergab sich kein signifikanter Unterschied.

Die VCAM-1 Zelllinie, die mit Doxycyclin inkubiert worden war, zeigte jedoch gegenüber allen anderen Ansätzen hochsignifikante Unterschiede $(p<0,001)$. Die Cytochalasin D Behandlung bewirkte hier eine Abnahme der gebundenen Monozyten von durchschnittlich $26,17 \%$ auf 6,2 \% und glich sich dadurch den prozentualen Werten der Kontrollen an.

Es konnte demnach gezeigt werden, dass VCAM-1 nach Cytochalasin D Behandlung nicht mehr in der Lage war, die Monozytenadhäsion zu vermitteln. Für einen funktionsfähigen VCAM-1 Rezeptor scheint die Verankerung im Zytoskelett unabkömmlich zu sein. Die Behandlung von CHO-CD7/VCAM\&VCAM-1 Zellen mit Cytochalasin D, die nur den nativen Oberflächenrezeptor exprimierten, hatte demnach einen vergleichbaren Effekt wie die Expression des Fusionsproteins CD7/VCAM (Abb. 3.9): In beiden Fällen ging die Monozytenadhäsion mit stati- 
stisch hoher Signifikanz zurück. Demzufolge konkurrierte CD7/VCAM mit VCAM-1 um Bindungsstellen zum Actinskelett und verhinderte dadurch die Adhäsion von Monozyten, die ansonsten über den Oberflächenrezeptor erfolgte.

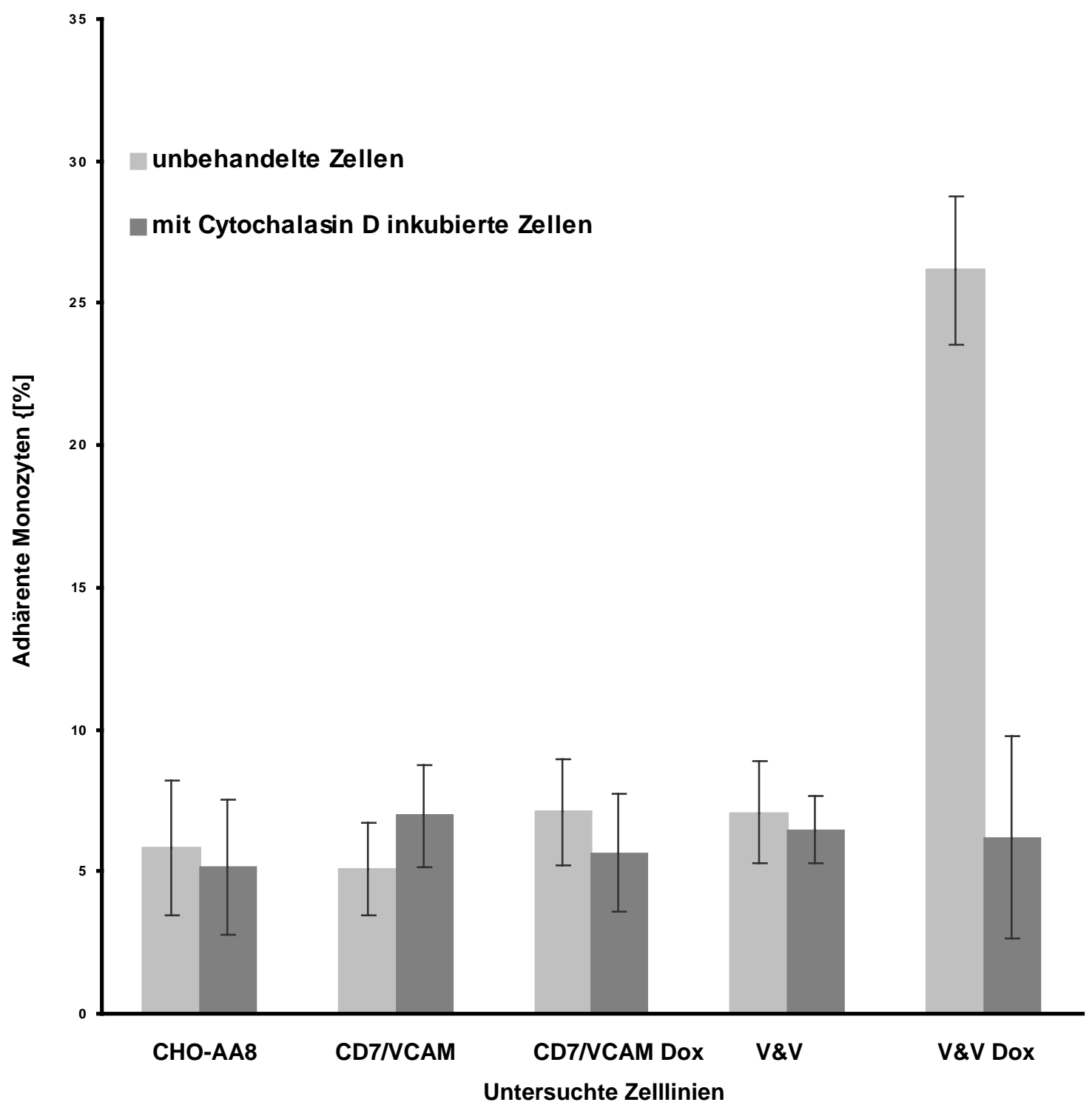

Abb. 3.12: Aggregate von Monozyten und CHO-AA8, CHO-CD7/VCAM bzw. CHOCD7/VCAM\&VCAM-1. Die Zellen wurden in den erforderlichen Ansätzen vor Zugabe der Monozyten mit Cytochalasin D inkubiert. Der Prozentsatz der gebundenen Monozyten wurde in der Durchflusszytometrie ermittelt. Untersuchte Zelllinien: CD7/VCAM: CHO-CD7/VCAM; CD7/VCAM Dox: Inkubation von CHO-CD7/VCAM mit Doxycyclin; V\&V: CHO-CD7/VCAM\&VCAM-1; V\&V Dox: Inkubation von CHO-CD7/VCAM\&VCAM-1 mit Doxycyclin. Vertikale Balken: Standardfehler 


\subsubsection{VCAM-1 vermittelte Transmigration von Monozyten}

Neben der Adhäsion war zu untersuchen, inwieweit der Oberflächenrezeptor VCAM-1 an der Transmigration von Monozyten beteiligt ist. Durch AntikörperBlockade wurde die Spezifität weiter aufgeklärt. Des weiteren wurde durch Behandlung der VCAM-1 exprimierenden Zellen mit Cytochalasin D ermittelt, inwieweit die Verankerung des Rezeptors an actinhaltige Strukturen bei diesem Prozess eine Rolle spielte.

Zunächst wurde die Transmigration durch eine VCAM-1 exprimierende Zellschicht untersucht. Wie aus Abb. 3.13 ersichtlich, konnten bei den Kontrollansätzen aus CHO-AA8 lediglich 4,17 \% der eingesetzten Monozyten die Zellschicht passieren. Die weiterhin zur Kontrolle und Spezifizierung eingesetzte Zelllinie $\mathrm{CHO}$ CD7/VCAM, die mit und ohne Doxycyclin-Inkubation untersucht wurde, wies in den unbehandelten Ansätzen 2,71 \%, und in den Doxycyclin-Ansätzen 3,26 \% migrierte Monozyten auf. Die statistische Auswertung zeigte, dass zwischen den drei genannten Kontrollen keine Unterschiede auf statistisch signifikantem Niveau erkennbar waren und bestätigte, dass die Transfektion mit dem Konstrukt cd7/vcam bzw. die Inkubation mit Doxycyclin keinen Einfluss auf die Penetrierbarkeit der Zellschicht oder die Transmigration der Monozyten ausübte.

Die Ansätze der Zelllinie CHO-CD7/VCAM\&VCAM-1, die mit Doxycyclin inkubiert wurden und somit das Fusionsprotein nicht exprimieren konnten, zeigten demgegenüber mit durchschnittlich 17,61 \% migrierten Monozyten hochsignifikante Unterschiede $z u$ den Kontrollen $(p<0,001)$. Mit den unbehandelten Ansätzen dieser Zelllinie, die im Mittel 3,07 \% Monozyten penetrieren ließen, konnte gezeigt werden, dass CD7/VCAM die VCAM-1 vermittelte Transmigration von Monozyten verhinderte. 


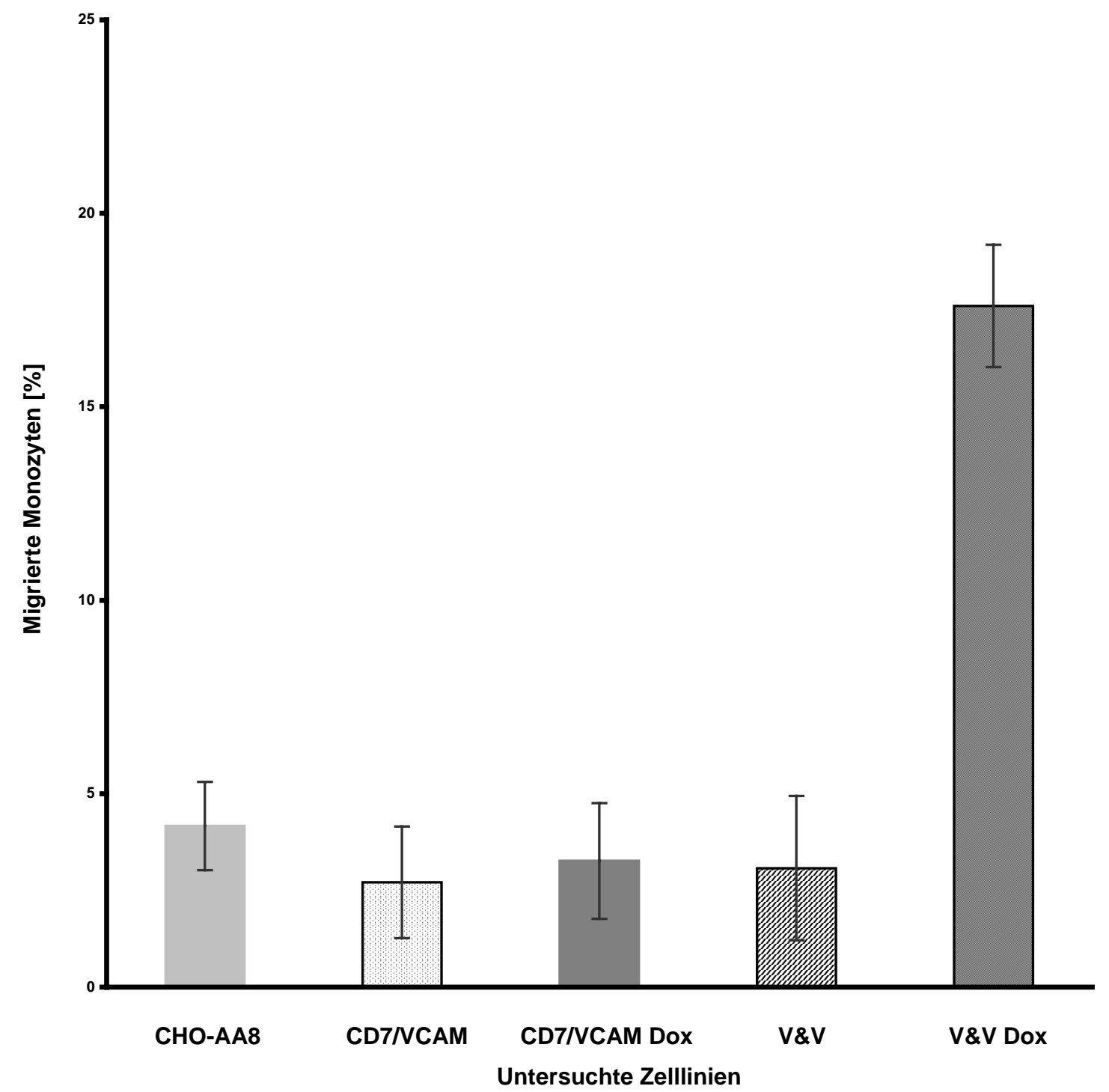

Abb. 3.13: Transmigration der Monozyten durch Zellschichten von CHO-AA8, CHOCD7/VCAM und CHO-CD7/VCAM\&VCAM-1. Der Prozentsatz der migrierten Monozyten wurde mikroskopisch in einer Neubauer-Zählkammer ermittelt. Untersuchte Zelllinien: CD7/VCAM: CHOCD7/VCAM; CD7/VCAM Dox: Inkubation von CHO-CD7/VCAM mit Doxycyclin; V\&V: CHOCD7/VCAM\&VCAM-1; V\&V Dox: Inkubation von CHO-CD7/VCAM\&VCAM-1 mit Doxycyclin. Vertikale Balken: Standardfehler 


\subsubsection{Blockade des Rezeptors mit anti-VCAM-1 in Transmigrationsversuchen}

Um die Aufgaben des endothelialen Oberflächenrezeptors weiter aufzuklären, wurden Transmigrationsversuche durchgeführt, bei denen VCAM-1 durch vorherige Inkubation mit anti-VCAM-1 blockiert worden war.

Bei den Kontrollen ([blockierte] CHO-AA8 bzw. CHO-CD7/VCAM\&VCAM-1) konnten durchschnittlich nur zwischen 3,06 und 3,54\% der eingesetzten Monozyten durch die Zellschicht migrieren (Abb. 3.14). Im Gegensatz dazu wurden ohne Blockade bei CHO-CD7/VCAM\&VCAM-1 Dox im Mittel 17,71\% migrierte Monozyten ermittelt. In denjenigen Ansätzen, bei denen diese Zelllinie zuvor mit anti-VCAM-1 behandelt worden war, ließ sich der Prozentsatz der Monozyten auf 3,75\% senken, ein Wert, der sich von den Kontrollen nicht signifikant unterschied. Die prozentualen Anteile an migrierten Monozyten bei unblockierten, Doxycyclin-inkubierten CHO-CD7/VCAM\&VCAM-1 Zellen unterschieden sich in der statistischen Analyse auf hochsignifikantem Niveau von allen übrigen Ansätzen $(p<0,001)$. Somit war die VCAM-1 vermittelte Transmigration von Monozyten weiter belegt und spezifiziert worden. 


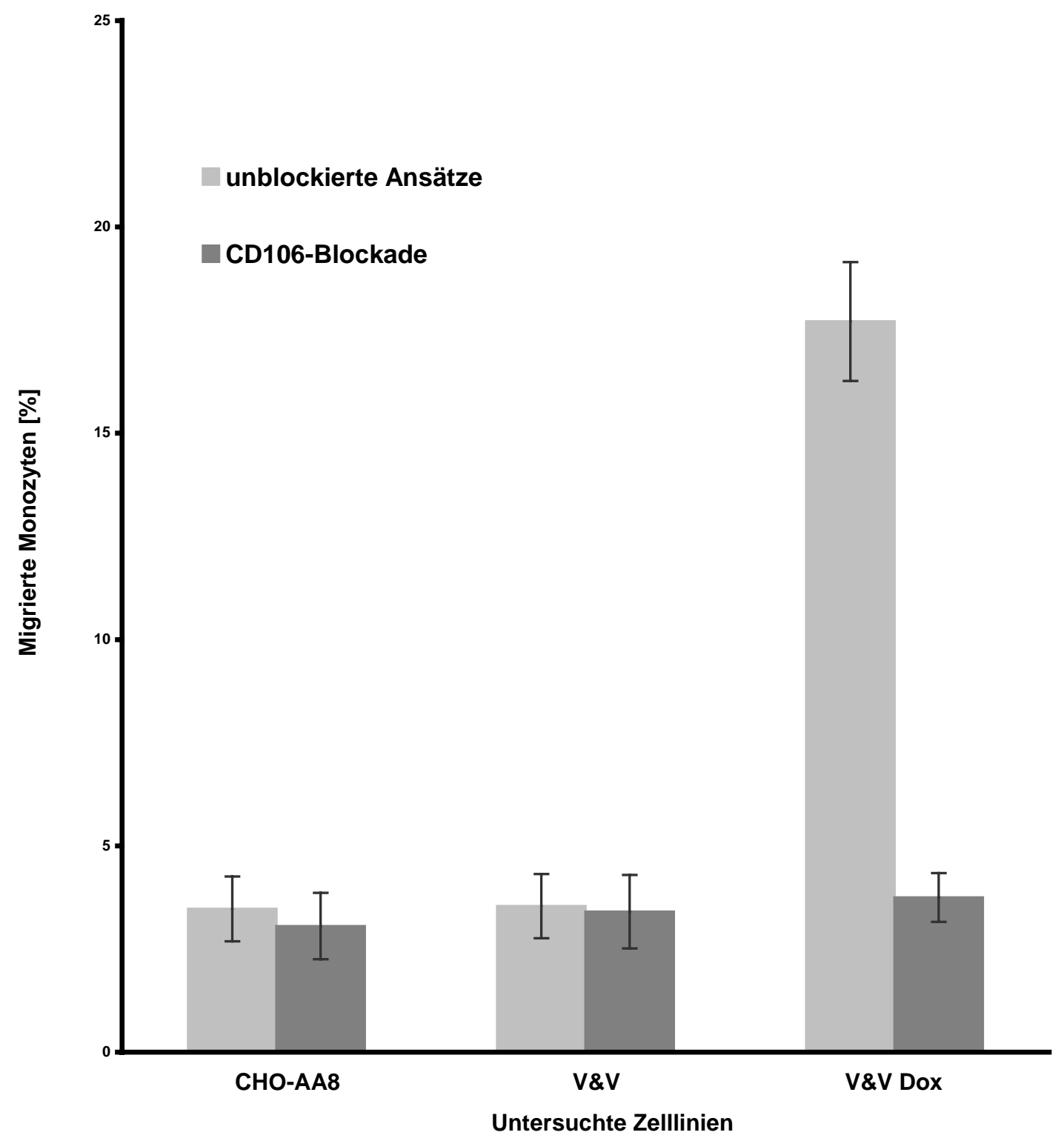

Abb. 3.14: Transmigration der Monozyten durch Zellschichten von CHO-AA8 und CD7/VCAM\&VCAM-1. Vor Zugabe der Monozyten waren die erforderlichen Ansätze mit antiVCAM-1 inkubiert worden. Der Prozentsatz der migrierten Monozyten wurde in einer NeubauerZählkammer ermittelt. Untersuchte Zelllinien: V\&V: CHO-CD7/VCAM\&VCAM-1; V\&V Dox: Inkubation von CHO-CD7/VCAM\&VCAM-1 mit Doxycyclin. Vertikale Balken: Standardfehler 


\subsubsection{Hemmung der VCAM-1 vermittelten Transmigration von Monozyten durch Cytochalasin D}

Es war des weiteren aufzuklären, inwieweit die Zytoskelettverankerung von VCAM-1 auch bei der Transmigration eine Rolle spielt.

Konnten in Abwesenheit von Cytochalasin D bei Zellen der Linie CHO-CD7/VCAM \&VCAM-1 Dox noch 18,06 \% der eingesetzten Monozyten die Zellschicht passieren, so waren es bei den mit dem Inhibitor behandelten Ansätzen im Mittel nur noch 4,45\% (Abb. 3.15). Die Inkubation mit Cytochalasin D verminderte somit den Prozentsatz der migrierten Monozyten auf vergleichbare Werte der Kontrollen CHO-AA8 und CHO-CD7/VCAM\&VCAM-1 (jeweils etwa $3 \%$ Monozyten). Die statistische Analyse bestätigte, dass zwischen den drei letztgenannten Ansätzen keine signifikanten Unterschiede vorlagen. Darüber hinaus konnten keine Unterschiede zwischen den unbehandelten bzw. Cytochalasin D inkubierten Kontrollen festgestellt werden, so dass ein unspezifischer Effekt des Cytochalasin D ausgeschlossen werden konnte. Der Oberflächenrezeptor VCAM-1 benötigte demzufolge auch für die Vermittlung der Transmigration von Monozyten die Verankerung an actinhaltigen Zytoskelettstrukturen.

Mit den Ergebnissen, die unter 3.3 wiedergegeben sind, konnte gezeigt werden, dass VCAM-1 für die Vermittlung der Adhäsion und der Transmigration von Monozyten eine Verankerung im actinhaltigen Zytoskelett benötigte. Diese Bindung wurde durch Einschleusung des Fusionsproteins verhindert, so dass der Oberflächenrezeptor VCAM-1 seine Aufgaben bei der Monozytenrekrutierung nicht mehr wahrnehmen konnte. Die Zerstörung des Actinskeletts durch Cytochalasin $D$ führte somit letztlich zur selben Konsequenz wie die Verdrängung von VCAM-1 durch das Fusionsprotein CD7/VCAM. 


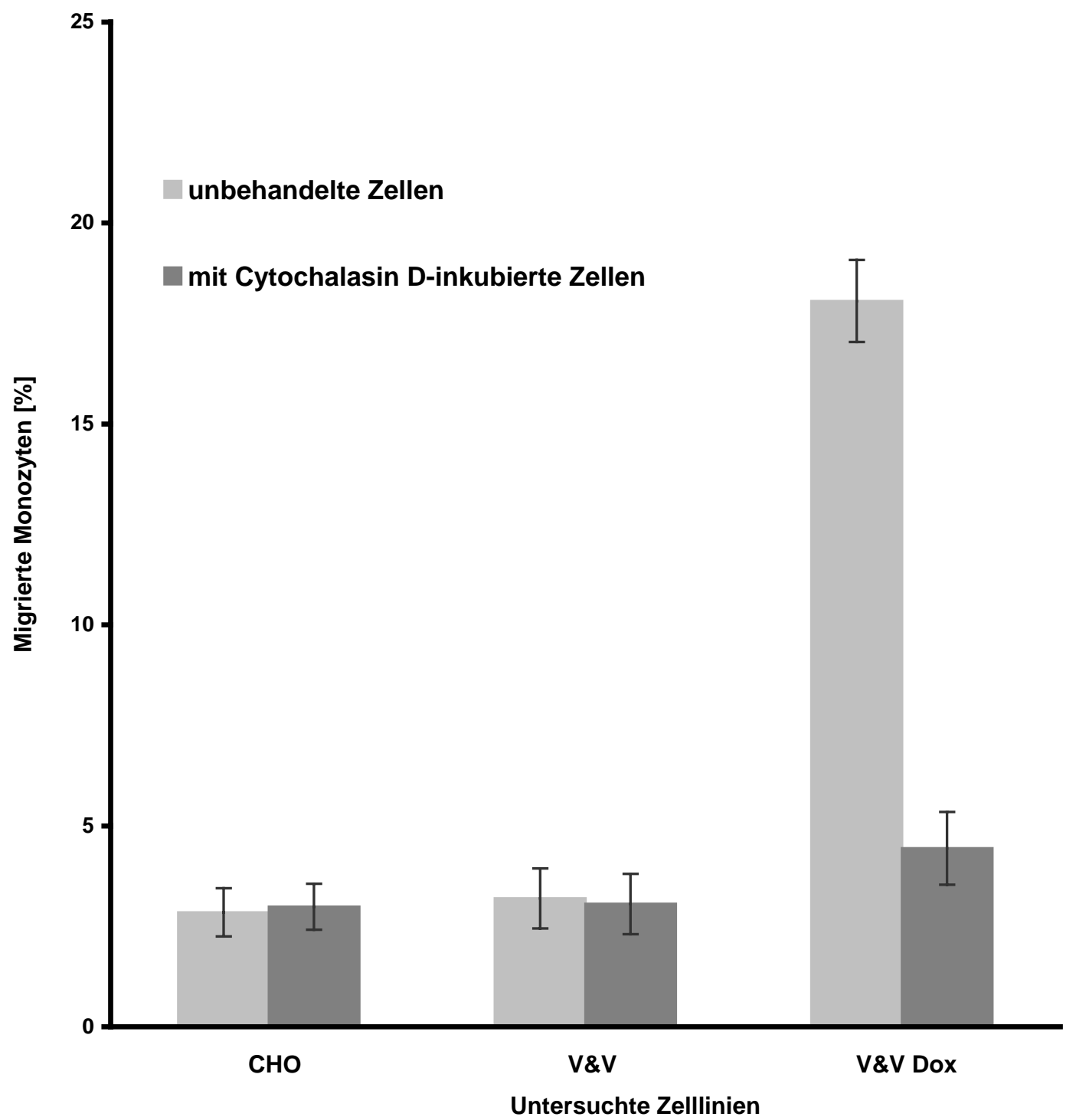

Abb. 3.15: Transmigration der Monozyten durch Zellschichten von $\mathrm{CHO}$ und $\mathrm{CHO}$ CD7/VCAM\&VCAM-1. Vor Zugabe der Monozyten waren die erforderlichen Ansätze mit Cytochalasin D inkubiert worden. Der Prozentsatz der migrierten Monozyten wurde mikroskopisch in einer Neubauer-Zählkammer ermittelt. Untersuchte Zelllinien: V\&V: CHO-CD7/VCAM\&VCAM-1; V\&V Dox: Inkubation von CHO-CD7/VCAM\&VCAM-1 mit Doxycyclin. Vertikale Balken: Standardfehler 


\subsection{Untersuchungen an dem Oberflächenrezeptor ICAM-1}

\subsubsection{ICAM-1 vermittelte Adhäsion von Monozyten}

Die transgene Zelllinie $\mathrm{CHO} / \mathrm{ICAM}-1$ wies bei Aggregationsversuchen im Mittel $54,23 \%$ gebundene Monozyten auf (Abb. 3.16). Gegenüber der Kontrolle, bei der durchschnittlich 9,14\% Monozyten aggregierten, liegt mit einer Irrtumswahrscheinlichkeit von $0,1 \%$ ein deutlicher Unterschied vor. Die Bindung der Leukozyten durch den endothelialen Oberflächenrezeptor ICAM-1 (CD54) konnte des weiteren durch Blockade mit anti-ICAM-1 näher belegt werden. In diesen Ansätzen war es möglich, den Prozentsatz der gebundenen Monozyten auf durchschnittlich 11,07 \% zu senken. Die statistische Analyse bestätigte den Effekt der Blockade bei dieser Zelllinie $(p<0,001)$ und belegte des weiteren, dass keine Unterschiede zwischen untransfizierten $\mathrm{CHO}$-Zellen und Antikörper-blockierten CHO/ICAM-1 vorlagen. Hiermit wurde eine ICAM-1 vermittelte Bindung von Monozyten nachgewiesen. 


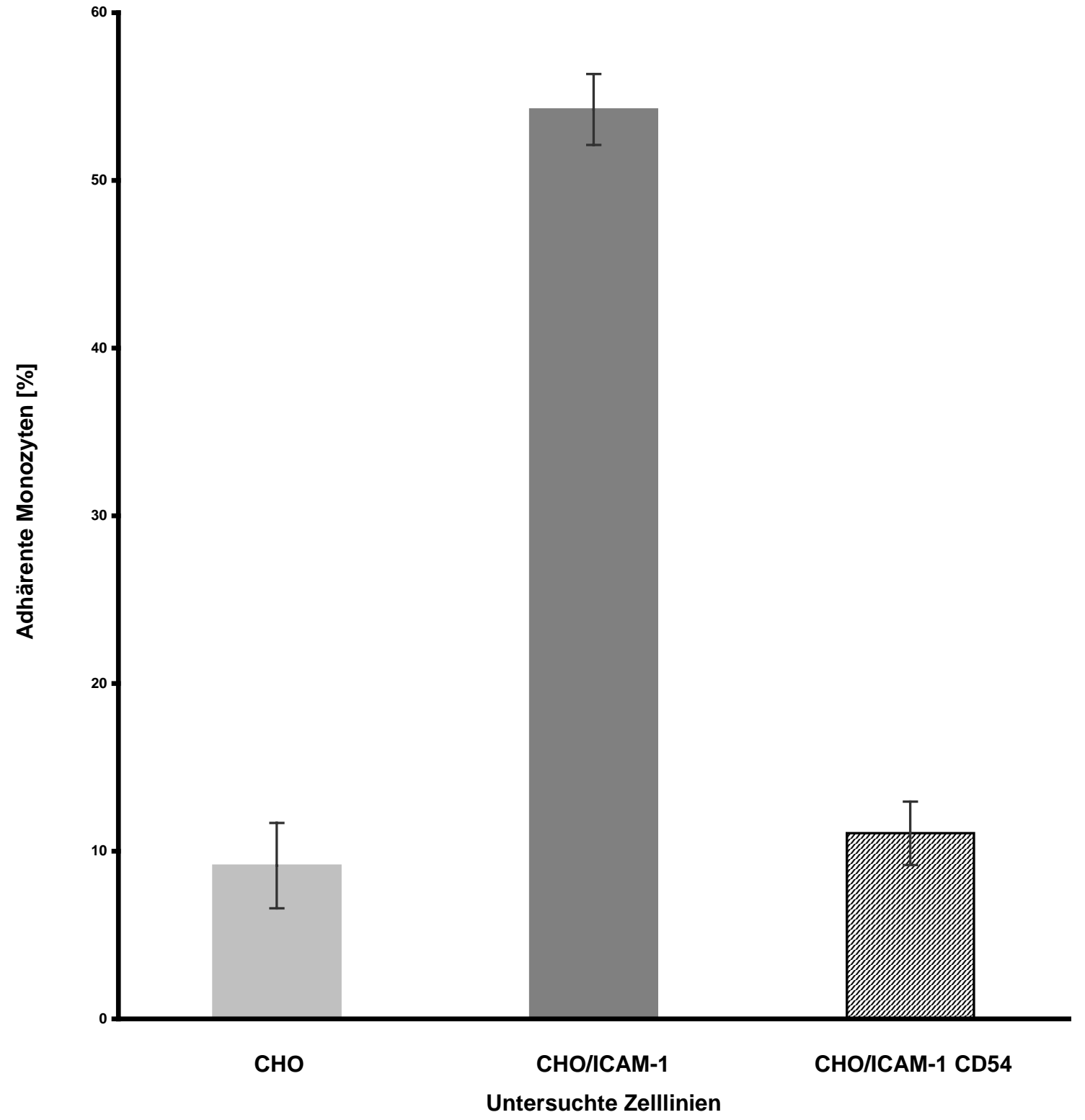

Abb. 3.16: Adhäsion von Monozyten an CHO und CHO/ICAM-1. Vor Zugabe der Monozyten waren die Ansätze im entsprechenden Experiment mit anti-ICAM-1 inkubiert worden. Der Prozentsatz der gebundenen Monozyten wurde in der Durchflusszytometrie ermittelt. Untersuchte Zelllinien: CHO/ICAM-1 CD54: anti-ICAM-1 blockierte CHO/ICAM-1. Vertikale Balken: Standardfehler 


\subsubsection{Vergleich der Monozytenadhäsion an die transgenen Zelllinien CHO/ICAM-1 und CHO/ICAM-1\&CD7/VCAM}

Im weiteren Verlauf war zu untersuchen, ob das Fusionsprotein die ICAM-1 vermittelte Adhäsion von Monozyten beeinflusste.

CHO/ICAM-1 hatten in dieser Versuchsreihe im Mittel 29,95 \% Monozyten gebunden (Abb. 3.17). Die Zellen, die zusätzlich das Fusionsmolekül exprimierten, wiesen durchschnittlich 27,3\% Monozyten auf, so dass die statistische Analyse der Daten wie zu erwarten keine Unterschiede zwischen den Zelllinien nachwies. Gegenüber der Kontrolle (7,14 \% Monozyten) wiesen beide hochsignifikante Unterschiede auf $(p<0,001)$. Das Fusionsprotein CD7/VCAM bedingte demnach bei CHO/ICAM-1 keine Abnahme der gebundenen Monozyten. 


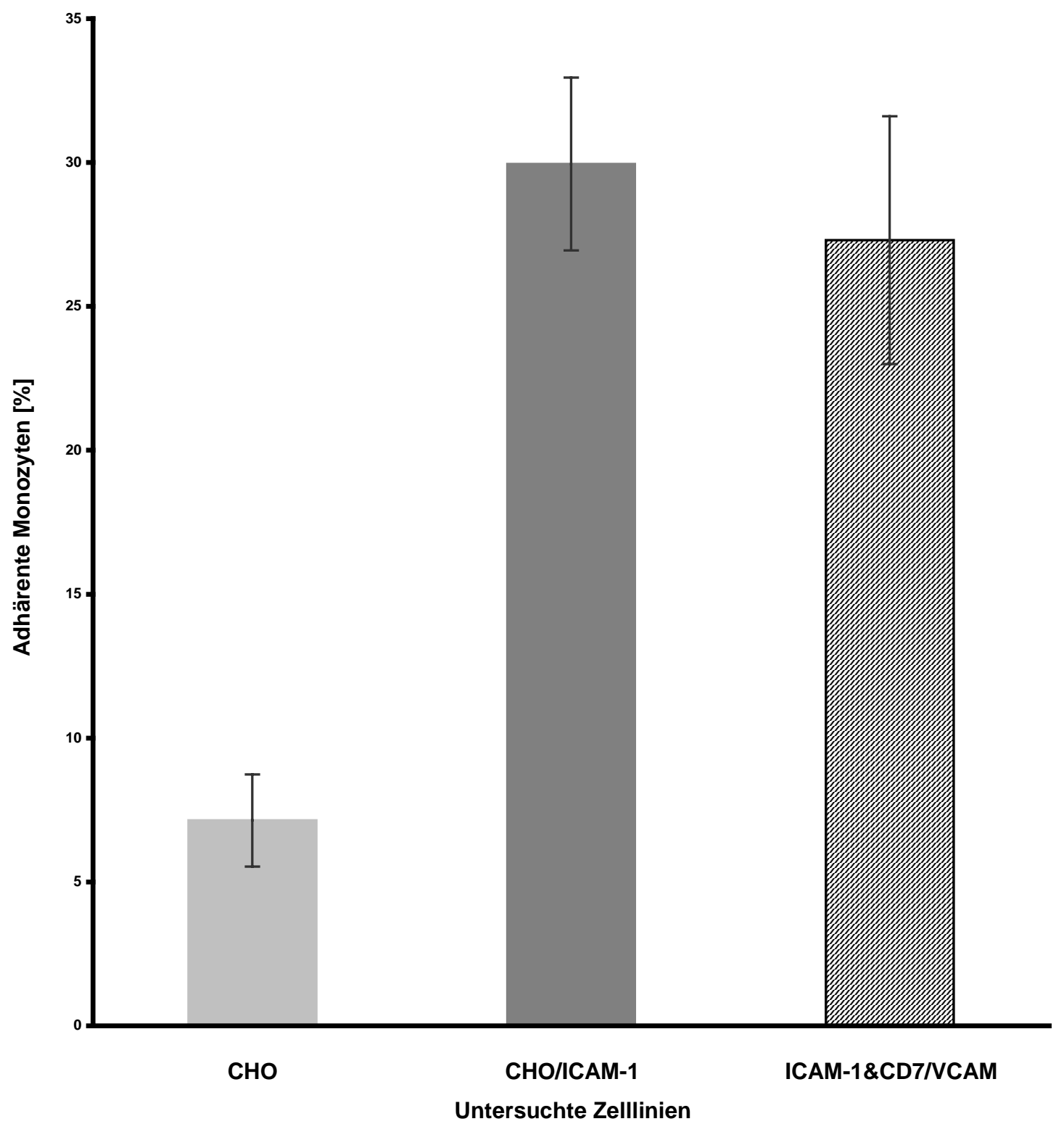

Abb. 3.17: Adhäsion von Monozyten an CHO, CHO/ICAM-1 und CHO/ICAM-1\&CD7/VCAM. Der Prozentsatz der gebundenen Monozyten wurde in der Durchflusszytometrie ermittelt. Untersuchte Zelllinien: ICAM-1\&CD7/VCAM: CHO/ICAM-1\&CD7/VCAM. Vertikale Balken: Standardfehler 


\subsubsection{Inhibition der ICAM-1 Zytoskelettverankerung durch Cytochalasin D}

Die folgenden Untersuchungen sollten die Zytoskelettverankerung von ICAM-1 aufklären. Zunächst wurde hierzu der Prozentsatz der gebundenen Monozyten an CHO/ICAM-1 ermittelt, die mit und ohne Cytochalasin D Behandlung eingesetzt wurden. In einer weiterführenden Versuchsreihe wurden CHO/ICAM-1\& CD7/VCAM damit verglichen.

Die Behandlung von CHO/ICAM-1 mit Cytochalasin D bewirkte, dass gegenüber unbehandelten Zellen der Prozentsatz der adhärenten Monozyten von im Mittel $51,91 \%$ auf $9,96 \%$ zurückging (Abb. 3.18). Vergleichbare prozentuale Anteile von Monozyten fanden sich bei den untransfizierten $\mathrm{CHO}$-Zellen (durchschnittlich 7,87 bzw. 6,43 \% Monozyten nach Cytochalasin D Behandlung). Die Analyse im Student's t-Test bestätigte, dass zwischen $\mathrm{CHO}$ und CHO/ICAM-1 hochsignifikante Unterschiede vorlagen $(p<0,001)$ und belegte mit einer Irrtumswahrscheinlichkeit von $0,1 \%$, dass die Cytochalasin $\mathrm{D}$ Behandlung die ICAM-1 vermittelte Adhäsion von Monozyten verhinderte. Demnach benötigte der Oberflächenrezeptor ICAM-1, um seine Funktion bei der Leukozytenadhäsion ausüben zu können, ebenso wie VCAM-1 eine Bindung an actinhaltige Strukturen des Zytoskeletts.

Die prozentualen Anteile von Monozyten, die an die Zelllinie CHO/ICAM-1\& CD7/VCAM gebunden hatten (durchschnittlich 36,52 \% Monozyten), wichen nicht von CHO/ICAM-1 (im Mittel 35,06 \% Monozyten) ab (Abb. 3.19). Die Behandlung beider Zelllinien mit Cytochalasin $D$ bewirkte eine Abnahme der Monozyten (CHO/ICAM-1\&CD7/VCAM: durchschnittlich 5,56 \% bzw. CHO/ICAM-1: 5,84\% Monozyten) auf vergleichbare Anteile, die bei $\mathrm{CHO}$ Ansätzen registriert wurden (im Mittel 6,06 \% bzw. 5,78 \% Monozyten für Cytochalasin D Ansätze). 


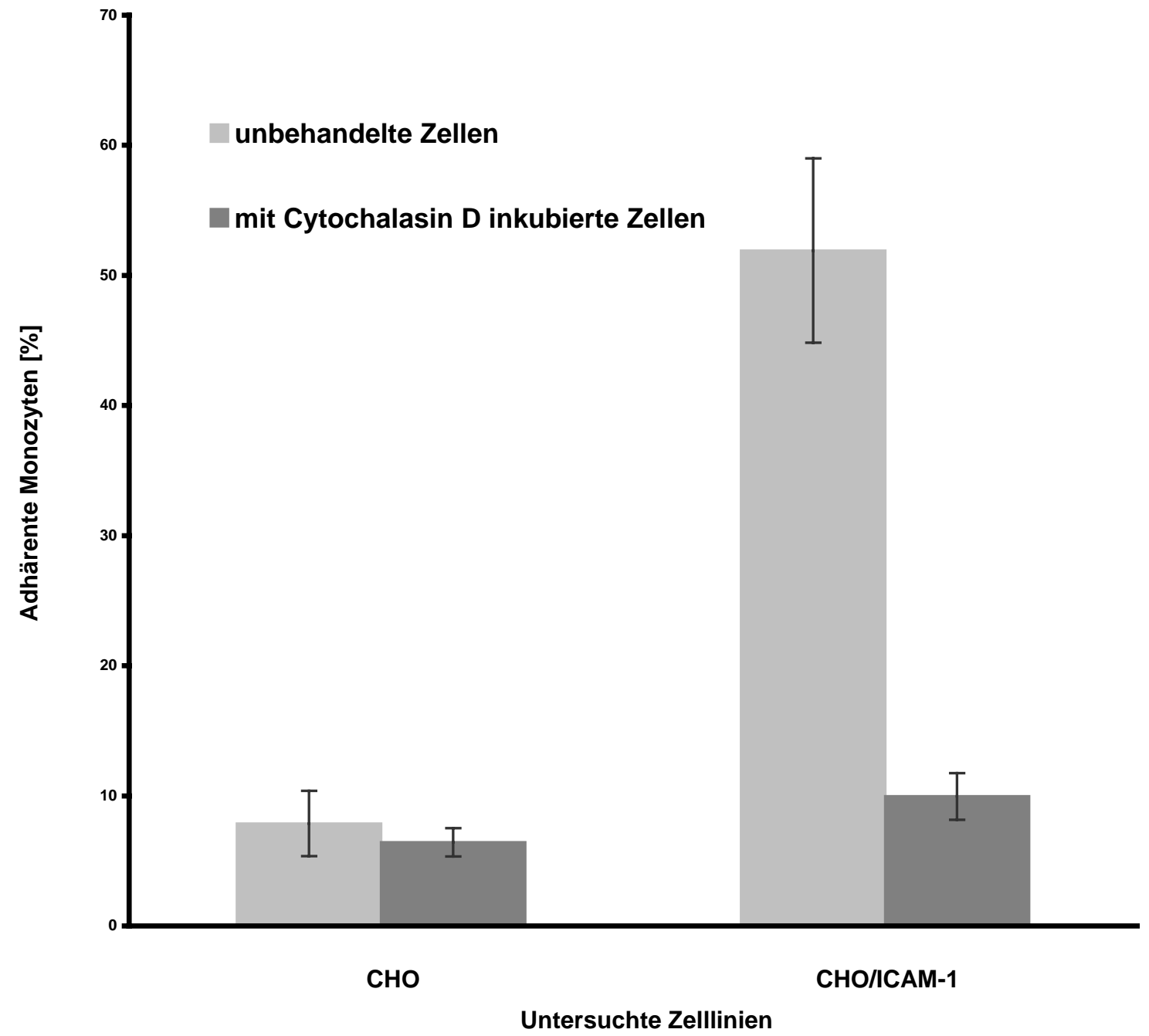

Abb. 3.18: Adhäsion von Monozyten an CHO und CHO/ICAM-1. Vor Zugabe der Monozyten waren die erforderlichen Ansätze mit Cytochalasin D inkubiert worden. Der Prozentsatz der gebundenen Monozyten wurde in der Durchflusszytometrie ermittelt. Vertikale Balken: Standardfehler 


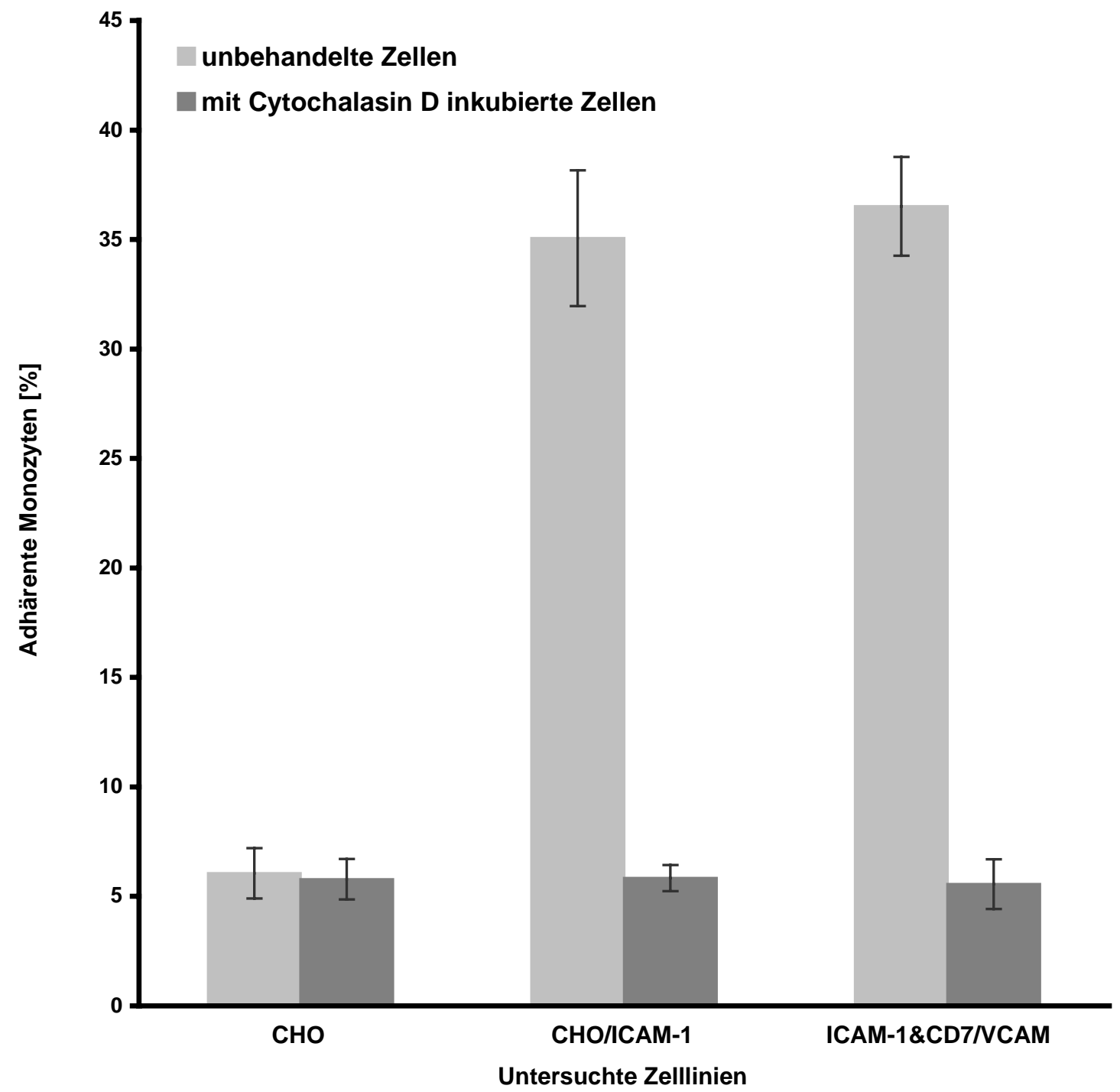

Abb. 3.19: Adhäsion von Monozyten an CHO, CHO/ICAM-1 und CHO/ICAM-1\&CD7/VCAM. Vor Zugabe der Monozyten waren die Ansätze im erforderlichen Experiment mit Cytochalasin D inkubiert worden. Der Prozentsatz der gebundenen Monozyten wurde in der Durchflusszytometrie ermittelt. Untersuchte Zelllinien: ICAM-1\&CD7/VCAM: CHO/ICAM-1\&CD7/VCAM. Vertikale Balken: Standardfehler

Die Untersuchungen, die in 3.4.2 und 3.4.3 dargestellt sind, belegten somit, dass das CD7/VCAM den Oberflächenrezeptor VCAM-1 selektiv blockieren konnte. Die Transfektion mit cd7/vcam bewirkte nur bei dem vaskulären Rezeptor eine signifikante Abnahme der gebundenen Monozyten. 
ICAM-1 benötigt ebenfalls eine Verankerung am Actinskelett, um seine Aufgaben wahrnehmen zu können. Die Einschleusung des Fusionsproteins konnte dies nicht verhindern und konkurrierte demzufolge offensichtlich selektiv mit VCAM-1 um Bindungsstellen zum Zytoskelett.

\subsubsection{ICAM-1 vermittelte Transmigration}

Der Oberflächenrezeptor ICAM-1 soll ebenfalls an der Vermittlung der Monozytentransmigration beteiligt sein (Languino et al., 1995).

In Ansätzen mit transgenen Zellen migrierten im Mittel 22,05 \% Monozyten, wohingegen CHO/ICAM-1 mit blockiertem Rezeptor nur durchschnittlich 3,4\% aufwiesen (Abb. 3.20). Diese Ergebnisse korrelierten mit den prozentualen Anteilen der Kontrollansätze (im Mittel 2,99 \% Monozyten). Die statistische Analyse bestätigte zum einen die Unterschiede zwischen Kontrollen und CHO/ICAM-1 $(p<0,001)$ und zum anderen die Vergleichbarkeit von anti-ICAM-1 blockierten CHO/ICAM-1 und CHO-Zellen. Die Transmigration von Monozyten durch ICAM-1 war somit nachgewiesen.

Die Einschleusung von cd7/vcam bedingte keine Veränderung der ICAM-1 vermittelten Transmigration. Bei der CHO-Kontrolle konnten im Mittel 3,75\% Monozyten durch die Zellschicht wandern (Abb. 3.21). Demgegenüber waren bei CHO/ICAM-1 durchschnittlich 23,75 \% Monozyten migriert, ein prozentualer Anteil, der auch bei der Zelllinie, die das Fusionsprotein exprimierte, ermittelt wurde (durchschnittlich 23,82 \% Monozyten). Demnach hatte die Transfektion mit cd7/vcam keinen Einfluss auf die Funktion von ICAM-1. 


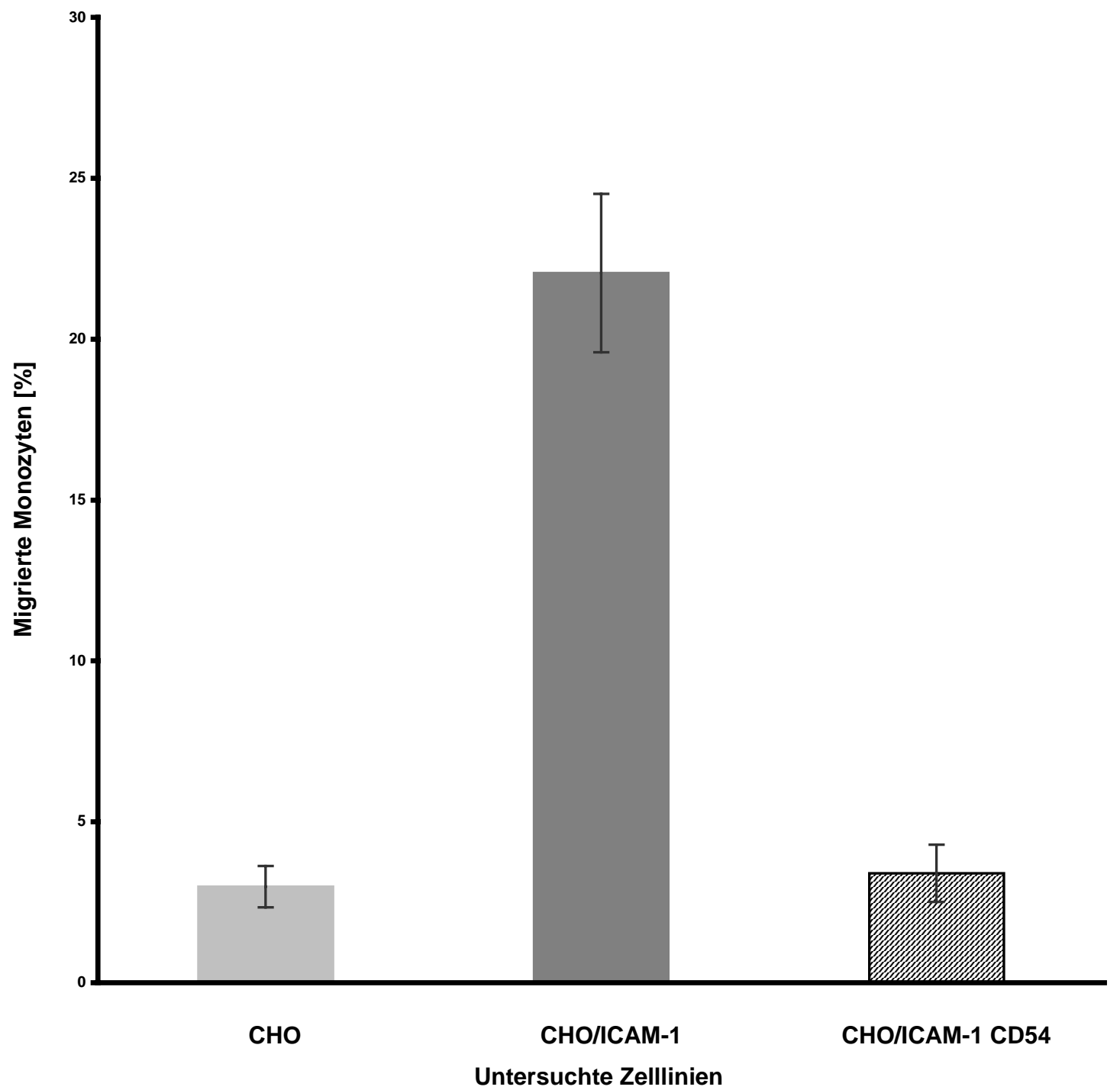

Abb. 3.20: Transmigration der Monozyten durch Zellschichten von CHO und CHO/ICAM-1. Vor Zugabe der Monozyten waren die Ansätze im entsprechenden Experiment mit anti-ICAM-1 blockiert worden. Der Prozentsatz der migrierten Monozyten wurde mikroskopisch in einer Neubauer-Zählkammer ermittelt. Vertikale Balken: Standardfehler 


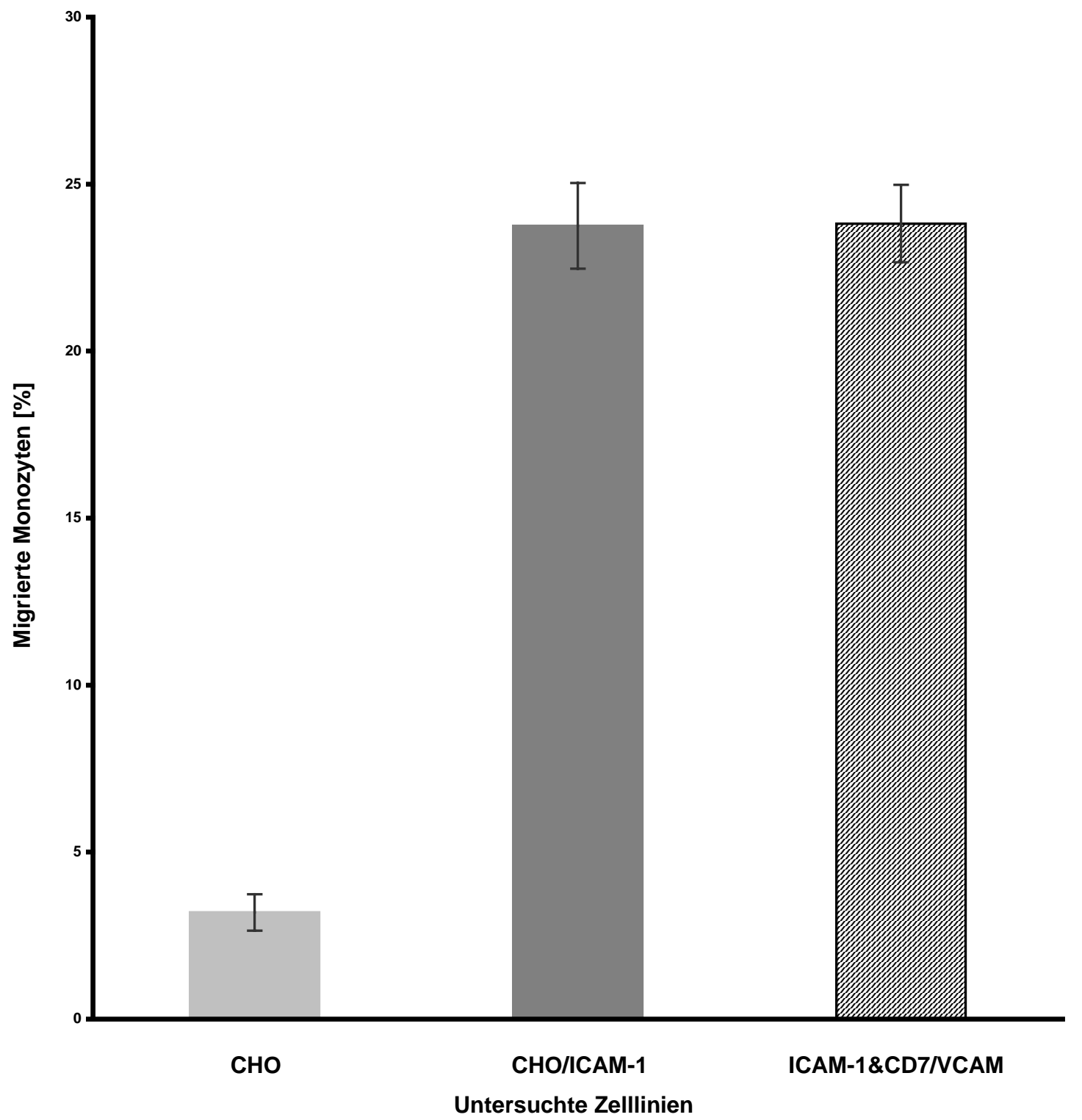

Abb. 3.21: Transmigration der Monozyten durch Zellschichten von $\mathrm{CHO}$, CHO/ICAM-1 und CHO/ICAM-1\&CD7/VCAM. Der Prozentsatz der migrierten Monozyten wurde mikroskopisch in einer Neubauer-Zählkammer ermittelt. Untersuchte Zelllinien: ICAM-1\&CD7/VCAM: CHO/ICAM1\&CD7/VCAM. Vertikale Balken: Standardfehler 


\subsubsection{Hemmung der ICAM-1 vermittelten Monozytenmigration durch Cytochalasin D}

Bei Zellen der Linie CHO/ICAM-1 konnten durchschnittlich 24,38 \% der eingesetzten Monozyten durch die Zellschicht migrieren (Abb. 3.22). Nach Behandlung mit Cytochalasin D wiesen sie im Mittel nur 3,75\% der Monozyten auf, was dem Niveau der Kontrollansätze von CHO-Zellen entsprach (durchschnittlich 2,85\% bzw. 3,75 \% Monozyten ohne bzw. nach Cytochalasin D Behandlung). Demnach ist auch für den Oberflächenrezeptor ICAM-1 eine Verankerung an das Zytoskelett unverzichtbar, um die Transmigration von Monozyten vermitteln zu können.

Die Untersuchungen an CHO/ICAM-1\&CD7/NCAM zeigten, dass hier durchschnittlich 22,01\% Monozyten durch die Zellschicht wanderten (Abb. 3.23). Ähnliche Resultate konnten für CHO/ICAM-1 beobachtet werden (im Mittel 22,09\%). Demgegenüber ließ die CHO-Kontrolle durchschnittlich nur 2,78 \% Monozyten migrieren. Im letzteren Fall hatte die Behandlung mit Cytochalasin D keinen Einfluss auf die Transmigration (im Mittel 3,2 \% Monozyten). Für CHO/ICAM-1 und CHO/ICAM-1\&CD7/VCAM hingegen nahmen die prozentualen Anteile bis zu 3,13\% (CHO/ICAM-1) bzw. 2,43\% Monozyten (CHO/ICAM-1\&CD7/VCAM) ab. Demnach übte die Transfektion mit cd7/vcam keinen Einfluss auf die ICAM-1 vermittelte Transmigration von Monozyten aus. 


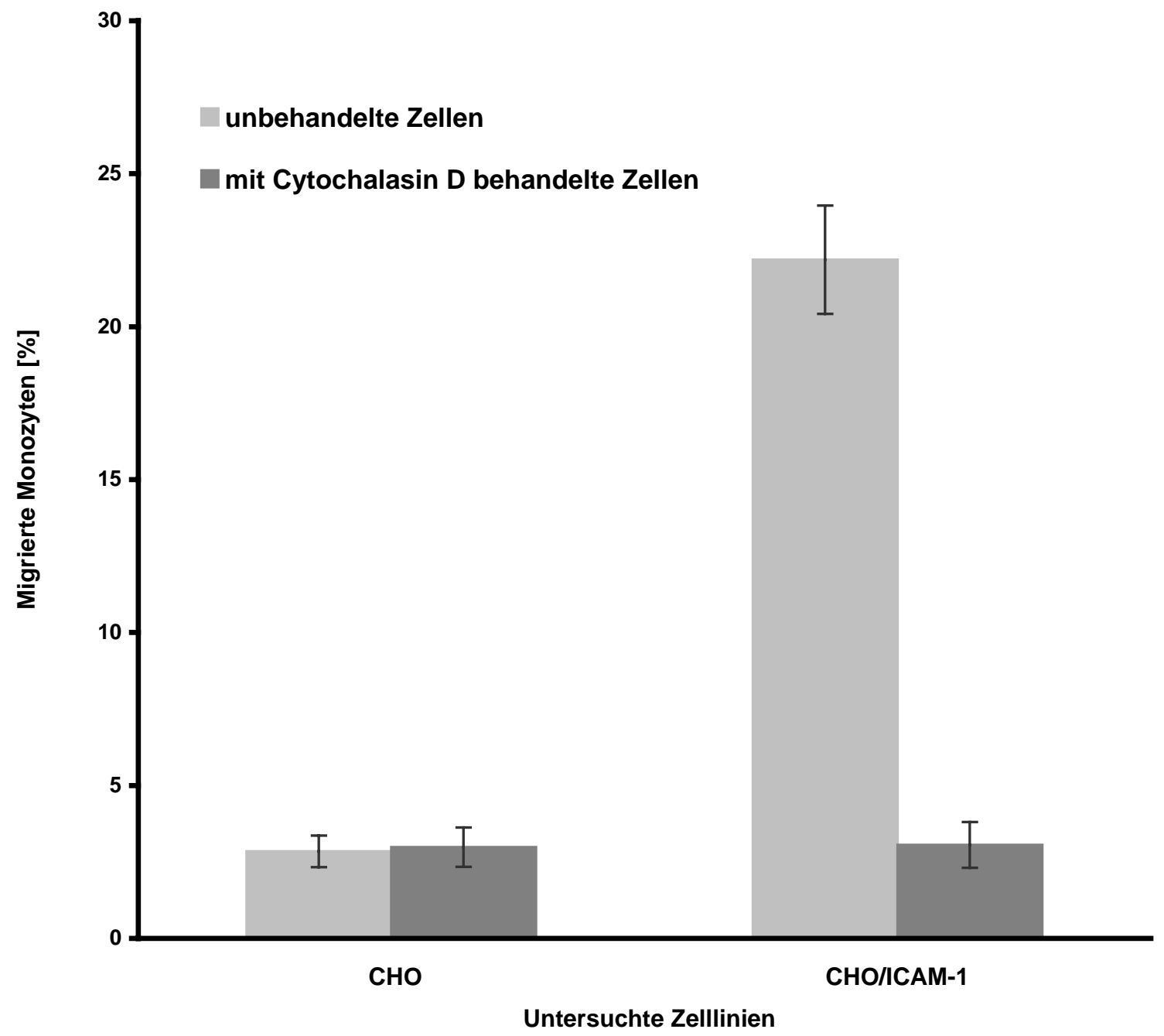

Abb. 3.22: Transmigration der Monozyten durch Zellschichten von CHO bzW. CHO/ICAM-1. Vor Zugabe der Monozyten waren die Ansätze in entsprechenden Experimenten mit Cytochalasin D behandelt worden. Der Prozentsatz der migrierten Monozyten wurde mikroskopisch in einer Neubauer-Zählkammer ermittelt. Vertikale Balken: Standardfehler 


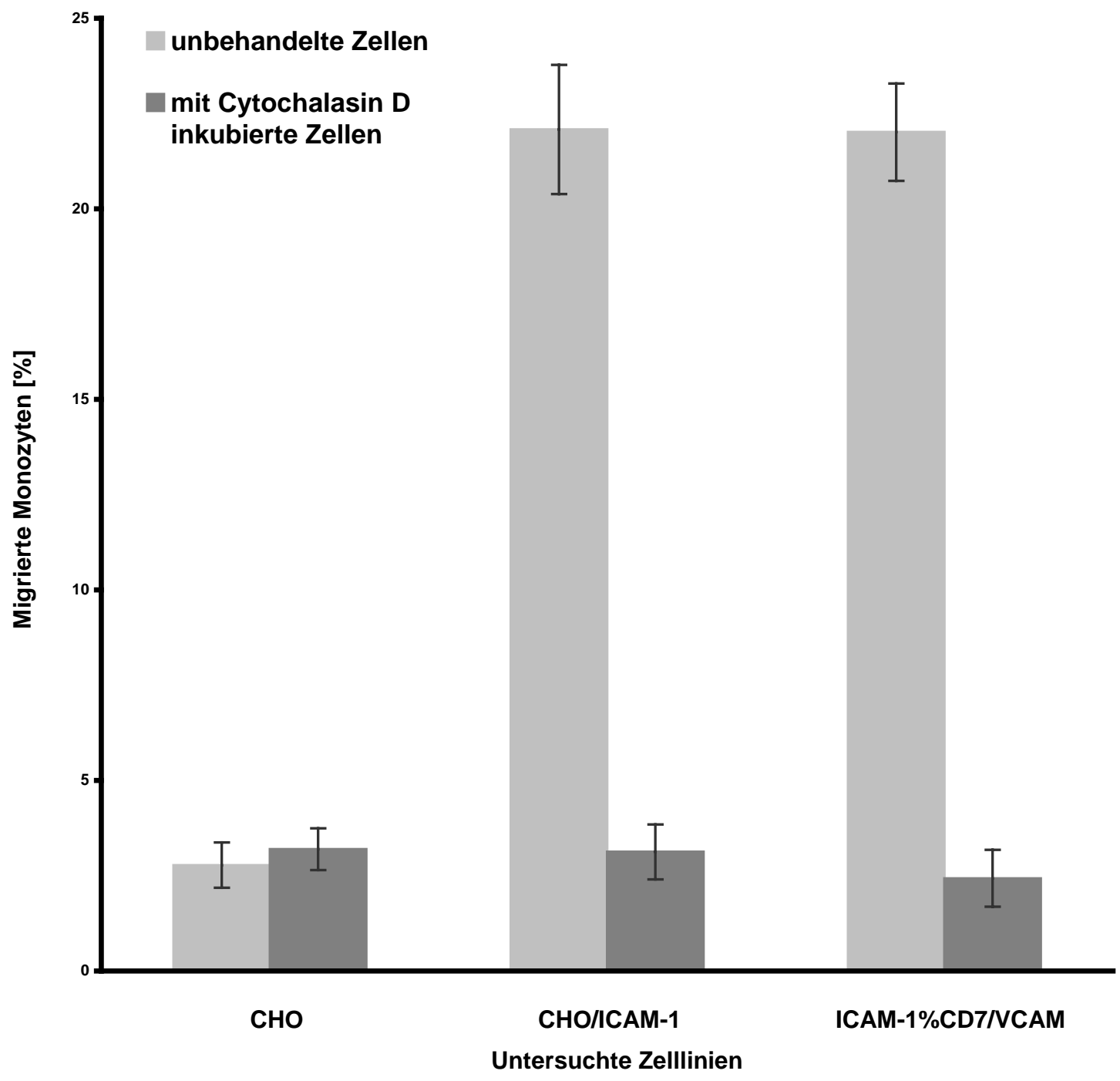

Abb. 3.23: Transmigration der Monozyten durch Zellschichten von $\mathrm{CHO}$, CHO/ICAM-1 und CHO/ICAM-1\&CD7/VCAM. Vor Zugabe der Monozyten wurden die Ansätze in entsprechenden Experimenten mit Cytochalasin D behandelt. Der Prozentsatz der migrierten Monozyten wurde mikroskopisch in einer Neubauer-Zählkammer ermittelt. Untersuchte Zelllinien: ICAM-1\& CD7/VCAM: CHO/ICAM-1\&CD7/VCAM. Vertikale Balken: Standardfehler 


\subsection{Untersuchungen an E-Selektin}

\subsubsection{E-Selektin-vermittelte Adhäsion der Monozyten}

Die CHO/E-Selektin-Zellen zeigten gegenüber der Kontrolle, bei der durchschnittlich 8,06 \% Monozyten adhärent waren, eine deutliche Bindung der Monozyten mit 40,3 \% (Abb. 3.24). Um die Bindung zu spezifizieren, wurde ferner der Prozentsatz der Aggregate ermittelt, die vorlagen, nachdem der Oberflächenrezeptor (CD62E) vor Zugabe der Monozyten durch anti-E-Selektin blockiert worden war. Gegenüber den unblockierten Ansätzen waren hier im Mittel $16,88 \%$ der Monozyten adhärent.

Der statistische Vergleich der Daten belegte, dass zwischen unblockierten und CD62E-blockierten $\mathrm{CHO} / \mathrm{E}$-Selektin hochsignifikante Unterschiede vorlagen $(p<0,001)$. Demnach war die Bildung der Aggregate durch den Rezeptor ESelektin spezifizierbar.

Allerdings ließen sich auch zwischen $\mathrm{CHO}$ und CD62E-blockierten $\mathrm{CHO} / \mathrm{E}$ Selektin hochsignifikante Unterschiede nachweisen $(p<0,001)$. In Vorversuchen war eine genaue Titration der Antikörper erfolgt, so dass von einer vollkommenen Blockade des Rezeptors in der Funktionsanalyse ausgegangen werden musste. Demnach konnte nicht eindeutig erwiesen werden, dass die Summe der vorliegenden Aggregate ausschließlich über E-Selektin vermittelt wurde. Eine Hintergrundbindung durch andere, hier nicht relevante Oberflächenrezeptoren oder unspezifische Adhäsion muss daher angenommen werden. 


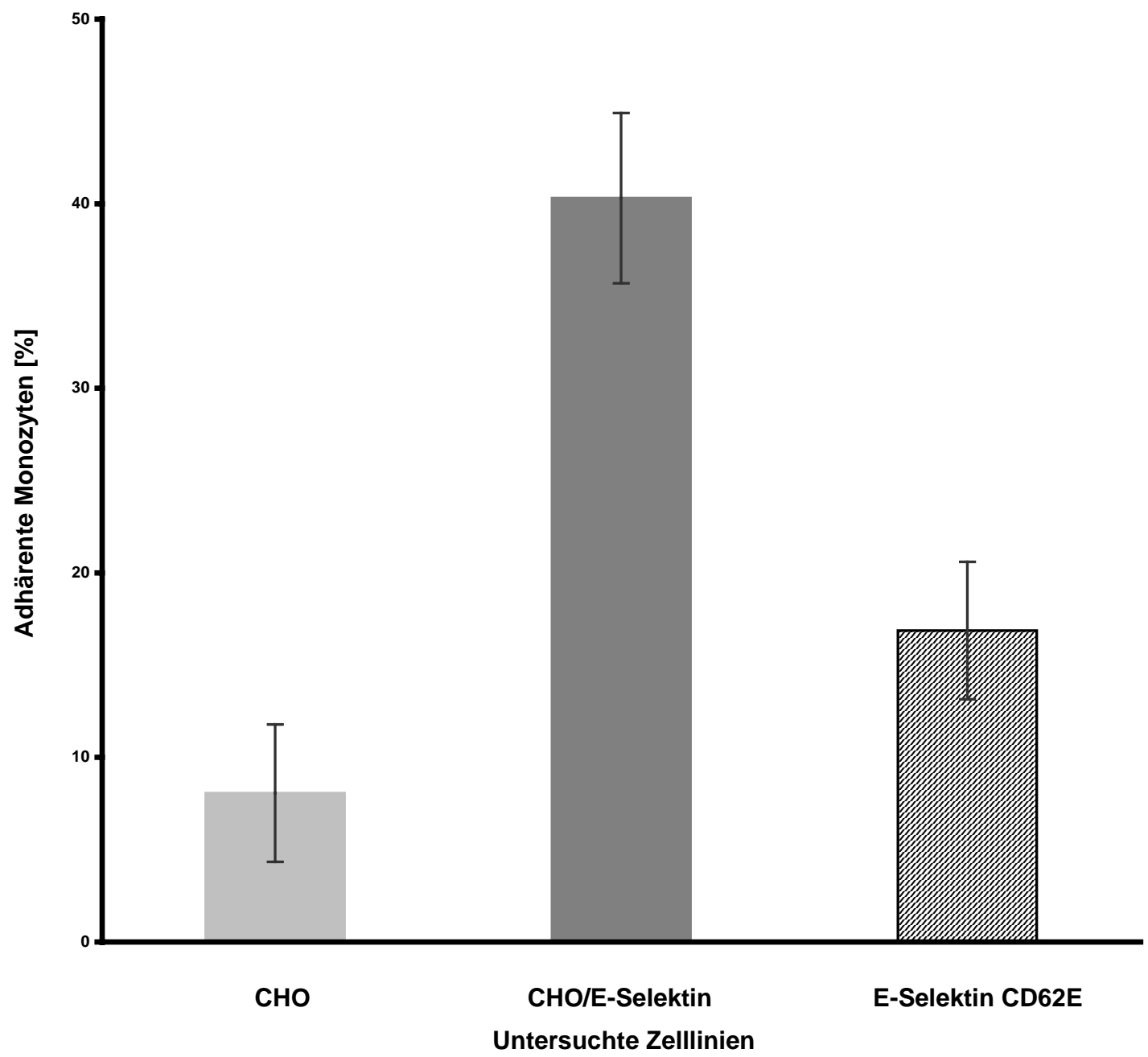

Abb. 3.24: Adhäsion von Monozyten an CHO/E-Selektin. Vor Zugabe der Monozyten war der Rezeptor in entsprechenden Experimenten mit anti-E-Selektin blockiert worden. Der Prozentsatz der gebundenen Monozyten wurde in der Durchflusszytometrie ermittelt. Untersuchte Zelllinien: ESelektin CD62E: anti-E-Selektin blockierte CHO/E-Selektin. Vertikale Balken: Standardfehler 


\subsubsection{Monozytenadhäsion an die Zelllinien CHO/E-Selektin und CHO/E-Selektin\&CD7/VCAM}

Die Zelllinie $\mathrm{CHO} / \mathrm{E}-$ Selektin wurde mit cd7/vcam transfiziert, um bei gezielter Hemmung von VCAM-1 durch Einschleusung des Fusionsmoleküls mögliche Interaktionen mit E-Selektin zu erfassen.

Bei den $\mathrm{CHO} / \mathrm{E}$-Selektin-Zellen wurden gegenüber 7,56 \% bei untransfizierten CHO-Kontrollen im Mittel 25,88 \% Monozyten gebunden (Abb. 3.25). CHO/E-Selektin\&CD7/VCAM wiesen durchschnittlich 29,37\% aggregierte Monozyten auf. Bei beiden transgenen Zelllinien konnte die E-Selektin-vermittelte Adhäsion durch anti-E-Selektin blockiert werden (CHO/E-Selektin: 16,15\% bzw. CHO/E-Selektin\&CD7/VCAM: 15,28\% Monozyten). In der statistischen Analyse zeigte sich, dass zwischen den transfizierten $\mathrm{CHO} / \mathrm{E}-S e l e k t i n-$ und den $\mathrm{CHO} / \mathrm{E}-S e l e k t i n-Z e l l e n$ keine Unterschiede vorlagen. Die Blockade mit anti-CD62E bewirkte bei beiden Zelllinien eine hochsignifikante Abnahme der gebundenen Monozyten $(p<0,001)$. Somit hatte die Transfektion des Fusionsmoleküls keinen Einfluss auf die E-Selektin-vermittelte Adhäsion von Monozyten. 


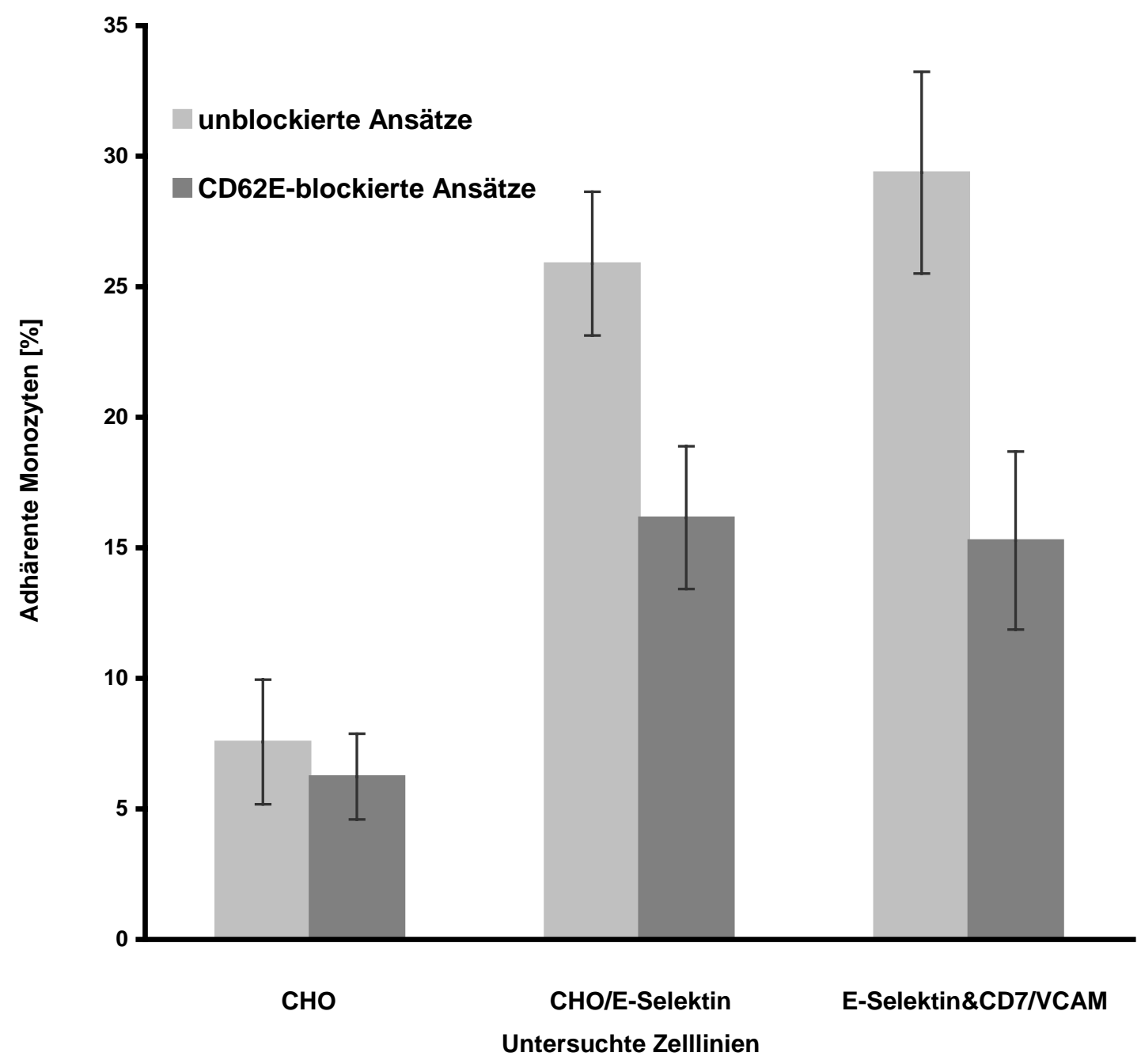

Abb. 3.25: Adhäsion von Monozyten an $\mathrm{CHO}, \mathrm{CHO} / \mathrm{E}-S e l e k t i n$ und $\mathrm{CHO} / \mathrm{E}-S e l e k t i n \&$ CD7/VCAM. Der Prozentsatz der gebundenen Monozyten wurde in der Durchflusszytometrie ermittelt. Untersuchte Zelllinien: E-Selektin\&CD7/VCAM: CHO/E-Selektin\&CD7/ VCAM. Vertikale Balken: Standardfehler

\subsubsection{Monozytenadhäsion an die Zelllinien CHO/E-Selektin und CHO/E-Selektin\&CD7/VCAM nach Behandlung mit Cytochalasin D}

Zur weiteren Aufklärung wurden die transgenen E-Selektin-Zelllinien auf ihre Bindung an das Actinskelett untersucht. Die Kontrollen ( $\mathrm{CHO}$ ) wiesen mit und ohne Cytochalasin D Behandlung durchschnittlich etwa $6 \%$ Monozyten auf (Abb. 
3.26). Demgegenüber konnten an unbehandelte Zellen der Linien $\mathrm{CHO} / \mathrm{E}-$ Selektin bzw. CHO/E-Selektin\&CD7/VCAM im Mittel 28,55 \% bzw. 28,36 \% Monozyten aggregieren. Beide Zelllinien zeigten durch die Behandlung mit Cytochalasin $\mathrm{D}$ keine Veränderungen der prozentualen Anteile von Monozyten (CHO/E-Selektin: im Mittel 29,14 \% bzw. CHO/E-Selektin\&CD7/VCAM: 29,52 \% Monozyten).

Die Bindung von Monozyten an E-Selektin verlangte demnach keine Verankerung des Oberflächenrezeptors an Komponenten des Actinzytoskeletts.

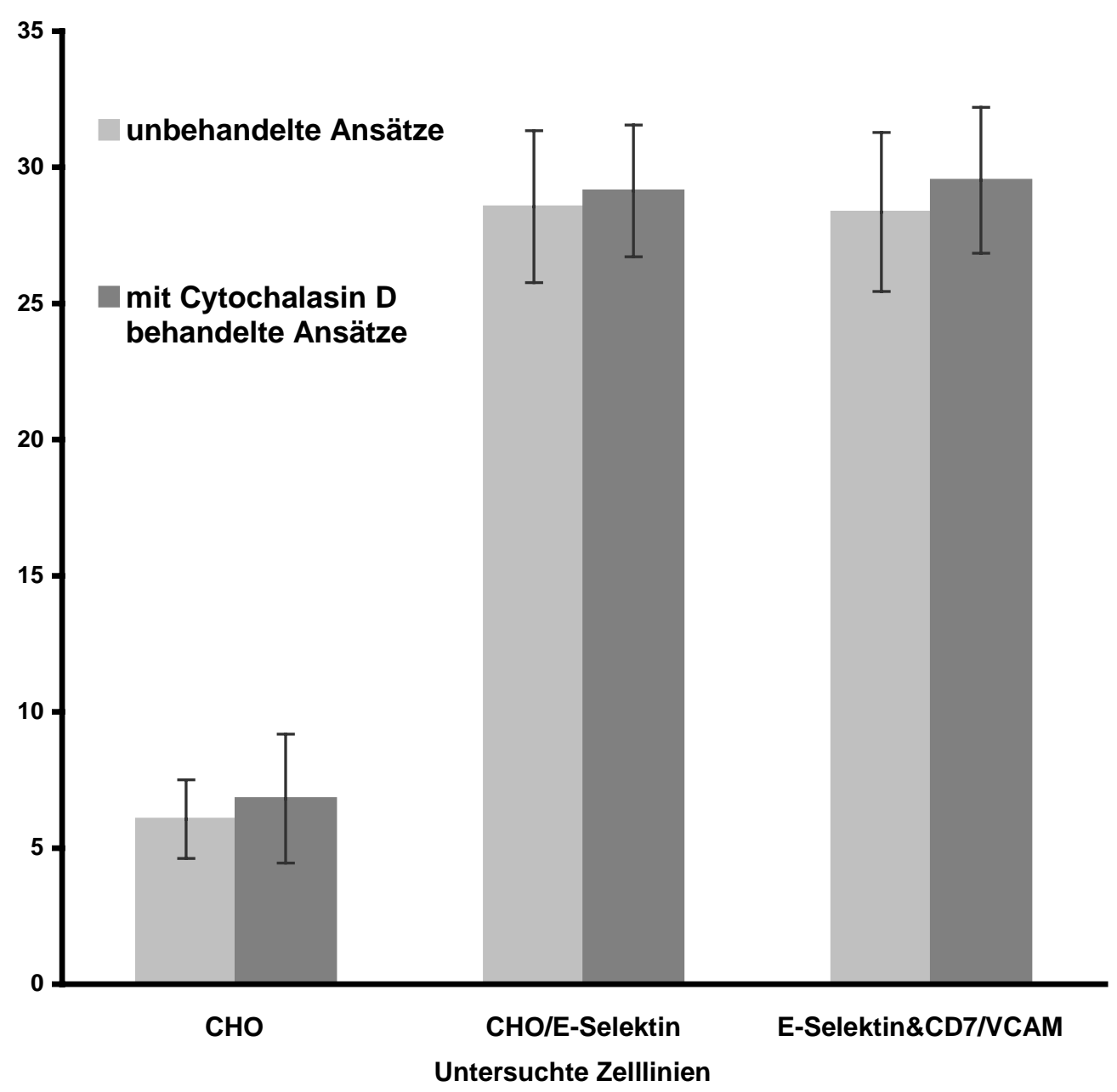

Abb. 3.26: Adhäsion von Monozyten an $\mathrm{CHO}, \mathrm{CHO} / \mathrm{E}-S e l e k t i n$ und $\mathrm{CHO} / \mathrm{E}-S e l e k t i n \&$

CD7/VCAM. Vor Zugabe der Monozyten waren die Ansätze in entsprechenden Experimenten mit Cytochalasin D inkubiert worden. Der Prozentsatz der gebundenen Monozyten wurde in der Durchflusszytometrie ermittelt. Untersuchte Zelllinien: E-Selektin\&CD7/VCAM: CHO/ESelektin\&CD7/VCAM. Vertikale Balken: Standardfehler 


\subsubsection{E-Selektin vermittelt keine Transmigration}

Bei der Kontrolle waren nach drei Stunden durchschnittlich 3,83 \% der eingesetzten Monozyten durch die $\mathrm{CHO}$-Zellschicht gewandert (Abb. 3.27). Die Ansätze der E-Selektin-Zelllinie wiesen im Mittel 4,53 \% migrierte Monozyten auf, ein Ergebnis, das sich mit ähnlichen prozentualen Anteilen bei $\mathrm{CHO} / \mathrm{E}-S e l e k-$ tin\&CD7/VCAM wiederholte (durchschnittlich 4,76 \% Monozyten). Die statistische Auswertung der Versuchanordnung bestätigte, dass zwischen den untransfizierten und transgenen Ansätzen keine Unterschiede vorlagen. Der endotheliale Oberflächenrezeptor E-Selektin ist demzufolge nicht an der Transmigration von Monozyten beteiligt. Die Einschleusung des Fusionsproteins CD7/VCAM konnte somit keinen Einfluss auf die durch diesen Rezeptor vermittelte Penetrierbarkeit ausüben. 


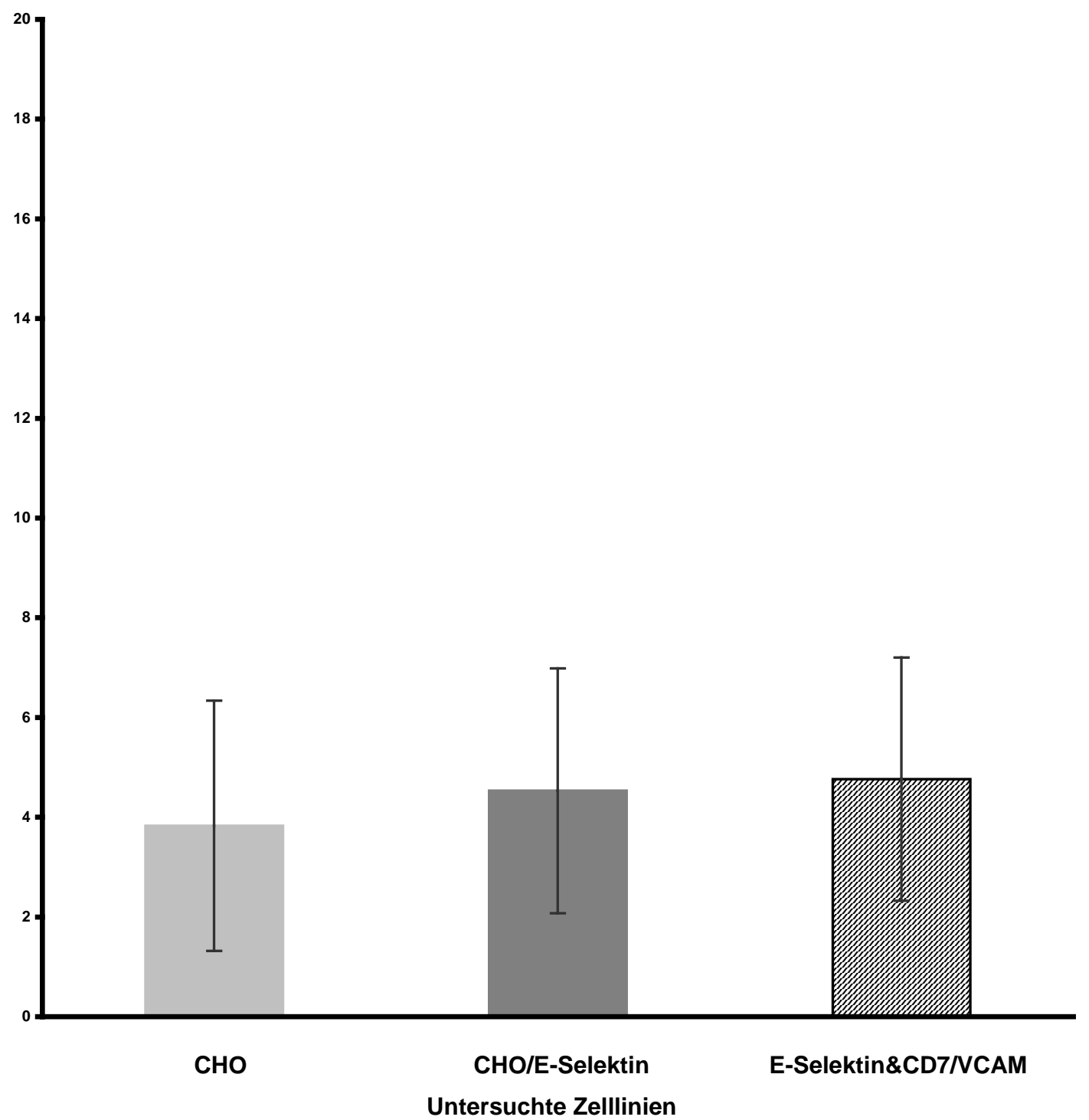

Abb. 3.27: Transmigration der Monozyten durch Zellschichten von $\mathrm{CHO}$, $\mathrm{CHO} / \mathrm{E}-$ Selektin und CHO/E-Selektin\&CD7/VCAM. Der Prozentsatz der migrierten Monozyten wurde mikroskopisch in einer Neubauer-Zählkammer ermittelt. Untersuchte Zelllinien: ESelektin\&CD7/VCAM: CHO/E-Selektin\&CD7/VCAM. Vertikale Balken: Standardfehler 


\subsection{Untersuchungen an HUVECs}

\subsubsection{Expression der Oberflächenrezeptoren E-Selektin, ICAM-1 und VCAM-1 durch Stimulation der HUVECs mit IL-1 $\beta$}

An den humanen Primärzellen wurde zunächst untersucht, inwieweit die Expression der untersuchten Oberflächenrezeptoren stimulierbar war. Als Zytokin wurde IL-1 $\beta$ eingesetzt, das laut Literatur in der Lage ist, die Transkription von sowohl E-Selektin, als auch ICAM-1 und VCAM-1 zu induzieren (Carlos \& Harlan, 1994; Scholz et al., 1996).

Die Abb. 3.28 gibt die Expressionskinetiken der drei Oberflächenrezeptoren über einen Zeitraum von zwölf Stunden wieder. ICAM-1 zeigte bereits nach zwei Stunden seine maximale Expression. Über den Zeitraum von zwei bis zwölf Stunden variierte die Expression kaum und hielt sich auf diesem Niveau. Im Gegensatz dazu nahm die Expression von E-Selektin deutlich zu. Bereits nach $2 \mathrm{~h}$ war die maximale Transkription dieses Gens erreicht, die bis zum Ende der Messung auch nicht mehr signifikant gesteigert wurde. Die Expression von VCAM1 erreichte nach sechs Stunden ihr Maximum. Ziel dieser Untersuchungen war es, die Stimulation der untersuchten Oberflächenrezeptoren nachzuweisen, um eine inflammatorische Situation des Endothels simulieren zu können. Da die VCAM-1 vermittelte Leukozytenadhäsion bzw. -transmigration und ihre Hemmbarkeit durch Transfektion mit cd7/vcam Hauptgegenstand der vorliegenden Arbeit war, wurden alle weiteren Untersuchungen an HUVECs zum Zeitpunkt der maximalen Expression dieses Rezeptors (sechs Stunden) im Vergleich zu unstimulierten Endothelzellen durchgeführt. 


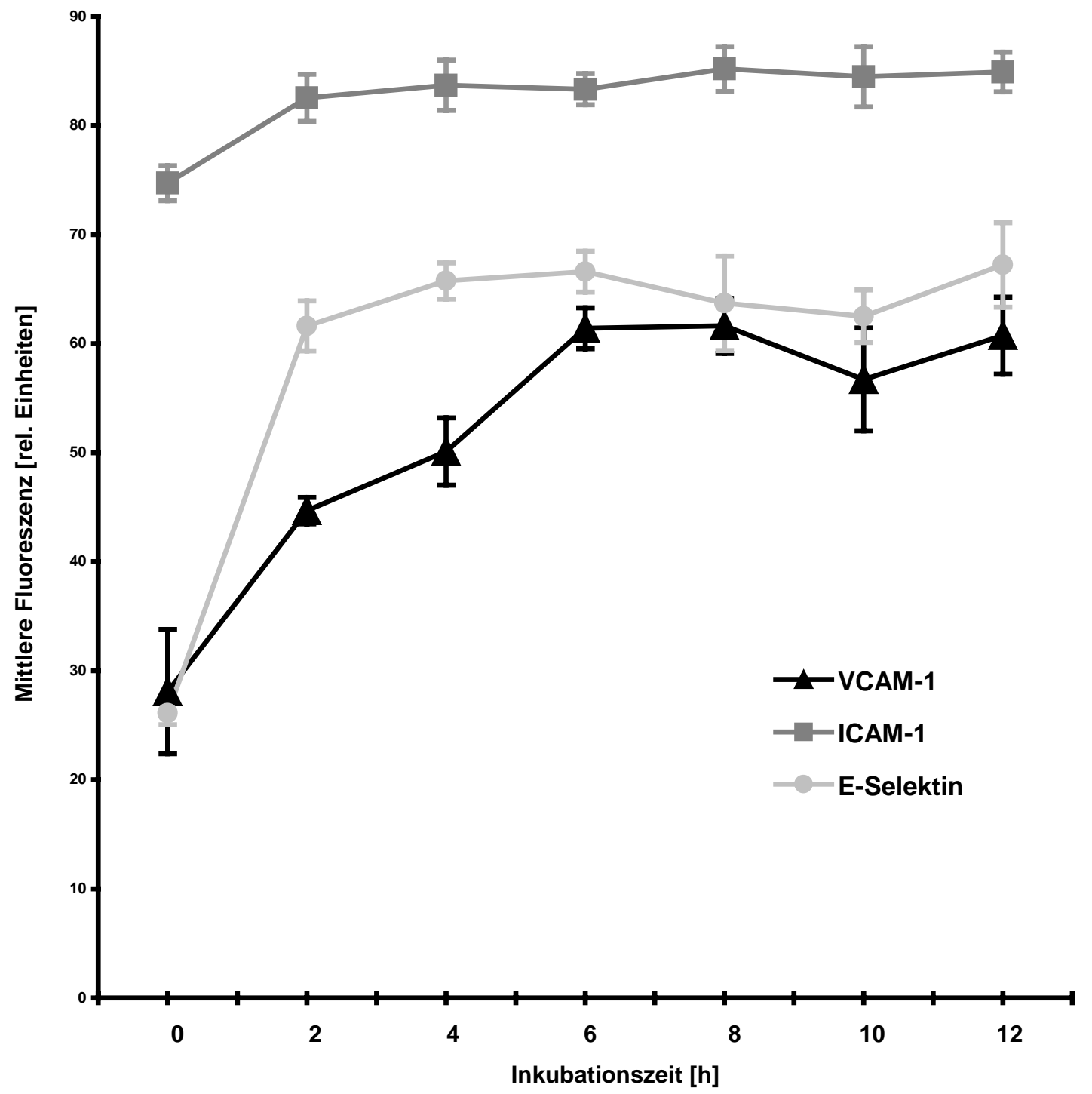

Abb. 3.28: Expressionskinetiken von E-Selektin, ICAM-1 und VCAM-1 auf humanen Nabelschnur-Endothelzellen (HUVECs) nach Stimulation mit $30 \mathrm{ng} / \mathrm{ml}$ IL-1 $\beta$. Die Expression wurde in der Durchflusszytometrie ermittelt. Vertikale Balken: Standardfehler 


\subsubsection{Adenovirus-assoziierte (AAV)-Transfektion der HUVECs}

Die erfolgreiche Transfektion der HUVECs wurde sowohl in der Durchflusszytometrie als auch in der Immunfluoreszenz ermittelt.

Die Detektion der CD7 Expression erfolgte mit Hilfe des spezifischen Antikörpers in der Durchflusszytometrie (Abb. 3.29). Die hier exemplarisch dargestellten CD7 Expressionen geben die minimalen und maximalen Transfektionsraten wieder, die in den einzelnen Versuchen zu verzeichnen waren. Der Prozentsatz der CD7 positiven Zellen variierte somit zwischen 23,06 und 61,96 \% (im Mittel 41,88 \pm $12,90 \%$ CD7 positive HUVECs). Um eine falsch positive Detektion der FITCEmission zu vermeiden, wurde die CD7 Expression gegenüber den gfp transfizierten Kontrollen wiedergegeben.
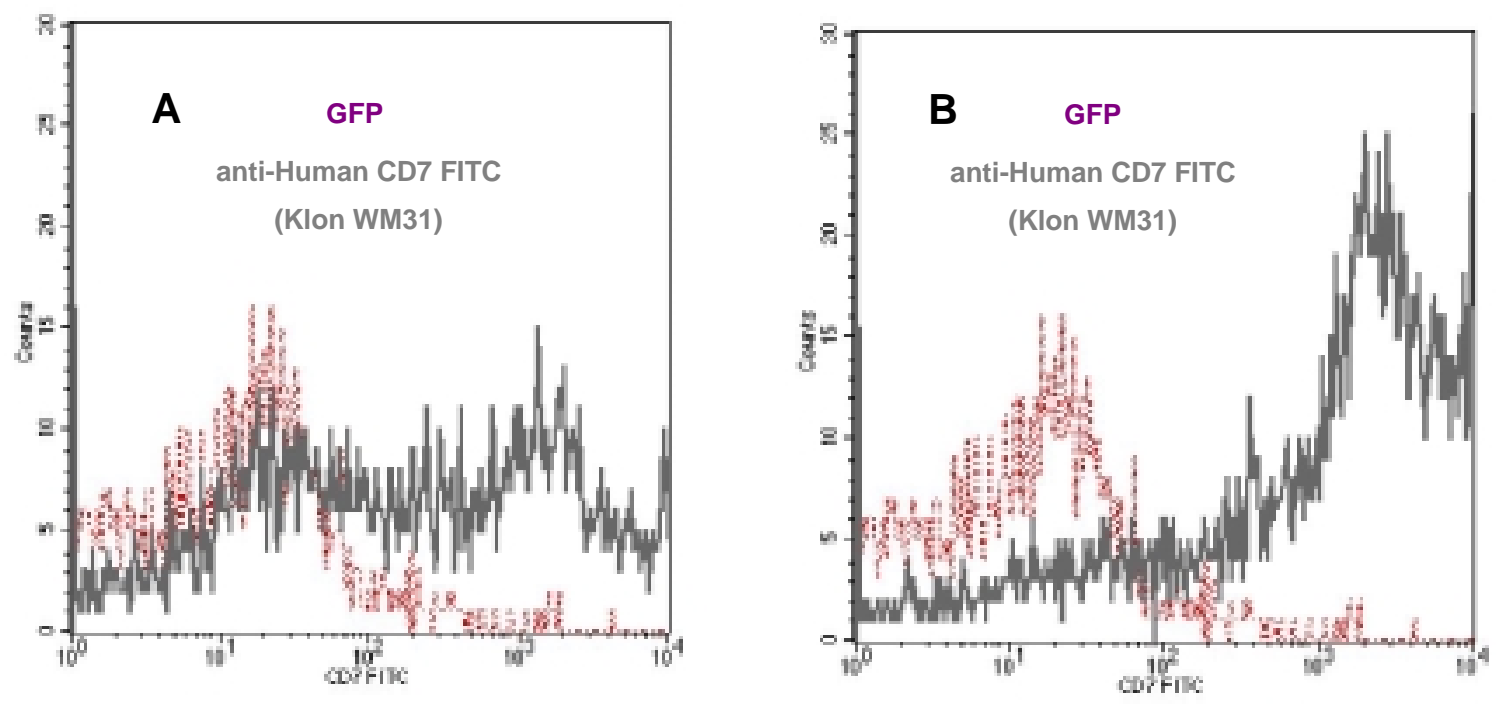

Abb. 3.29: CD7/VCAM transfizierte HUVECs. Der Oberflächenrezeptor wurde mit FITCgekoppeltem anti-CD7 markiert und in der Durchflusszytometrie detektiert. A) minimale CD7Expression; B) maximale CD7-Expression.

Zusätzlich konnte die erfolgreiche Transfektion des Vektors nachgewiesen werden (Abb. 3.30). Der Vektor pTR-UF5, in den cd7/vcam für die AAV-Transfektion der HUVECs kloniert worden war, kodierte zusätzlich für das Gen gfp, dessen 
Expression in der Immunfluoreszenz durch seine grüne Emission gut zu detektieren war. Gegenüber untransfizierten Zellen konnte dabei ein deutlicher Unterschied zwischen GFP exprimierenden und untransfizierten HUVECs sichtbar gemacht werden.
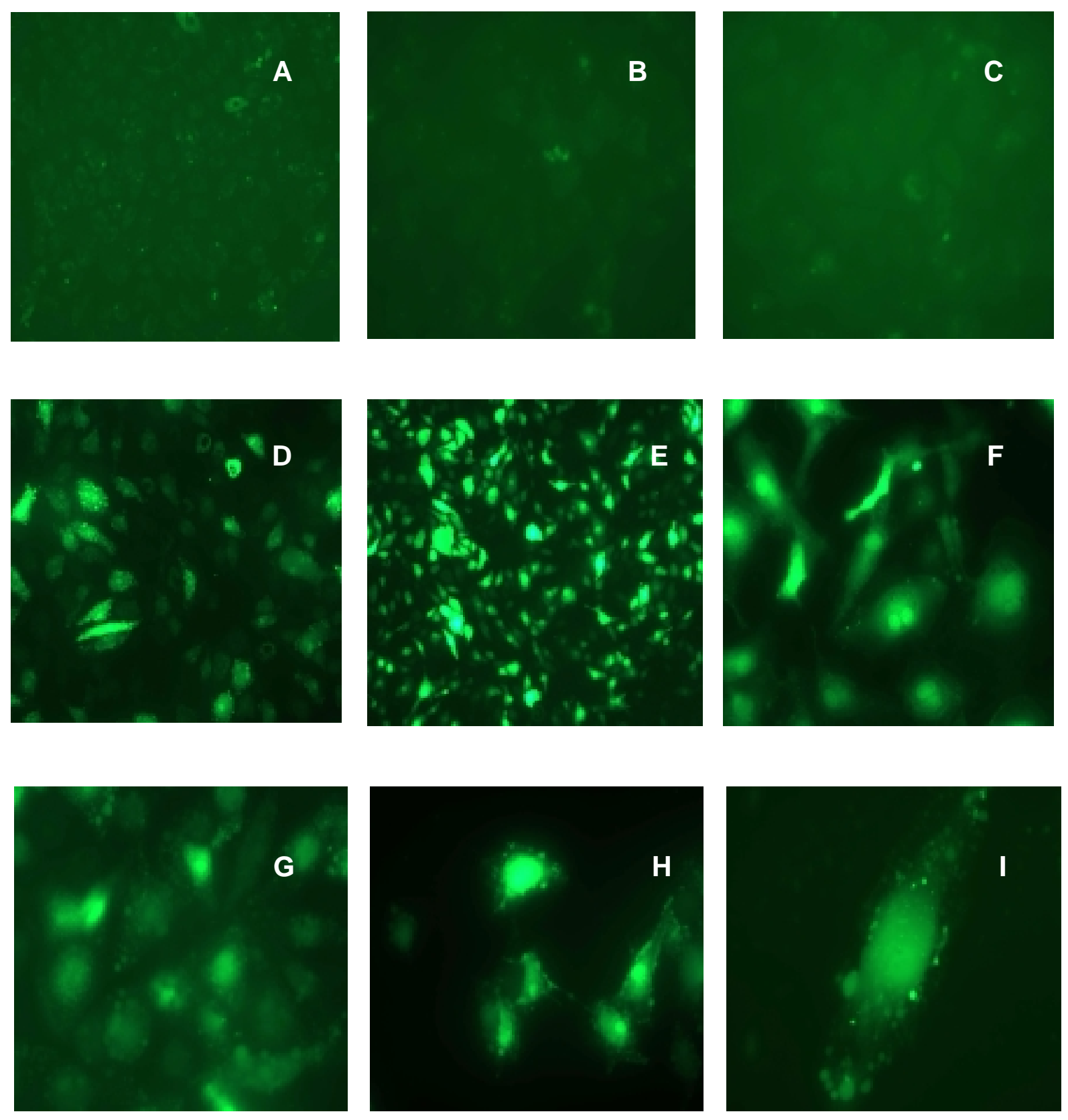

Abb. 3.30: Nachweis der AAV-Transfektion von HUVECs. Die Expression des GFP wurde im Fluoreszenzmikroskop überprüft. A-C) Kontrolle: untransfizierte HUVECs; D-I) transfizierte Zellen. 


\subsubsection{Adhäsion von Monozyten an CD7/VCAM exprimierende HUVECs}

Zur Verifikation der Ergebnisse, die in den Untersuchungen an transgenen $\mathrm{CHO}-$ Zellen erlangt wurden, war der Einfluss der Transfektion von cd7/vcam auf die Adhäsion von Monozyten an Endothelzellen zu erfassen.

Die Abb. 3.31 stellt die Ergebnisse dar. Um ausschließlich die VCAM-1 vermittelte Adhäsion zu ermitteln, wurden in den einzelnen Versuchen jeweils Ansätze mitgeführt, in denen der Oberflächenrezeptor zuvor mit anti-VCAM-1 blockiert worden war. Die Differenz der prozentual gebundenen Monozyten zwischen unblockierten und Antikörper-blockierten Zellen stellte somit die VCAM-1 vermittelte Adhäsion dar und wird hier wiedergegeben.

Somit konnten an endothelialen Zellen, die vor dem Versuch stimuliert worden waren, deutlich mehr Monozyten adhärieren als an unstimulierten HUVECs. Gegenüber unbehandelten Zellen, bei denen im Mittel 4,43\% Monozyten über VCAM-1 gebunden wurden, zeigten sich bei IL-1 $\beta$ stimulierten Zellen durchschnittlich 9,19\%. Die Transfektion mit cd7/vcam verringerte die Zahl der Monozyten in beiden Fällen signifikant $(p<0,01)$ : Bei unstimulierten, transfizierten Zellen wurden im Mittel nur 2,52 \% Monozyten gebunden, bei stimulierten HUVECs ging der Prozentsatz auf 1,93 \% zurück. Mittels der Kontrolle, die aus gfp transfizierten Endothelzellen bestand, konnte die Spezifität der Inhibition des weiteren belegt werden, da hier keine Unterschiede zu untransfizierten Zellen zu beobachten waren (durchschnittlich 4,97 bzw. 8,15\% adhärierte Monozyten).

Es konnte auch im endothelialen Zellmodell eine VCAM-1 vermittelte Adhäsion von Monozyten nachgewiesen werden. Darüber hinaus gelang es, sowohl bei unstimulierten als auch stimulierten HUVECs durch Transfektion von $c d / v c a m$ die über VCAM-1 vermittelte Bindung von Monozyten signifikant $(p<0,01)$ zu verringern. Die Expression des Fusionsproteins drängte unter inflammatorischen Bedingungen die Adhäsion der Monozyten auf vergleichbare Anteile zurück, wie sie ansonsten im unstimulierten Zustand zu beobachten waren. 


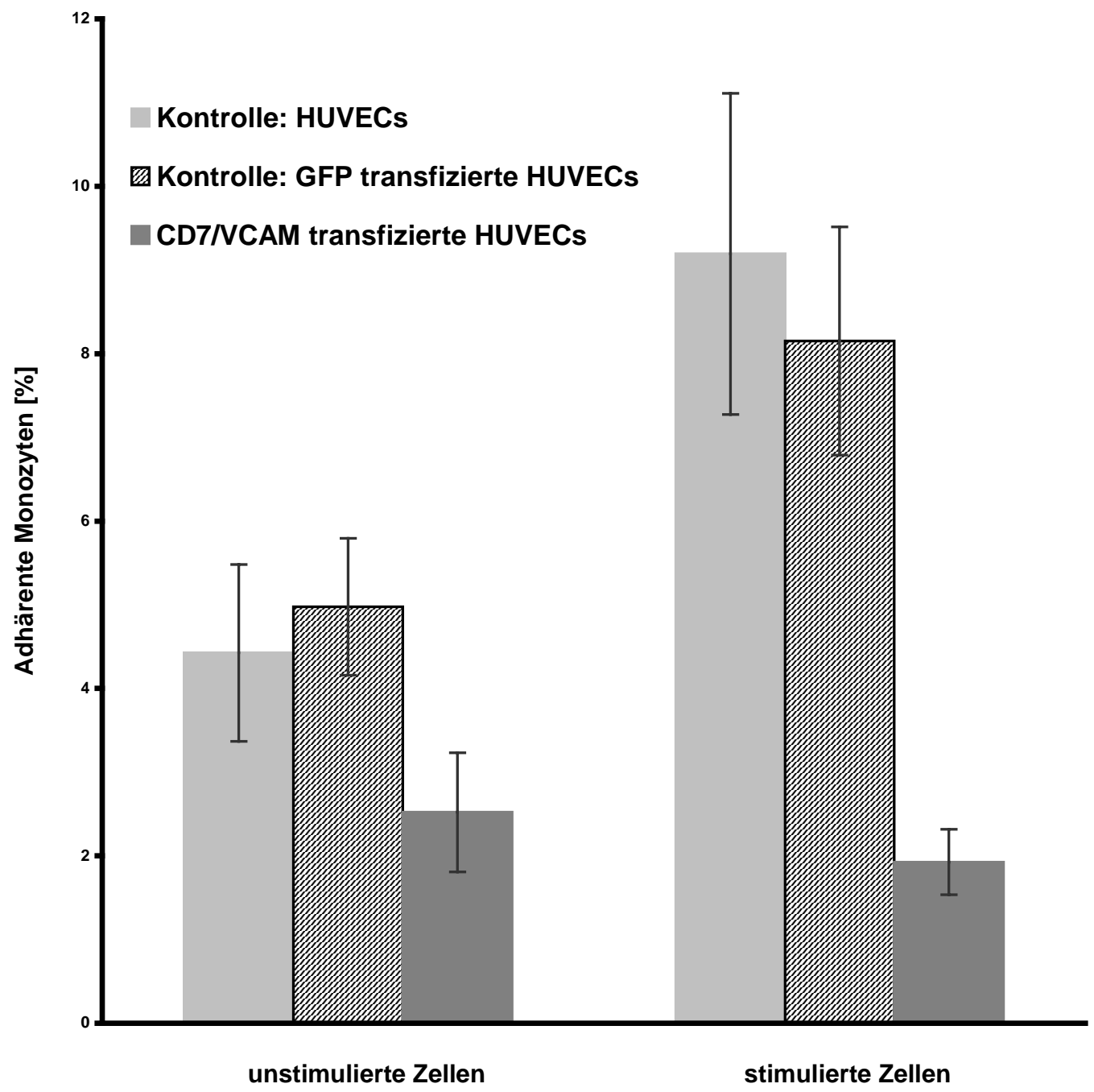

Abb. 3.31: Adhäsion von Monozyten an unstimulierte und IL-1 $\beta$ stimulierte HUVECs. Der Prozentsatz der gebundenen Monozyten wurde in der Durchflusszytometrie ermittelt. Vertikale Balken: Standardfehler 


\subsubsection{Transmigration von Monozyten durch eine Zellschicht transgener HUVECs}

Bei den unstimulierten Ansätzen (HUVECs, GFP- und CD7/VCAM-HUVECs) konnten keine Unterschiede zwischen den VCAM-1 vermittelten Prozentsätzen an migrierten Monozyten ausgemacht werden (Abb. 3.32). Durch die Stimulation mit IL-1 $\beta$ stieg bei untransfizierten Kontrollen der prozentuale Anteil der Monozyten jedoch von durchschnittlich 0,97 auf 7,43 \% an. Vergleichbare Werte lieferten die gfp transfizierten Kontrollansätze (im Mittel 0,70 bzw. 7,29 \% migrierte Monozyten).

Die transgenen Zellen, die cd7/vcam exprimierten, ließen demgegenüber auch nach Stimulation nur durchschnittlich 3,34 \% Monozyten passieren. Eine signifikante Verringerung der VCAM-1 vermittelten Transmigration durch CD7/VCAM war somit möglich $(p<0,01)$. 


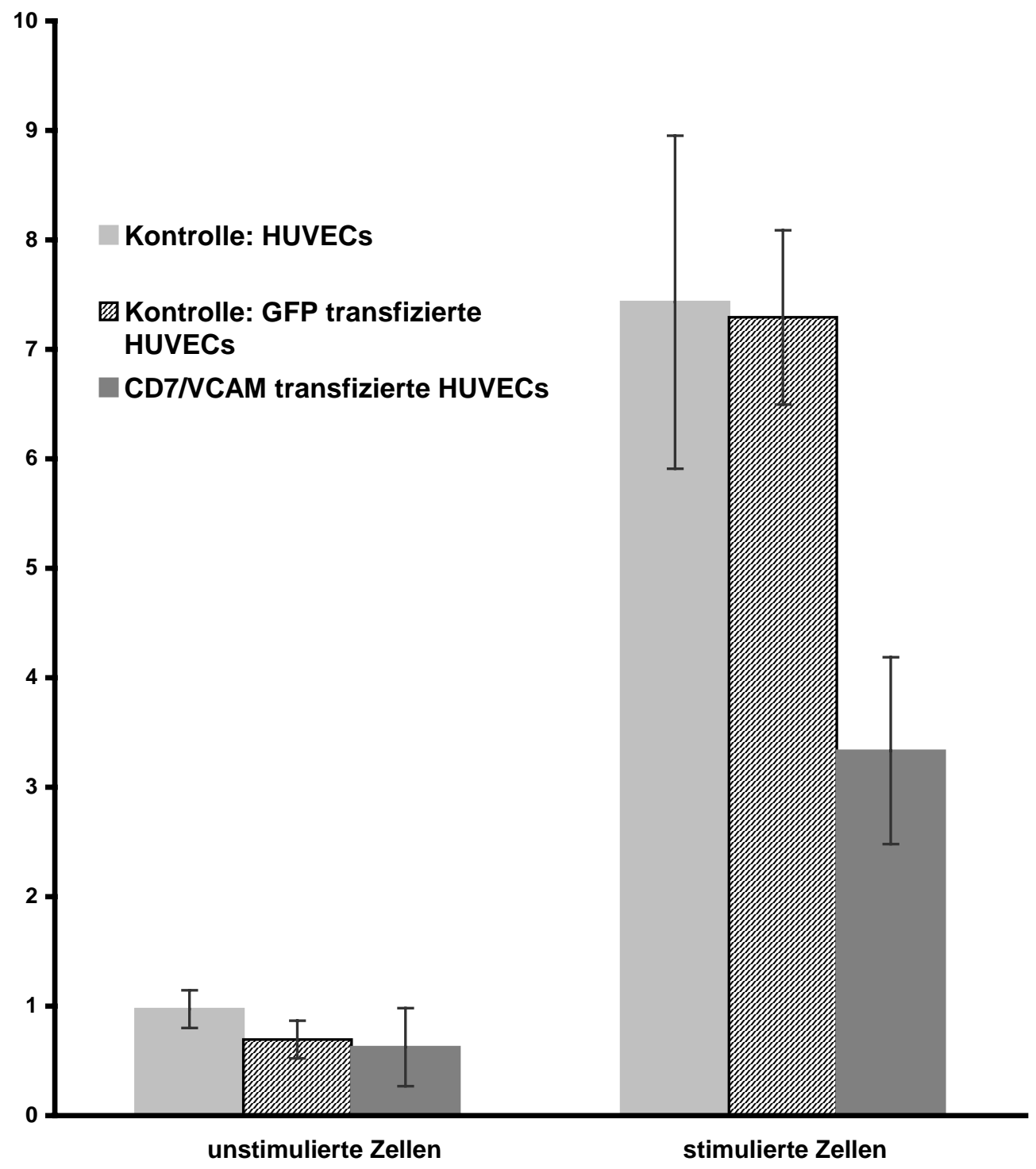

Abb. 3.32: Transmigration von Monozyten durch eine unstimulierte und IL-1 $\beta$ stimulierte HUVECs-Zellschicht. Der Prozentsatz der migrierten Monozyten wurde mikroskopisch in einer Neubauer-Zählkammer ermittelt. Vertikale Balken: Standardfehler 


\section{Diskussion}

In der vorliegenden Arbeit sollte untersucht werden, ob durch die funktionelle Blockade eines endothelialen Oberflächenrezeptors die chronische Rekrutierung von Monozyten an das vaskuläre Endothel, wie es bei der Atherosklerose zu beobachten ist, zurückgedrängt werden kann.

Da zahlreiche Untersuchungen VCAM-1 als einen der wichtigsten endothelialen Mediatoren bei der Adhäsion und Transmigration von Monozyten bei diesem Phänomen beschreiben, versprach seine Blockade den effektivsten Rückgang der Immunantwort. VCAM-1 wurde daher zunächst auf seine Interaktion mit Monozyten untersucht. Die Analysen zeigten, dass der Rezeptor sowohl Adhäsion als auch Transmigration der Monozyten vermittelte. Basierend auf diesen Erkenntnissen sollte die Funktion von VCAM-1 durch Transfektion des Fusionsproteins CD7/VCAM bei den genannten Prozessen inhibiert werden. Ausschlaggebend für einen solchen Ansatz waren vorangehende Versuche über die Inhibition der Integrin-vermittelten Zelladhäsion durch Einschleusung von Fusionsproteinen. Bei dem Fibrinogenrezeptor $\alpha_{\| 1 b} \beta_{3}$ (CD41; GPIIb/llla), der von Thrombozyten exprimiert wird, konnte durch verschiedene $\mathrm{CD} 7 / \beta_{3^{-}}$ Fusionsmoleküle je nach Konstrukt die Verankerung des Rezeptors am Zytoskelett kompetitiv bzw. dominant negativ gehemmt werden. Die Bindung von GPIlb/Illa exprimierenden $\mathrm{CHO}-Z e l l e n$ an Fibrinogen ging daraufhin entsprechend zurück (Lee, 1997).

In Bezug auf VCAM-1 ließen sich durch Transfektion von CD7/VCAM vergleichbare Ergebnisse erzielen. Es wurde nachgewiesen, dass die VCAM-1 vermittelte Adhäsion und Transmigration von Monozyten durch CD7/VCAM signifikant verringert werden konnte. Durch Inkubation der transgenen Zellen mit Cytochalasin D konnte der gleiche Effekt erzielt werden, so dass des weiteren nachgewiesen war, dass die funktionelle Inhibition von VCAM-1 über eine verhinderte Anlagerung an das Zytoskelett erfolgte. 
Darüber hinaus konnte die funktionelle Blockade von VCAM-1 spezifiziert werden. Die Untersuchungen wurden auf die endothelialen Oberflächenrezeptoren ICAM-1 und E-Selektin ausgeweitet, da sie neben VCAM-1 zu den wichtigsten Molekülen zählen, die zu entzündlichen Reaktionen und somit auch zu der Entstehung und dem Fortschreiten der Atherosklerose beitragen. Die Ergebnisse belegten, dass das Fusionsprotein CD7/VCAM den nativen Rezeptor VCAM-1 spezifisch blockierte und keinen Einfluss auf die Funktionen von ICAM-1 und E-Selektin bei der Monozytenrekrutierung ausübte.

Alle im ersten Abschnitt der vorliegenden Arbeit durchgeführten Experimente wurden mit Zellen durchgeführt, die zuvor mit dem erforderlichen Gen stabil transfiziert worden waren. Da die Aufgaben des jeweiligen Rezeptors ohne Einfluss weiterer Faktoren zu untersuchen war, sollte eine Wechselwirkung mit anderen Oberflächenrezeptoren möglichst ausgeschlossen werden können. Aus diesem Grund wurde die Zelllinie CHO-K1 verwendet.

\subsection{Das CHO-Zellmodell}

Die epitheliale Zelllinie CHO-K1 stellt neben HeLa, Cos, Jurkat oder U937 sicherlich eines der etabliertesten Zellmodelle für immunologische und zellbiologische Fragestellungen dar. Neben der hohen Vermehrungsrate und den relativ anspruchslosen Kulturbedingungen ist nicht zuletzt die hohe Transfektionseffizienz ein Grund, warum sie immer wieder eingesetzt wird.

Ein Nachteil bei der Subkultivierung ist sicherlich immer durch die Gefahr des Überwachsens gegeben und die daraus resultierende Notwendigkeit, die gewünschte Population zu selektionieren. Weiterhin können Differenzierungsmerkmale verloren gehen oder die Populationen können bei der Dissoziation enzymatische oder mechanische Schädigungen erleiden.

Im Gegensatz zu heterogenen Primärkulturen, die oftmals viele der im Originalgewebe enthaltenen Zelltypen umfassen, liegt bei der Subkultur allerdings immer eine homogene Zelllinie vor. Durch den potentiellen Anstieg der Zellzahl 
und die Einheitlichkeit der Zellen wird ein viel größerer Bereich experimenteller Möglichkeiten eröffnet. Weiterhin wird eine wissenschaftliche Auswertung erst durch die Vergleichbarkeit von Parallelproben und die Reproduktion eines Experiments möglich. Eine Propagation ist ebenfalls nur bei kontinuierlichen Zelllinien gegeben. Darüber hinaus konnte gegenüber den oftmals verwendeten Primärzellkulturen die Funktion eines Oberflächenmoleküls isoliert untersucht werden.

Die Überlegung, die Rezeptoren in einer immortalen endothelialen Zelllinie zu untersuchen, musste leider zu Beginn der Arbeiten verworfen werden. Die einzige gut etablierte Zelllinie ECV 304, die bis Mitte 1998 zu solcherlei Untersuchungen herangezogen worden war, stellte sich aufgrund eines DNA-Fingerprints des DSMZ als epitheliale Harnblasenzelllinie heraus und stand somit nicht mehr zur Verfügung. Darüber hinaus hatten erste Versuche gezeigt, dass die Zellen dieser Linie nur schlecht zu transfizieren waren (max. $10 \%$ positive Zellen), was eine Unterscheidung zwischen nativen und transgenen Zellen schwierig gemacht hätte.

\subsection{Die Rolle von CD7 als extrazellulärer Marker}

Die Verwendung von CD7 als extrazellulärer inerter Marker ist gut etabliert (Aruffo \& Seed, 1987; Lee, 1997). Humanes CD7 ist ein relativ kleines Membranmolekül (40 kDa) und gehört zu der Familie der Ig-Superfamilie (Eisenbarth et al., 1980). Neben reifen T-Zellen und natürlichen Killerzellen (Barcena et al., 1993; Rabinowich et al., 1994) wird es sowohl von diesen als auch von B-Zellen oder myeloiden Vorläuferzelllinien vor deren Eindringen in den Thymus während der embryonalen Entwicklung exprimiert (Haynes et al., 1980; Vodinelich et al., 1983) und in der klinischen Diagnose häufig als Marker für lymphatische T-Zell Leukämie eingesetzt (Haynes et al., 1981). Obwohl eine Bindung an die Fc-Region des IgM berichtet wurde (Sandrin et al., 1987), sind bisher keine Liganden klar definiert worden. Die Rolle, die das Membranmolekül im Immunsystem übernimmt, ist bisher ungeklärt. Vormalige Überlegungen, dass CD7 eine wichtige Rolle bei der 
Thymozytenreifung übernimmt (Haynes et al., 1995), sind überholt. Stattdessen wird angenommen, dass es die Zytokinproduktion dieser Zellen reguliert (Heinly et al., 2001).

Aufgrund der hier zusammengestellten Eigenschaften von CD7 war eine Interaktion mit anderen Oberflächenmolekülen nicht zu erwarten. Eine Missinterpretation in der Durchflusszytometrie konnte ausgeschlossen werden, da native $\mathrm{CHO}$-Zellen und Monozyten nicht in der Lage waren, anti-CD7 zu binden. Induzierende Eigenschaften oder outside-in-signaling werden dem Molekül ebenfalls nicht zugeschrieben und waren in dieser Arbeit im CHO-Modell nicht zu erwarten oder zu beobachten. Demnach konnte CD7 seiner Rolle als inerter Marker gerecht werden.

\subsection{Die VCAM-1 vermittelte Adhäsion von Monozyten im CHO- Zellmodell}

Bisherige Untersuchungen implizierten eine VCAM-1 vermittelte Monozytenadhäsion. So wird beschrieben, dass VCAM-1 in humanen atherosklerotischen Läsionen nachgewiesen wurde und mit der Akkumulation von Monozyten korreliert zu sein schien (O'Brien et al., 1996). In einfachen in vitro Versuchen konnte gezeigt werden, dass VCAM-1, welches von glatten Muskelzellen oder Endothelzellen exprimiert wird, die Adhäsion von Monozyten und Lymphozyten unterstützte (Carlos et al., 1990; Cybulsky \& Gimbrone, 1991; Henseleit et al., 1994). Bei Ratten bedingte die erhöhte VCAM-1 Expression nach der Verletzung von Arterien die Adhäsion von Monozyten und Makrophagen (Landry et al., 1997). Ferner bewirkte die Blockade des Rezeptors mit anti-VCAM1 in Durchflussexperimenten, bei denen die Arteria carotis aus ApoE-defizienten Mäusen mit Monozyten durchspült wurde, eine Abnahme der gebundenen Monozyten um $75 \pm 12 \%$ (Huo et al., 2000). Auch unstimulierte HUVECs, die mit dem Gen vcam-1 von Kaninchen transfiziert worden waren, zeigten bei laminaren 
Durchflussversuchen gegenüber nativen Zellen eine signifikante Erhöhung von gebundenen Monozyten (Gerszten et al., 1998).

Allen Untersuchungen ist jedoch gemeinsam, dass VCAM-1 immer im Verbund mit weiteren endothelialen Oberflächenrezeptoren exprimiert wurde. Noch dazu sollte vor allem Aufschluss über die Rolle des Oberflächenmoleküls bei der Atherosklerose erhalten werden, so dass von einer inflammatorischen Situation ausgegangen wurde. Unter solchen Umständen werden neben VCAM-1 aber auch E-Selektin und ICAM-1 verstärkt exprimiert (Carlos \& Harlan, 1994), so dass nicht zweifelsfrei geklärt werden konnte, inwieweit die Rekrutierung von Monozyten tatsächlich VCAM-1 zugeschrieben werden kann. So wäre es doch möglich, dass erst die lockere Bindung, die durch E-Selektin vermittelt wird, die Ausbildung einer festen Bindung von Monozyten an VCAM-1 ermöglicht oder dass vor allem ICAM-1 die Adhäsion der Monozyten vermittelte. Derlei Signalfunktion wurde schon in früheren Untersuchungen vermutet (Yoshida et al., 1996). Die Koexpression von E-Selektin und ICAM-1 könnte demnach bei den erwähnten Experimenten zu Fehlschlüssen geführt haben.

Auch die Spezifizierung der vermittelten Leukozytenrekrutierung durch gezielte Blockade von VCAM-1 mit anti-VCAM-1 oder die verstärkte Expression von VCAM-1 gegenüber anderen Rezeptoren, die Gerszten et al. (1998) erzielten, erlaubten den Schluss einer Beteiligung. Inwiefern aber durch die gleichzeitige Expression verschiedener Rezeptoren möglicherweise intrazellulär Signale generiert wurden, die wiederum die bereits erwähnten oder noch weitere Rezeptoren (in)aktivierten, blieb bisher ungeklärt.

Eine mögliche Funktion von VCAM-1 als Signalrezeptor sollte jedoch nicht außer acht gelassen werden. Versuche zur Interaktion zwischen VCAM-1 und VLA-4 zeigten, dass dadurch auch die Bindung von LFA-1 exprimierenden T-Zellen an immobilisiertes ICAM-1 induziert wurde (Porter \& Hogg, 1997; Chan et al., 2000). Eine andere Untersuchung belegte, dass die Blockade des Oberflächenmoleküls mit anti-VCAM-1 Veränderungen im intrazellulären $\mathrm{Ca}^{2+}$-Spiegel und die Ausbildung von Stressfasern bedingte (Lorenzon et al., 1998). Solche 
Interaktionen könnten demzufolge mit in die zu untersuchende Rolle von VCAM-1 hineinspielen und Aussagen über die dem Rezeptor innewohnende Funktion verfälschen.

In der vorliegenden Arbeit wurde die Funktion von VCAM-1 daher unabhängig von anderen Oberflächenrezeptoren untersucht. Es konnte gezeigt werden, dass der Rezeptor ohne Interaktion mit anderen Oberflächenmolekülen in der Lage war, die Adhäsion von Monozyten zu vermitteln. Der prozentuale Anteil von adhärenten Monozyten kann hier demzufolge ausschließlich VCAM-1 zugeschrieben werden.

\subsection{Die VCAM-1 vermittelte Transmigration von Monozyten}

Vergleichbare Resultate lieferten die Untersuchungen über die Beteiligung von VCAM-1 an der Transmigration von Monozyten. Es gelang in der vorliegenden Arbeit, eine Beteiligung des Rezeptors an diesem Prozess ohne Hilfe weiterer Oberflächenrezeptoren nachzuweisen. Darüber hinaus konnte die VCAM-1 vermittelte Transmigration von Monozyten durch Blockade des Rezeptors mit anti-VCAM-1 weiter spezifiziert werden.

Auch über die Beteiligung an dem Vorgang der Transmigration liegen bisher ausschließlich Ergebnisse aus Untersuchungen vor, in denen VCAM-1 immer mit weiteren Oberflächenrezeptoren koexprimiert wurde und die daher die Aussagekraft der Erkenntnisse möglicherweise verringern.

So gelang es im atherosklerotischen Tiermodell, bei dem hypercholesterolämische Mäuse untersucht wurden, durch Antikörper-Blockade von VCAM-1 die Entstehung der Neointima zu inhibieren (Slepian et al., 1998; Oguchi et al., 2000). Diese Beobachtung wird infolgedessen auf die blockierte Transmigration von glatten Muskelzellen zurückgeführt, die in diesem Modell ansonsten nach einer Verletzung der Arteria carotis auftritt und von VCAM-1 vermittelt wird. In Versuchen, welche die Interaktion von VLA-4 und VCAM-1 an HUVECs analysierten, konnte gezeigt werden, dass VCAM-1 die laterale Migration von 
Monozyten ermöglichte (Weber \& Springer, 1998). Koch et al. (1995) gelang es zu zeigen, dass VCAM-1 die Chemotaxis von Endothelzellen stimulierte. In der gleichen Studie wurde nachgewiesen, dass die corneale Angiogenese und die damit einhergehende Wanderung von Endothelzellen durch VCAM-1 bestimmt wurde. Ähnliche Beobachtungen wurden bei der Transmigration von humanen Melanoma-Zelllinien gemacht (Mould et al., 1994). Auch Gerszten et al. (1998) wiesen darauf hin, dass bei ihren Untersuchungen VCAM-1 offensichtlich an allen vier Schritten der Leukozytenrekrutierung beteiligt war. Die transendotheliale Migration von Monozyten durch HUVECs konnte durch anti-VCAM-1 ebenfalls komplett geblockt werden (Shang et al., 1998).

Natürlich darf nicht außer acht gelassen werden, dass erst die Interaktion mit anderen, bei der Atherosklerose involvierten Oberflächenrezeptoren die zu beobachtende Immunantwort ausmacht. Um einen Rezeptor allerdings gezielt inhibieren zu können, ist es unabdingbar, seine Funktion zu kennen. Erst wenn ein fundiertes Wissen darüber erlangt worden ist, kann an die Übertragbarkeit der Befunde auf Tierversuche oder gar der Entwicklung von Medikamenten gedacht werden. Aus diesem Grund stellte die Klärung des zugrunde liegenden Mechanismus eine so wichtige Untersuchung dar. Darüber hinaus bildeten die Erkenntnisse das Fundament für die Versuche mit CD7/VCAM transfizierten Zellen, wovon sich möglicherweise gentherapeutische Strategien ableiten lassen.

\subsection{Die Auswirkung von CD7/VCAM auf die VCAM-1 vermittelten Prozesse der Leukozytenrekrutierung}

Durch die Transfektion des Fusionsproteins CD7/VCAM wurde die VCAM-1 vermittelte Monozytenadhäsion inhibiert. Zu gleichen Resultaten führten die Versuche, in denen darauffolgend die Transmigration von Monozyten beobachtet wurde. Damit gelang es, eine direkte Hemmung von VCAM-1 durch die Expression von CD7/VCAM nachzuweisen. 
In der Literatur sucht man vergeblich nach vergleichbaren experimentellen Ansätzen. Die bisherigen Untersuchungen beschränken sich klassischerweise auf die Blockade des Rezeptors mit anti-VCAM-1, um eine Beteiligung des Oberflächenrezeptors an den Vorgängen der Adhäsion und Transmigration nachzuweisen. Eine gezielte Hemmung durch Einschleusung eines Fusionsproteins ist bisher noch nicht beschrieben worden. Für den Rezeptor finden sind nicht einmal Untersuchungen mit trunkiertem oder deletiertem VCAM-1.

Derlei Studien sind aber von besonderem Interesse: Die Blockade von endothelialem VCAM-1 mit anti-VCAM-1 bewirkte die bereits erwähnte Erhöhung des intrazellulären $\mathrm{Ca}^{2+}$-Spiegels, infolgedessen die Ausbildung von Stressfasern induziert wurde (Lorenzon et al., 1998). Somit übernehmen die Oberflächenmoleküle der lg-Superfamilie eventuell ebenfalls Signalfunktion, die bisher meist den Mitgliedern der Integrine zugesprochen wurde. Zudem besteht der zytoplasmatische Anteil von VCAM-1 aus einer Reihe sich wiederholender Sequenzen, an denen eine Serin / Threonin-Phosphorylierung möglich erscheint (Kishimoto et al., 1985; Woodgett et al., 1986). Darüber hinaus soll VCAM-1 durch die Aktivierung von endothelialer NADPH-Oxidase auch zur Änderung der Zellform beitragen, welche die Transmigration von Lymphozyten erst ermöglichte (Matheny et al., 2000). Für das Oberflächenmolekül ICAM-1, das innerhalb der IgSuperfamilie zu den engsten Verwandten von VCAM-1 gezählt wird, wurde nachgewiesen, dass es nach Trunkierung der zytoplasmatischen Domäne nicht mehr die Transmigration von Neutrophilen vermitteln konnte (Sans et al., 2001). Demnach kommt der zytoplasmatischen Domäne von Mitgliedern der lgSuperfamilie ebenfalls eine essentielle Rolle bei der jeweils ausgeübten Funktion zu.

Aufgrund dieser Überlegungen und der in der vorliegenden Arbeit erlangten Resultate waren weitere Untersuchungen durchzuführen, die eine Bindung des Rezeptors an das Zytoskelett als Voraussetzung für seine Funktion belegen sollten. 


\subsection{Behandlung der VCAM-1 exprimierenden Zelllinie mit Cytochalasin D}

Die Beobachtung, dass die doppelt transgene Zelllinie CHO-CD7/VCAM\&VCAM-1 nicht in der Lage war, die VCAM-1 abhängige Adhäsion und Transmigration von Monozyten bei gleichzeitiger Expression von CD7/VCAM zu vermitteln, implizierte eine Bindung von VCAM-1 an Strukturen des Zytoskeletts. Um dies jedoch zu belegen, waren Versuche durchzuführen, in denen die Bindung an Zytoskelettstrukturen verhindert wurde, um einen direkten Zusammenhang zwischen „intaktem“ Rezeptor und der notwendigen Verankerung an derlei Strukturen nachzuweisen.

Es wurden Adhäsions- und Transmigrationsversuche durchgeführt, denen eine Inkubation der Zelllinie mit Cytochalasin D vorausging, welches die Ausbildung eines intakten Actinskeletts (Cooper, 1987) - und somit unter Umständen auch die Verankerung von VCAM-1 - verhinderte. Neben der Behandlung von Zellen mit Phalloidin zur Stabilisierung von Zytoskelettstrukturen ist dies eine der klassischen zellbiologischen Methoden, um die Anlagerung von Monomeren an Actinfilamente zu verhindern. So konnte durch Cytochalasin $D$ neben zahlreichen anderen Untersuchungen auch die Integrin-vermittelte Adhäsion von transgenen $\mathrm{CHO}$ Zellen, die LFA-1 exprimierten, inhibiert werden (Peter \& O'Toole, 1995).

In den vorliegenden Untersuchungen bewirkte Cytochalasin D ebenfalls eine signifikante Abnahme sowohl der durch VCAM-1 vermittelten adhärenten als auch migrierten Monozyten. Demnach muss eine Bindung von VCAM-1 an actinhaltige Strukturen der Zelle vorliegen, damit der Rezeptor seine Funktion ausüben kann. Des weiteren konnte bei VCAM-1 exprimierenden Zellen mittels Cytochalasin D der gleiche Effekt erzielt werden wie bei gleichzeitiger Expression von CD7/VCAM. Diese Beobachtungen bestätigen die Inhibition von VCAM-1 durch die verhinderte Bindung des Rezeptors an das Actinskelett.

Über die Verankerung am Zytoskelett ist für die Mitglieder der Ig-Superfamilie - und somit auch für VCAM-1 - bisher wenig bekannt. Die Interaktionen zwischen 
intrazellulären Zytoskelettanteilen und Zelloberflächen-Adhäsionsmolekülen sind ausgiebig untersucht worden, da sie Einfluss nehmen sowohl auf Zell / Zell- bzw. Zell / Matrix-Adhäsion als auch auf die Internalisierung von Rezeptoren (Pavalko \& Otey, 1994). Dabei sind bisher aber vor allem Integrine untersucht worden. Für die Ig-Superfamilie stehen derlei Untersuchungen noch aus.

In der Literatur findet sich bezüglich VCAM-1 eine Untersuchung an stimulierten HDMECs (human dermal microvascular endothelial cells). Dabei wird die Inhibition der VCAM-1 Expression, die nach Behandlung der Zellen mit Colchicin zu beobachten ist, in einen unmittelbaren Zusammenhang mit der (verhinderten) TubulinPolymerisation gesetzt (Asahina et al., 2001). Funktionelle Untersuchungen liegen jedoch nicht vor, so dass dieser indirekte Zusammenhang mit Zurückhaltung bewertet werden sollte. Die Befunde von Wójciak-Stothard et al. (1999) wiesen demgegenüber eine durch Cytochalasin D inhibierte Bindung von VCAM-1 an das Actinskelett nach, was mit der hier vorliegenden Untersuchung in Einklang steht.

\subsection{Die Adhäsion und Transmigration von Monozyten unter der Vermittlung von ICAM-1 und E-Selektin}

Nachdem die Inhibition von VCAM-1 durch CD7/VCAM nachgewiesen worden war, wurde auch mit Blick auf einen möglichen therapeutischen Einsatz untersucht, wie spezifisch die Hemmung durch das Fusionsprotein war. Aus diesem Grund wurden die Funktionen von E-Selektin und ICAM-1 analysiert, da innen bei der Entstehung und dem Fortschreiten der Atherosklerose neben VCAM-1 ebenfalls eine wichtige Bedeutung zugeschrieben wird.

Die Expression von E-Selektin, ICAM-1 und VCAM-1 wird bei inflammatorischen Reaktionen, die eine Aktivierung des Endothels bedingen, parallel induziert (Carlos \& Harlan, 1994). E-Selektin wird durch Stimulation oder Aktivierung von Endothelzellen als Antwort auf inflammatorische Zytokine verstärkt exprimiert und ermöglicht dadurch in vitro die Vermittlung des rolling von Leukozyten (Bevilacqua et al., 1987; Lawrence \& Springer, 1991; Hogg \& Landis, 1993). ICAM-1 ist neben 
VCAM-1 für die stabile Adhäsion der Monozyten (Marlin \& Springer, 1987; Makgoba et al., 1988), die Ausbreitung und die Diapedese notwendig (Bevilacqua \& Nelson, 1993; Languino et al., 1995; Luscinskas et al., 1996).

Wie VCAM-1 sind die beiden Rezeptoren bisher meist im Zusammenhang mit anderen Oberflächenmolekülen unter inflammatorischen Bedingungen untersucht worden. Demzufolge war die innen innewohnende Funktion und der Einfluss von CD7/VCAM zunächst ebenfalls ohne mögliche Interaktionen mit anderen Oberflächenmolekülen am transgenen CHO-Zellmodell aufzuklären. Die vorliegende Arbeit zeigt, dass E-Selektin und ICAM-1 allein bereits die Adhäsion von Monozyten gewährleisteten. Diese Beobachtung ließ sich weiter spezifizieren, da die vermittelte Adhäsion des jeweiligen Oberflächenmoleküls durch AntikörperBlockade signifikant gehemmt werden konnte.

Gegenüber ICAM-1 war bei E-Selektin jedoch keine vollständige Inhibition der Monozytenadhäsion möglich. Die Ursache hierfür ist nur schwer zu lokalisieren. Wie im Fall von VCAM-1 kann aber auch für E-Selektin eine Signalfunktion angenommen werden. Die Blockade des Oberflächenmoleküls mit anti-E-Selektin oder die Bindung von Monozyten an stimulierte HUVECs bewirkte laut Literatur ebenfalls eine Erhöhung des intrazellulären $\mathrm{Ca}^{2+}$-Spiegels der Endothelzellen und die Entstehung von Stressfasern (Lorenzon et al., 1998). Den Signalen, die während des clustering von E-Selektin generiert und intrazellulär weitergeleitet werden, werden darüber hinaus Einflüsse auf andere endotheliale Adhäsionsmoleküle wie ICAM-1 und VCAM-1 zugeschrieben (Yoshida et al., 1996). Möglicherweise werden durch E-Selektin aufgrund der Bindung seines Liganden auch auf monozytärer Seite Signale erzeugt, die sich von der Signalwirkung des Rezeptors VCAM-1 unterscheiden. Daraus könnte eine umfassendere Aktivierung monozytärer Liganden und somit die beobachtete stärkere Bindung resultieren.

Die Auswirkung des Effekts, der durch die Bindung von Monozyten an E-Selektin hervorgerufen wurde, war jedoch nicht Gegenstand der hier durchgeführten Analysen und hatte keinerlei Relevanz für die hier separat untersuchte Funktion 
von E-Selektin bei der Adhäsion von Monozyten, so dass dieses Phänomen nicht weiter verfolgt wurde.

Bei den anschließenden Untersuchungen über die Rolle von ICAM-1 und E-Selektin bei der Transmigration von Monozyten konnten die Beobachtungen, die in der genannten Literatur beschrieben worden sind, bestätigt werden. ICAM-1 war auch im transgenen CHO-Zellmodell ohne Hilfe anderer relevanter Oberflächenmoleküle in der Lage, die Transmigration von Monozyten zu gewährleisten. Demgegenüber scheint E-Selektin nur am rolling oder der hier verzeichneten Adhäsion von Monozyten beteiligt zu sein, da keine darüber vermittelte Transmigration nachgewiesen werden konnte.

\subsection{Die Auswirkung von Cytochalasin D auf die Funktion von ICAM-1 und E-Selektin}

Die vorliegende Arbeit zeigt, dass ICAM-1 ebenfalls mit actinhaltigen Zytoskelettstrukturen assoziiert sein muss, um seine Funktion wahrnehmen zu können, da eine Behandlung der Zellen der Linie CHO/ICAM-1 mit Cytochalasin D eine signifikante Abnahme der adhärenten Monozyten bewirkte. In der Literatur wurde eine Bindung an actinhaltige Zytoskelettstrukturen mehrfach beschrieben (Vogetseder \& Dierich, 1991; Carpén et al., 1992; Heiska et al., 1998). Das clustering von ICAM-1 konnte ebenfalls in HUVECs durch Cytochalasin D und C3Transferase inhibiert werden. In einer anderen Studie ließ sich mittels C3Transferase im CHO/ICAM-1 Zellmodell die ICAM-1 vermittelte Adhäsion und Transmigration von Neutrophilen verhindern (Sans et al., 2001) und bestätigt die hier erlangten Ergebnisse.

Allen bisherigen Untersuchungen ist jedoch gemeinsam, dass sie sich fast ausschließlich um einen Nachweis der Assoziation bemüht haben; selten wurden funktionelle Tests durchgeführt (Sans et al., 2001). Die Resultate dieser Arbeit zeigen daher umso eindringlicher, wie wichtig die Assoziation zum Actinskelett auch für Mitglieder der lg-Superfamilie ist, um ihre Funktion ausüben zu können. 
Die Behandlung von E-Selektin exprimierenden Zellen mit Cytochalasin D hatte demgegenüber keinen Effekt auf die Funktion dieses Rezeptors. Für die zytoplasmatische Domäne von E-Selektin wird aber angenommen, dass sie nicht konstitutiv mit dem Actinskelett assoziiert ist, sondern erst durch Bindung von Leukozyten an das vaskuläre Endothel induziert wird (Yoshida et al., 1996). Damit deckt sich auch die weitere Beobachtung, dass E-Selektin ohne Kopplung an $\alpha$ Actinin die Adhäsion von Leukozyten vermitteln kann (Kansas \& Pavalko, 1996), mit den hier erlangten Resultaten und unterstreicht nochmals, warum die Behandlung mit Cytochalasin D in Bezug auf die Selektin-vermittelte Monozytenadhäsion wirkungslos war.

\subsection{CD7/VCAM hat keinen Einfluss auf ICAM-1 und E-Selektin}

Die Transfektion des Fusionsmoleküls CD7/VCAM in stabil exprimierende ICAM-1 und E-Selektin Zelllinien belegte, dass die Inhibition von VCAM-1 spezifisch war. Die Expression von CD7/VCAM übte weder einen Einfluss auf die E-Selektin oder ICAM-1 vermittelte Adhäsion noch auf die ICAM-1 abhängige Transmigration von Monozyten aus.

Diese Beobachtung verwundert nicht, wenn wie bei E-Selektin keine konstitutive Bindung an das Zytoskelett Voraussetzung ist, um die Adhäsion von Monozyten vermitteln zu können. Für ICAM-1 wäre aber eventuell ein gleicher Effekt von CD7/VCAM auf die ausgeübte Funktion zu erwarten gewesen wie für VCAM-1.

Eine mögliche Erklärung könnte in der Art der Bindung an das Actinskelett liegen. Selbst in Bezug auf einen der Rezeptoren liefert die Literatur dabei bisher kein ganz eindeutiges Bild. So wird die zytoplasmatische Domäne von E-Selektin zum einen in Zusammenhang mit den Actin-assoziierten Proteinen $\alpha$-Actinin, Vinculin, Filamin, Paxillin und fokaler Adhäsionskinase beschrieben (Yoshida et al., 1996), zum anderen konnten Wójciak-Stothard et al. (1999) jedoch nachweisen, dass die cluster von E-Selektin mit Ezrin, Radixin und Moesin (ERM-Proteine) kolokalisiert waren. Auch für ICAM-1 liegen unterschiedliche Ergebnisse vor: Einerseits konnte 
es mit seiner zytoplasmatischen Domäne mit $\alpha$-Actinin assoziieren (Vogetseder \& Dierich, 1991; Carpén et al., 1992), andererseits wurde es über Ezrin gebunden (Heiska et al., 1998). Wójciak-Stothard et al. (1999) wiesen neben E-Selektin auch die cluster von ICAM-1 und VCAM-1, die aufgrund von Monozytenadhäsion oder Antikörper-Inkubation entstanden, in Assoziation mit den bereits genannten ERMProteinen nach.

Möglicherweise spielt bei der Bindung an actinhaltige Strukturen neben den vermittelnden Bindungsproteinen, über die bisher noch nicht einmal Einigkeit herrscht oder die eventuell bei unterschiedlichen Prozessen involviert sind, auch die Existenz einer bestimmten Sequenz innerhalb der intrazellulären Domäne des jeweiligen Rezeptors eine Rolle, die es jedem einzelnen von ihnen ganz spezifisch erlaubt, mit dem Actinskelett zu assoziieren. Offensichtlich wurde dadurch die gezielte Blockade von VCAM-1 durch CD7/VCAM ermöglicht. Diese wichtige Fragestellung sollte aber Gegenstand zukünftiger Untersuchungen sein. In der vorliegenden Arbeit sollte und konnte die Spezifität der Inhibition nachgewiesen werden.

\subsection{Die Expression von CD7/VCAM in HUVECs verringerte die VCAM-1 vermittelte Adhäsion und Transmigration von Monozyten}

Mit der Transfektion von cd7/vcam konnte der Prozentsatz von adhärenten oder migrierten Monozyten an bzw. durch humane Endothelzellen signifikant verringert werden. Durch die Untersuchungsergebnisse, die in der vorliegenden Arbeit zuvor im transgenen Zellmodell erlangt wurden, kann ein Einfluss von CD7/VCAM auf andere endotheliale Oberflächenrezeptoren wie E-Selektin oder ICAM-1, die ebenfalls an der Etablierung chronisch entzündlicher Krankheiten wie der Atherosklerose beteiligt sind, ausgeschlossen werden.

Der durch CD7/VCAM erzielte Rückgang von adhärenten bzw. migrierten Monozyten erscheint dabei auf den ersten Blick trotz der Signifikanz, die hierdurch erzielt werden konnte, nur relativ gering. Es ist aber zu beachten, dass selbst 
durch die Technik der AAV-Transfektion im Mittel nur knapp $42 \%$ der Zellen das Fusionsmolekül in ihr Genom integrierten und CD7 positiv erschienen. Möglicherweise ließe sich in einem anderen, besser transfizierbaren Modell ein höherer Wirkungsgrad erzielen, der den Prozentsatz der Monozyten womöglich auf die Hälfte des hier verzeichneten Rückgangs zurückdrängen konnte. Die Wahl des humanen Endothelmodells war aber in Hinblick auf diese grundlegenden Untersuchungen richtig, da hier die Interaktionen der relevanten Oberflächenmoleküle, wie sie im humanen Organismus zu beobachten sind, am besten etabliert und somit am aussagekräftigsten sind. Für weitere Untersuchungen ist aber in Zukunft zunächst vom Tiermodell auszugehen, um weiteren Aufschluss zu erlangen.

Weitere Analysen sollten vor allem nicht versäumen aufzuklären, inwiefern durch die Expression von CD7/VCAM eventuell auch andere Prozesse der Monozytenrekrutierung beeinflusst werden. Dabei sollte sich ein Augenmerk vor allem auf die möglicherweise existierende Signalfunktion von VCAM-1 richten. Aufgrund der durch CD7/VCAM fehlenden oder unterbrochenen Signalkaskade werden u.U. andere Rezeptor-Liganden-Interaktionen ebenfalls verringert. Dies könnte zum einen positiv für die Hemmung der Monozytenadhäsion und -transmigration bei chronisch entzündlichen Prozessen sein, zum anderen wäre aber zu untersuchen, inwiefern das Fusionsmolekül Einfluss auf andere, durchaus notwendige Interaktionen zwischen Endothel und Monozyten bei der normalen, akuten Immunabwehr ausübt.

\subsection{Zukunftsperspektive}

In der Vergangenheit sind die verschiedensten Methoden entwickelt worden, um die unerwünschte Leukozytenrekrutierung bei chronisch-inflammatorischen Phänomenen zu verhindern. Oftmals werden dazu Medikamente eingesetzt, die eigentlich nicht anti-inflammatorisch wirken, die aber als Nebenwirkung sowohl Expression als auch Funktion von zellulären Adhäsionsmolekülen verändern. So 
können durch antioxidativ wirksame Medikamente auch die Expressionen von Oberflächenrezeptoren wie ICAM-1 und VCAM-1 reprimiert werden (Cominacini et al., 1997). Andere Therapien bekämpfen die Rekrutierung auf indirektem Weg, indem sie entweder die Aktivierung von Leukozyten, oder aber die Aktivität proinflammatorischer Zytokine verhindern. Die Expression und Aktivierung der zellulären Adhäsionsmoleküle (Dibasio \& LoBuglio, 1996) oder ihre Funktion (Sekido et al., 1993; Eigler et al., 1997) werden dadurch allerdings nur sekundär bekämpft.

Eleganter erscheint der Einsatz von Medikamenten, welche die zellulären Adhäsionsmoleküle direkt betreffen: Nichtsteroidale anti-inflammatorische Medikamente wie Acetylsalicylsäure, Indomethacin oder Aceclofenac sind an der Regulierung der Expression von Oberflächenmolekülen wie L-Selektin beteiligt und verhindern dadurch Prozesse wie das rolling von Leukozyten. Weiter hemmen sie die Aktivierung der $\beta_{2}$-Untereinheiten von LFA-1 oder Mac-1 und können dadurch mitunter alle Vorgänge der Leukozytenrekrutierung inhibieren (GonzálezAlvaro et al., 1996; García-Vicuña et al., 1997).

Darüber hinaus bietet auch die Blockade der Adhäsionsmoleküle einen möglichen Angriffspunkt. Die Funktion einiger Integrine, die Bindemotive wie die Sequenzen RGD und LDV enthalten, lässt sich effektiv durch monoklonale Antikörper oder Peptide hemmen (Buckley \& Simmons, 1997; Archelos \& Hartung, 1997), und auch die Blockade von Selektinen durch synthetische $s L e^{\mathbf{x}}$ oder $s L e^{\mathbf{x}}$-Analoga belegen in zahlreichen in vivo Studien, dass dadurch das Ausmaß eines Infarkts oder die Anhäufung von Neutrophilen bei Okklusion/Reperfusions-Versuchen an koronaren Arterien verringert werden konnten (Buerke et al., 1994; Birnbaum et al., 1997). Ähnliche Beobachtungen lassen sich auch für ICAM-1 beschreiben, das hinsichtlich Gewebeschäden untersucht wurde, die mit Ischämie-Reperfusion assoziiert sind (Zhao et al., 1997).

Die in letzter Zeit propagierte Strategie, mittels antisense-Oligonucleotiden die Translation von mRNA zu verhindern und somit eine spezifische Inhibition der Protein-Expression zu ermöglichen (Agrawal, 1996), konnte in Tierstudien ebenfalls inflammatorische Krankheiten zurückdrängen. So wurde durch eine Inhibition der ICAM-1 Translation bei Mäusen die Entwicklung einer Kolitis 
(Bennett et al., 1997), und in Ratten die Abstoßung von transplantierten Herzen verhindert (Stepkowski et al., 1994). Nicht zuletzt sei auf die Entwicklung synthetischer dsDNA-Moleküle hingewiesen, die spezifische KonsensusSequenzen enthalten und um die Bindung von Transkriptionsfaktoren konkurrieren, die für die Expression eines bestimmten Gens erforderlich ist. Für $\mathrm{NF \kappa B}$ konnten damit sowohl in vitro als auch in vivo positive Effekte erzielt werden (Morishita et al., 1997).

Alle Therapien greifen jedoch erst auf der Ebene der Genexpression ein. Mit dem in dieser Arbeit beschriebenen gentherapeutischen Ansatz wäre es im Rahmen der Atherosklerose jedoch möglich, durch die funktionelle Blockade von Adhäsionsmolekülen, bei der die Bindung an Zytoskelettstrukturen verhindert wird, direkt die Funktion eines betroffenen Gens zu inhibieren und die Rekrutierung von Monozyten zu verhindern.

Das Ziel einer Gentherapie ist immer, die Funktion von (mutierten) Genen zu ergänzen oder zu ersetzen. Hiermit kann theoretisch mit der Modifikation spezifischer Gene die Ursache einer Krankheit direkt korrigiert werden, im Gegensatz zu den genannten Therapieformen, bei denen der Phänotyp einer Krankheit durch den Einsatz von Medikamenten verändert werden soll, die mit den Genprodukten interagieren oder selbst welche darstellen.

Ursprünglich war die genetische Therapie zur Behandlung von Erbkrankheiten gedacht, bei denen die Expression eines schon bei der Geburt defekten Gens in kurzer Zeit zu einer Vielzahl pathologischer Begleitumstände führte. Die Gentherapie sollte hier das defekte Gen lebenslang ersetzen und vor den pathologischen Konsequenzen schützen. Grundlage dafür ist allerdings, dass Vektoren zur Verfügung stehen, die eine robuste Genexpression in einer großen Population von Zielzellen oder sogar Organen für einen sehr langen, wenn nicht sogar lebenslangen Zeitraum garantieren können.

Es verwundert nicht, dass solche Ansätze bei der Verfügbarkeit der bisherigen Vektoren zu geringen Ergebnissen führten (Knowles et al., 1995; Meddell et al., 
1995), denn eine der Hürden bei der Gentherapie ist die ausreichende Verfügbarkeit der Gene, da sie nur für kurze Zeit im Organismus haltbar, und dem Abbau durch Lysosomen oder Proteinserum ausgesetzt sind. Darüber hinaus ist oftmals die Effizienz der einzelnen Transfektionsmethoden zu gering. Die verschiedensten Systeme sind entwickelt worden, um Zellen zu penetrieren und DNA einzuschleusen. Dazu zählen sowohl replikationsdefiziente virale Vektoren wie Adenovirus (Ko et al., 1996), Retrovirus (Wiznerowicz et al., 1997), adenoassoziierter Virus (Braun-Falco et al., 1999) und Herpes simplex Virus (Blasberg \& Tjuvajev, 1999) als auch synthetische, nicht-virale Vektoren wie Liposomen, Polylysin oder Dendrimere (Smaglik, 1998), des weiteren die Transfektion nackter DNA (Yang \& Huang, 1996) oder die Kombination der verschiedenen Methoden (Wagner et al., 1992). Sie alle haben ihre Vor- und Nachteile. Virale Systeme sind derzeit am häufigsten in Gebrauch, da sie eine ausreichende Genmenge in die Zelle schleusen können. Allerdings können sie sich teilweise nur in teilenden Zellen vermehren, sind sehr kompliziert gebaut oder kostspielig in der Produktion und rufen nicht zuletzt eine Immunreaktion hervor. Die nicht-viralen Systeme haben oftmals den Nachteil, dass sie nur wenig effizient sind, ein Hindernis, dass bei der Einschleusung von DNA in Primärzellen wie HUVECs oder gar in vivo-Therapie nicht zu unterschätzen ist.

Bei der Atherosklerose liegt eine Krankheit vor, die sich meist erst im Laufe des Lebens ausbildet. Oftmals ist eine Etablierung allein deswegen möglich, da zu einem bestimmten Zeitpunkt die vermehrte Expression eines relevanten Gens, das als Antwort auf einen bestimmten Stimulus erforderlich ist, unzureichend war und somit lokal die Entstehung oder das Fortschreiten der Atherosklerose begünstigt wurde. Die transiente Ersetzung des defekten Gens durch ein eingeschleustes, intaktes Gen, das in der Lage ist, die notwendige biologische Antwort zum richtigen Zeitpunkt zu generieren, kann demnach vor pathologischen Konsequenzen schützen.

Dies kann u.U. ein enormer Vorteil sein. Die Therapien, die nur eine lokalisierte kurzzeitige Expression von eingeschleusten Genen erfordern, benötigen sehr viel einfacher konstruierte Vektoren. Aus diesem Grund liegen gerade auf dem Sektor 
der Herz- und Gefäßkrankheiten mit fast 50 \% sehr viele Untersuchungen vor, bei denen auch nicht-virale Vektoren bemerkenswerte Ergebnisse erzielten (Isner et al., 2001) und somit den Vorteil bieten, eine unkontrollierbare Immunreaktion, die durch virale Vektoren $u$. U. hervorgerufen werden könnte, zu umgehen. Darüber hinaus zeigten Studien an VEGF, dass eine zwei- bis dreiwöchige Expression ausreichte, um die Neovaskularisation zu unterstützen (Isner et al., 2001).

Klinische Untersuchungen von gentherapeutischen Ansätzen, die kardiovaskuläre Krankheiten betreffen, haben in der ersten klinischen Phase durchaus hoffnungsvolle Ergebnisse geliefert. Dazu zählen:

- Rettung von Gliedmaßen bei Patienten, bei denen aufgrund Ischämie eine Amputation der unteren Extremitäten unvermeidbar schien (Baumgartner et al., 1998; Isner et al., 1998)

- Beseitigung von sensorischen Defiziten bei Patienten mit ischämischer peripheraler Neuropathie (Simovic et al., 2001)

- Rückgang von Angina pectoris bei koronarer Herzkrankheit (Losordo et al., 1998)

- Erhöhte myocardiale Durchblutung bei Patienten mit koronarer Herzkrankheit (Vale et al., 2001)

- Verringerte Abstoßung von Bypass-Transplantaten (Mann et al., 1999)

Natürlich darf nicht vergessen werden, dass Studien der ersten klinischen Phase dazu dienen sollen, Wissen über die Sicherheit und Toxizität zu sammeln. Es muss sicherlich noch viel überprüft werden wie Spezifität, in vivo-Stabilität und der Abbau der Stoffwechselprodukte. Die Daten, die hier ermittelt werden, legen jedoch das Fundament für das Sicherheitsprofil und sind somit die grundsätzliche Dominante, die festlegt, ob eine Studie weitergeführt wird und die dritte Phase erreicht. 
Für VCAM-1 sind noch keine klinischen Studien durchgeführt worden. Allerdings stellt der Oberflächenrezeptor durch seine Beteiligung an den Prozessen der Monozytenrekrutierung ein potentielles Ziel dar. Eine erst kürzlich veröffentlichte Untersuchung zeigt, wie bei Mäusen mit einer reduzierten VCAM-1 Expression der Rückgang von adhärenten Monozyten resultierte (Dansky et al., 2001). Mäuse, die homozygot defizient für die vierte VCAM-1 Domäne waren, über die der monozytäre Ligand VLA-4 gebunden wird, wurden mit ApoE-/- Mäusen gekreuzt und bewirkten neben dem Rückgang der gebundenen Monozyten aufgrund der verringerten VCAM-1 Expression eine $84 \%$ ige Abnahme von Läsionen an der Aortenwurzel.

Der in der vorliegenden Arbeit beschriebene Ansatz, die VCAM-1 vermittelte Rekrutierung von Monozyten zu verhindern, indem die Zytoskelettverankerung des nativen Rezeptors blockiert wird, könnte ebenfalls dazu beitragen, die Atherosklerose mit neuen Mitteln zu bekämpfen. Durch die Einschleusung von cd7Ncam ließe sich möglicherweise über einen absehbaren Zeitraum die Monozytenrekrutierung bei diesem chronisch-inflammatorischen Phänomen zurückdrängen, wodurch wieder eine nicht-inflammatorische Situation des Endothels, und somit seine Rehabilitation erzielt werden könnte. Die hier erlangten Erkenntnisse lassen weitere Analysen zum Einsatz des Fusionsproteins CD7/VCAM als Mittel der gentherapeutischen Therapie durchaus sinnvoll erscheinen. 


\section{Zusammenfassung}

In der vorliegenden Arbeit wurde der endotheliale Oberflächenrezeptor VCAM-1 hinsichtlich seiner Funktion bei der Monozytenrekrutierung während chronischentzündlicher Prozesse untersucht. Basierend auf diesen Ergebnissen folgten Versuche zur funktionellen Blockade des Rezeptors durch Transfektion des Fusionsmoleküls cd7/vcam, das mit dem nativen Rezeptor selektiv um Bindungsstellen zum Zytoskelett konkurrieren sollte. Um die Spezifität der Hemmung nachzuweisen, waren die Analysen auf ICAM-1 und E-Selektin auszudehnen, die neben VCAM-1 ebenfalls maßgeblich inflammatorische Prozesse auf endothelialer Seite vermitteln sollen. Die Funktion der einzelnen Zelladhäsionsmoleküle wurde isoliert am $\mathrm{CHO}$-Zellmodell untersucht, wodurch eine Beteiligung anderer endothelialer Oberflächenmoleküle per se ausgeschlossen wurde.

Alle drei Oberflächenrezeptoren vermittelten die Adhäsion von Monozyten. ICAM-1 und VCAM-1 waren darüber hinaus an dem Vorgang der Transmigration beteiligt. Demgegenüber war E-Selektin bei diesem Prozess nicht involviert.

Sowohl ICAM-1 als auch VCAM-1 benötigten für die Vermittlung der Prozesse eine Bindung an das Actinskelett. Durch die Behandlung mit Cytochalasin D konnte gezeigt werden, dass die transgenen Zellen anschließend nicht mehr in der Lage waren, ihre Funktion bei der Monozytenrekrutierung auszuüben. Das Oberflächenmolekül E-Selektin zeigte demgegenüber keine funktionelle Beeinträchtigung durch Cytochalasin D.

Die Transfektion des Fusionsmoleküls cd7/vcam bedingte eine Abnahme von Monozyten bei den VCAM-1 vermittelten Prozessen der Adhäsion und Transmigration. Die Funktionen von ICAM-1 oder E-Selektin wurden dadurch nicht beeinflusst, so dass die Koexpression von CD7/VCAM und VCAM-1 eine spezifische und funktionelle Blockade des zellulären Rezeptors erzielte. 
Die gleichzeitige Expression von VCAM-1 und CD7/VCAM bedingte eine Abnahme der Monozyten, der dem Effekt der Cytochalasin D Behandlung entsprach. Das Konstrukt CD7/VCAM konkurrierte demzufolge erfolgreich mit dem nativen Rezeptor um die Bindung an das Actinskelett und verhinderte so die VCAM-1 vermittelte Monozytenrekrutierung.

Da die Einschleusung des Fusionsproteins in ICAM-1 exprimierende Zellen im Gegensatz zur Cytochalasin D Behandlung keinen Einfluss auf gebundene oder migrierte Monozyten zur Folge hatte, kann eine unterschiedliche Bindung der intrazellulären Komponenten von VCAM-1 und ICAM-1 an das Actinskelett angenommen werden, die es ermöglichte, VCAM-1 selektiv zu blockieren.

Mit Blick auf eine mögliche gentherapeutische Anwendung des Fusionsmoleküls CD7/VCAM wurden Versuche mit humanen Primärzellkulturen durchgeführt, wobei durch Stimulation der Zellen eine chronisch-inflammatorische Situation mit erhöhter Expression der drei Oberflächenrezeptoren simuliert wurde.

Die VCAM-1 vermittelte Adhäsion und Transmigration von Monozyten konnte auch in diesem Zellmodell nachgewiesen werden. Dabei unterschied sich der Prozentsatz der Monozyten bei beiden Vorgängen der Monozytenrekrutierung unter inflammatorischen Bedingungen von unstimulierten Kontrollansätzen.

Das Fusionsmolekül CD7/VCAM verminderte sowohl beim unstimulierten als auch stimulierten Endothel den Prozentsatz der über VCAM-1 gebundenen Monozyten. Die VCAM-1 vermittelte Transmigration der Monozyten ließ sich unter inflammatorischen Bedingungen durch die Einschleusung von CD7/VCAM ebenfalls zurückdrängen, so dass eine Weiterentwicklung dieses gentherapeutischen Ansatzes durchaus positive Resultate bei der Bekämpfung chronisch entzündlicher Prozesse erzielen könnte. 


\section{Literatur}

Abe, Y., El-Masri, B., Kimball, K.T., Pownall, H., Reilly, C.F., Osmundsen, K., Smith, C.W. and Ballantyne, C.M. 1998. Soluble cell adhesion molecules in hypertriglyceridemia and potential significance on monocyte adhesion. Arterioscler. Thromb. Vasc. Biol. 18:723-731.

Alon, R., Kassner, P.D., Carr, M.W., Finger, E.B., Hemler, M.E. and Springer, T.A. 1995. The integrin VLA-4 supports tethering and rolling in flow on VCAM-1. J. Cell Biol. 128:1243-1253.

Altieri, D.C., Plescia, J. and Plow, E.F. 1993. The structural motif glycine 190valine 202 of the fibrinogen gamma chain interacts with CD11b/CD18 integrin $\alpha_{m} \beta_{2}$, (Mac-1) and promotes leukocyte adhesion. J.Biol. Chem. 268:1847-1853.

Agrawal, S. 1996. Antisense oligonucleotides: towards clinical trials. Trends Biotechnol. 14:376-387.

Archelos, J.J. and Hartung, H.P. 1997. The role for adhesion molecules in multiple sclerosis: biology, pathogenesis and therapeutic implications. Mol. Med. Today 3:310-321.

Aruffo, A. and Seed, B. 1987. Molecular cloning of two CD7 (T-cell leukemia antigen) CDNAs by a COS cell expression system. EMBO J. 6:3313-3316.

Asahina, A., Tada, Y., Nakamura, K. and Tamaki, K. 2001. Colchicine and griseofulvin inhibit VCAM-1 expression on human vascular endothelial cells evidence for the association of VCAM-1 expression with microtubules. J. Dermatol. Sci. 25:1-9.

Barcena, A., Muench, M.O., Galy, A.H., Cupp, J., Roncarolo, M.G., Phillipps, J.H. and Spits, H. 1993. Phenotypic and functional analysis of T-cell precursors in the 
human fetal liver and thymus: CD7 expression in the early stages of $\mathrm{T}$ - and myeloid-cell development. Blood 82:3401-3414.

Baumgartner, I., Pieczek, A., Manor, O., Blair, R., Kearney, M., Walsh, K. and Isner, J.M. 1998. Constitutive expression of phVEGF ${ }_{165}$ following intramuscular gene transfer promotes collateral vessel development in patients with critical limb ischemia. Circulation 97:1114-1123.

Bennett, C.F., Kornbrust, D., Henry, S., Stecker, K., Howard, R., Cooper, S., Dutson, S. and Jacoby, H.I. 1997. An ICAM-1 antisense oligonucleotide prevents and reverses dextran sulfate sodium-induced colitis in mice. J. Pharmacol. Exp. Ther. 280:988-1000.

Berlin, C., Bargatze, R.F., Campbell, J.J., von Andrian, U.H., Szabo, M.C., Hasslen, S.R., Nelson, R.D., Berg, E.L., Erlandsen, S.L. and Butcher, E.C. 1995. $\alpha 4$ integrins mediate lymphocyte attachment and rolling under physiologic flow. Cell 80:413-422.

Bevilacqua, M.P. 1993. Endothelial-leukocyte adhesion molecules. Annu. Rev. Immunol. 11:767-804.

Bevilacqua, M.P. and Nelson, R.M. 1993. Selectins. J. Clin. Invest. 91:379-387.

Bevilacqua, M.P., Pober, J.S., Mendrick, D.L., Cotran, R.S. and Gimbrone, M.A. 1987. Identification of an inducible endothelial-leukocyte adhesion molecule. Proc. Natl. Acad. Sci. USA 84:9238-9242.

Birnbaum, Y., Patterson, M. and Kloner, R.A. 1997. The effect of CY1503, a sialyl Lewis $^{\mathbf{x}}$ analog blocker of the selectin adhesion molecules, on infarct size and „noreflow" in the rabbit model of acute infarction/reperfusion. J. Mol. Cell Cardiol. 29:2013-2025. 
Birnboim, H.C. and Doly, J. 1979. A rapid alkaline extraction procedure for screening recombinant plasmid DNA. Nucl. Acids. Res. 7:1513-1523.

Blankenberg, S., Rupprecht, H.J., Bickel, C., Peetz, D., Hafner, G., Tiret, L. and Meyer, J. 2001. Ciculating cell adhesion molecules and death in patients with coronary artery disease. Circulation 104:1336-1342.

Blasberg, R. and Tjuvajev, J. 1999. Herpes simplex virus thymidine kinase as a marker/reporter gene for PET imaging of gene therapy. Q. J. Nucl. Med. 43:163169.

Braun-Falco, M., Doenecke, A., Smola, H. and Hallek, M. 1999. Efficient gene transfer into human keratinocytes with recombinant adeno-associated virus vectors. Gene Ther. 6:432-441.

Brenner, G., Gulbins, E. and Schlottmann, K. 1996. L-selectin activates the Ras pathway via the tyrosine kinase p56lck. Proc. Natl. Acad. Sci. USA 93:1537615381.

Braunwald, E. 1997. Shattuck Lecture - cardiovasculare medicine at the turn of the millenium: triumphs, concerns, and opportunities. N. Engl. J. Med. 337:13601369.

Breslow, J.L. 1997. Cardiovascular disease burden increases, NIH funding decreases. Nat. Med. 3:600-601.

Briscoe, D.M., Cotran, R.S. and Pober, J.S. 1992. Effects of tumor necrosis factor, lipopolysaccharide, and IL-4 on the expression of vascular cell adhesion molecule1 in vivo. Correlation with CD3+T cell infiltration. J. Immunol. 149:2954-2960. 
Briskin, M.J., McEvoy, L.M. and Butcher, E.C. 1993. MAdCAM-1 has homology to immunoglobulin and mucin-like adhesion receptors and to IgA1. Nature 363:461464.

Buckley, C.D. and Simmons, D.L. 1997. Cell adhesion: a new target for therapy. Mol. Med. Today 3:449-456.

Buerke, M., Weyrich, A.S., Zheng, Z., Gaeta, F.C., Forrest, M.J. and Lefer, A.M. 1994. Sialyl Lewis ${ }^{\mathbf{x}}$-containing oligosaccharide attenuates myocardial reperfusion injury in cats. J. Clin. Invest. 93:1140-1148.

Burridge, K. and Chrzanowska-Wodnicka, M. 1996. Focal adhesions, contractility and signaling. Annu. Rev. Cell. Dev. Biol. 12:463-518.

Carlos, T.M. and Harlan, J.M. 1994. Leukocyte-endothelial adhesion molecules. Blood 84:2068-2101.

Carlos, T.M., Schwartz, B.R., Kovach, N.L., Yee, E., Rosa, M., Osborn, L., ChiRosso, G., Newman, B., Lobb, R. and Roso, M. 1990. Vascular cell adhesion molecule-1 mediates lymphocyte adherence to cytokine-activated cultured human endothelial cells [published erratum appears in Blood 1990 Dec 1;76:2420]. Blood 76:965-970.

Carpén, O., Pallai, P., Staunton, D.E. and Springer, T.A. 1992. Association of intercellular adhesion molecule-1 (ICAM-1) with actin-containing cytoskeleton and $\alpha$-actinin. J. Cell. Biol. 118:1223-1234.

Carter, R.A. and Wicks, I.P. 2001. Vascular cell adhesion molecule 1 (CD106). A Multifaceted Regulator of Joint Inflammation. Arthritis Rheum. 44:985-994. 
Chan, J.R., Hyduk, S.J. and Cybulsky, M.I. 2000. $\alpha_{4} \beta_{1}$ Integrin/VCAM-1 interaction activates $\alpha_{\llcorner} \beta_{2}$ Integrin-mediated adhesion to ICAM-1 in human T cells. J. Immunol. 164:746-753.

Chobanian, A.V. and Dzau, V.J. 1996. Renin angiotensin system and atherosclerotic vascular disease. In: Atherosclerosis and coronary artery disease (ed. by Fuster, V., Ross, R. \& Topol, E.J.), Vol.1, Lippincott-Raven, Philadelphia, pp. 237-242.

Clark, E.A. and Brugge, J.S. 1995. Integrins and signal transduction pathways: the road taken. Science 268:233-238.

Cominacini, L., Garbin, U., Pasini, A.F., Davoli, A., Campagnola, M., Contessi, G.B., Pastorini, A.M. and Lo Cascio, V. 1997. Antioxidants inhibit the expression of intercellular cell adhesion molecule-1 and vascular cell adhesion molecule-1 induced by oxidized LDL on human umbilicial vein endothelial cells. Free Radic. Biol. Med. 22:117-127.

Cooper, J.A. 1987. Effects of cytochalasin and phalloidin on actin. J. Cell Biol. 105:1473-1478.

Corbí, A.L. 1996. Leukocyte integrins, structure, expression and function. Springer, Heidelberg.

Couffinal, T., Duplàa, C., Moreau, C., Lamaziere, J.M.D. and Bonnet, J. 1994. Regulation of vascular cell adhesion molecule- 1 and intercellular cell adhesion molecule-1 in human vascular smooth muscle cells. Circ. Res. 74:225-234.

Cross, C.E., van der Vliet, A. and Eiserich, J.P. 1998. Cigarette smokers and oxidant stress: a continuing mystery. Am J. Clin. Nutr. 67:184-185. 
Cybulsky, M.I. and Gimbrone, M.A. 1991. Endothelial expression of a mononuclear leukocyte adhesion molecule during atherogenesis. Science 251:788-791.

Cybulsky, M.I., Fries, J.W., Williams, A.J., Sultan, P., Eddy, R., Byers, M., Shows, T. Gimbrone, M.A., Jr. and Collins, T. 1991a. Gene structure, chromosomal location, and basis for alternative mRNA splicing of the human VCAM1 gene. Proc. Natl. Acad. Sci. USA 88:7859-7863.

Cybulsky, M.I., Fries, J.W.U., Williams, A.J.,Sultan, P., Davis, V.M., Gimbrone, M.A., Jr. and Collins, T. 1991b. Alternative splicing of human VCAM-1 in activated vascular endothelium. Am. J. Pathol. 138:815-820.

Dansky, H.M., Barlow, C.B., Lominska, C., Sikes, J.L., Kao, C., Weinsaft, J., Cybulsky, M.I. and Smith, J.D. 2001. Adhesion of monocytes to arterial endothelium and initiation of atherosclerosis are critically depending on vascular cell adhesion molecule-1 gene dosage. Arterioscler. Thromb. Vasc. Biol. 21:16621667.

Davies, M.J., Gordon, J.L., Gearing, A.J., Pigott, R., Woolf, N., Katz, D. and Kyriakopoulos, A. 1993. The expression of the adhesion molecules ICAM-1, VCAM-1, PECAM, and E-selectin in human atherosclerosis. J. Pathol. 171:223229.

Davies, P.F. and Tripathi, S.C. 1993. Mechanical stress mechanisms and the cell: an endothelial paradigm. Circ. Res. 72:239-245.

Dawber, T.R. and Kannel, W.B. 1966. The Framingham study. An epidemiological approach to coronary heart disease. Circulation 34:553-555.

Dibasio, R.B. and LoBuglio, A.F. 1996. Immunomodulators: immunosuppressive agents and immunostimulants. In: Hardman, J.G., Limbird, L.E., editors. Goodman 
\& Gilman: the pharmacological basis of therapeutics. New York: McGraw-Hill, pp. 1291-1308.

Dustin, M.L., Rothlein, R., Bhan, A.K., Dinarello, C.A. and Springer, T.A. 1986. Induction of IL 1 and interferon-gamma: tissue distribution, biochemistry, and function of a natural adherence molecule (ICAM-1). J. Immunol. 137:245-254.

Dustin, M.L., Staunton, D.E. and Springer, T.A. 1988. Supergene families meet in the immune system. Immunol. Today 9:213-215.

Ebnet, K., Brown, K.D., Siebenlist, U.K., Simon, M.M. and Shaw, S. 1997. Borrelia burgdorferi activates nuclear factor- $\mathrm{kB}$ and is a potent inducer of chemokine and adhesion molecule gene expression in endothelial cells and fibroblasts. J. Immunol. 158:3285-3292.

Eigler, A., Sinha, B., Hartmann, G. and Endres, S. 1997. Taming TNF: strategies to restrain this proinflammatory cytokine. Immunol. Today 18:487-491.

Eisenbarth, C.A., Haynes, B.F., Schroer, J.A. and Fauci, A.S. 1980. Production of monoclonal antibodies reacting with peripheral blood mononuclear cell surface differentiation antigens. J. Immunol. 124:1237-1244.

Falk, E., Shah, P.K. and Fuster, V. 1996. Pathogenesis of plaque disruption. In: Atherosclerosis and coronary artery disease (ed. by Fuster, V., Ross, R. \& Topol, E.J.), Vol.1, Lippincott-Raven, Philadelphia, pp. 492-510.

Fawcett, J., Holness, C.L., Needham, L.A., Turley, H., Gatter, K.C., Mason, D.Y. and Simmons, D.L. 1992. Molecular cloning of ICAM-3, a third ligand for LFA-1, constitutively expressed on resting leukocytes. Nature 360:481-484.

Federici, C., Camoin, L., Hattab, M., Strosberg, A.D. and Courand, P.-O. 1996. Association of the cytoplasmic domain of intercellular-adhesion molecule-1 with 
glyceraldehyde-3-phosphate dehydrogenase and $\beta$-tubulin. Eur. J. Biochem. 238:173-180.

Freedman, A.S., Munro, J.M., Rice, G.E., Bevilacqua, M.P., Morimoto, C., McIntyre, B.W., Rhynhart, K., Pober, J.S. and Nadler, L.M. 1990. Adhesion of human B cells to germinal centers in vitro involves VLA-4 and INCAM-110. Science 249:1030-1033.

Frenette, P.S. and Wagner, D.D. 1996a. Adhesion molecules - part I. N. Engl. J. Med. 334:1526-1529.

Frenette, P.S. and Wagner, D.D. 1996b. Adhesion molecules - part II: blood vessels and blood cells. N. Engl. J. Med. 335:43-45.

Furie, M.B., Tancinco, M.C. and Smith, C.W. 1991. Monoclonal antibodies to leukocyte integrins $\mathrm{CD} 11 \mathrm{a} / \mathrm{CD} 18$ and $\mathrm{CD} 11 \mathrm{~b} / \mathrm{CD} 18$ or intercellular adhesion molecule-1 inhibit chemoattractant-stimulated neutrophil transendothelial migration in vitro. Blood 78:2089-2097.

García-Vicuña, R., Díaz-González, F., González-Alvaro, I., del Pozo, M.A., Mollinedo, F., Cabañas, C., González-Amaro, R. and Sánchez-Madrid, F. 1997. Prevention of cytokine-induced changes in leukocyte adhesion receptors by nonsteroidal antiinflammatory drugs from oxicam family. Arthritis Rheum. 40:143153.

Gearing, A.J.H. and Newman, W. 1993. Circulating adhesion molecules in disease. Immunol. Today 14:506-512.

Gerszten, R.E., Lim, Y.-C., Ding, H.T., Snapp, K., Kansas, G., Dichek, D.A., Cabañas, C., Sánchez-Madrid, F., Gimbrone, M.A., Jr., Rosenzweig, A. and Luscinskas, F.W. 1998. Adhesion of monocytes to vascular cell adhesion 
molecule-1-transduced human endothelial cells. Implications for atherogenesis. Circ. Res. 82:871-878.

Gimbrone, M.A., Jr., Cotran, R.S. and Folkman, J. 1974. Human vascular endothelial cells in culture, growth and DNA synthesis. J. Cell. Biol. 60:673-684.

Gimbrone, M.A., Jr., Nagel, T. and Topper, J.N. 1997. Biomechanical activation: an emerging paradigma in endothelial adhesion biology. J. Clin. Invest. 99:18091813.

Glakov, S., Weisenberg, E., Zarins, C.K., Stankunavicius, R. and Kolettis G.J. 1987. Compensatory enlargement of human atherosclerotic coronary arteries. $\mathrm{N}$. Engl. J. Med. 316:1371-1375.

González-Alvaro, I., Carmona, L., Díaz-González, F., González-Amaro, R., Mollinedo, F., Sánchez-Madrid, F., Laffon, A. and García-Vicuña, R. 1996. Aceclofenac, a new nonsteroidal antiinflammatory drug, decreases the expression and function of some adhesion molecules on human neutrophils. J. Rheumatol. 23:723-729.

González-Amaro, R., Díaz-González, F. and Sánchez-Madrid, F. 1998. Adhesion molecules in inflammatory disease. Drugs 56:977-988.

Gossen, M. and Bujard, H. 1992. Tight control of gene expression in mammalian cells by tetracycline-responsive promoters. Proc. Natl. Acad. Sci. 89:5547-5551.

Gossen, M., Freundlieb, S., Bender, G., Müller, G., Hillen, W. and Bujard, H. 1995. Transcriptional activation by tetracyclines in mammalian cells. Science 268:27232739. 
Greve, J.M., Davis, G., Meyer, A.M., Forte, C.P., Yost, S.C., Marlor, C.W., Kamarck, M.E. and McClelland, A. 1989. The major human rhinovirus receptor is ICAM-1. Cell 56:839-847.

Griendling, K.K. and Alexander, R.W. 1997. Oxidative stress and cardiovascular disease. Circulation 96:3264-3265.

Gurtner, G.C., Davis, V., Li, H., McCoy, M.J., Scarpe, A. and Cybulsky, M.I. 1995. Targeted disruption of the murine VCAM-1 gene: essential role of VCAM-1 chorioallantoic fusion and placentation. Genes Dev. 9:1-14.

Haynes, B.F., Mann, D.L., Hemler, M.E., Schroer, J.A., Shelhamer, J.H., Eisenbarth, G.S., Stromiger, J.L. Thomas, C.A., Mostowski, H.S. and Fauci, A.S. 1980. Charakterization of a monoclonal antibody that defines an immunoregulatory T cell subset for immunoglobulin synthesis in humans. Prov. Natl. Acad. Sci. USA 77:2914-2918.

Haynes, B.F., Metzgar, R.S., Minna, J.D. and Bunn, P.A. 1981. Phenotypic characterization of cutaneous T-cell lymphoma. Use of monoclonal antibodies to compare with other malignant T cells. N. Engl. J. Med. 304:1319-1323.

Haynes, B.F. and Heinly, C.S. 1995. Early human T cell development: analysis of the human thymus at the time of initial entry of hematopoietic stem cells into the fetal thymic microenvironment. J. Exp. Med. 181:1445-1458.

Heinly, C.S., Sempowski, G.D., Lee, D.M., Patel, D.D., McDermott, P.M., Scearce, R.M., Thompson, C.B. and Haynes, B.F. 2001. Comparison of thymocyte development and cytokine production in CD7-deficient, CD28- deficient and CD7/CD28 double-deficient mice. Int. Immunol. 13:157-166. 
Heiska, L., Alfthan, K., Grönholm, M., Vilja, P., Vaheri, A. and Carpén, O. 1998. Association of ezrin with interzellular adhesion molecule-1 and -2 (ICAM-1 and ICAM-2). J. Biol. Chem. 273:21893-21900.

Hemler, M.E. 1998. Integrin associated proteins. Curr. Opin. Cell Biol. 10:578-585.

Henseleit, U., Steinbrink, K., Sunderkotter, C., Goebeler, M., Roth, J. and Sor, C. 1994. Expression of murine VCAM-1 in vitro and in different models of inflammation in vivo: correlation with immigration of monocytes. Exp. Dermatol. 3:249-256.

Hogg, N. and Landis, R.C. 1993. Adhesion molecules in cell interactions. Curr. Opin. Immunol. 5:383-390.

Huber, S.A. 1994. VCAM-1 is a receptor for encephalomyocarditis virus on murine vascular endothelial cells. J. Virol. 68:3453-3458.

Huo, Y., Hafezi-Moghadam, A. and Ley, K. 2000. Role of vascular cell adhesion molecule-1 and Fibronectin connecting segment-1 in monocyte rolling and adhesion on early atherosclerotic lesions. Circ. Res. 87:153-159.

Hynes, R.O. 1992. Integrins: versatility, modulation, and signaling in cell adhesion. Cell 69:11-25.

Hynes, R.O. and Lander, A.D. 1992. Contact and adhesive specificities in the associations, migrations, and targeting of cells and axons. Cell 68:303-322.

lademarco, M.F., McQuillan, J.J., Rosen, G.D. and Dean, D.C. 1992. Characterization of the promoter for vascular adhesion molecule-1 (VCAM-1). J. Biol. Chem. 267:16323-16329. 
lademarco, M.F., McQuillan, J.J. and Dean, D.C. 1993. Vascular cell adhesion molecule 1: contrasting transcriptional control mechanisms in muscle and endothelium. Proc. Natl. Acad. Sci. USA 90:3943-3947.

liyama, K., Hajra, L., liyama, M., Li, H., DiChiara, M., Medoff, B.D. and Cybulsky, M.I. 1999. Patterns of vascular cell adhesion molecule-1 expression in rabbit and mouse atherosclerotic lesions and at sites predisposed to lesion formation. Circ. Res. 85:199-207.

Isner, J.M., Baumgartner, I., Rauh, G., Schainfeld, R., Blair, R., Manor, O., Razvi, S. and Symes, J.F. 1998. Treatment of thromboangiitis obliterans (Buerger's disease) by intramuscular gene transfer of vascular endothelial growth factor: preliminary clinical results. J. Vasc. Surg. 28:964-975.

Isner, J.M., Vale, P.R., Symes, J.F. and Losordo, D.W. 2001. Assessment of risks associated with cardiovascular gene therapy in human subjects. Circ. Res. 89:389-400.

Jackson, L.A., Campbell, L.A. and Schmidt, R.A. 1997. Specificity of detection of Chlamydia pneumoniae in cardiovascular atheroma: evaluation of the innocent bystander hypothesis. Am. J. Pathol. 150:1785-1790.

Jaffe, E.A., Nachman, R.L., Becker, G.C. and Minick, C.R. 1973. Culture of human endothelial cells derived from umbilical veins. J. Clin. Invest. 52:2745-2754.

Juliano, R.L. and Haskill, S. 1993. Signal transduction from the extracellular matrix. J. Cell Biol. 120:577-585.

Kaapa, A., Peter, K. and Ylänne, J. 1999. Effects of mutations in the cytoplasmic domain integrin beta(1) to talin binding and cell spreading. Exp. Cell. Res. 250:524-534. 
Kansas, G.S. 1996. Selectins and their ligands: current concepts and controversies. Blood 88:3259-3287.

Kansas, G.S. and Pavalko, F.M. 1996. The cytoplasmic domains of E- and Pselectin do not constitutively interact with $\alpha$-actinin and are not essential for leukocyte adhesion. J. Immunol. 157:321-325.

Kaplanski, G., Marin, V., Fabrigoule, M., Boulay, V., Benoliel, A.-M., Bongrand, P., Kaplanski, S. and Farnarier, C. 1998. Thrombin-activated human endothelial cells support monocyte adhesion in vitro following expression of intercellular adhesion molecule-1 (ICAM-1; CD54) and vascular cell adhesion molecule-1 (VCAM-1; CD106). Blood 92:1259-1267.

Kienzle, G. and Kempis, J. 1998. Vascular cell adhesion molecule 1 (CD106) on primary human articular chondrocytes: functional regulation of expression by cytokines and comparison with intercellular adhesion molecule 1 (CD54) and very late activation antigen 2. Arthritis Rheum. 41:1296-1305.

Kishimoto, A., Nishiyama, K., Nakanishi, H., Uratsuji, Y., Nomura, H., Takeyama, Y. and Nishizuka, Y. 1985. Studies on the phosphorylation of myelin basic protein by protein kinase $\mathrm{C}$ and adenosine $3^{‘}: 5^{‘}$-monophosphate-dependent protein kinase. J.Biol. Chem. 260:12492-12499.

Knowles, M.R., Hohneker, K.W., Shou, Z., Olsen, J.C., Noah, T.L., Hu, P.-C., Leigh, M.W., Engelhardt, J.F., Edwards, L.J., Jones, K.R., Grossman, M., Wilson, J.M., Johnson, L.G. and Boucher, R.C. 1995. A controlled study of adenoviralvector-mediated gene transfer in the nasal epithelium of patients with cystic fibrosis. N. Engl. J. Med. 333:823-831.

Ko, S.C., Gotoh, A., Thalmann, G.N., Zhau, H.E., Johnston, D.A., Zhang, W.W., Kao, C. and Chung, L.W. 1996. Molecular therapy with recombinant p53 
adenovirus in an androgen-independent, metastatic human prostate cancer model. Hum. Gene Ther. 7:1683-1691.

Koch, A.E., Halloran, M.M., Haskell, C.J., Shah, M.R. and Polverini, P.J. 1995. Angiogenesis mediated by soluble forms of E-selectin and vascular cell adhesion molecule-1. Nature 376:517-519.

Koopman, G., Parmentier, H.K., Schuurman, H.J., Newman, W., Meijer, C.J. and Pals, S.T. 1991. Adhesion of human B cells to follicular dendritic cells involves both the lymphocyte function-associated antigen 1/intercellular adhesion molecule 1 and very late antigen 4/vascular cell adhesion molecule 1 pathways. J. Exp. Med. 173:1297-1304.

Kullo, I.J., Gau, G.T. and Tajik, A.J. 2000. Novel risk factors for atherosclerosis. J. Clin. Invest. 102:145-152.

Kwee, L., Baldwin, H.S., Shen, H.M., Stewart, C.L., Buck, C., Buck, C.A. and Labow, M.A. 1995. Defective development of the embryonic and extraembryonic circulatory systems in vascular cell adhesion molecule (VCAM-1) deficient mice. Development 121:489-503.

Landry, D.B., Couper, L., Bryant, S.R. and Linder, V. 1997. Activation of the NK$\kappa \mathrm{B}$ and $\mathrm{l} \mathrm{KB}$ system in smooth muscle cells after rat arterial injury: induction of vascular cell adhesion molecule-1 and monocyte chemoattractant protein-1. Am. J. Pathol. 151:1085-1095.

Languino, L.R., Duperray, A., Joganic, K.J., Fornaro, M., Thornton, G.B. and Altieri, D.C. 1995. Regulation of leukocyte-endothelium interaction and leukocyte transendothelial migration by intercellular adhesion molecule 1-fibrinogen recognition. Proc. Natl. Acad. Sci. USA 92:1505-1509. 
Lawrence, M.B. and Springer, T.A. 1991. Neutrophils roll on E-selectin. J. Immunol. 151:6338-6346.

Lee, Y.S. 1997. Hemmung der Zelladhäsion durch Inhibition der Zytoskelettverankerung von Adhäsionsmolekülen mittels Gentransfer. Dissertation, RuprechtKarls-Universität Heidelberg.

Li, H., Cybulsky, M., Gimbrone, M.A., Jr. and Libby, P. 1993. Inducible expression of vascular cell adhesion molecule-1 by vascular smooth muscle cells in vitro and within rabbit atheroma. Am. J. Pathol. 143:1551-1559.

Libby, P., Egan, D. and Skarlatos, S. 1997. Roles of infectious agents in atherosclerosis and restenosis: an assessment of the evidence and need for future research. Circulation 96:4095-4103.

Libby, P. and Ross, R. 1996. Cytokines and growth regulatory molecules. In: Atherosclerosis and coronary artery disease (ed. by Fuster, V., Ross, R. \& Topol, E.J.), Vol.1, Lippincott-Raven, Philadelphia, pp. 585-594.

Lo, S.K., Golenbock, D.T., Sass, P.M., Maskati, A., Xu, H. and Silverstein, R.L. 1997. Engagement of the Lewis $X$ antigen (CD15) results in monocyte activation. Blood 89:307-314.

Lorenzon, P., Vecile, E., Nardon, E., Ferrero, E., Harlan, J.M., Tedesco, F. and Dobrina, A. 1998. Endothelial cell E- and P-selectin and vascular cell adhesion molecule-1 function as signaling receptors. J. Cell Biol. 142:1381-1391.

Losordo, D.W., Vale, P.R., Symes, J., Dunnington, C., Esakof, D., Maysky, M., Ashare, A., Lathi, K. and Isner, J.M. 1998. Gene therapy for myocardial angiogenesis: initial clinical results with direct myocardial injection of phVEGF 165 as sole therapy for myocardial ischemia. Circulation 98:2800-2804. 
Luscinskas, F.W., Ding, H., Tan, P., Cumming, D., Tedder, T.F. and Gerritsen, M.E. 1996. L- and P-selectins, but not CD49d (VLA-4) integrins, mediate monocyte initial attachment to TNF- $\alpha$-activated vascular endothelium under flow in vitro. J. Immunol. 157:326-335.

Machelska, H., Cabot, P.J., Mousa, S.A., Zhang, Q. and Stein, C. 1998. Pain control in inflammation governed by selectins. Nature Med. 4:1425-1428.

Makgoba, M.W., Sanders, M.E., Ginther Luce, G.E., Gugel, E.A., Dustin, M.L., Springer, T.A., Clark, E.A., Mannoni, P. and Shaw, S. 1988. ICAM-1 is a ligand for LFA-1 dependent adhesion of B, T and myeloid cells. Nature 31:86-88.

Mann, M.J., Whittemore, A.D., Donaldson, M.C., Belkin, M., Conte, M.S., Polak, J.F., Orav, E.J., Ehsan, A., Dell'Acqua, C. and Dzau, V.J. 1999. Ex-vivo gene therapy of human vascular bypass grafts with E2F decoy: the PREVENT singlecentre, randomised controlled trial. Lancet 354:1493-1498.

Marlin, S.D. and Springer, T.A. 1987. Purified intercellular cell adhesion molecule1 (ICAM-1) is a ligand for lymphocyte function-associated antigen 1 (LFA-1). Cell 51:813-819.

Masinovsky, B., Urdal, D. and Gallatin, W.M. 1990. IL-4 acts synergistically with IL-1 beta to promote lymphocyte adhesion to microvascular endothelium by induction of vascular cell adhesion molecule-1. J. Immunol. 145:2886-2895.

Matheny, H.E., Deem, T.L. and Cook-Mills, J.M. 2000. Lymphocyte migration through monolayers of endothelial cell lines involves VCAM-1 signaling via endothelial cell NADPH oxidase. J Immunol 164:6550-6559.

Mazo, I.B., Gutierrez-Ramos, J.C., Frenette, P.S., Hynes, R.O., Wagner, D.D. and von Andrian, U.H. 1998. Hematopoietic progenitor cell rolling in bone marrow 
microvessels: parallel contributions by endothelial selectins and vascular cell adhesion molecule 1. J. Exp. Med. 188:465-474.

Meddell, J.R., Kissel., J.T., Amato, A.A., King, W., Signore, L., Prior, T.W., Sahenk, Z., Benson, S., McAndrew, P.E., Rice, R., Nagaraja, H., Stephens, R., Lantry, L., Morris, G.E. and Burghes, A.H.M. 1995. Myoblast transfer in the treatment of Duchenne's muscular dystrophy. N. Engl. J. Med. 333:832-838.

Meerschaert, J. and Furie, M.B. 1994. Monocytes use either CD11/CD18 or VLA-4 to migrate across human endothelium in vitro. J. Immunol. 152:1915-1926.

Miyake, K., Medina, K., Ishihara, K., Kimoto, M., Auerback, R. and Kincade, P.W. 1991. VCAM-1-like adhesion molecule on bone marrow stromal cells mediates binding of lymphocyte precursors in culture. J. Cell Biol. 114:557-565.

Morishita, R., Sugimoto, T., Aoki, M., Kida, I., Tomita, N., Moriguchi, A., Maeda, K., Sawa, Y., Kaneda, Y., Higaki, J. and Ogihara, T. 1997. In vivo transfection of cis element "decoy“ against nuclear factor-kappaB binding site prevents myocardial infarction. Nat. Med. 3:894-899.

Mould, A.P., Askari, J.A., Craig, S.E., Garratt, A.N., Clements, J. and Humphries, M.J. 1994. Integrin $\alpha 4 \beta 1$-mediated melanoma cell adhesion and migration on vascular cell adhesion molecule-1 (VCAM-1) and the alternatively spliced IIICS region of fibronectin. J. Biol. Chem. 269:27224-27230.

Nakashima, Y., Raines, E.W., Plump, A.S., Breslow, J.L. and Ross, R. 1998. Upregulation of VCAM-1 and ICAM-1 at atherosclerosis-prone sites on the endothelium in the ApoE-deficient mouse. Arterioscler. Thromb. Vasc. Biol. 18:842-851. 
National Cholesterol Education Program. Second report of the Expert Panel on Detection, Evaluation, and Treatment of High Blood Cholesterol in Adults (Adult Treatment Panel II). Bethesda, Md.: National Heart, Lung, and Blood Institute, 1993. (NIH publication no. 93-3095.)

Nehler, M.R., Taylor, L.M., Jr. and Porter, J.M. 1997. Homocysteinemia as a risk factor for atherosclerosis: a review. Cardiovasc. Surg. 6:559-567.

Neish, A.S., Williams, A.J., Palmer, H.J., Whitley, M.Z. and Collins, T. 1992. Functional analysis of the human vascular adhesion molecule 1 promoter. J. Exp. Med. 176:1583-1593.

Neumann, E., Schaeffer-Ridder, M., Wang, Y. and Hofschneider, P.H. 1982. Gene transfer into mouse myeloma cells by electroporation in high electric fields. EMBO J. 1:841-845.

O’Brien, K.D., McDonald, T.O., Chait, A., Allen, M.D. and Alpers, C.E. 1996. Neovascular expression of E-selectin, intercellular adhesion molecule-1, and vascular cell adhesion molecule-1 in human atherosclerosis and their relation to intimal leukocyte content. Circulation 93:672-682.

Ockenhouse, C.F., Tegoshi, T., Maeno, Y., Benjamin, C., Ho, M., Kan, K.E., Thway, Y., Win, K., Aikawa, M. and Lobb, R.R. 1992a. Human vascular endothelial cell adhesion receptors for Plasmodium falciparum-infected erythrocytes: roles for endothelial leukocyte adhesion molecule 1 and vascular cell adhesion molecule 1. J. Exp. Med. 176:1183-1189.

Ockenhouse, C.F., Betageri, R., Springer, T.A. and Staunton, D.E. 1992b. Plasmodium falciparum-infected erythrocytes bind ICAM-1 at a site distinct from LFA-1, Mac-1, and human rhinovirus. Cell 68:63-69. 
Oguchi, S., Dimayuga, P., Zhu, J., Chyu, K.-Y., Yano, J., Shah, P.K., Nilsson, J. and Cercek, B. 2000. Monoclonal antibody against vascular cell adhesion molecule-1 inhibits neointimal formation after periadventitial carotid artery injury in genetically hypercholesterolemic mice. Arterioscler. Thromb. Vasc. Biol. 20:17291736.

Osborn, L., Hession, C., Tizard, R., Vassallo, C., Luhowskyj, S., Chi-Rosso, G., and Lobb, R. 1989. Direct expression cloning of vascular cell adhesion molecule 1, a cytokine-induced endothelial protein that binds to lymphocytes. Cell 59:12031211.

Osborn, L., Vassallo, C. and Benjamin, C.D. 1992. Activated endothelium binds lymphocytes through a novel binding site in the alternately spliced domain of vascular cell adhesion molecule-1. J. Exp. Med. 176:99-107.

Osborn, L., Vassallo, C., Browning, B.G., Tizard, R., Haskard, D.O., Benjamin, C.D., Dougas, I. and Kirchhausen, T. 1994. Arrangement of domains, and amino acid residues required for binding of vascular cell adhesion molecule-1 to its counter-receptor VLA-4 (alpha 4 beta 1). J. Cell Biol. 124:601-608.

O'Toole, T.E., Loftus, J.C., Du, X.P., Glass, A.A., Ruggeri, Z.M., Shattil, S.J., Plow, E.F. and Ginsberg, M.H. 1990. Affinity modulation of the alpha IIb beta 3 integrin (platelet GPIIb-IIIa) is an intrinsic property of the receptor. Cell Regul. 1:883-893.

Parks, W.M., Gingrich, R.D., Dahle, C.E. and Hoak, J.C. 1985. Identification and characterization of an endothelial, cell-specific antigen with a monoclonal antibody. Blood 66:816-823.

Pavalko, F.M. and Otey, C.A. 1997. Role of adhesion molecule cytoplasmic domains in mediating interactions with the cytoskeleton. Proc. Soc. Exp. Biol. Med. $205: 282-293$. 
Peter, K. and O'Toole, T.E. 1995. Modulation of cell adhesion by changes in $\alpha \mathrm{L} \beta 2$ (LFA-1, CD11a/CD18) cytoplasmic domain/cytoskeleton interaction. J. Exp. Med. 181:315-326.

Peter, K., Weirich, U., Nordt, T., Ruef, J. and Bode, C. 1999. Soluble vascular cell adhesion molecule-1 (VCAM-1) as a potential marker of atherosclerosis. Thromb. Hemost. 82:38-43.

Pigott, R., Dillon, L.P., Hemingway, I.H. and Gearing, A.J. 1992. Soluble forms of E-selectin, ICAM-1 and VCAM-1 are present in the supernatants of cytokine activated cultured endothelial cells. Biochem. Biophys. Res. Commun. 187:584589.

Porter, J.C. and Hogg, N. 1997. Integrin cross talk: activation of lymphocyte function-associated antigen- 1 on human T cells alters $\alpha 4 \beta 1$ - and $\alpha 5 \beta 1$-mediated Function. J. Cell Biol. 138:1437-1447.

Postigo, A.A., Teixidó, J. and Sánchez-Madrid, F. 1993. The $\alpha 4 \beta 1 /$ VCAM-1 adhesion pathway in physiology and disease. Res. Immunol. 144:723-735.

Potter, H. 1988. Electroporation in biology: methods, application and instrumentation. Anal. Biochem. 174:361-373.

Puck, T.T., Cieciuara, S.J. and Robinson, A. 1958. Genetics of somatic mammalian cells: III. Long-term cultivation of euploid cells from human and animal subjects. J. Exp. Med. 108:945-956.

Rabinowich, H., Pricop, L., Herberman, R.B. and Whiteside, T.L. 1994. Expression and function of CD7 molecule on human natural killer cells. J. Immunol. 152:517526. 
Radbruch, A. 1992. Immunofluorescence: basic considerations. In: Flow cytometry and cell sorting (ed. by Radbruch, A.), Springer Verlag, Berlin, pp. 34-46.

Raines, E.W., Rosenfeld, M.E. and Ross, R. 1996. The role of macrophages. In: Atherosclerosis and coronary artery disease (ed. by Fuster, V., Ross, R. \& Topol, E.J.), Vol.1, Lippincott-Raven, Philadelphia, pp. 539-555.

Raines, E.W. and Ross, R. 1996. Multiple growth factors are associated with lesions of atherosclerosis: specificity or redundancy? Bioessays 18:271-282.

Rice, G.E. and Bevilacqua, M.P. 1989. An inducible endothelial cell surface glycoprotein mediates melanoma adhesion. Science 246:1303-1306.

Rice, G.E., Munro, J.M., Corless, C. and Bevilacqua, M.P. 1991. Vascular and nonvascular expression of INCAM-110: a target for mononuclear leukocyte adhesion in normal and inflamed human tissues. Am. J. Pathol. 138:385-393.

Rosen, S.D. and Bertozzi, C.R. 1994. The selectins and their ligands. Curr. Opin. Cell Biol. 6:663-373.

Ross, R. 1999. Atherosclerosis: an inflammatory disease. N. Engl. J. Med. 340:115-126.

Ross, R. and Glomset, J.A. 1973. Atherosclerosis and the arterial smooth muscle cell: proliferation of smooth muscle is a key event in the genesis of the lesions of atherosclerosis. Science 180:1332-1339.

Rothlein, R., Dustin, M.L., Marlin, S.D. and Springer, T.A. 1986. A human intercellular adhesion molecule (ICAM-1) distinct from LFA-1. J. Immunol. 137:1270-1274. 
Rothlein, R., Czajkowski, M., O’Neill, M.M., Marlin, S.D., Mainolfi, E. and Merluzzi, V.J. 1988. Induction of intercellular adhesion molecule 1 on primary and continuous cell lines by pro-inflammatory cytokines. Regulation by pharmacologic agents and neutralizing antibodies. J. Immunol. 141:1665-1669.

Sako, D., Chang, X.J., Barone, K.M., Vachino, G., White, H.M., Shaw, G., Veldman, G.M., Bean, K.M., Ahern, T.J. and Furie, B. 1993. Expression cloning of a functional glycoprotein ligand for P-selectin. Cell 75:1179-1186.

Salomon, D.R., Crisa, L., Mojcik, C.F., Ishii, J.K., Klier, G. and Shevach, E.M. 1997. Vascular cell adhesion molecule-1 is expresses by cortical thymic epithelial cells and mediates thymocyte adhesion: implications for the function of $\alpha 4 \beta 1$ (VLA4) integrin in T-cell development. Blood 89:2461-2471.

Sánchez-Mateos, P., Cabañas, C. and Sánchez-Madrid, F. 1996. Regulation of integrin function. Semin. Cancer Biol. 7:99-109.

Sandrin, M.S., Vaughan, H.A., Loverting, K.E., Curnow, K., Deacon, N.J. and McKenzie, I.F. 1987. Characterization of the gene coding for the human lymphocyte surface antigen HuLy-m2(CD7) in Leucocyte Typing III. Oxford University Press, p. 216.

Sans, E., Delachanal, E. and Duperray, A. 2001. Analysis of the roles of ICAM-1 in neutrophil transmigration using a reconstituted mammalian expression model: implication of ICAM-1 cytoplasmic domain and Rho-dependent signaling pathway. J. Immunol. 166:544-551.

Scholz, D., Devaux, B., Hirche, A., Pötsch, B., Kropp, B., Schaper, W. and Schaper, J. 1996. Expression of adhesion molecules is specific and timedependent in cytokine-stimulated endothelial cells in culture. Cell Tissue Res 284:415-423. 
Sekido, N., Mukaida, N., Harada, A., Nakanishi, I., Watanabe, Y. and Matsushima, K. 1993. Prevention of lung reperfusion injury in rabbits by a monoclonal antibody against interleukin-8. Nature 365:654-657.

Shang, X.-Z., Lang, B.J. and Issekutz, A.C. 1998. Adhesion molecule mechanisms mediating monocyte migration through synovial fibroblast and endothelium barriers: role for CD11/CD18, very late antigen-4 (CD49d/CD29), very late antigen-5 (CD49e/CD29), and vascular cell adhesion molecule-1 (CD106). J. Immunol. 160:467-474.

Shattil, S.J. and Ginsberg, M.H. 1997. Integrin signaling in vascular biology. J. Clin. Invest. 100:91-95.

Silverstein, R.L. 1998. Cell adhesion molecules. Cancer Invest. 16:175-182.

Simovic, D., Isner, J.M., Ropper, A.H., Pieczek, A. and Weinberg, D.H. 2001. Improvement in chronic ischemic neuropathy following intramuscular phVEGF ${ }_{165}$ gene transfer in patients with critical limb ischemia. Arch. Neurol. 58:761-768.

Slepian, M.J., Fritz, A. and Dehdashti, B. 1998. Smooth muscle cell $\alpha 4 \beta 1$ integrinmatrix interactions participate in migration and neointimal thickening following injury. Circulation 98 (supl. I):I-227. Abstract.

Sluiter, W., Pietersma, A., Lamers, J.M.J. and Koster, J.F. 1993. Leukocyte adhesion molecules on the vascular endothelium: their role in the pathogenesis of cardiovascular disease and the mechanisms underlying their expression. J. Cardiovasc. Pharmacol. 22:37-44.

Smaglik, P. 1998. Viral vs. nonviral in gene therapy: which vector will prevail? Scientist 12:5-6. 
Springer, T.A. 1990. Adhesion receptors of the immune system. Nature 346:425434.

Springer, T.A. 1994. Traffic signals for lymphocyte recirculation and leukocyte emigration: the multistep paradigm. Cell 76:301-314.

Springer, T.A. and Cybulsky, M.I. 1996. Traffic signals on endothelium for leukocytes in health, inflammation, and atherosclerosis. In: Atherosclerosis and coronary artery disease (ed. by Fuster, V., Ross, R. \& Topol, E.J.), Vol.1, Lippincott-Raven, Philadelphia, pp. 511-538.

Staunton, D.E., Marlin, S.D., Stratowa, C., Dustin, M.L. and Springer, T.A. 1988. Primary structure of ICAM-1 demonstrates interaction between members of the immunoglobulin and supergene family. Cell 56:925-933.

Staunton, D.E., Dustin, M.L. and Springer, T.A. 1989. Functional cloning of ICAM2, a cell adhesion ligand for LFA-1 homologous to ICAM-1. Nature 339:61-64.

Steegmaier, M., Levinovitz, A., Isenmann, S., Borges, E., Lenter, M., Kocher, H.P., Kleuser, B. and Vestweber, D. 1995. The E-selectin-ligand ESL-1 is a variant of a receptor for fibroblast growth factor. Nature 373:615-620.

Steinberg, D. 1997. Low density lipoprotein oxidation and its pathobiological significance. J. Biol. Chem. 272:20963-20966.

Stepkowski, S.M., Tu, Y., Condon, T.P. and Bennett, C.F. 1994. Blocking of heart allograft rejection by intercellular cell adhesion molecule-1 anti-sense oligonucleotides alone or in combination with other immunosuppressive modalities. J. Immunol. 153:5336-5346.

Sukharev, S.I., Titomirov, A.V. and Klenchin, V.A. 1994. Electrically-induced DNA transfer into cells. Electrotransfection in vivo. In: Gene Therapeutics. Methods and 
Applications of Direct Gene Transfer (ed. by Wolff, J.A.), Birkhäuser, Boston, pp. 210-232.

Thornhill, M.H., Wellicome, S.M., Mahiouz, D.L., Lanchbury, J.S., Kyan-Aung, U. and Haskard, D.O. 1991. Tumor necrosis factor combines with IL-4 or IFN-gamma to selectively enhance endothelial cell adhesiveness for T cells: the contribution of vascular cell adhesion molecule-1 dependent and independent binding mechanisms. J. Immunol. 146:592-598.

Tokuhira, M., Hosaka, S., Volin, M.V., Haines, G.K. 3rd, Katschke, K.J., Jr., Kim, S. and Koch, A.E. 2000. Soluble vascular cell adhesion molecule 1 mediation of monocyte chemotaxis in rheumatoid arthritis. Arthritis Rheum. 43:1122-1133.

Travis, J. 1993. Biotech gets a grip on cell adhesion. Science 260:906-908.

Triezenberg, S.J., LaMarco, K.L. and McKnight, S.L. 1988. Evidence of DNA:protein interactions that mediate HSV-1 immediate early gene activation by VP16.

Vale, P.R., Losordo, D.W., Milliken, C.E., Maysky, M., Esakof, D.D., Symes, J.F. and Isner, J.M. 2000. Left ventricular electromechanical mapping to assess efficacy of phVEGF 165 gene transfer for therapeutic angiogenesis in chronic myocardial ischemia. Circulation 102:965-974.

Van de Stolpe, A. and van der Saag, P.T. 1996. Intercellular adhesion molecule-1. J. Mol. Med. 74:13-33.

Verbeek, M., Westphal, J.R., Ruiter, D.J. and de Waal, R.M. 1995. T lymphocyte adhesion to human brain pericytes is mediated via very late antigen-4/vascular cell adhesion molecule-1 interactions. J. Immunol. 154:5876-5884. 
Vodinelich, L., Tax, W., Bai, Y., Pegram, S., Capel, S. and Greaves, M.F. 1983. A monoclonal antibody (WT1) for detecting leukemias of T-cell precursors. Blood 62:1108-1113.

Vogetseder, W. and Dierich, M.P. 1991. Intercellular adhesion molecule-1 (ICAM1, CD54) is associated with actin-filaments. Immunobiol. 182:143-151.

Vonderheide, R.H., Tedder, T.F., Springer, T.A. and Staunton, D.E. 1994. Residues within a conserved amino acid motif of domains 1 and 4 of VCAM-1 are required for binding VLA-4. J. Cell Biol. 125:215-222.

Wagner, E., Zatloukal, K., Cotten, M., Kirlappos, H., Mechtler, K., Curiel, D.T. and Birnstiel, M.L. 1992. Coupling of adenovirus to transferrin-polylysine/DNA complexes greatly enhances receptor-mediated gene delivery and expression of transfected genes. Proc. Natl. Acad. Sci. USA 89:6099-6103.

Wang, P.H., Lau, J. and Chalmers, T.C. 1993. Meta-analysis of effects of intensive blood-glucose control on late complications of type I diabetes. Lancet 341:13061309.

Weber, C. and Springer, T.A. 1998. Interaction of very late antigen-4 with VCAM-1 supports transendothelial chemotaxis of monocytes by facilitating lateral migration. J. Immunol. 161:6825-6834.

Wiznerowicz, M., Fong, A.Z.C., Mackiewicz, A. and Hawley, R.G. 1997. Doublecopy bicistronic retroviral vector platform for gene therapy and tissue engineering: application to melanoma vaccine development. Gene Ther. 4:1061-1068.

Wójciak-Stothard, B., Williams, L. and Ridley, A.J. 1999. Monocyte adhesion and spreading on human endothelial cells is dependent on Rho-regulated receptor clustering. J. Cell Biol. 145:1293-1307. 
Woodgett, J.R., Gould, K.L. and Hunter, T. 1986. Substrate specificity of protein kinase $\mathrm{C}$ : use of synthetic peptides corresponding to physiological sites as probes for substrate recognition requirements. Eur. J. Biochem. 161:177-184.

Yang, J.P. and Huang, L. 1996. Direct gene tranfer to mouse melanoma by intratumor injection of free DNA. Gene Ther. 3:542-548.

Yoshida, M., Westlin, W.F., Wang, N., Ingber, D.E., Rosenzweig, A., Resnick, N. and Gimbrone, Jr., M.A. 1996. Leukocyte adhesion to vascular endothelium induces E-selectin linkage to the actin cytoskeleton. J. Cell. Biol. 133:445-455.

Zapolska-Downar, D., Naruszewicz, M., Zapolski-Downar, A., Markiewski, M., Bukowska, H. and Millo, B. 2000. Ibuprofen inhibits adhesiveness of monocytes to endothelium and reduces cellular oxidative stress in smokers and non-smokers. Eur. J. Clin. Invest. 30:1002-1010.

Zhao, Z.Q., Lefer, D.J., Sato, H., Hart, K.K., Jefforda, P.R. and Vinten-Johansen, J. 1997. Monoclonal antibody to ICAM-1 preserves postischemic blood flow and reduces infarct size after ischemia/reperfusion in rabbit. J. Leukoc. Biol. 62:292300. 


\section{Danksagung}

Ich danke Herrn Prof. Dr. R. Hardeland ganz herzlich für seine Bereitschaft, die Betreuung dieser Arbeit an den Mathematisch-Naturwissenschaftlichen Fakultäten der Universität Göttingen zu übernehmen. Trotz der räumlichen Distanz unterstützte er mich mit vielen Tipps und Anregungen und hatte immer ein offenes Ohr für meine Fragen und Zweifel.

Herrn PD Dr. K. Peter danke ich für die Überlassung des interessanten Themas, die fruchtbaren Diskussionen und die Betreuung in Heidelberg und Freiburg.

Herr Prof. Dr. C. Bode ermöglichte mir, meine Dissertation zunächst in seinem Labor in Heidelberg, und im weiteren Verlauf in Freiburg anfertigen zu können. Auch inm gilt mein Dank.

Bei Herrn Prof. Dr. K. Jungermann möchte ich mich ganz herzlich für die Übernahme des Korreferats bedanken.

Danke an alle Mitarbeiter in den Laboratorien in Heidelberg und Freiburg: Eure Tipps haben mir viel geholfen und Euer Humor mich in manch frustrierender Phase wieder aufgebaut. Ohne die technische Unterstützung von Simone Bauer und Nicole Baßler wäre ich oft genug verzweifelt.

Meiner Familie danke ich in besonderer Weise für ihre Unterstützung. 


\section{Lebenslauf}

Name:

Geburtsdatum:

Geburtsort:

1978-1982

1982-1991

1991

1994

1996

1998

1998-2002
Sabine Marheineke

4. Oktober 1971

Hildesheim

Grundschule Hasede (Gemeinde Giesen)

Gymnasium Marienschule in Hildesheim

Aufnahme des Studiums an der Georg-August-

Universität Göttingen, Fachrichtung Biologie

Vordiplom in den Fächern Zoologie, Mikrobiologie, anorganische und physikalische Chemie; Beginn des Hauptstudiums mit Schwerpunkten in Zoophysiologie, Mikrobiologie und organischer Chemie

Mündliche Diplomprüfung; Aufnahme der Studien zur Diplomarbeit „Zur Frage der Existenz circadianer Rhythmen von antioxidativen Enzymen und deren Beeinflussbarkeit durch oxidativen Stress bei Drosophila melanogaster" bei Prof. Dr. R. Hardeland

Abschluss des Studiums als Diplom-Biologin Anfertigung der vorliegenden Dissertation „Interaktion von Leukozyten mit endothelialen Adhäsionsmolekülen und ihre Inhibition durch Expression von konkurrierenden Fusionsproteinen" an der Ludolf-Krehl-Klinik der Ruprecht-Karls-Universität Heidelberg und am Universitätsklinikum der Albert-Ludwigs-Universität Freiburg Anleiter: PD Dr. K. Peter

Betreuer: Prof. Dr. R. Hardeland 